\title{
Reducción de estrés en pacientes con Diabetes Mellitus
}

Diana Lucero Muñoz Arellano, Yunery Marlen Bautista Gómez, Andrea Ortega Mondragón, Ana Leticia Becerra Gálvez y Leonardo Reynoso Erazo

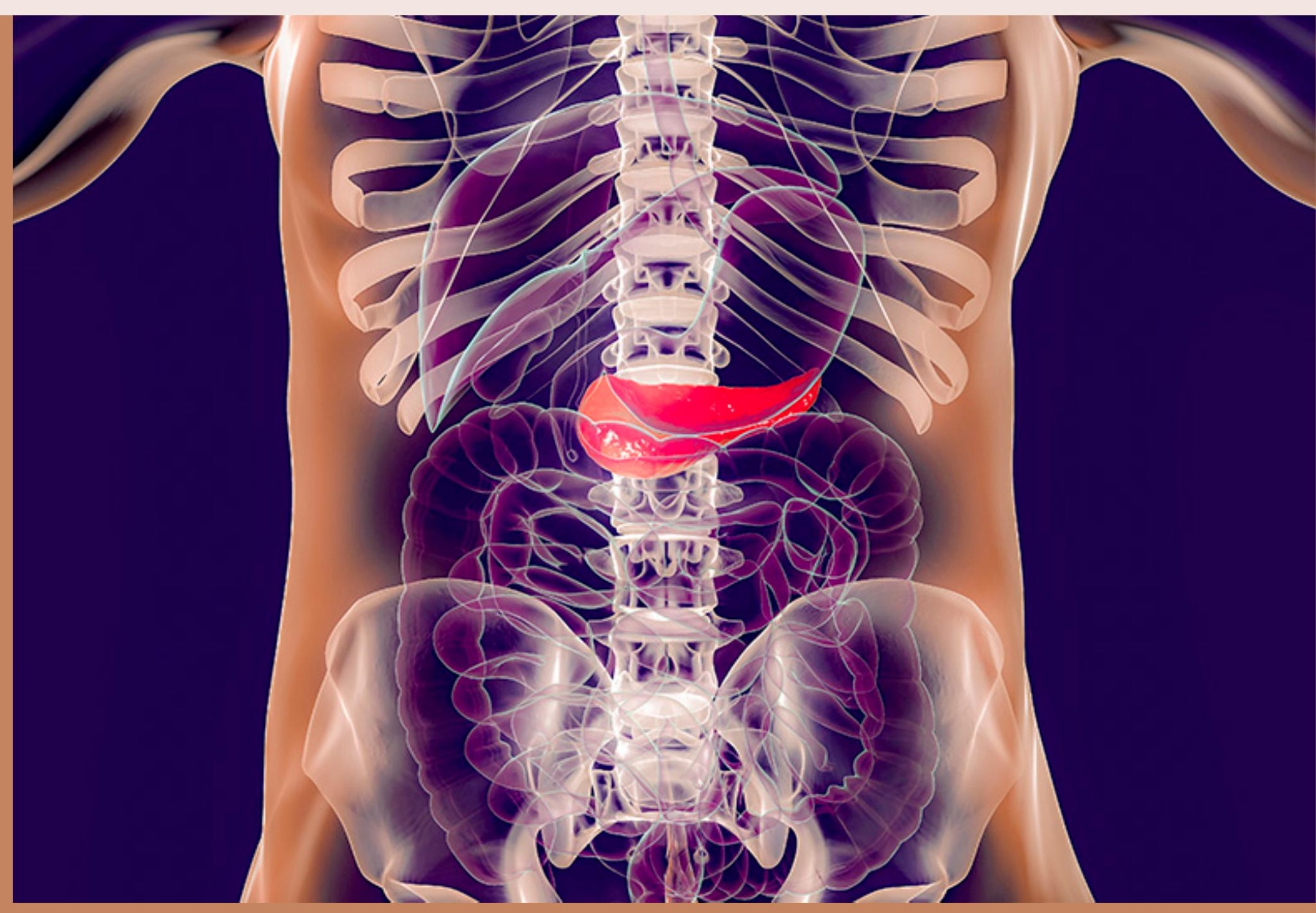

\section{Qartuppi}




\section{(1)(1)(2) (1)}

Esta obra se edita bajo una Licencia Creative Commons

Atribución-NoComercial-Compartirlgual 4.0 Internacional. 


\section{Reducción de estrés \\ en pacientes con \\ Diabetes Mellitus}

Diana Lucero Muñoz Arellano, Yunery Marlen Bautista Gómez, Andrea Ortega Mondragón, Ana Leticia Becerra Gálvez y Leonardo Reynoso Erazo

Qartuppi 
Reducción de estrés en pacientes con Diabetes Mellitus

1era. edición, marzo 2021

ISBN 978-607-8694-06-8

DOI 10.29410/QTP.21.05

D.R. $\odot$ 2021. Qartuppi, S. de R.L. de C.V.

Villa Turca 17, Villas del Mediterráneo

Hermosillo, Son. 83220 México

http://www.qartuppi.com

Edición y Diseño: Qartuppi, S. de R.L. de C.V.

Imagen de portada: Kateryna_Kon/Adobe Stock 


\section{Tabla de Contenido}

$8 \quad$ Índice de tablas

$9 \quad$ Índice de figuras

10 Índice de anexos

11 Introducción

\section{PRIMERA PARTE}

14 1. Estrés y enfermedad

142 2. Diabetes mellitus

14 2.1. Clasificación

15 2.2. Factores de riesgo

17 2.3. Sintomatología

19 3. Epidemiología

19 3.1. En el mundo

19 3.2. En México

4. Diabetes: un problema de comportamiento

4.1. Historia natural y complicaciones

4.2. Tratamiento

4.2.1. Farmacológico

4.2.2. No farmacológico

4.2.2.1. Modificaciones en la alimentación

4.2.2.2. Modificaciones a la actividad física

4.2.2.3. Modificaciones conductuales

4.3. Historia natural de la diabetes en relación con el tratamiento

4.4. Estrés y diabetes 


\section{Medicina conductual}

6.1. Qué es Medicina Conductual (MC)

6.2. Actividades del especialista en MC con pacientes que viven con enfermedad crónica

6.3. Evidencia de la efectividad de las intervenciones cognitivo conductuales

\section{Propuesta de guía}

7.1. Justificación de la migración de modalidad

7.2. Objetivos

7.2.1. Generales

7.2.2. Específicos

\section{SEGUNDA PARTE}

\section{Un modelo de intervención supervisada en estrés (para terapeuta)}

8.1. Generalidades

8.2. El modelo de supervisión

8.2.1. Uso de las TIC's para la supervisión

8.3. Acciones del terapeuta

8.4. Evaluación conductual

8.4.1. Instrumentos

8.4.2. Evaluación inicial

8.4.3. Entrevista conductual

8.4.4. Análisis Funcional de la Conducta (AFC)

8.4.5. Evaluación complementaria

8.5. Canalización

8.6. Planeación de la intervención

8.6.1. Identificación de áreas problema

8.6.2. Selección de estrategias

8.6.3. Selección de las TIC's

8.6.3.1. Normatividad (reglas generales)

8.7. Elección y descripción de las técnicas

8.7.1. Psicoeducación

8.7.2. Estrategias de relajación

8.7.2.1. Relajación pasiva

8.7.2.2. Respiración diafragmática

8.7.3. Autoinstrucciones

8.7.4. Solución de problemas

8.7.5. Uso de técnicas complementarias 
9. Tratamiento

9.1. Sistema de registros

9.1.1. Escalas visuales análogas

9.1.2. Registro de frecuencia cardiaca

9.1.3. Registro de eventos estresantes

9.1.4. Registro de autoinstrucciones

9.1.5. Identificación del problema

9.1.6. Generación de alternativas

9.1.7. Toma de decisiones

9.2. Mantenimiento

9.3. Seguimiento

107 Referencias

$122 \quad$ Anexos 


\section{Índice de tablas}

Tabla 1. Clasificación de factores de riesgo para Diabetes Mellitus (DM)

Tabla 2. Síntomas presentes de acuerdo con el nivel de glucosa en sangre Tabla 3. Síntomas de DM

Tabla 4. Complicaciones patológicas relacionadas con la diabetes mellitus Tabla 5. Clasificación de insulina con base en sus tiempos de efectividad Tabla 6. Actividades del especialista en Medicina Conductual Tabla 7. Evidencia de la efectividad de la TCC en el tratamiento del estrés en pacientes con DM

Tabla 8. Acciones del terapeuta en la intervención en línea

Tabla 9. Fases de la evaluación conductual

Tabla 10. Listas de verificación que constituyen la evaluación inicial

Tabla 11. Escalas que integran la evaluación inicial

Tabla 12. Propuesta de listas de verificación para evaluación complementaria

Tabla 13. Escalas propuestas para la evaluación complementaria

Tabla 14. Fases que componen la psicoeducación

Tabla 15. Pasos para realizar la técnica de autoinstrucciones

Tabla 16. Proceso para el entrenamiento en solución de problema

Tabla 17. Técnicas utilizadas en la TCC para el manejo del estrés

Tabla 18. Generalidades de las etapas de tratamiento

Tabla 19. Distribución de técnicas de acuerdo con las sesiones

Tabla 20. Objetivos y acciones de la intervención en crisis

Tabla 21. Modelo BASIC-ID

Tabla 22. Carta descriptiva de la sesión 1

Tabla 23. Carta descriptiva de la sesión 2

Tabla 24. Carta descriptiva de la sesión 3

Tabla 25. Carta descriptiva de la sesión 4

Tabla 26. Carta descriptiva de la sesión 5

Tabla 27. Carta descriptiva de la sesión 6

Tabla 28. Carta descriptiva de la sesión 7

Tabla 29. Carta descriptiva de la sesión 8

Tabla 30. Carta descriptiva de la sesión 9

Tabla 31. Carta descriptiva de la sesión 10

Tabla 32. Carta descriptiva de seguimiento 


\section{Índice de figuras}

21 Figura 1. Evolución de la enfermedad

25 Figura 2. Historia natural de la DM

27 Figura 3. Modelo transaccional de estrés

28 Figura 4. Ejemplo transacción del estrés en paciente con DM

40 Figura 5. Flujograma de supervisión en el Programa de residencia en MC

47 Figura 6. Flujograma de sesiones de evaluación

51 Figura 7. Flujograma para la toma de decisión sobre canalización

55 Figura 8. Flujograma para solicitud de intervención

56 Figura 9. Flujograma para procedimiento por inasistencia del paciente a sesión

57 Figura 10. Flujograma para procedimiento de canalización

58 Figura 11. Flujograma procedimiento ante desconexión de internet

59 Figura 12. Flujograma de mecanismos para dar de baja del servicio

60 Figura 13. Flujograma de mecanismos para dar de alta del servicio

65 Figura 14. Instrucciones para la respiración diafragmática

71 Figura 15. Flujograma de aplicación de técnicas complementarias

76 Figura 16. Flujograma para uso de registros 


\section{Índice de anexos}

123 Anexo 1. Consentimiento informado

125 Anexo 2. Breve Checklist de Afrontamiento

126 Anexo 3. Checklist Síntomas de Estrés

128 Anexo 4. Escala de Ansiedad y Depresión Hospitalaria (HADS)

130 Anexo 5. Escala de Estrés Percibido (PSS-14)

131 Anexo 6. Checklist Ansiedad A

132 Anexo 7. Checklist Ansiedad B

133 Anexo 8. Inventario de Estrategias de Afrontamiento (CSI)

136 Anexo 9. Cuestionario sobre Calidad de Vida Diabetes

140 Anexo 10. Versión actualizada de la Escala de Adherencia Terapéutica

142 Anexo 11. Escala Reporte de Adherencia a la Medicación (MARS) 


\section{Introducción}

Debido a la situación sanitaria por la COVID-19, el año 2020 representó un cambio a nivel mundial, donde la sociedad se ha visto en la necesidad de adaptarse a diversas situaciones que anteriormente se llevaban a cabo sin restricciones. En el campo de la salud, adaptarse a estos cambios ha sido una tarea difícil debido a las actividades a desempeñar fuera de los contextos hospitalarios. Para los profesionales en formación, particularmente todos aquellos que dejaron de realizar sus actividades en el hospital, ha representado un reto, pero también, una oportunidad para diseñar e implementar novedosas formas de atención a los usuarios que requieren de atención médica y psicológica. A partir de la emergencia de SARS-COV-2, la Universidad Nacional Autónoma de México (UNAM) a través de la Facultad de Estudios Superiores Iztacala, específicamente la residencia en Medicina Conductual (MC), se vio en el menester de adecuar sus actividades siguiendo los lineamientos sanitarios pertinentes para reducir la propagación del virus.

En ese sentido, el programa de esta residencia se caracteriza por la inserción del psicólogo al campo de la salud, atendiendo problemáticas psicológicas que pueden generar enfermedades o ser consecuencias de estas. Si bien la residencia fue planeada para la atención psicológica desde el modelo de la Terapia Cognitivo Conductual (TCC) en pacientes de enfermedades crónico degenerativas tales como: enfermedad renal crónica, diabetes meIlitus, hipertensión arterial, cáncer, entre otras, es común brindar atención a pacientes con enfermedades agudas.

Las enfermedades crónicas precisan del empleo puntual de medicamentos, seguir un régimen alimentario y promover conductas de autocuidado. Para facilitar este tipo de cambios se requiere de un profesional de la salud, un psicólogo conductual, que evalúe las razones de origen que obstaculizan el cumplimiento del tratamiento, además de fomentar estrategias para actuar sobre estos. Lo ideal es desarrollar estrategias de salud desde un tratamiento integral que considere elementos médicos y psicológicos de forma paralela.

Dado que la enfermedad crónica representa cambios y vivir situaciones que se evalúan como estresantes, ya que representan un reto o amenazas para el individuo, es necesario entrenar al paciente en el uso de estrategias de afrontamiento. Las consecuencias de evaluar una situación como estresante posibilitan la aparición de respuestas en niveles conductual, 
cognitivo y fisiológico; las cuales deben abordarse en conjunto, ya que pueden significar un riesgo a la salud, ya sea por las consecuencias directas (aumento en presión arterial) o indirectas (ingesta de alimentos no saludables o pérdida de apetito).

Si bien es cierto, las estrategias de afrontamiento no son iguales para todos (e.g. unos pueden resolver aquello que les causa estrés, mientras que otros pueden ignorar ese evento) aunque tengan características similares, la forma en que afrontan las problemáticas en su día a día dependerá en gran medida de su experiencia previa, pero también de su repertorio conductual, el cual puede ser susceptible de modificación gracias a las estrategias de intervención cognitivo conductual. La TCC ha demostrado ser pertinente en el entrenamiento para el manejo de estrés, donde los pacientes aprenden y ensayan diferentes técnicas enfocadas en la modificación de respuestas en los tres niveles.

Por ello, se elaboró la presente guía adecuando las actividades de intervención dirigidas a pacientes con enfermedades crónico degenerativas y haciendo uso de plataformas online. Esta guía tiene como objetivo proporcionar al especialista en MC las directrices de la intervención cognitivo conductual enfocadas a disminuir el nivel de estrés en personas con diagnóstico de Diabetes Mellitus (DM) tipo 2. A partir de ese objetivo, el contenido se divide en dos apartados.

El primer apartado incluye la contextualización de la enfermedad (definición, clasificación, epidemiología, tratamiento y complicaciones) y la explicación de la historia natural de la enfermedad. Aunado a ello, se aborda el modelo transaccional de estrés y un ejemplo de este. Adicionalmente, se conceptualiza a la MC, se definen las actividades del especialista en esta área, se presentan los resultados de las intervenciones basadas en la evidencia que utilizan la TCC en pacientes con dicha enfermedad tanto en intervenciones presenciales como aquellas basadas en el uso de las Tecnologías de la Información y Comunicación (TIC's).

En el segundo apartado, se aborda la operatividad de la nueva modalidad de intervención: supervisión, normatividad, forma de evaluación y descripción tanto de los instrumentos y plataformas, como de las técnicas a implementar. A su vez, se detalla el tratamiento en sus diferentes etapas (difusión, envío de datos, contacto al paciente, evaluación, intervención, mantenimiento, evaluación post intervención y seguimientos que abarcan monitoreos e intervención en crisis). Para finalizar la sección se añaden las cartas descriptivas de las sesiones. Es imperante recalcar que la guía es flexible y tiene un enfoque individualizado, lo que implica que el terapeuta tomará decisiones - añadiendo sesiones o técnicas - considerando las características del paciente y las deficiencias o excesos conductuales que se presenten como parte de la misma problemática asociada al estrés.

De este modo, el objetivo general del programa de intervención propuesto en esta guía es disminuir el nivel de estrés presente en personas con diagnóstico de DM tipo 2, a partir de una intervención cognitivo conductual centrada en la adquisición de estilos de afrontamiento funcionales en situaciones evaluadas como estresantes. 
Primera Parte 


\section{Estrés y enfermedad}

Los pacientes con enfermedades crónico degenerativas se enfrentan con distintas situaciones que resultan amenazantes para ellos, por ejemplo, un diagnóstico, el ambiente hospitalario, procedimientos quirúrgicos, tratamientos, entre otras. En ese sentido, al ser una situación evaluada como amenazante, cada individuo la enfrentará de diferente manera, ello dependerá de una serie de factores como: percepción y etapa de la enfermedad, apoyo social, personalidad y algunas variables demográficas (Petrie \& Jones, 2019).

\section{Diabetes Mellitus}

La Diabetes Mellitus (DM) es una enfermedad crónico degenerativa y endocrina metabólica que se origina cuando existe una deficiencia en la secreción o acción de la insulina que es una hormona reguladora de los niveles de glucosa en la sangre (Klandorf \& Stark, 2019). Por ello, la consecuencia de la deficiencia en la acción de la insulina es la hiperglucemia.

\subsection{Clasificación}

La DM tiene una etiología múltiple e incluye un grupo de enfermedades que presentan variados procesos patogénicos como trastornos genéticos y ambientales. Se clasifica con base en su etiología y por el proceso que desencadena la hiperglucemia. Así que, según la American Diabetes Association (ADA, 2019a) se clasifica en cuatro tipos: diabetes mellitus tipo 1 , diabetes mellitus tipo 2, diabetes gestacional y otros tipos específicos de diabetes. 
La DM tipo 1 se caracteriza por la deficiencia en la producción de insulina y una tendencia a sufrir cetosis (Kasper et al., 2017). Según el National Institute of Diabetes and Digestive and Kidney Diseases (NIDDK, 2019), la causa de la DM tipo 1 aún es desconocida, aunque se argumenta que puede deberse a factores genéticos y ambientales como virus y se le relaciona con una enfermedad autoinmune, donde el sistema inmunitario destruye las células que producen la insulina. Los pacientes pueden ser de cualquier edad, casi siempre delgados y los síntomas pueden aparecer antes de los 30 años.

Por otra parte, la DM tipo 2 es un grupo heterogéneo de trastornos que se caracteriza por grados variables de resistencia a la insulina, alteraciones en la secreción de insulina y una producción excesiva de glucosa hepática (Kasper et al., 2017). En el caso de la DM2, la combinación del factor genético (Klandorf \& Stark, 2019), aunado al estilo de vida (Barba, 2019), posibilita la aparición de la misma. De acuerdo con Barba (2019) este tipo de DM se diagnostica normalmente en personas con obesidad después de los 30 años. No obstante, en la actualidad está incrementando su prevalencia en niños y adolescentes con obesidad (Ali, Abdallah, Abdallah, \& Hussein, 2013; Copeland et al., 2013; Craig, Femia, Broyda, Lloyd, \& Howard, 2007; Fazeli, van der Aa, van der Vorst, Knibbe, \& de Boer, 2013; Hannon, Rao, \& Arslanian, 2005; Liese, Ma, Maahs, \& Trilk, 2013; Springer et al., 2013) o con el desarrollo de síndrome metabólico (Barba, 2019).

El tercer tipo de diabetes es la gestacional, Barba (2019) señala que es la alteración en el metabolismo que, como su nombre lo indica, se diagnostica durante el embarazo, específicamente en el segundo o tercer trimestre. Las causas de esta condición no se conocen; sin embargo, la ADA (2019a) establece que las hormonas involucradas en el embarazo pueden bloquear la acción de la insulina de la madre en su cuerpo y causar un problema llamado resistencia a la insulina.

Finalmente, el cuarto grupo corresponde a otros tipos específicos de diabetes debido a otras causas, entre ellas se encuentran: síndromes de diabetes monogénica, enfermedades del páncreas exocrino, endocrinopatías, diabetes inducida por fármacos o sustancias químicas, otros síndromes genéticos asociados, defectos genéticos en la función de las células del páncreas, defectos genéticos en la acción de la insulina, endocrinopatías e infecciones (Sanzana \& Durruty, 2016).

No obstante, cabe destacar lo mencionado por Díaz y Delgado (2016) quienes describen que la mayoría de los casos de diabetes se pueden encuadrar en dos grandes categorías: DM tipo 1 y DM tipo 2.

\subsection{Factores de riesgo}

La causa del desarrollo de la enfermedad ha sido reportada como multifactorial, encontrando que existen factores genéticos, biológicos, ambientales y comportamentales, como se observa en la tabla 1. 


\section{Tabla 1}

\section{Clasificación de factores de riesgo para Diabetes Mellitus (DM)}

\begin{tabular}{|c|c|c|}
\hline Nivel & Caracterizados & Factores \\
\hline \multirow{6}{*}{ Genético } & \multirow{2}{*}{$\begin{array}{l}\text { Anomalías cromosómicas de nueva } \\
\text { aparición o heredadas }\end{array}$} & Síndrome de Down \\
\hline & & Síndrome de Turner \\
\hline & \multirow{4}{*}{$\begin{array}{l}\text { Alteraciones en ADN transmitidas por } \\
\text { herencia }\end{array}$} & Resistencia a la insulina tipo A \\
\hline & & Diabetes lipoatrófica \\
\hline & & Porfiria \\
\hline & & Ataxia de Friedreich \\
\hline \multirow{15}{*}{ Biológico } & \multirow{15}{*}{$\begin{array}{l}\text { Condiciones del organismo que hacen } \\
\text { posible la aparición de esta enfermedad }\end{array}$} & Hipertensión arterial \\
\hline & & Sobrepeso \\
\hline & & Obesidad \\
\hline & & Pancreatitis \\
\hline & & Trauma/pancreatectomía \\
\hline & & Neoplasia \\
\hline & & Fibrosis quística \\
\hline & & Hemocromatosis \\
\hline & & Pancreatopatía fibrocalculosa Acromegalia \\
\hline & & Síndrome de Cushing \\
\hline & & Hipertiroidismo \\
\hline & & Glucagonoma \\
\hline & & Feocromocitoma \\
\hline & & Somatostatinoma \\
\hline & & Aldosteronoma \\
\hline \multirow{13}{*}{ Ambiental } & \multirow{2}{*}{$\begin{array}{l}\text { Virus que pueden comprometer } \\
\text { la función del páncreas }\end{array}$} & Rubéola congénita \\
\hline & & Citomegalovirus \\
\hline & \multirow{11}{*}{$\begin{array}{l}\text { Medicamentos que pueden comprometer } \\
\text { la función del páncreas }\end{array}$} & Vacor \\
\hline & & Pentamidina \\
\hline & & Ácido nicotínico \\
\hline & & Glucocorticoides \\
\hline & & Hormona tiroidea \\
\hline & & Diazóxido \\
\hline & & Agonistas betaadrenérgicos \\
\hline & & Tiazidas \\
\hline & & Difenilhidantoína \\
\hline & & IFN-alfa \\
\hline & & Estatinas \\
\hline \multirow{5}{*}{ Comportamental } & \multirow{5}{*}{$\begin{array}{l}\text { Estilos de vida que ha llevado el individuo } \\
\text { durante su vida }\end{array}$} & Nivel de actividad \\
\hline & & Hábitos comportamentales \\
\hline & & Tipo de alimentación \\
\hline & & Cantidad de alimentos \\
\hline & & Consumo de tabaco \\
\hline
\end{tabular}

Nota: Elaboración propia. A partir de “Diabetes Mellitus" por H. Klandorf y S. Stark, 2019, Magill's Medical Guide (Online Edition); "Factores asociados al desarrollo de diabetes mellitus tipo 2 en Chile" por A. M. Leiva, M. A. Martínez, F. Petermann Rocha, A. Garrido, F. Poblete, X. Díaz, y C. Celis, 2018, Nutrición Hospitalaria, 35(2); y “Diabetes mellitus. Criterios diagnósticos y clasificación. Epidemiología. Etiopatogenia. Evaluación inicial del paciente con diabetes" por L. Díaz y E. Delgado, 2016, Medicine - Programa de Formación Médica Continuada Acreditado, 12(17). 
Es preciso esclarecer que se entiende como estilo de vida al conjunto de comportamientos relativamente estables en la historia del individuo y que son aprendidos en el transcurso de la experiencia personal (Mulder, Ranchor, Sanderman, Bouma, \& van den Heuvel, 1998; Reynoso \& Seligson, 2005). Específicamente en el caso del DM tipo 2, el estilo de vida se puede caracterizar por el sedentarismo e inactividad física (Leiva et al., 2018), el consumo de tabaco (Borba et al., 2018) o una dieta alta en carbohidratos (ADA, 2015).

\subsection{Sintomatología}

Los pacientes con DM con glicemia elevada suelen presentar síntomas como los que se describen en la tabla 2; estos se asocian a los tipos de DM, en donde los del tipo 1 pueden aparecer rápidamente. Adicionalmente, existen los síntomas relacionados a los diferentes niveles de glicemia que se muestran en la tabla 2. Mientras que los de la DM tipo 2 suelen progresar lentamente, a lo largo de varios años y pueden ser tan leves que a veces ni siquiera son visibles en lo inmediato. De hecho, un porcentaje de pacientes que viven con esta última condición son asintomáticos y son diagnosticados cuando surgen problemas de salud relacionados con la diabetes (Boronat \& Wägner, 2016).

\section{Tabla 2}

Síntomas presentes de acuerdo con el nivel de glucosa en sangre

\begin{tabular}{|c|c|c|}
\hline Afección & Niveles & Síntomas \\
\hline \multirow{18}{*}{ Hipoglucemia } & \multirow{18}{*}{ Inferior a 70 mg/dl } & Temblor \\
\hline & & Nerviosismo \\
\hline & & Sudoración, escalofríos y humedad \\
\hline & & Irritabilidad o impaciencia \\
\hline & & Confusión \\
\hline & & Latidos cardíacos acelerados \\
\hline & & Sentirse aturdido o mareado \\
\hline & & Hambre \\
\hline & & Náusea \\
\hline & & Palidez \\
\hline & & Sueño \\
\hline & & Debilidad o sin energía \\
\hline & & Visión borrosa / deteriorada \\
\hline & & Hormigueo o entumecimiento en los labios, la lengua o las mejillas \\
\hline & & Dolores de cabeza \\
\hline & & Problemas de coordinación, torpeza \\
\hline & & Pesadillas o gritos durante el sueño \\
\hline & & Convulsiones \\
\hline Normoglucemia & Entre 70 y $140 \mathrm{mg} / \mathrm{dl}$ & - \\
\hline
\end{tabular}




\begin{tabular}{|c|c|c|}
\hline \multirow{5}{*}{ Hiperglucemia } & \multirow{5}{*}{ Entre 140 y 240 mg/dl } & Nivel alto de azúcar en sangre \\
\hline & & Niveles altos de azúcar en la orina \\
\hline & & Micción frecuente \\
\hline & & Aumento de la sed \\
\hline & & Fatiga \\
\hline \multirow{10}{*}{ Cetoacidosis } & \multirow{10}{*}{ Superior a 240 mg/dl } & Sed o boca muy seca \\
\hline & & Micción frecuente \\
\hline & & Niveles altos de glucosa en sangre \\
\hline & & Niveles altos de cetonas en la orina \\
\hline & & Constantemente sentirse cansado \\
\hline & & Piel seca o enrojecida \\
\hline & & Náuseas, vómitos o dolor abdominal \\
\hline & & Respiración dificultosa \\
\hline & & Olor afrutado en el aliento \\
\hline & & Dificultad para prestar atención o confusión \\
\hline
\end{tabular}

Nota: Elaboración propia a partir de "DKA (Ketoacidosis) \& Ketones" por American Diabetes Association (ADA), 2019b; "Hyperglycemia (High Blood Glucose)" por American Diabetes Association (ADA), 2019c; y "Hypoglycemia (Low Blood Glucose)" por American Diabetes Association (ADA), 2019d.

\section{Tabla 3}

\section{Síntomas de DM}

\begin{tabular}{ll}
\hline \multicolumn{1}{c}{ Síntomas } & Tipo de diabetes \\
\hline Pérdida de peso & DM1 \\
\hline Hormigueo o entumecimiento de las extremidades (manos y pies) & DM2 \\
\hline Dolor en las extremidades (manos y pies) & DM1 y 2 \\
\hline Excreción excesiva de orina (poliuria) & DM1 y 2 \\
\hline Sed excesiva (polidipsia) & DM1 y 2 \\
\hline Hambre constante (polifagia) & DM1 y 2 \\
\hline Deshidratación & DM1 y 2 \\
\hline Presión arterial baja & DM1 y 2 \\
\hline Fatiga & DM1 y 2 \\
\hline Náuseas & DM1 y 2 \\
\hline Vómitos & DM1 y 2 \\
\hline Visión borrosa & DM1 y 2 \\
\hline Infecciones superficiales frecuentes & DM1 y 2 \\
\hline Mala cicatrización y heridas & \\
\hline
\end{tabular}

Nota: DM1 diabetes tipo 1, DM2 diabetes tipo 2, DM1 y 2 para ambos tipos de diabetes mellitus. Elaboración propia. A partir de "Diabetes Mellitus" por H. Klandorf y S. Stark, 2019, Magill's Medical Guide (Online Edition); “Diabetes Overview Symptoms, Causes, Treatment" por American Diabetes Association (ADA), 2019a; y Harrison. Manual de Medicina por D. L. Kasper, A. S. Fauci, S. L. Hauser, D. L. Longo, J. L. Jameson, y J. Loscalzo, 2017, México: McGraw-Hill Medical. 


\section{Epidemiología}

\subsection{En el mundo}

Durante el 2020, la International Diabetes Federation (IDF) estimó que 463 millones de personas tienen DM. Las cifras estimadas previamente no hacen distinción entre edades; sin embargo, la Secretaría de Salud (2016) reportó que el número de adultos con diabetes que se calculaba alrededor del mundo era de 387 millones. Por otro lado, en el 2014 la Organización Mundial para la Salud (OMS, 2020) estableció que hubo un incremento en la incidencia de personas con diabetes de 108 millones en 1980 a 422 millones. Entre los años 2014 y 2020, la incidencia del padecimiento ha incrementado en aproximadamente 40 millones.

\subsection{En México}

Por su parte, en nuestro país, la Secretaría de Salud (2016) registró un incremento en la prevalencia de los factores conductuales asociados al desarrollo de la enfermedad para seguir un régimen alimentario, por lo que se podría señalar que en el país las enfermedades relacionadas a comportamientos ocupan los primeros lugares como causa de muerte.

Según la IDF (2020), se estima que en México existen alrededor de 84296800 adultos con diabetes, lo que indicaría que más de la mitad de la población tiene esta enfermedad. Adicionalmente, el Instituto Nacional de Geografía e Informática (INEGI, 2020) reportó que el número de defunciones relacionadas a esta condición en el año 2018 fue de 49679 (12.2\%) en hombres y de 51576 (16.4\%) para las mujeres. Aunado a lo anterior, se estima que alrededor de 4504 personas en México desconocen que padecen diabetes, lo que provoca que no tengan un tratamiento. La IDF (2017) calculó que 85000 personas en México mueren al año a consecuencia de la diabetes o sus complicaciones. Un año antes, la Secretaria de Salud (2016) destacó a nivel nacional que la diabetes mellitus, sin distinción entre los tipos, fue la segunda causa de muerte en el país con $9.4 \%$ del total. Para la actualización de ese mismo año, el INEGI (2016) informó que la diabetes mellitus es la tercera causa de muerte en nuestro país, detrás de la enfermedad cardiovascular.

Por su parte, el Institute of Health Metrics and Evaluation (IHME, 2013) realizó un análisis abarcando las causas de los años de vida saludables perdidos y de los años vividos con una discapacidad en México, encontrando que la diabetes es la primera causa (7.1\%) y la tercera causa (6.3\%), respectivamente. Cabe señalar que la DM es la tercera causa de pérdidas por muerte prematuras con el $7.6 \%$ de las muertes, esto indica que esta enfermedad no solamente es de las principales causas de mortalidad en nuestro país, sino que también es un factor que afecta nuestra calidad y esperanza de vida. 


\section{Diabetes: un problema de comportamiento}

\subsection{Historia natural y complicaciones}

Leavell y Clark (1958) presentaron un modelo para estudiar el desarrollo de las enfermedades (figura 1). En este se destaca el progreso del padecimiento en relación con la temporalidad y el tipo de intervenciones pertinentes. Este modelo permite estudiar el proceso saludenfermedad con una perspectiva multicausal, sistemática y científica (Fraga \& Valles, 2019).

De acuerdo con Fraga y Valles (2019), el estado de salud de un individuo depende de una interacción entre estímulos y el equilibrio de tres elementos: huésped, agente y medio ambiente, conocidos como tríada ecológica, en ella se incluyen las múltiples influencias, reacciones y características entre los elementos. Esta relación dinámica mantiene la salud del individuo, concibiendo a la enfermedad como la alteración en el equilibrio de la triada.

Los mismos autores destacan que los agentes son aquellos elementos o sustancias, cuya ausencia o presencia, pueden causar en el ser humano un padecimiento al estar en contacto directo en adecuadas condiciones medio ambientales. Se clasifican en cinco: biológicos, nutrimentales, mecánicos, químicos y físicos (Fraga \& Valles, 2019). Por su parte, Jenicek (1996) agrega otro grupo: psicológicos.

El estudio de las enfermedades en el modelo propuesto por Leavell y Clark (1958) fue concebido ante dos etapas. La primera de ella es la prepatogénica, misma que Fraga y Valles (2019) mencionan que incluye las circunstancias de la tríada ecológica que rodean al individuo antes de la adquisición de la enfermedad. Representa la suma de los factores protectores y de riesgo, mismos que pueden convertirse en desencadenantes, para determinar el equilibrio o desequilibrio de la tríada y, por ende, pueden aumentar o disminuir la vulnerabilidad del potencial huésped ante la enfermedad.

La segunda etapa es la patogénica, que inicia con la interacción del agente y el huésped, obteniendo como respuesta cambios orgánicos y funcionales, en otras palabras, es la presencia de la enfermedad (Fraga \& Valles, 2019). Aquí se aborda la evolución de esta desde el momento en que se propicia la respuesta hasta su terminación. Debido a ello, se divide en subetapas, iniciando con un tiempo de incubación o patogénesis temprana que da lugar al inicio de cambios tisulares, progresando hacia la presencia de signos y síntomas, posibilitando la emergencia del horizonte clínico, en el cual la enfermedad deja de ser subclínica y se vuelve clínica. Si la enfermedad no se interrumpe con un tratamiento, sigue su curso, ya sea de carácter agudo o crónico y alcanza la convalecencia. De este modo, la enfermedad puede curarse, generar incapacidad y secuelas, provocar la muerte de manera directa o indirecta (al presentar complicaciones) o puede evolucionar hacia la curación.

El modelo sugiere tres niveles de prevención de acuerdo con las etapas: primaria, relacionada con la prepatogénica, mientras que la secundaria y terciaria están incluidas en la patogénica (Leavell \& Clark, 1958). Al respecto, Chang y Wong (2020) describen que la primera se centra en prevenir la aparición de las enfermedades y a reducir los factores de 
riesgo mediante reglamentos, programas de salubridad y educación sanitaria. Estos mismos autores señalan que la segunda se enfoca en la detención del progreso del padecimiento, lo que implica una detección temprana para aumentar la probabilidad de intervenir de manera oportuna con el objetivo de evitar la progresión y desarrollo de síntomas. Finalmente, exponen que la prevención terciaria encamina los recursos para minimizar las discapacidades y complicaciones para restaurar las funciones corporales que se han visto afectadas por la enfermedad, comprende tratamiento, rehabilitación y cuidados paliativos.

\section{Figura 1}

Evolución de la enfermedad

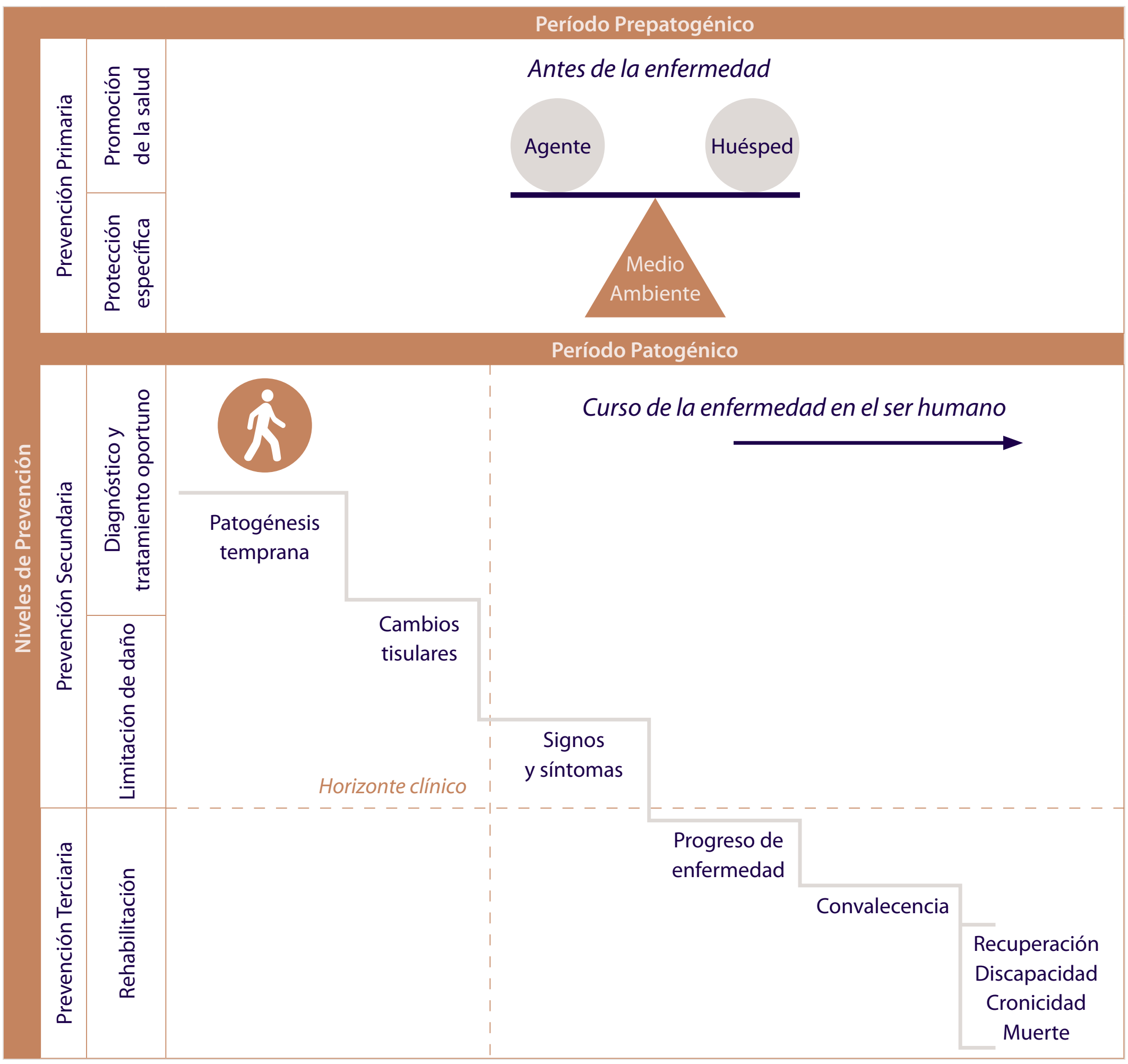

Nota: Adaptado de "Historia natural de la enfermedad" por M. A. Fraga y A. M. Valles, 2019. En A. M. Valles (Ed.), Modelos y teorías de salud pública, p. 38. 
La presente guía utiliza este modelo dirigido a enfermedades crónicas, aquellas que no tienen cura y se caracterizan por un daño progresivo del cuerpo. La intervención para pacientes diagnosticados con este tipo de enfermedades se centra en la implementación de estrategias focalizadas al segundo nivel de prevención para detener su evolución y retrasar la manifestación de complicaciones asociadas a ella.

Los pacientes que viven con DM presentan complicaciones a largo plazo, no siendo la intensidad y duración de la hiperglucemia los únicos factores determinantes para la aparición de estas. En la tabla 4 se presentan las comorbilidades crónicas relacionadas a la diabetes que se clasifican acorde con los sistemas orgánicos comprometidos (Kasper et al., 2017).

\section{Tabla 4}

Complicaciones patológicas relacionadas con la diabetes mellitus

\begin{tabular}{ll} 
Sistemas orgánicos & \\
Oftalmológicas & Retinopatía diabética, edema macular, rubeosis del iris, glaucoma y cataratas. \\
\hline Renales & Proteinuria, Enfermedad Renal Crónica en fase Terminal (ERCT) y acidosis tubular renal de tipo IV. \\
\hline Neurológicas & Polineuropatía simétrica distal, polirradiculopatía, mononeuropatía y neuropatía autonómica. \\
\hline Gastrointestinales & Gastroparesia, diarrea y estreñimiento. \\
\hline Genitourinarias & Cistopatía, disfunción eréctil, disfunción sexual en la mujer y candidiasis vaginal. \\
\hline Cardiovasculares & Coronariopatía, insuficiencia cardiaca congestiva, vasculopatía periférica y evento vascular cerebral. \\
\hline Extremidades & Deformidad de los pies (dedo en martillo, dedo en garra y pie de Charcot), úlceras y amputación. \\
inferiores & Infecciones (foliculitis, furunculosis, celulitis), necrobiosis, mala cicatrización, úlceras y gangrena. \\
\hline Dermatológicas & Enfermedad periodontal. \\
\hline Dentales &
\end{tabular}

Nota: Elaboración propia a partir de Harrison. Manual de Medicina, por D. L. Kasper, A. S. Fauci, S. L. Hauser, D. L. Longo, J. L. Jameson, y J. Loscalzo, J., 2017.

\subsection{Tratamiento}

El tratamiento de las enfermedades crónicas se dirige al control glicémico, donde se busca mantener los niveles de glucosa en el rango normal (Mezitis \& Mezitis, 2017) y así prevenir en lo posible futuras complicaciones. Ese control es el que permitirá reducir los síntomas y postergar la aparición de las consecuencias mencionadas en la tabla 4.

Para poder cumplir con este objetivo, el manejo terapéutico se aborda desde una perspectiva integral que incluye tratamiento farmacológico y no farmacológico. Este último incorpora las modificaciones en la alimentación, la actividad física y la conducta.

\subsubsection{Farmacológico}

El tratamiento médico abarca las sustancias químicas que sirven para mantener los niveles de glucosa bajos y se prescriben a partir de la clasificación de la diabetes. De acuerdo con 
la ADA (2019a) el tratamiento para la DM consiste en la administración de insulina, la cual puede ser usada tanto en paciente con DM tipo 1 como en pacientes con DM tipo 2, aunque estos últimos pueden recibir medicación con hipoglucemiantes orales, cuyo mecanismo de acción consiste en impulsar a las células beta del páncreas a liberar más insulina de lo habitual con lo que se reduce la glicemia (Klandorf \& Stark, 2019).

La insulina se prescribe porque el cuerpo no la produce (DM tipo 1) o porque no se utiliza adecuadamente (DM tipo 2). Actualmente existen distintos tipos de insulina que se clasifican de acuerdo con el inicio de la acción en el organismo, el punto más alto de la actividad y la duración total de funcionamiento (ADA, 2019a; Klandorf \& Stark, 2019). En la tabla 5 se presenta dicha clasificación, de acuerdo con la ADA (2019a).

\section{Tabla 5}

Clasificación de insulina con base en sus tiempos de efectividad

\begin{tabular}{llll}
\multicolumn{1}{c}{ Tipo de insulina } & \multicolumn{1}{c}{ Inicio de acción } & Punto más alto & \multicolumn{1}{c}{ Duración de funcionamiento } \\
Acción rápida & $15 \mathrm{~min}$ & 1 hora & De 2 a 4 horas \\
\hline Acción regular & $30 \mathrm{~min}$ & De 2 a 3 horas & De 3 a 6 horas aproximadamente \\
\hline Acción intermedia & 2 a 4 horas & De 4 a 12 horas & De 12 a 18 horas aproximadamente \\
\hline Acción prolongada & Varias horas después de la inyección & Acción uniforme & 24 horas aproximadamente \\
\hline
\end{tabular}

Nota: Elaboración propia a partir de "Medication management" por American Diabetes Association (ADA), $2019 \mathrm{e}$, Diabetes.

\subsubsection{No farmacológico}

De acuerdo con la Organización Panamericana de la Salud (OPS) y la OMS (2017), el manejo de un paciente con enfermedad no transmisible implica la implementación de tratamiento no farmacológico, asociado a cambios en los hábitos de vida que puedan suponer una barrera; la adopción de hábitos saludables incrementa la eficacia del tratamiento farmacológico, estos hábitos implican modificaciones en la alimentación y la actividad física, restricciones en el consumo de bebidas alcohólicas o cualquier hábito nocivo para el paciente (tabaquismo, drogadicción, sedentarismo, entre otros).

La OMS (2003) indica que, para mejorar la efectividad del tratamiento y la calidad de vida en el paciente, es fundamental la adherencia al tratamiento, definida como el grado en el que la conducta del paciente se relaciona con la toma del medicamento, el seguimiento de una dieta y las modificaciones de los hábitos de vida. Por lo tanto, la adquisición de un estilo de vida saludable repercutirá positivamente en la salud.

\subsubsection{Modificaciones en la alimentación}

Como se abordó en el apartado de factores de riesgo, existen comportamientos que contribuyen al desarrollo de la DM como lo es la ingesta de una dieta alta en carbohidratos. Estos 
mismos se relacionan con los niveles de hiperglucemia en los pacientes y el desarrollo de complicaciones posteriores. Son los profesionales en nutrición (nutriólogos o bariatras) los encargados de elaborar las adecuaciones necesarias a la dieta de las personas que tienen esta condición. En general, estas recomendaciones se centran en una dieta balanceada, baja en carbohidratos y control del peso corporal (Kasper et al., 2017; Klandorf \& Stark, 2019).

\subsubsection{Modificaciones a la actividad física}

Aunado al tratamiento descrito previamente, es necesario que los pacientes modifiquen su estilo de vida, específicamente realizando cambios en el nivel de actividad física (Kasper et al., 2017; Klandorf \& Stark, 2019). El tratamiento para pacientes con esta condición consiste en aumentar el nivel de actividad física, realizando diferentes ejercicios o movimientos, con base en las características de cada paciente. Los encargados de evaluar, adecuar y brindar un plan de actividades al individuo son los profesionales especializados en el área de fisioterapia y de la salud.

\subsubsection{Modificaciones conductuales}

La modificación de los estilos de vida es el eje rector del tratamiento cuando hablamos de $\mathrm{DM}$, este incluye los comportamientos relacionados con los cambios en el nivel de actividad física, la alimentación, los hábitos poco saludables, además de la adherencia a la dieta y al medicamento, ya sea oral o inyectado. Por su parte, Mendoza (2017) destaca la importancia de que el tratamiento de un individuo con DM consista en proporcionar conocimientos, entrenar habilidades psicomotoras, de afrontamiento psicológico efectivo y realizar modificaciones en el estilo de vida que proporcionan autonomía, capacidades de manipulación, pensamiento y relación social. Así, se destaca la relevancia de la modificación en los comportamientos para propiciar comportamientos saludables.

\subsection{Historia natural de la diabetes en relación con el tratamiento}

En la figura 2 se expone el modelo de Fraga y Valles (2019) sobre la historia natural de la enfermedad adaptado a la DM. En ella se puede observar que se abordan los factores de riesgo, niveles de glicemia y complicaciones del padecimiento, asociados a la evolución de la enfermedad. Asimismo, se ejemplifica el efecto tanto del tratamiento como de la adherencia que, en consecuencia, definen la progresión de la enfermedad a través del tiempo. Podemos observar que sin tratamiento las complicaciones aparecen rápidamente, en el caso de contar con tratamiento, pero sin adherencia al mismo, hace que los síntomas progresen un poco más lento mientras que, cuando se cuenta con adherencia al tratamiento, la ocurrencia se atrasa con mayor medida. 
Figura 2

Historia natural de la DM

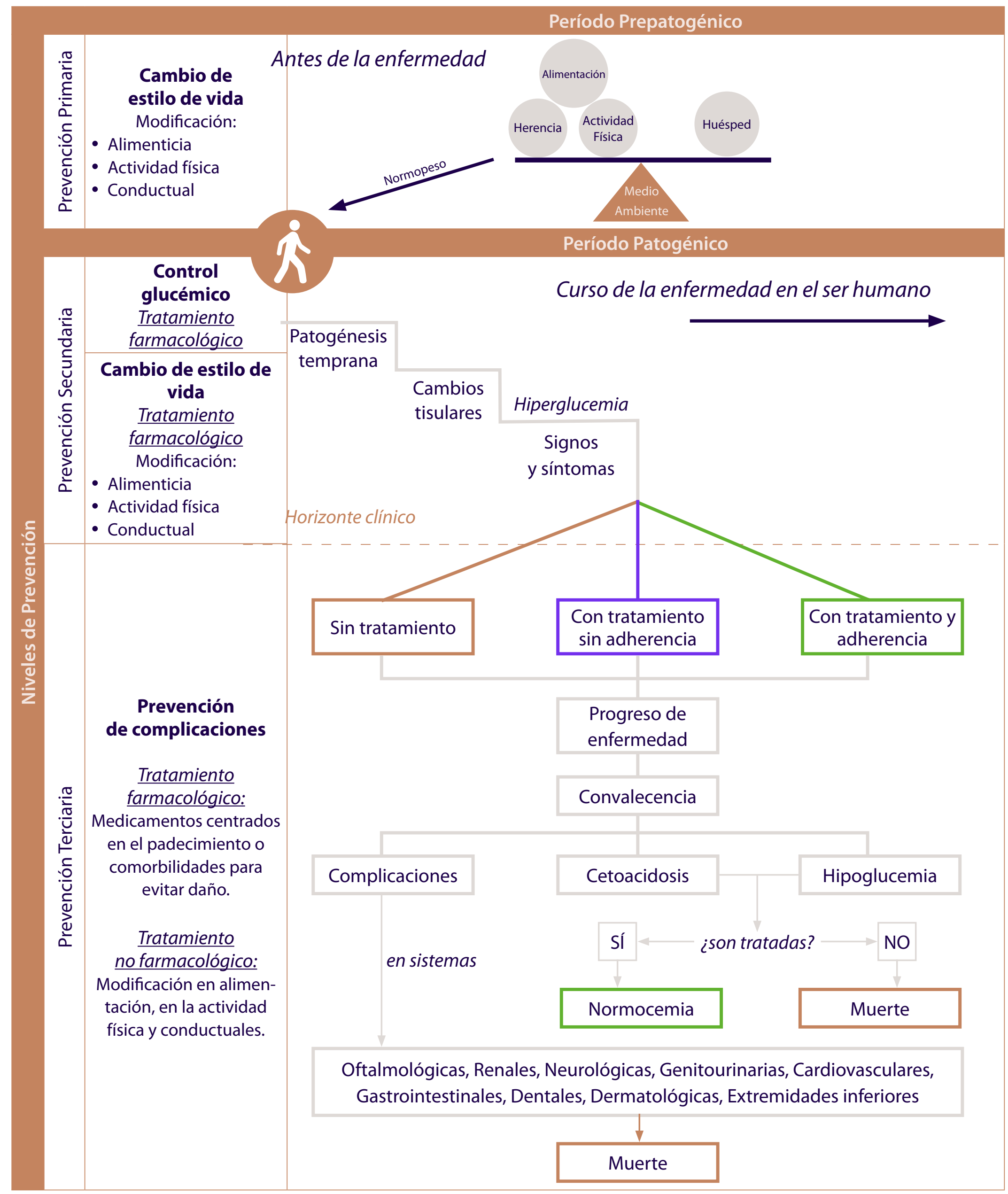

Nota: Adaptado de "Historia natural de la enfermedad" por M. A. Fraga y A. M. Valles, 2019. En A. M. Valles (Ed.), Modelos y teorías de salud pública, p. 38. 


\subsection{Estrés y diabetes}

Una persona diagnosticada con una enfermedad crónica como la diabetes puede experimentar estrés. En este sentido, Björntorp (1997) formuló una teoría sobre la respuesta biológica de la asociación entre el estrés y la diabetes, en donde afirma que el estrés percibido como una reacción de impotencia, conduce a una activación del eje hipotálamo-hipófisis-adrenal - parte del sistema endocrino-, lo que a su vez da como resultado anormalidades endocrinas (Anguiano, 2014). Entre esas anormalidades se incluyen: altos niveles de cortisol y bajos de esteroides sexuales, que antagonizan las acciones de la insulina. Adicionalmente, este desequilibrio hormonal causa adiposidad visceral, la cual desempeña un papel central en la diabetes y la enfermedad cardiovascular, al contribuir al desarrollo de resistencia a la insulina (Björntorp, 1991; Björntorp, 1997). En el año 2000, Mooy, de Vries, Grootenhuis, Bouter y Heine realizaron un estudio para comprobar la teoría de Björntorp, en donde los resultados fueron parcialmente consistentes con la teoría de que los eventos vitales estresantes, que indican estrés crónico, están asociados con diabetes no detectada y con adiposidad visceral. Adicionalmente, se han realizado varios estudios (Surwit, Schneider, \& Feinglos, 1992; Wales, 1995) donde se ha reportado que el estrés puede inducir hiperglucemia en individuos con diabetes.

\section{Modelo de estrés}

\subsection{El modelo de estrés y afrontamiento}

Las personas experimentan situaciones evaluadas como estresantes todos los días, la diferencia en los resultados o soluciones es la manera como se afrontan. Para Lazarus y Folkman (1984), el estrés es el resultado de la evaluación del individuo respecto a su bienestar y sus recursos, si están agotados o son excedidos, ante una situación calificada como estresante, es decir, el estrés supone la interacción entre una persona y su ambiente. Estos autores destacan una tríada básica para definir a las situaciones evaluadas como estresantes y están relacionadas con pérdidas o daños, amenazas o desafíos. Son determinadas mediante un proceso de evaluación que es un ejercicio cognitivo de identificación de características situacionales, si el evento es cambiante o no y estrategias de afrontamiento posibles a utilizar.

Existe una variedad de eventos que pueden ser evaluados como estresantes, entre ellos se encuentran: molestias diarias, eventos de vida personal o desastres a gran escala. Por otra parte, los eventos de cualquier tipo pueden ser considerados estresantes solo con base en la intensidad del daño que causan, además, pueden variar en otras dimensiones siendo de corto plazo o crónicos, esperados o inesperados, ambiguos o no ambiguos, y controlados o incontrolables. La evaluación realizada determina tanto las respuestas de carácter emocional, fisiológico y cognitivo, como las estrategias de afrontamiento a emplear (Ben-Zur, 2019).

Las estrategias de afrontamiento se refieren a los repertorios que las personas implementan para abordar la situación, estas se traducen en estrategias cognitivas o conductuales 
que median la relación entre la percepción del estrés y el proceso de adaptación (Rodríguez, Zúñiga, Contreras, Gana, \& Fortunato, 2016). La habilidad para manejar situaciones estresantes depende de las estrategias de afrontamiento, su eficacia y los resultados asociados dependen tanto de los aspectos estables (valores y creencias personales) como de los elementos inherentes a la propia situación (Lazarus, 2000; Ortega \& Salanova, 2016). Las estrategias propuestas por Lazarus y Folkman (1984) son el afrontamiento centrado en la acción, en esta se engloban todas aquellas actividades o manipulaciones orientadas a modificar o alterar el problema y su resultado; mientras que el afrontamiento dirigido a la emoción está orientado a regular las respuestas emocionales a las que la situación da lugar (Folkman, Lazarus, Dunkel-Schetter, DeLongis, \& Gruen, 1986). En la figura 3 se presenta el esquema de transacción de estrés.

Según la teoría transaccional de Lazarus y Folkman (1984), la persona que experimenta los eventos como amenazantes para su bienestar, toma en cuenta los recursos con los que cuenta en el momento que ocurren como, por ejemplo, el estado económico y el apoyo social, por lo que la evaluación de la situación y su afrontamiento están en constante cambio.

\section{Figura 3}

Modelo transaccional de estrés

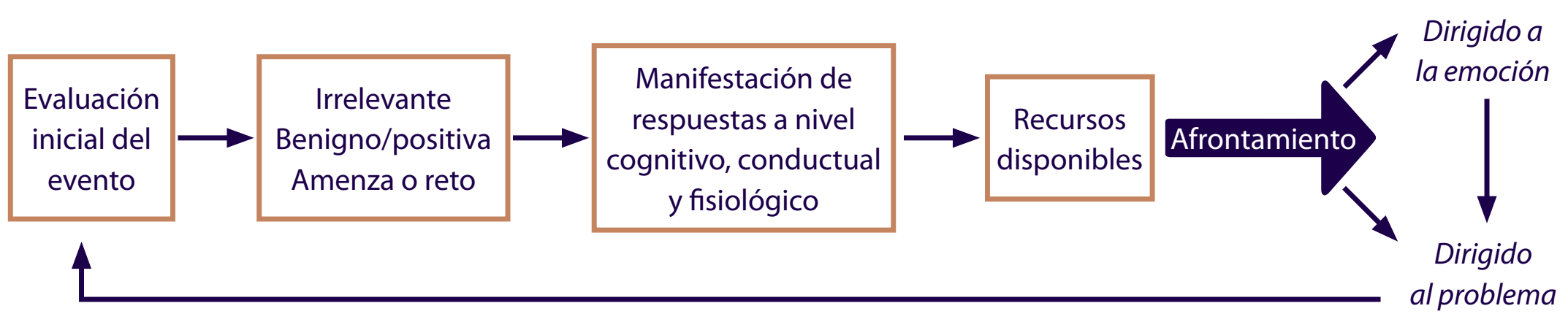

Nota: Recuperado de Trastorno de estrés postraumático en adultos. Intervención cognitivo-conductual para víctimas de sismos por L. Reynoso, A. L. Becerra, e I. Lugo, 2019, México: Qartuppi.

Un paciente con enfermedad crónica se enfrenta a diferentes escenarios que pueden ser percibidos como estresantes debido a la historia natural de la misma condición, afectada por la naturaleza, los recursos psicosociales y patrones aprendidos de afrontamiento (Ghosh \&Verma, 2018), dando como resultado un ajuste en las estrategias a emplear de acuerdo con la etapa de la enfermedad en la que se encuentre y a su evolución.

Como ejemplo, se presenta la figura 4 donde se ilustra el caso de Ofelia. La paciente acude a su cita médica, en donde el médico le recomienda modificar su dieta, debido a que sigue manteniendo altos niveles de glucosa. Ella evalúa el evento como estresante, específicamente como una amenaza (¿cómo voy a cocinar algo diferente a lo acostumbrado?). Esta situación la lleva a pensar en trabajar doble, preparar dos comidas diferentes de manera simultánea, 
gastar más dinero para la comida pues tiene como creencias que la alimentación saludable es más cara y de sabor desagradable. Al respecto, Ofelia refiere cogniciones como: "será hacer dos comidas"; "será doble trabajo"; "será mucho gasto"; lo que se acompaña de aceleración del ritmo cardíaco, sudoración de frente y manos, a su vez, mantiene las características de alimentación previas a la instrucción médica.

En las estrategias de afrontamiento centradas en la emoción Ofelia podría ejercer la evitación, las creencias mágicas ("inventarán una cura") y la normalización ("de algo nos tenemos que morir"). Respecto a los recursos, Ofelia identifica que cuenta con apoyo social, económico, habilidades sociales y, debido a la psicoeducación, adquirió conocimientos sobre el componente hereditario de la DM. Por otro lado, en las estrategias dirigidas al problema o acción, Ofelia identifica que podría favorecer el reconocimiento del problema, la comunicación y petición de apoyo social, y prevenir tanto las complicaciones como el desarrollo de la enfermedad en sus familiares. Por ello, la paciente identifica esta última como la estrategia más funcional.

\section{Figura 4}

Ejemplo transacción del estrés en paciente con DM

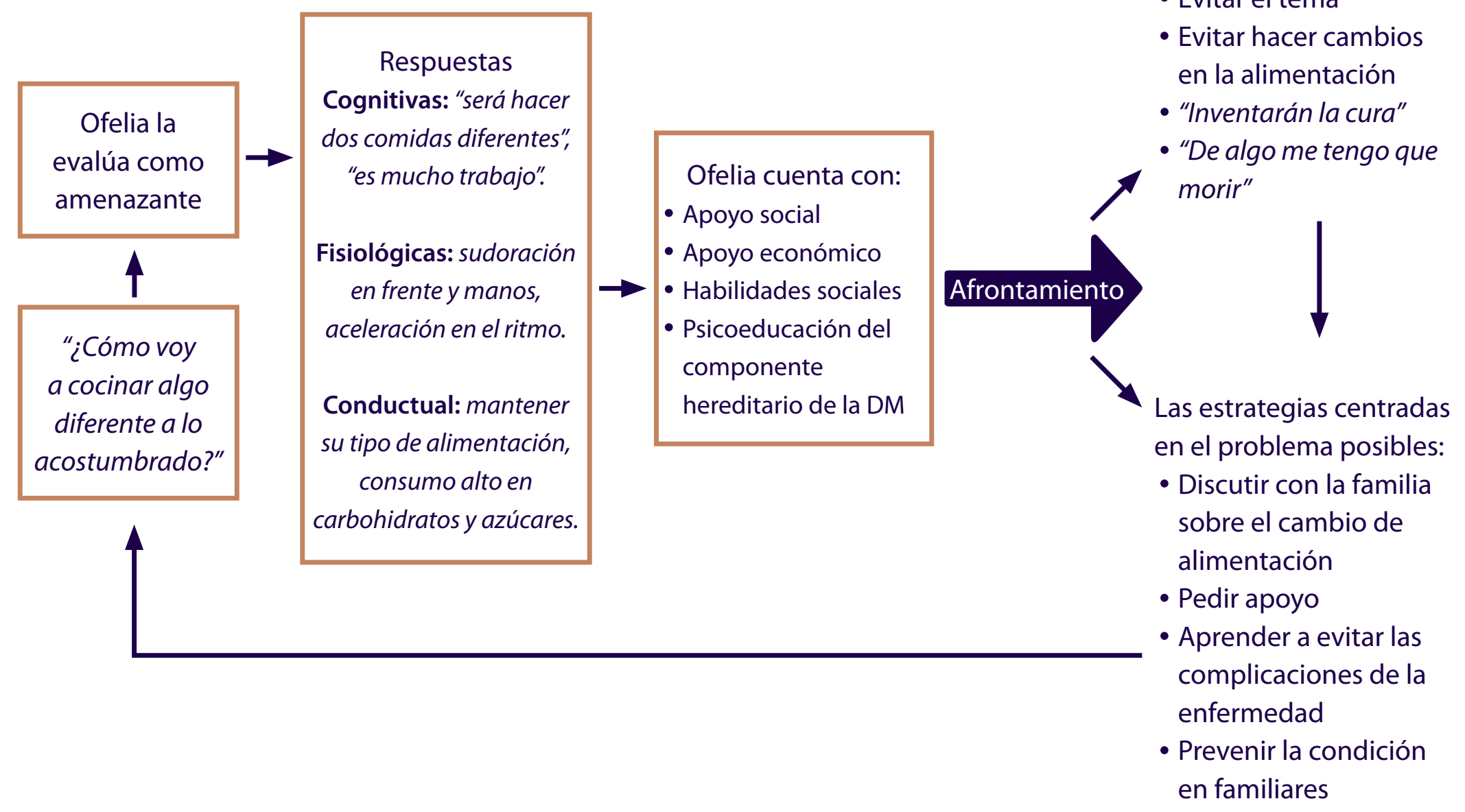

Las estrategias centradas en la emoción que puede implementar son:

- Evitar el tema

- Evitar hacer cambios en la alimentación

"Inventarán la cura"

"De algo me tengo que

Apoyo social

- Apoyo económico

- Psicoeducación del componente hereditario de la DM

Las estrategias centradas en el problema posibles:

- Discutir con la familia sobre el cambio de enfermedad

en familiares

Nota: Adaptado de Trastorno de estrés postraumático en adultos. Intervención cognitivo-conductual para víctimas de sismos por L. Reynoso, A. L. Becerra, e I. Lugo, 2019, México: Qartuppi. 
El estrés se conceptualiza mediante dos procesos, el primero como respuesta adaptativa en la vida cotidiana, es decir, a la manera de afrontar el estrés en situaciones diarias; en cuanto a la segunda se centra al estrés como generador de problemas, donde la cronicidad e intensidad del evento estresante hace más probable la aparición de las algunas complicaciones o persistencia de sensaciones fisiológicas desfavorables para la salud del paciente.

Al respecto, Caballo y Anguiano (2002) reportan que el estrés puede tener diferentes efectos en el organismo del paciente que lo experimenta, entre ellos: incrementar la vulnerabilidad, ser un agente potenciador de aparición de una comorbilidad, incrementar la incidencia de comportamiento no saludables (e.g. consumo de sustancias psicoactivas, alcohol, tabaco o alimentos con alto contenido calórico) y ser un agravante de la condición médica. Así, el comportamiento del individuo frente a ciertas situaciones constituye un factor que define psicológicamente el proceso que propicia la presencia o ausencia de enfermedad (Ribes, 1990) o complicaciones.

\section{Medicina Conductual}

\subsection{Qué es Medicina Conductual (MC)}

Debido a la incidencia de los factores conductuales y el tratamiento en modificación conductual, se retoma a la Medicina Conductual (MC), que es el campo interdisciplinario encargado de la integración de la ciencia de conducta y la ciencia biomédica, con el objetivo de desarrollar e implementar el conocimiento y las técnicas encaminadas a la promoción de la salud, en sus diferentes etapas: prevención, diagnóstico, tratamiento y rehabilitación de la enfermedad (Schwartz \& Weiss, 1978). Por su parte, Reynoso (2014) establece que la MC consiste en un abordaje integral del paciente, en donde la conducta puede generar enfermedades y estas a la vez modifican el comportamiento, siendo este el foco de atención del especialista en este campo, debido a que la alteración del comportamiento en personas con enfermedades crónicas puede reducir los síntomas que experimentan.

\subsection{Actividades del especialista en MC con pacientes que viven con enfermedad crónica}

El especialista en MC adquiere las habilidades de evaluar y diagnosticar tanto las conductas problema como las necesidades del paciente respecto a su salud; de seleccionar técnicas y procedimientos pertinentes para una intervención psicológica respaldando sus decisiones con investigaciones científicas; de evaluar la eficacia de los programas implementados basándose en los resultados del paciente, lo que también le permite redireccionar su intervención; y de trabajar en equipos multidisciplinarios, como se puede ver en la tabla 6 . Además, el especialista en MC elabora, adecua y desarrolla programas de intervención en los diferentes niveles de atención sanitaria con base en las necesidades particulares del paciente y de la sociedad. Por ello, está capacitado para evaluar e intervenir las problemáticas psicológicas que se presentan en un paciente durante el curso de una enfermedad crónica. 
Tabla 6

Actividades del especialista en Medicina Conductual

\begin{tabular}{|c|c|}
\hline Actividades & Descripción \\
\hline Evaluación & $\begin{array}{l}\text { Realiza entrevista conductual al paciente y aplica instrumentos con el objetivo de detectar } \\
\text { aquellas problemáticas que puedan perjudicar el estado de salud del paciente. La entrevista } \\
\text { se centra en la obtención de información de la problemática, recabando los datos necesarios } \\
\text { para realizar el análisis funcional de la conducta problema. }\end{array}$ \\
\hline Investigación & $\begin{array}{l}\text { Realiza la búsqueda bibliográfica de evidencias científicas sobre técnicas cognitivo } \\
\text { conductuales que han demostrado ser eficaces en la problemática de cada paciente. }\end{array}$ \\
\hline $\begin{array}{l}\text { Retroalimentación } \\
\text { de evaluación }\end{array}$ & $\begin{array}{l}\text { Expone al paciente los resultados del proceso de evaluación tanto de lo obtenido en la } \\
\text { entrevista como a través de los cuestionarios. Además, explica las hipótesis funcionales que } \\
\text { obtuvo del análisis funcional. Presenta las opciones de las técnicas que podrían beneficiar al } \\
\text { paciente y seleccionan en conjunto una o varias. }\end{array}$ \\
\hline Planeación & $\begin{array}{l}\text { Realiza una adecuación de la técnica acorde al marco teórico, a las características y } \\
\text { habilidades de cada paciente. Establece objetivos generales y específicos basándose en } \\
\text { criterios de cambio. }\end{array}$ \\
\hline Intervención & $\begin{array}{l}\text { Implementa la(s) técnica(s) seleccionada(s) con el objetivo de que el paciente adquiera los } \\
\text { conocimientos y habilidades. Además, propicia el mantenimiento de estas habilidades en el } \\
\text { repertorio conductual del paciente en el futuro. }\end{array}$ \\
\hline Evaluación de resultados & $\begin{array}{l}\text { Retoma los objetivos específicos y el cumplimiento o no de los criterios de cambio, para } \\
\text { evaluar la efectividad de la técnica respecto a cada paciente. De este modo, puede evaluar si } \\
\text { continúa o no con el entrenamiento de cada técnica. }\end{array}$ \\
\hline Seguimientos & $\begin{array}{l}\text { Terminada la intervención realiza seguimientos con el fin de evaluar el mantenimiento de } \\
\text { las habilidades entrenadas en el paciente. Así, puede tomar decisiones terapéuticas para } \\
\text { beneficiar al paciente con la misma problemática u otra diferente. }\end{array}$ \\
\hline Atención en crisis & $\begin{array}{l}\text { Si en algún momento del proceso terapéutico se presenta una crisis, se realiza la } \\
\text { intervención en ese momento con base en los primeros auxilios psicológicos y procurando } \\
\text { salvaguardar el bienestar físico y psicológico del paciente. }\end{array}$ \\
\hline Trabajo multidisciplinario & $\begin{array}{l}\text { En caso de que detecte la necesidad de derivar o solicitar el apoyo de otro profesional, } \\
\text { proporciona los datos de contacto, ya sea de una institución o programa. }\end{array}$ \\
\hline
\end{tabular}

Nota: Elaboración propia.

\subsection{Evidencia de la efectividad de las intervenciones cognitivo conductuales}

Las intervenciones psicológicas sustentadas en el modelo cognitivo conductual se han implementado con enfermedades crónicas. De este modo, enseguida se exponen diversos metaanálisis y estudios en pacientes con DM tipo 1, tipo 2 y gestacional. Estos artículos evidencian la efectividad de: 1) intervenciones centradas en el entrenamiento en solución de problemas en relación con problemáticas psicológicas, 2) las intervenciones basadas en la TCC y sus resultados relacionadas con estrés, 3 ) las intervenciones basadas en la TCC con modalidad en línea. En la tabla 7 se muestran algunos artículos sobre la evidencia de la TCC en pacientes con DM. 
Tabla 7

\section{Evidencia de la efectividad de la TCC en el tratamiento del estrés en pacientes con DM}

\begin{tabular}{|c|c|c|c|}
\hline Autores & Objetivos & Estrategias/sesiones & Resultados \\
\hline \multirow[t]{3}{*}{$\begin{array}{l}\text { Carpenter, } \\
\text { DiChiacchio } \\
\text { y Barker (2019) }\end{array}$} & $\begin{array}{l}\text { Proporcionar un } \\
\text { resumen y una crítica } \\
\text { de las intervenciones } \\
\text { que apoyan el auto- } \\
\text { control en el paciente } \\
\text { con DM tipo } 2 \text {. }\end{array}$ & $\begin{array}{l}\text { Compararon un programa } \\
\text { intensivo que incluye ocho } \\
\text { sesiones de entrenamiento } \\
\text { en solución de problemas } \\
\text { (PST) con un programa } \\
\text { condensado que incluye } \\
\text { solo una sesión PST. }\end{array}$ & $\begin{array}{l}\text { PST facilita reacciones emocionales positivas y re- } \\
\text { duce las negativas. Además, ha sido efectiva ante } \\
\text { diferentes problemáticas psicológicas, entre ellas, } \\
\text { el afrontamiento de estrés. } \\
\text { Demostraron diferencias significativas en } \\
\text { hemoglobina glicosilada (Hba } 1 c)(0.71 \%) \text { en el } \\
\text { grupo del programa intensivo. }\end{array}$ \\
\hline & Revisión sistemática. & $\begin{array}{l}\text { Evaluaron } 56 \text { artículos } \\
\text { explorando la asociación } \\
\text { de PST al autocontrol y } \\
\text { control de la diabetes. }\end{array}$ & $\begin{array}{l}\text { Seis utilizaron PST como una intervención para } \\
\text { adultos, este análisis sugiere que la evidencia de la } \\
\text { efectividad de PST en Hba1c es débil. } \\
\text { Un metaanálisis que evaluó } 16 \text { intervenciones } \\
\text { aleatorizadas, siete específicas para PST, demostró } \\
\text { una diferencia media de } 0.39 \% \text { al realizar la com- } \\
\text { paración de la intervención con los grupos con- } \\
\text { trol, lo que evidenció una reducción significativa } \\
\text { en Hba1c. }\end{array}$ \\
\hline & $\begin{array}{l}\text { Metaanálisis haciendo } \\
\text { referencia a diferentes } \\
\text { modalidades } \\
\text { incluidas teléfono, } \\
\text { teleconferencia por } \\
\text { video, computadora e } \\
\text { Internet / tecnología } \\
\text { basada en la web. }\end{array}$ & $\begin{array}{l}\text { Dos estudios examinaron } \\
\text { los módulos asistidos por } \\
\text { computadora (CAM), el } \\
\text { impacto en la fisiología y } \\
\text { resultados psicosociales. }\end{array}$ & $\begin{array}{l}\text { Examinaron } 16 \text { ensayos aleatorizados, analizando } \\
\text { el impacto de la intervención basada en compu- } \\
\text { tadora, mostrando un pequeño beneficio en la } \\
\text { reducción del nivel de Hba1c. Adicionalmente, } \\
\text { analizaron siete estudios; examinaron las inter- } \\
\text { venciones basadas en la web y el impacto en los } \\
\text { resultados fisiológicos y psicosociales. } \\
\text { - Uno mostró resultados significativos en mejora } \\
\text { de Hba1c, peso y circunferencia de la cintura a } \\
\text { los cuatro meses. } \\
\text { - Tres mostraron niveles de Hba1c mejorados } \\
\text { a los seis meses ( }-0.2 \% ;-0.34 \text { puntos; - } 0.13 \\
\text { puntos). } \\
\text { Dos mostraron una mejora en los puntajes } \\
\text { de conocimiento, atención médica } \\
\text { comportamientos y Hba1c ( } 0.71 \% ; p>1 \%) \text {. }\end{array}$ \\
\hline $\begin{array}{l}\text { Aljawarneh, } \\
\text { Al-Qaissi y } \\
\text { Ghunaim } \\
(2020)\end{array}$ & $\begin{array}{l}\text { Resumir e identificar } \\
\text { las variaciones en } \\
\text { la efectividad de } \\
\text { las intervenciones } \\
\text { psicológicas sobre } \\
\text { adherencia, control } \\
\text { metabólico y } \\
\text { manejo del estrés en } \\
\text { adolescentes con DM } \\
\text { tipo } 1 .\end{array}$ & Se analizaron 24 estudios. & $\begin{array}{l}\text { Las intervenciones basadas en la TCC y el } \\
\text { entrenamiento de habilidades de afrontamiento } \\
\text { mostraron efectos sobre adherencia }(P<0.01) \text {, } \\
\text { control metabólico (TCC: } P=0.05 \text {; ) y manejo del } \\
\text { estrés }(P=0.019) \text { en adolescentes con DM tipo } 1 \text {. } \\
\text { El entrenamiento en afrontamiento para el estrés } \\
\text { mostró resultados significativos con respecto al } \\
\text { afrontamiento de situaciones evaluadas como } \\
\text { estresantes cotidianas relacionadas con el futuro } \\
\text { de la DM }(P=0.011) \text {. }\end{array}$ \\
\hline
\end{tabular}




\section{Autores Objetivos Rstrategias/sesiones Rultados}

Zaheri, Najar Examinar la efectiy Abbaspoor vidad de TCC en el (2016) manejo de estrés y el control glucémico en mujeres con diabetes gestacional.
Con 88 mujeres elegibles para la intervención (44 participantes) y el grupo control (44 participantes), cada grupo se dividió en tres grupos y dos subgrupos. Intervención: entrenamiento en manejo de estrés, se realizaron seis sesiones de dos horas en tres semanas. Técnicas: psicoeducación, relajación progresiva, solución de problemas, manejo del tiempo, control de ira, reestructuración cognitiva, estilos de vida saludable y consejos prácticos para lidiar con el estrés.

Se realizó pretest y posttest, dos semanas después del tratamiento, usando la Escala de Depresión Ansiedad Estrés 42.

Winkley et al. (2020)

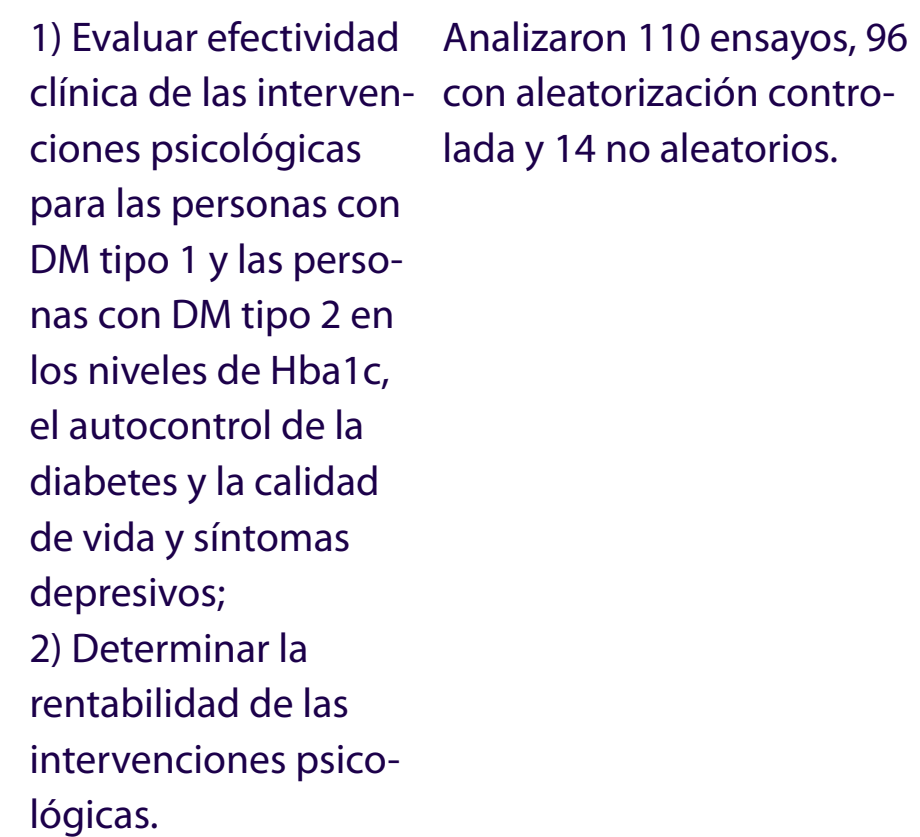

Grupo de entrenamiento de TCC: reducción estadísticamente significativa de los puntajes de estrés dos semanas después (6.8 puntos; $p=.0 .01$ ). Grupo control: aumento significativo en puntajes de estrés (3.12 puntos; $p=0.028$ ) (el estrés aumentó sin intervención) y con el progreso de la gestación. Hubo diferencia significativa entre dos grupos en el estrés $(p=0.001)$. Glicemia en ayunas: el grupo TCC tuvo una reducción estadísticamente significativa (10 puntos; $p=$ 0.048 ) después del entrenamiento.

Hubo diferencia significativa $(p=0.01)$ en glicemia en ayunas entre los grupos dos semanas después de la intervención.

Se concluye que la TCC mejora el bienestar psicológico y el control glucémico dos semanas después de la intervención.
El primer objetivo:

- El grupo de intervención de afrontamiento demostró diferencias estadísticamente significativas en los niveles de $\mathrm{HbA} 1 \mathrm{c}$ y depresión (ambos con $p<0.001$ ) en comparación con el grupo control.

- De 14 estudios, tres estudios informaron que el grupo de intervención tuvo diferencias estadísticamente significativas en comparación con el grupo de control para la disposición de autoreporte al cambio, autoeficacia, el cuidado personal, la depresión, la ansiedad y el estrés.

El segundo objetivo:

- Para DM tipo 1, el mindfulness $(-0.456 ; p=0.009)$ y la TCC $(-0.256 ; p=0.011)$ son clínicamente efectivos considerando los efectos directos e indirectos de las comparaciones de tratamientos múltiples,

- Para DM tipo 2, la TCC y el asesoramiento son eficaces (Sucra $=0.80$ ).

En general, la TCC es potencialmente más rentable. 


\section{Autores Objetivos \\ Estrategias/sesiones \\ Resultados}

Mochari- $\quad$ Evaluar la viabilidad y Analizaron 466 registros de Greenberger, el impacto potencial diabetes identificados en Vue, Luka, de un programa de AbilTo.

Peters y Pande atención médica de (2016) la conducta diseñado para tratar los Intervención: problemas de salud conductual asociados con la diabetes para cambiar las medidas de depresión, ansiedad y estrés de los participantes.

herramientas de cambio comportamental, incluida la TCC, terapia de aceptación y compromiso, mindfulness, entrevista motivacional y pautas clínicas para reducir la depresión, la ansiedad y el estrés.

Intervención: una consulta inicial y 15 sesiones dentro de un período de 8 semanas mediante llamada telefónica o videollamada. Se realizó pretest y posttest, usando la Escala de Depresión Ansiedad Estrés 21.

Hubo reducciones significativas en los puntajes que se observaron para depresión (-8.8 puntos $(-51 \%) ; \mathrm{p}<0.0001)$, ansiedad $(-6.9$ puntos $(-45 \%)$; $\mathrm{p}<0.0001$ y estrés $(-9.9$ puntos $(-45 \%) ; \mathrm{p}<$ $0.0001)$. Indicando una disminución de los síntomas.

El 70\% de participantes con puntajes de estrés basales elevados pasó a puntajes normales de graduación.

Los niveles medios de glucosa en la mañana disminuyeron $(-12.3 \mathrm{mg} / \mathrm{dL}(\mathrm{p}=0.0002)$.

La frecuencia de las pruebas automáticas de glucosa aumentó un $69 \%$.

Demostró la viabilidad e impacto potencial de un programa comportamental digital para mejorar las afecciones psicológicas y autocontrol.

\section{Se realizaron 26 comparaciones.}

- Intervenciones basadas en la computadora y en la web para el manejo del estrés pueden ser eficaces para reducir el estrés y mantenerse hasta por seis meses.

- Intervenciones de TCC ( $d$ de Cohen $=0.40$, 95\% Intervalo de confianza 0.19-0.61) y de tercera ola ( $d$ de Cohen $d=0.53,95 \%$ intervalo de confianza 0.35-0.71), demostraron ser moderadamente eficaces para reducir el estrés.

- Intervenciones cortas ( $\mathrm{d}$ de Cohen $=0.33,95 \%$, intervalo de confianza 0.22-0.44) y medianas ( $d$ de Cohen $=0.59 ; 95 \%$ intervalo de confianza $0.45-0.74$ ), son más efectivas que las largas ( $d$ de Cohen $=0.21,95 \%$, intervalo de confianza -0.05 to $0.47 ; \mathrm{P}=.006$ ).

- Las intervenciones guiadas produjeron un mayor tamaño del efecto $(\mathrm{d}$ de Cohen $=0.64$, $95 \%$, intervalo de confianza $0.50-0.79 ; n=7$ ) en comparación de intervenciones sin guía ( $d$ de Cohen $=0.33,95 \%$, intervalo de confianza $0.20-0.46 ; \mathrm{n}=18 ; \mathrm{P}=.002$ ).

Concluyendo que las intervenciones en línea de TCC fueron eficaces.

Nota: Elaboración propia. 
De acuerdo con la información de la tabla 7, existe evidencia de que las intervenciones psicológicas con base en la TCC tienen influencia favorable en el manejo de la enfermedad, en la reducción de sintomatología relacionada al estrés y otras problemáticas psicológicas. Se establece que la TCC es efectiva generando cambios estadísticamente significativos (Winkley et al., 2020), además proporciona una reducción estadísticamente significativa de los puntajes de estrés de dos semanas después (Zaheri et al., 2016). Por su parte, la intervención en línea obtiene resultados favorables, las intervenciones psicoeducativas demostraron que había mejora en niveles de glucosa, reducción de peso y circunferencia (mejorando hasta seis meses). Sin embargo, en los estudios revisados no se demuestra que la modalidad terapéutica presencial es mejor que la modalidad online, empero la modalidad en línea es efectiva con una guía (Heber et al., 2017).

En cuanto al entrenamiento en la TCC se incluyeron sesiones de un programa multicomponente con técnicas como psicoeducación, relajación progresiva, solución de problemas, donde se observaron cambios al igual que el programa intensivo de ocho sesiones de PST aplicado con resultados significativos en el nivel de hemoglobina glicosilada. Adicionalmente, se establece en diferentes estudios que se realizan intervenciones respecto a la forma de afrontamiento, adherencia terapéutica hacia la toma de glucosa, control metabólico y manejo del estrés.

De esta manera, incluir técnicas como psicoeducación es una base importante para conocer la enfermedad y proporciona la oportunidad de entrenar las habilidades para afrontar el estrés. A su vez, la técnica de solución de problemas tiene un efecto mayor en intervenciones largas de ocho sesiones (que demostró una diferencia media de 0.39\%), en comparación con la intensiva, promoviendo un entrenamiento más largo en esta opción terapéutica. No obstante, los resultados también resaltan que las intervenciones más efectivas son las breves o de mediano plazo de hasta ocho sesiones (Heber et al., 2017). Adicionalmente, estos resultados pueden generarse en ambas modalidades, presencial o haciendo uso de las nuevas tecnologías. Por ello, el entrenamiento en el manejo de estrés centrado en psicoeducación, técnicas en relajación y solución problemas, puede disminuir la prevalencia de síntomas de estrés y propiciar un control de la enfermedad. Con esta breve revisión, se examinó que el tipo de entrenamiento de pacientes con DM basado en intervenciones en línea bajo el enfoque de la TCC es una habilidad por entrenar para mantener los niveles de glucosa en sangre en la normalidad, disminuir la probabilidad de aparición de comorbilidades y modificar la manera de afrontar las situaciones estresantes futuras.

Además, en los procedimientos empleados en los diferentes estudios se incluyen las técnicas de relajación que promueven reducciones en el nivel de estrés percibido por pacientes que viven con DM. Con la evidencia mostrada se observa que se abordan dos niveles de respuesta, fisiológico y conductual, mas no el cognitivo. Lo anterior, pudiéndose atribuir a que las técnicas cognitivas necesitan más tiempo de intervención. En la presente guía, se 
aborda este nivel de respuesta con la técnica de autoinstrucciones, que focalizaría la atención del individuo en aquello que puede hacerse para manejar el estrés y favoreciendo un efecto mayor.

\section{Propuesta de guía}

Se caracteriza por la implementación de un programa multicomponente cognitivo conductual para entrenar en el manejo de estrés a pacientes que padecen $D M$, mediante la enseñanza y aplicación de técnicas entre las que se encuentran: psicoeducación, relajación, autoinstrucciones y solución de problemas.

El desarrollo de la guía se centra en el uso de intervenciones nomotéticas, debido a que se diseñó un programa general para las personas que viven con DM. No obstante, la aproximación a cada paciente debe de realizarse desde un enfoque ideográfico, lo que quiere decir que se atienden las necesidades específicas de cada paciente dependiendo de las características y problemáticas encontradas mediante el análisis funcional del comportamiento. Este enfoque favorece el establecimiento de una relación terapéutica y permite un trabajo colaborativo terapeuta-paciente, característica del modelo de la TCC, debido a que permite que el terapeuta resuelva dudas, mientras que al paciente se le asignan resolver tareas antes de la próxima sesión, ya sean registros o ejercicios.

A pesar de que la guía describe objetivos y sesiones de intervención precisas, al hacer referencia del enfoque ideográfico, la guía adquiere flexibilidad respecto a los objetivos, las necesidades, las problemáticas y las características de cada paciente, es el especialista en MC quien tomará las decisiones terapéuticas necesarias a partir del modelo cognitivo conductual con la puesta en marcha de estrategias complementarias en caso de ser necesario.

\subsection{Justificación de la migración de modalidad}

Durante el año 2020, la realización de actividades cotidianas ha tenido que ser modificada atendiendo a las recomendaciones sanitarias debidas a la pandemia del virus SARS-COV-2. Una de ellas ha sido la prestación de servicios psicológicos que migró a una modalidad online a través del uso de las Tecnologías de Información y Comunicación (TIC's), utilizando recursos como Zoom ${ }^{\circledR}$ y Google ${ }^{\circledast}$ (Gmail y Google Forms). Este cambio de modalidad presenta nuevos escenarios y retos, tales como la pérdida de conexión con el paciente en plena sesión, la protección de datos y privacidad, y el desarrollo de expediente clínico digital. Por ello, se deben establecer protocolos que regulen las acciones y la toma de decisiones del terapeuta.

Esta guía propone el uso de etapas para la intervención con respecto a los elementos de la terapia presencial, como lo son: evaluación, intervención, mantenimiento, seguimiento y protocolo de intervención en crisis. Además, debido a la migración se plantean nuevas etapas: difusión online, envío de datos por parte del paciente y contacto con el paciente para concretar la primera sesión. 


\subsection{Objetivos}

\subsubsection{Generales}

Esta guía tiene como fin facilitar las pautas de un programa de intervención cognitivo conductual centrado en la reducción del nivel de estrés en personas con diagnóstico de DM tipo 2. Por su parte, el programa tiene como objetivo la disminución del nivel de estrés presente en personas con diagnóstico DM tipo 2, mediante una intervención cognitivo conductual basada en el entrenamiento de técnicas para la adopción de estilos de afrontamiento funcionales en situaciones evaluadas como estresantes.

\subsubsection{Específicos}

- Exponer tanto la conceptualización como la contextualización de la DM a nivel mundial y en nuestro país (México).

- Explicar las características de la manifestación del estrés en la interacción de un individuo con DM tipo 2 y su contexto, desde el modelo propuesto por Lazarus y Folkman, 1984.

- Examinar la evidencia científica sobre la eficacia de la TCC para el manejo del estrés y otras emociones asociadas a personas con DM tipo 2.

- Describir minuciosamente las directrices de evaluación e intervención acorde a la TCC en el tratamiento del estrés y otras emociones relacionadas en pacientes con DM tipo 2.

- Proveer de flujogramas relacionados a la toma de decisiones en la implementación del tratamiento basado en la TCC para el abordaje del estrés y otras emociones relacionadas en personas con DM tipo 2.

- Explicar los mecanismos de acción durante el tratamiento dada la modalidad online, en supervisión y en intervención, en caso de presentarse una crisis en pacientes con DM tipo 2 que reciban el tratamiento que se plantea en esta guía. 
Segunda Parte 


\section{Un modelo de intervención supervisada en estrés (para terapeuta)}

\subsection{Generalidades}

La emergencia sanitaria que se ha manifestado durante el 2020 por el virus SARS-COV-2 ha dado como resultado la modificación comportamental de las personas en general. El confinamiento mantenido desde marzo ha generado la necesidad de cambiar tanto las rutinas como los estilos de vida a partir de cambios conductuales y arreglos ambientales apegados a las recomendaciones sanitarias, entre ellas: distanciamiento social, evitación de lugares públicos o concurridos, de clínicas y hospitales por probable contagio. Representando un reto para la sociedad, ya que muchos sectores (e.g. académico, económico, sanitario, comercial y lúdico) han tenido que adaptarse a las condiciones con el objetivo de seguir proporcionando servicios.

Al inicio del confinamiento, el programa de Posgrado de Maestría y Doctorado en Psicología de la Universidad Nacional Autónoma de México (UNAM), específicamente la Residencia en MC optó como medida institucional y preventiva suspender actividades presenciales tanto académicas como prácticas profesionales en instalaciones hospitalarias. Esto no significó una detención en las actividades centradas en el desarrollo profesional de los alumnos, sino un ajuste para garantizar el alcance de los objetivos ante las condiciones sanitarias presentes y futuras, migrando de la modalidad presencial a online.

Ante el nuevo escenario que representa la pandemia, los retos y nuevas necesidades y condiciones que esta representa, ante la incidencia de enfermedades crónico degenerativas en México y acorde con los objetivos del programa de MC se planteó la creación de una guía para la atención psicológica centrada en las actividades de un especialista en MC para pacientes que viven con enfermedades crónico-degenerativas atendiendo a sus necesidades actuales, mediante el uso de TIC's para acatar los lineamientos de salubridad.

\subsection{El modelo de supervisión}

El plan de estudios de la Maestría en Psicología tiene como objetivo formar profesionales que evalúen, detecten e intervengan en el entorno mediante un plan coherente, articulado y flexible, a partir de la integración de los alumnos a programas de residencia con práctica profesional supervisada, desarrollando competencias in situ, en los escenarios donde se realiza el ejercicio de la profesión (Ayala et al., 1998).

El modelo de la guía se basa en el Programa Institucional de Residencia de Medicina Conductual con sede en la Facultad de Estudios Superiores Iztacala, UNAM, que señala que los egresados deberán contar con los conocimientos, competencias necesarias para prevenir y solucionar problemas mediante la aplicación de las técnicas, métodos y procedimientos terapéuticos que forman el quehacer disciplinario a nivel individual y grupal (Reynoso \& Seligson, 1998). En este sentido, se hace hincapié en las competencias profesionales, donde el alumno practica a partir de lo aprendido, sustentando que lo primordial es la aplicación de conocimientos, mas no la posesión de ellos. Estas competencias se promueven y se mantienen por un sistema de supervisión. 
En el contexto del plan de la residencia, la supervisión se centra en una interacción enfocada en las competencias del supervisado, donde el supervisor es una figura que tiene habilidades clínicas avanzadas y se relaciona con sus supervisados, generando una relación de aprendizaje. Además, como equipo de trabajo planifican, direccionan, evalúan y llevan a cabo tareas de planeación, dirección y evaluación de la práctica asistencial a través de actividades clínicas profesionales, las cuales son: detección, evaluación, prevención, intervención e investigación, que garantizan la adquisición y el dominio de competencias profesionales en contextos de salud. Durante este trabajo, el supervisor evalúa el desempeño práctico del alumno.

La meta de la supervisión asume la adquisición de estándares máximos para ofrecer una adecuada calidad de los servicios para los individuos y la comunidad. Así, en la interacción de aprendizaje supuesta en la supervisión, los alumnos adquieren conocimientos y habilidades, examinan sus propias creencias, actitudes y sentimientos respecto de los sujetos como individuos en su contexto social. Todo esto promueve en los alumnos el desarrollo de una identidad profesional. La supervisión se concibe como una piedra angular en las actividades dentro del programa, este sistema está formado por dos tipos de supervisores:

1. Supervisor in situ. Es un psicólogo contratado por la institución de salud, que posibilita la formación de los residentes, responsabilizándose de ellos en el escenario de práctica mediante el seguimiento de horarios, políticas, reglamentos de la sede y de la UNAM. En cada una de las instituciones hospitalarias, al menos un profesional del área de psicología colaborará con el programa de la residencia en esta categoría.

2. Supervisor académico. Es un psicólogo posgraduado con adscripción a la plantilla académica de la UNAM. Esta figura acude una vez a la semana, por dos horas, a la sede para trabajar con los alumnos en la discusión de revisiones bibliográficas y casos clínicos, así como brindar retroalimentación y supervisión de los casos atendidos por cada alumno, de los cuales es responsable. Funge como coadyuvante en el entrenamiento y aprendizaje de los supervisados. Ambos supervisores colaboran para la formación y evaluación al residente. Al no pertenecer a la institución, este personaje no lleva actividades clínicas ni de servicio.

Este último tipo de supervisión (académica) tiene como objetivo brindar estrategias y habilidades teórico-prácticas para favorecer el desempeño del residente. Este supervisor tiene la responsabilidad de encontrar, valorar y apoyar las habilidades del supervisado mediante diferentes métodos y tareas solicitadas, para favorecer su autonomía respecto al trabajo clínico.

En este sentido, se requiere que tanto el supervisor como los supervisados desarrollen un programa de entrenamiento secuencial. Este programa inicia en las instalaciones universitarias, realizando revisiones bibliográficas de distintas estrategias de recolección de información, técnicas y modelos teóricos, acompañado de sesiones de discusión; posteriormente, 
se proporciona el entrenamiento en la aplicación de estrategias terapéuticas mediante el modelado por parte del supervisor y la práctica entre los supervisados, donde el supervisor retroalimenta el desempeño del alumno, esto se ve favorecido por sesiones de práctica videograbada y juego de roles, para retroalimentar y promocionar la autoobservación. Después, se acude a las sedes en donde se desarrolla un modelo de supervisión en cascada entre los alumnos, el supervisor in situ y el supervisor académico. Dentro del hospital, se elaboran notas clínicas, se presentan casos y se monitorea el trabajo de los alumnos, aunado a estas actividades se brinda retroalimentación. La figura 5 ejemplifica el presente apartado.

\section{Figura 5}

Flujograma de supervisión en el Programa de residencia en MC.

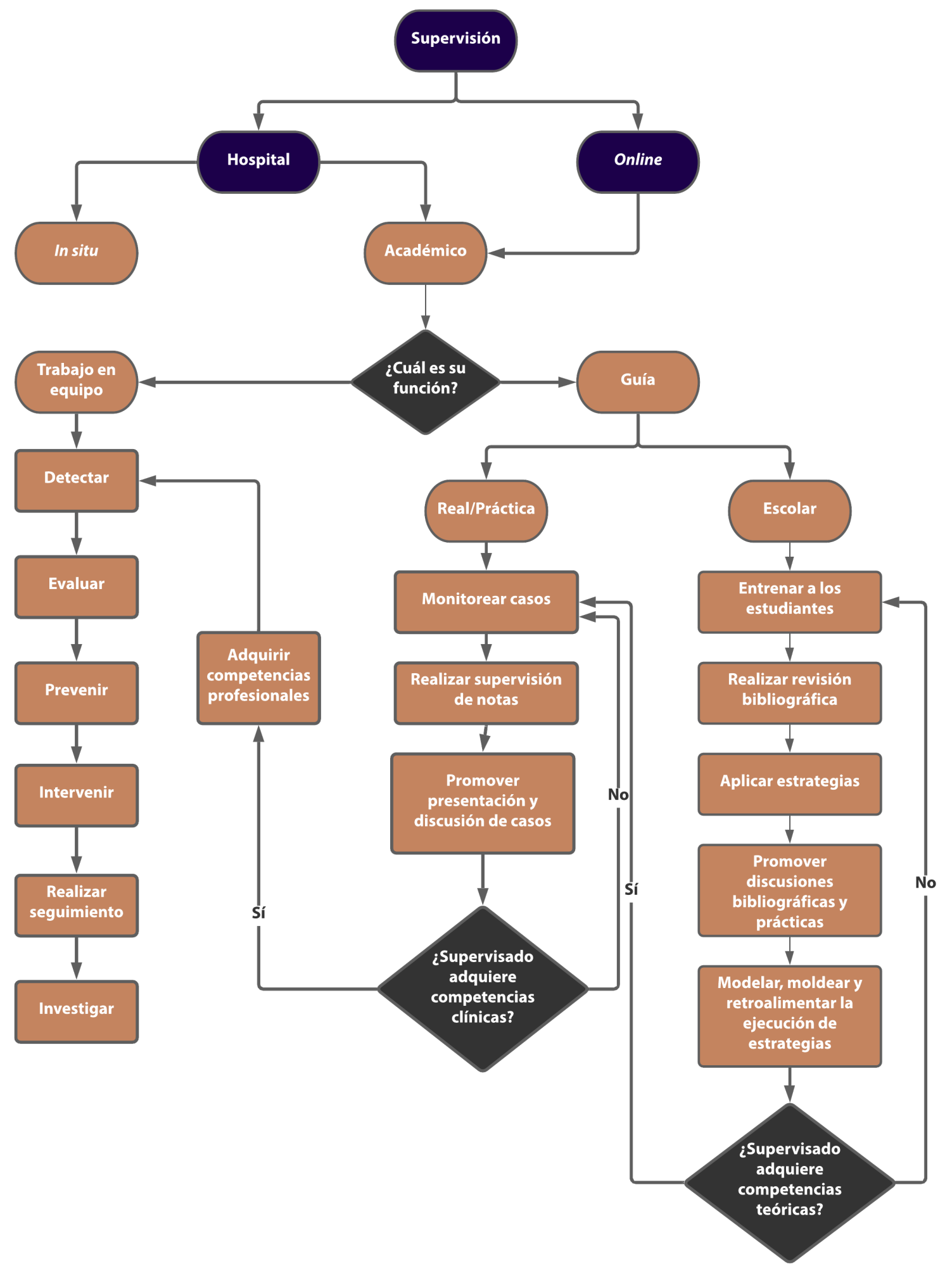




\subsubsection{Uso de las TIC's para la supervisión}

A partir de los últimos años del Siglo XX se inició la práctica de la psicología a distancia, acuñando el término telepsicología, cuyo origen está basado en el término telesalud (del inglés telehealth) e incluye la supervisión de la práctica clínica. La telesalud recurre a las telecomunicaciones y la tecnología de la información para brindar una opción en la implementación de las actividades sanitarias (evaluación, diagnóstico, intervención, consulta, supervisión, educación e información a distancia), mientras que el término telesalud conductual se concibe como la aplicación de esta tecnología para proveer servicios de salud centrado en el modelo conductual (Nickelson, 1998). Desde ese momento, se ha aceptado que aquellos profesionales de la educación y supervisión de estudiantes de programas de posgrado se entrenen en la integración de estos elementos (Myers, Endres, Ruddy, \& Zelikovsky, 2012).

Respecto a la supervisión en MC se han implementado diversas estrategias que implican el uso de TIC's, inicialmente mediante el correo electrónico. En seguida durante el 2009 y el 2011 se formuló el proyecto Desarrollo de un sistema de tutoría y supervisión online para la residencia en Medicina Conductual, identificado con las siglas PE301409 a partir de recursos de la Dirección General de Asuntos del Personal Académico en el marco del Programa de Apoyo a Proyectos para Innovar y Mejorar la Educación (PAPIME). En él se proponía que la tutoría y supervisión online proporcionaría apoyos para fomentar la autonomía y mejorar las habilidades, destrezas y competencias profesionales del alumno. Esta experiencia no se pudo completar y se centró en la utilización y aprovechamiento de diversas TIC's, como: bancos de recursos, la videograbación del desempeño de los alumnos en situaciones de evaluación de competencias profesionales, el uso de un portafolio inicialmente desarrollado con Moodle ${ }^{\circledR}$ y, posteriormente, las aulas virtuales de la UNAM, la página web de la residencia', sitios como Facebook $^{\circledast}$, Twitter $^{\circledast}$, YouTube $^{\oplus 2}$, Dropbox ${ }^{\circledast}$, Google Drive ${ }^{\circledR}$, para almacenar información y disponer de ella. Adicionalmente, se añadió el uso de WhatsApp ${ }^{\circledast}$ como una forma de mensajería asincrónica y, ante la emergencia sanitaria en los últimos seis meses, se ha migrado a la realización de videoconferencias a través de $\mathrm{ZOOM}^{\circledR}$.

La supervisión implementando las TIC's tiene varias ventajas, entre ellas permite observar la práctica del supervisado, independientemente de la distancia geográfica. Se deben preparar los recursos para realizar las sesiones dentro del marco ético que rige la profesión por parte del supervisor y los supervisados. Por su parte, la supervisión respecto de actividades clínicas online no cambia mucho de la realizada de manera presencial y comparten las normas éticas (American Psychological Association, 2014; Association of State and Provincial Psychology Boards, 2015; Consejo General de la Psicología, 2017; De la Torre \& Pardo, 2018; Joint Task Force for the Development of Telepsychology Guidelines for Psychologists, 2013).

1 https://www.medicinaconductual-unam-fesi.org

2 https://www.youtube.com/channel/UCuGUYoeylmaTvtR4ePGbmEQ/videos 
No obstante, esta modalidad de trabajo online solo se implementará si los supervisados fueron entrenados previamente de manera presencial.

La formación académica de los supervisores permite fundamentar sus acciones dentro del marco teórico conductual y deben ser capaces de proporcionar retroalimentación respetuosa, objetiva, clara y oportuna a los supervisados, además de cumplir con las normas éticas y legales correspondientes, para fortalecer la relación colaborativa y propiciar conductas relacionadas a la responsabilidad con el trabajo.

Se deben incluir prácticas y entrenamiento sobre el manejo del equipo y TIC's enfocada en supervisores y supervisados, con la presentación de casos simulados utilizando el modelo de solución de problemas y toma de decisiones, antes de realizar el trabajo clínico online. Este entrenamiento tiene el propósito de manejar adecuadamente el ambiente electrónico y tener alternativas para la solución de problemas durante la sesión.

Enseguida, se proporciona otro entrenamiento supervisado antes del trabajo con pacientes reales. Se centra en la práctica con casos simulados ejemplificando dilemas éticos para el análisis y discusión con el grupo de trabajo. Al ser limitada la visión del terapeuta por el uso de las herramientas tecnológicas, algunas conductas que manifiesten los pacientes pueden no ser observadas por los terapeutas, por lo que se resalta la necesidad de observar y registrar la conducta verbal del paciente como al comportamiento no verbal. La implementación del trabajo a distancia requiere escuchar más atentamente (Marrow, Hollyoake, Hamer, \& Kenrick, 2002). La supervisión utilizando las TIC's tiene un impacto en la relación supervisor-supervisado, pues permite una discusión más honesta de aspectos relacionados con el diagnóstico y tratamiento (Wood, Miller, \& Hargrove, 2005).

\subsection{Acciones del terapeuta}

Al ser una guía de intervención, es necesario especificar las acciones realizadas por el especialista de MC tanto de manera general como específica ante ciertas condiciones que pueden presentarse, como puede observarse en la tabla 8.

\section{Tabla 8}

Acciones del terapeuta en la intervención en línea

\section{Actividades}

Apoyar al paciente con la utilización de la plataforma digital (Zoom $\left.{ }^{\circledast}\right)$.

Resolver dudas con respecto a la dinámica de la terapia en línea.

Establecer componentes de relación con el paciente.

Enviar y explicar el consentimiento informado. Resolviendo dudas en caso de presentarse.

Realizar entrevistas de primera vez bajo un enfoque conductual y con modalidad semiestructurada.

Identificar la conducta problema en sus tres niveles de respuesta: motor, cognitivo-afectivo y fisiológico. 
Actividades

Realizar un análisis funcional de la conducta problema y elaborar una serie de hipótesis de mantenimiento.

Tomar decisiones terapéuticas según la problemática, sus manifestaciones y las características del paciente.

Realizar notas clínicas en formato SOAP, las cuales serán revisadas por un supervisor académico.

En caso de ser necesario, enviar los enlaces de los instrumentos de evaluación, escalas o formatos de registro.

Realizar una intervención psicológica con el objetivo de reducir el estrés empleando técnicas cognitivo-conductuales con amplia evidencia empírica. Dichas técnicas pueden complementarse con otras distintas a las propuestas en esta guía, siempre y cuando estén en apego al enfoque teórico.

Enviar los enlaces correspondientes o el material psicoeducativo al paciente, con el fin de proporcionar datos relevantes de la problemática o las técnicas a emplear y así, potenciar un cambio en el comportamiento.

Enviar y explicar los registros que se lleguen a utilizar en terapia.

Programar la siguiente sesión en la plataforma digital y mandar el acceso al paciente.

En el caso de usar aplicaciones relacionadas al biofeedback, solicitar al paciente evidencias (e.g. capturas de pantalla) de su utilización.

Atender alguna crisis en caso de presentarse y dar monitoreos en caso de ser necesario.

Nota: Elaboración propia.

\subsection{Evaluación conductual}

Es un tamizaje que se presenta en todo momento durante el proceso terapéutico, desde el primer contacto hasta los seguimientos. Proporciona evidencia de los cambios y obstáculos que se presentan en el repertorio conductual del paciente, señalando áreas de oportunidad o necesidades del paciente para favorecer la toma de decisiones terapéuticas.

Nelson y Hayes (1986) la definen como la identificación de unidades de respuesta significativas y sus variables controladoras para obtener una explicación del mantenimiento del comportamiento y generar alteraciones. Así, al ser algo tangible y observable, la conducta ha sido el objeto de interés en la medición, por lo que se pretende analizar la misma recuperando los parámetros de la conducta tales como: frecuencia, latencia, duración, tiempo entre respuestas, intensidad y topografía (Tron, Ávila, \& Reynoso, 2014). Esta evaluación se realiza a través de la recolección de información mediante diversos métodos, entre ellos observación directa o indirecta, entrevistas, registros, instrumentos, listas de verificación y entrevistas (Vargas \& Ibañez, 1998).

Es de carácter ideográfico, pues el terapeuta examina las causas particulares de los problemas conductuales de cada paciente, sus diferencias respecto al tiempo, contextos, e identifica las relaciones causales y funcionales entre individuos que refieren una problemática similar (Kaholokula, Bello, Nacapoy, \& Haynes, 2009).

La evaluación tiene tres objetivos principales: 1) describir la conducta problema y seleccionar conductas objetivo; 2) diseñar un programa de intervención; y 3) evaluar los resultados del tratamiento, no obstante, en la presente se hace referencia a una evaluación continua del tratamiento. El desarrollo de este tamizaje se aborda por fases, en consecuencia, se centra en la realización y resolución de preguntas en cada una, que son presentadas en la tabla 9. 


\section{Tabla 9}

Fases de la evaluación conductual

\begin{tabular}{|c|c|c|}
\hline & Fase & Preguntas \\
\hline 1 & $\begin{array}{l}\text { Selección } \\
\text { inicial }\end{array}$ & $\begin{array}{l}\text { ¿La demanda del paciente se ajusta a las posibilidades del servicio que se presta? } \\
\text { Si el paciente no cumple con los criterios ¿a quién se debe derivar? }\end{array}$ \\
\hline 2 & $\begin{array}{l}\text { Identificación } \\
\text { y análisis del } \\
\text { problema }\end{array}$ & $\begin{array}{l}\text { ¿Cuál es la naturaleza de la problemática del cliente? } \\
\text { ¿Las problemáticas del cliente deben tratarse? } \\
\text { ¿Cuáles son los factores que mantienen el problema del paciente? }\end{array}$ \\
\hline 3 & $\begin{array}{l}\text { Selección del } \\
\text { tratamiento }\end{array}$ & $\begin{array}{l}\text { ¿Qué prerrequisitos de las alternativas de tratamiento disponibles satisface el paciente, el } \\
\text { ambiente del paciente y el terapeuta? } \\
\text { ¿Cuál es el tratamiento óptimo para el problema del paciente? }\end{array}$ \\
\hline 4 & $\begin{array}{l}\text { Evaluación del } \\
\text { tratamiento }\end{array}$ & $\begin{array}{l}\text { ¿Cómo se ha administrado el tratamiento? ¿Fielmente o ha habido cambios? } \\
\text { ¿Qué cambios ha habido en las conductas problema y otras colaterales? } \\
\text { Estos cambios ¿pueden atribuirse al tratamiento? } \\
\text { ¿Qué costos ha contraído el tratamiento? } \\
\text { ¿Los beneficios del tratamiento son adecuados? } \\
\text { ¿El tratamiento se debe mantener, terminar o modificar? }\end{array}$ \\
\hline
\end{tabular}

Nota: Adaptado de "On the changing nature of behavioral assessment" por B. A. Barrios, 1998. En A. S. Bellack y M. Hersen (Eds.), Behavioral assessment: A practical handbook, pp. 3-41.

La guía retoma las fases propuestas por Barrios (1998). Las primeras dos constituyen parte del proceso de evaluación necesario para la aplicación del programa. Por otra parte, la tercera y cuarta representan la flexibilidad con la que fue concebida esta propuesta, ya que posibilitan el ajuste terapéutico, pudiendo añadir y modificar las técnicas propuestas en este material.

\subsubsection{Instrumentos}

Los instrumentos de evaluación posibilitan la obtención de datos del paciente. Los cuestionarios, las listas de verificación y las escalas psicométricas, son algunos de los instrumentos que se utilizan con mayor frecuencia. Los cuestionarios consisten en un listado de preguntas sobre datos sociodemográficos, antecedentes y prácticas del paciente. Por otra parte, las listas de verificación o checklists miden la presencia o frecuencia de un síntoma o conducta; finalmente, las escalas psicométricas evalúan un constructo en particular y se caracterizan por ser escalas estandarizadas, válidas y confiables. A continuación, en la tabla 10 se presentan las listas de verificación seleccionadas para constituir la evaluación inicial. 
Tabla 10

\section{Listas de verificación que constituyen la evaluación inicial}

\begin{tabular}{|c|c|c|c|}
\hline Lista de verificación & Autores & Reactivos & ¿Qué evalúa? \\
\hline $\begin{array}{l}\text { Breve Checklist de } \\
\text { Afrontamiento } \\
\text { (Anexo 1) }\end{array}$ & $\begin{array}{l}\text { Abaroa, González, Ortega, } \\
\text { Reyes y Reynoso (2020) }\end{array}$ & 10 & $\begin{array}{l}\text { Estilo de afrontamiento: } 5 \text { reactivos se dirigen al } \\
\text { estilo de afrontamiento centrado en el problema y } \\
\text { los } 5 \text { restantes al estilo de afrontamiento centrado } \\
\text { en la emoción }\end{array}$ \\
\hline $\begin{array}{l}\text { Checklist } \\
\text { Síntomas de estrés } \\
\text { (Anexo 2) }\end{array}$ & Reynoso y Seligson (2005) & 28 & $\begin{array}{l}\text { Síntomas de estrés en sus tres niveles de respuesta: } \\
18 \text { reactivos evalúan síntomas fisiológicos, } 5 \\
\text { síntomas conductuales y } 5 \text { síntomas cognitivos }\end{array}$ \\
\hline
\end{tabular}

Nota: Elaboración propia.

En cuanto a las escalas incluidas en la evaluación inicial, en la tabla 11 se especifican las propiedades psicométricas de estas.

\section{Tabla 11}

\section{Escalas que integran la evaluación inicial}

\begin{tabular}{|c|c|c|c|}
\hline Escala & $\begin{array}{l}\text { Escala de Ansiedad y Depresión } \\
\text { Hospitalaría (HADS) (Anexo 3) }\end{array}$ & $\begin{array}{l}\text { Escala de estrés percibido } \\
\text { (PSS-14) (Anexo 4) }\end{array}$ & $\begin{array}{l}\text { Inventario de Estrategias de } \\
\text { Afrontamiento (CSI) } \\
\text { (Anexo 5) }\end{array}$ \\
\hline Autores & Zigmond y Snaith (1983) & $\begin{array}{l}\text { Cohen, Kamarck y Mermelstein } \\
\text { (1983) }\end{array}$ & Cano, Rodríguez y García (2007) \\
\hline $\begin{array}{l}\text { Propósito } \\
\text { y administración }\end{array}$ & $\begin{array}{l}\text { Evalúa malestar emocional } \\
\text { (ansiedad y depresión) en } \\
\text { poblaciones con enfermedad } \\
\text { física }\end{array}$ & $\begin{array}{l}\text { Mide el grado en que las } \\
\text { situaciones en la vida se } \\
\text { evalúan como estresantes }\end{array}$ & $\begin{array}{l}\text { Evalúa estrategias de } \\
\text { afrontamiento }\end{array}$ \\
\hline $\begin{array}{l}\text { Reactivos } \\
\text { y dominios }\end{array}$ & $\begin{array}{l}14 \text { reactivos; } 2 \text { dominios: } \\
\text { depresión (pares) y ansiedad } \\
\text { (impares) }\end{array}$ & 14 reactivos; escala unifactorial & $\begin{array}{l}40 \text { reactivos; } 8 \text { dominios: } \\
\text { Resolución de problemas, } \\
\text { Reestructuración cognitiva, } \\
\text { Apoyo social, Expresión } \\
\text { emocional, Evitación de } \\
\text { problemas, Pensamiento } \\
\text { desiderativo, Retirada social y } \\
\text { Autocrítica }\end{array}$ \\
\hline $\begin{array}{l}\text { Formato } \\
\text { del instrumento }\end{array}$ & $\begin{array}{l}\text { Escala tipo Likert que va del } 0 \text { al } \\
3 \text {, donde: } 0-7=\text { rango de nor- } \\
\text { malidad, } 8-10=\text { caso probable, } \\
11-21=\text { caso de ansiedad o de } \\
\text { depresión clínico }\end{array}$ & $\begin{array}{l}\text { Escala tipo Likert que va de } 0 \\
\text { "nunca" a } 4 \text { "siempre". Para ob- } \\
\text { tener la puntuación total de la } \\
\text { escala se invierten las puntua- } \\
\text { ciones de los reactivos }(4,5,6, \\
7,9,10 \text { y } 13) \text { y, posteriormente, } \\
\text { se suman los } 14 \text { elementos. Los } \\
\text { puntajes indican: } 0-14=\text { casi } \\
\text { nunca o nunca está estresado; } \\
15-28=\text { de vez en cuando está } \\
\text { estresado; } 29-42=\text { a menudo } \\
\text { está estresado, y } 43-56=\text { muy a } \\
\text { menudo está estresado }\end{array}$ & $\begin{array}{l}\text { Primero se describe detallada- } \\
\text { mente una situación estresante; } \\
\text { posteriormente, se responde } \\
\text { cada reactivo en escala tipo } \\
\text { Likert de cinco puntos. Cuenta } \\
\text { con un reactivo adicional que } \\
\text { evalúa la autoeficacia percibida } \\
\text { del afrontamiento }\end{array}$ \\
\hline
\end{tabular}




\begin{tabular}{|c|c|c|c|}
\hline $\begin{array}{l}\text { Consistencia } \\
\text { interna de versión } \\
\text { original }\end{array}$ & $a=0.85$ para toda la escala & $\begin{array}{l}a=0.84 \text { (para estudiantes va- } \\
\text { rones universitarios), } .85 \text { (para } \\
\text { estudiantes mujeres universita- } \\
\text { rias), y } .86 \text { (en la muestra para } \\
\text { dejar de fumar) en cada una de } \\
\text { las tres muestras }\end{array}$ & $\begin{array}{l}a=0.81 \text { para toda la escala. Los } \\
\text { dominios de la escala oscilan } \\
\text { entre } a=0.70-0.86\end{array}$ \\
\hline $\begin{array}{l}\text { Validación en } \\
\text { población } \\
\text { mexicana }\end{array}$ & $\begin{array}{l}\text { Pacientes con enfermedad } \\
\text { cardiovascular; } a=.94 \text { (Herrera } \\
\text { et al., 2017). } \\
\text { Pacientes con ERC en hemodiá- } \\
\text { lisis; } a=.80 \\
\text { (Lugo, Pérez, \& Sánchez, 2018). } \\
\text { Pacientes con diversos pade- } \\
\text { cimientos crónicos, a = .90 } \\
\text { (Anguiano, Mora, Reynoso, \& } \\
\text { Vega, 2017). } \\
\text { Población con obesidad; a = } \\
.82 \text { (Morales, Alfaro, Sánchez, } \\
\text { Guevara, \& Vázquez, 2007). }\end{array}$ & $\begin{array}{l}\text { Mujeres mexicanas puérperas; } \\
a=0.71 \text { (Torres, Vega, Vinalay, } \\
\text { Arenas, \& Rodríguez, 2015). } \\
\text { Colegiados de Monterrey a = } \\
.79 \text { (Moral \& Cazares, 2014). } \\
\text { Universitarios, a = } 0.83 \text { (Gonzá- } \\
\text { lez \& Landero, 2007) }\end{array}$ & $\begin{array}{l}\text { En población mexicana, los } \\
\text { niveles de consistencia interna } \\
\text { fueron satisfactorios } a=0.63 \text { - } \\
0.80 \text {, en los resultados de Cano } \\
\text { et al. (2007) y Nava, Ollua, Vega } \\
\text { y Soria (2010) }\end{array}$ \\
\hline
\end{tabular}

Nota: Elaboración propia.

\subsubsection{Evaluación inicial}

Representa el primer contacto con el paciente y es la base para establecer una relación terapeuta-paciente orientada a los objetivos de la TCC. El trabajo terapéutico es colaborativo entre ambos involucrados. Para cumplir con este aspecto, desde el inicio, se debe favorecer la libre expresión, el flujo de emociones mediante el establecimiento del rapport, que tiene como objetivo propiciar un ambiente de confianza y cordialidad para aumentar la probabilidad de asistencia a las sesiones posteriores.

El rapport se vuelve un componente central para la TCC tanto para el trabajo colaborativo como la relación terapeuta-paciente, por tanto, el último debe entrenarse en él. Al respecto, se retoman las recomendaciones de Bados y García (2011) sobre las habilidades del terapeuta, no limitadas al establecimiento del rapport, sino para fomentar la interacción entre ambas partes durante todo el proceso terapéutico. Estos autores las dividen en: 1) habilidades básicas del profesional destacando la escucha activa, empatía, aceptación y autenticidad; 2) habilidades que favorecen la relación entre ellas la cordialidad competencia, confianza y cierto grado de directividad; y 3) habilidades de comunicación donde se incluyen las de escucha (reflejo, paráfrasis y síntesis) y de acción (realizar preguntas, informar e interpretación). Adicionalmente, dichas habilidades permiten favorecer la logística de la evaluación e intervención y la comunicación entre los participantes.

Para ello es necesario preparar el escenario desde el que se brindará el servicio, es recomendable que sea un lugar privado y neutral. Para esta modalidad, el terapeuta deberá seguir los mismos estándares para prestación de servicios presenciales: un adecuado arreglo tanto en vestimenta como en peinado (Labrador, 2011). 
Se realiza la presentación del terapeuta, incluyendo datos como el nombre, el grado académico $y$, en este caso, mencionar que forman parte del programa de Maestría y Doctorado en Psicología de la UNAM. A continuación, se explica la dinámica de la modalidad online. De acuerdo con Bados y García (2009), en esta fase se explica la confidencialidad de la información y sus límites, además de establecer una buena relación con el paciente (rapport).

Se propone que se realice la presentación del terapeuta y paciente, enseguida se explica la dinámica de la terapia online aclarando dudas al respecto, finalmente, se procede al envío del consentimiento informado, el cual debe leerse y ser aceptado por el paciente. En la figura 6 se puede observar el proceso para iniciar la evaluación.

\section{Figura 6}

Flujograma de sesiones de evaluación

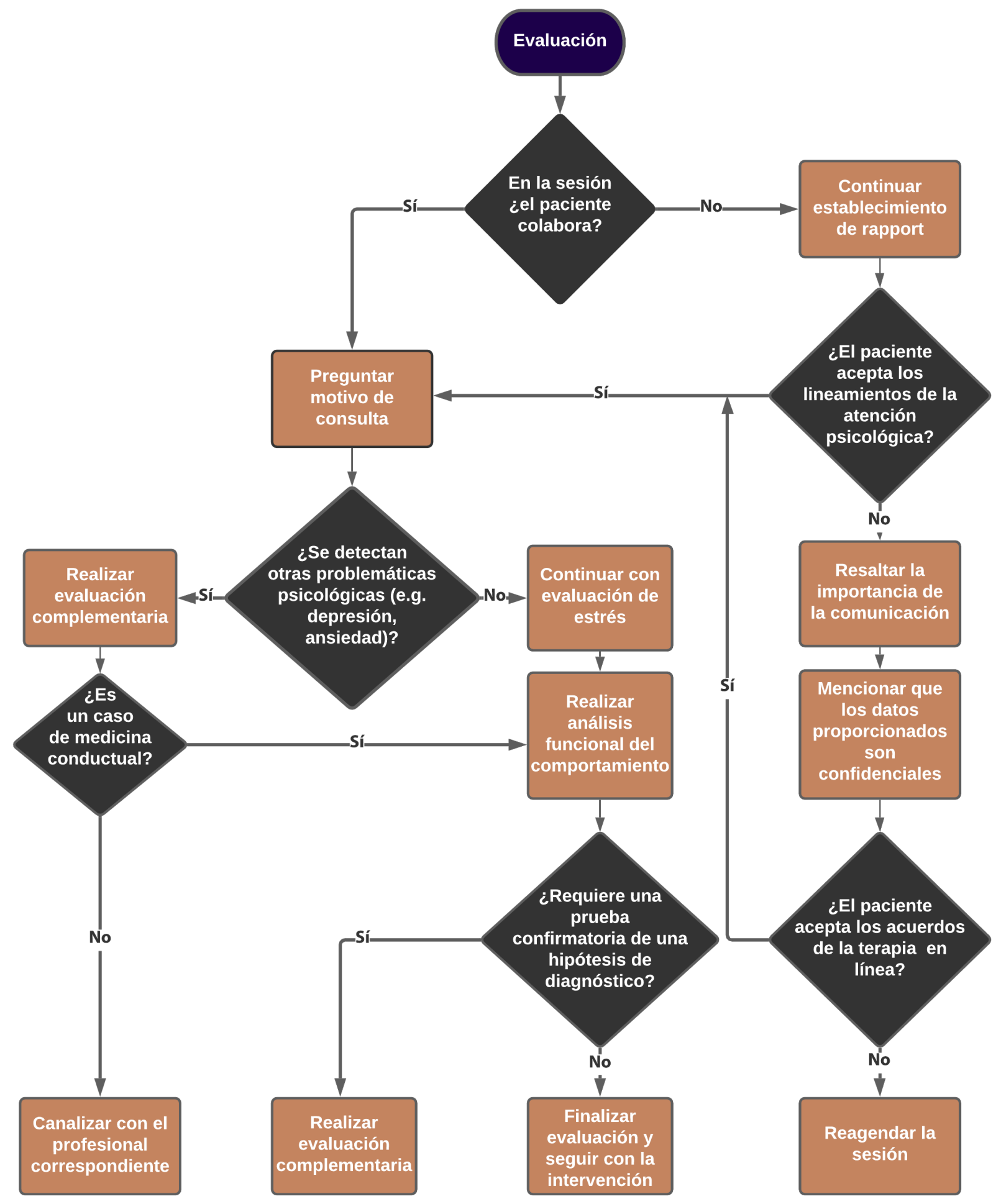




\subsubsection{Entrevista conductual}

La entrevista conductual es una herramienta que permite la recolección de información sobre el paciente y las relaciones funcionales de la conducta problema, suele ser dirigida por el terapeuta y se da de una forma bidireccional (Consejo General de la Psicología, 2017; Perpiña, 2012).

Aspectos por considerar en la entrevista:

1. Datos sociodemográficos: nombre, edad, lugar de origen, religión, ocupación, estado civil, hijos, nivel de estudios.

2. Atención psicológica previa (solo en los casos que hayan llevado un proceso terapéutico): hace cuánto, cuánto tiempo estuvo en terapia, motivo general de consulta, bajo qué enfoque, qué hicieron.

3. Historia de la enfermedad: antecedentes heredofamiliares, qué enfermedad tiene, desde cuándo, tratamiento (medicamento, alimentación, actividad física, sustitutivo), cirugías, comorbilidades, tipo de tratamiento que tiene de acuerdo con su enfermedad.

4. Tratamiento: medicamento (cuáles son, desde cuándo los toma, cuáles son las dosis, el horario), alimentación (qué come, cuándo come, en qué horarios, cantidad de lo que come, lo hace solo o acompañado), actividad física (si realiza ejercicio, cuánto tiempo al día y cuántos días a la semana, qué tipo de ejercicio).

5. Consumo de sustancias nocivas: alcohol, tabaco, sustancias psicoactivas (desde cuándo, frecuencia, cantidad).

6. Trabajo interdisciplinario: si acude con algún otro especialista nutriólogo, médico, etcétera.

7. Conducta problema (estrés): desde cuándo empezó, qué ocurre antes de la conducta problema (estímulos externos e internos), que ocurre durante la conducta problema (respuestas fisiológicas, motoras y cognitivas), qué ocurre después (respuestas fisiológicas, motoras y cognitivas), en presencia de quién o quiénes ocurre, dónde ocurre, ante qué situaciones.

Al finalizar la entrevista inicial se realiza un resumen de la sesión, se agradece y refuerza al paciente por conectarse, en caso de dejar algún registro se envía y explica y, por último, se agenda una próxima cita.

\subsubsection{Análisis Funcional de la Conducta (AFC)}

Es el eje rector del análisis conductual. Se define como un modelo conceptual de proceso que permite la identificación de relaciones funcionales (causales o correlacionales) que pueden aplicarse a un conjunto particular de conductas objetivo para un individuo. Además, este análisis favorece la formulación de hipótesis, objetivos generales y particulares de la 
intervención, al igual que la elección de las técnicas. Así, el análisis funcional permite la comprensión de los factores relacionados con la problemática y, por añadidura, el diseño de la intervención (Bravo \& Mora, 2014; Haynes \& O'Brien, 1990; Kaholokula, Godoy, O'Brien, Haynes, \& Gavino, 2013; Kanfer \& Saslow, 1969).

\subsubsection{Evaluación complementaria}

Además del proceso de evaluación inicial (entrevista, aplicación de instrumentos y AFC) el terapeuta puede requerir de información complementaria para constatar un diagnóstico psicológico con la finalidad de favorecer un tratamiento terapéutico o canalizar al paciente. Lo anterior resultará pertinente en aquellos casos donde se identifiquen algunos tipos de trastornos de personalidad, del estado de ánimo (ansiedad, depresión) o problemáticas relacionadas con las habilidades sociales.

En cuanto a la necesidad de indagar información acerca de la conducta problema o motivo de consulta, se deben detectar faltantes de información dentro del AFC para ser abordados en la entrevista conductual. Si es necesario verificar un probable diagnóstico, se utilizarán escalas adicionales que se han seleccionado para favorecer la toma de decisiones terapéuticas con base en la problemática y las necesidades del paciente. En la tabla 12 se enlistan las listas de verificación consideradas para conformar esta evaluación.

\section{Tabla 12}

Propuesta de listas de verificación para evaluación complementaria

\begin{tabular}{llcl}
\multicolumn{1}{c}{ Lista de verificación } & \multicolumn{1}{c}{ Autores } & Reactivos & ¿Qué evalúa? \\
$\begin{array}{l}\text { Ansiedad A } \\
\text { (Anexo 6) }\end{array}$ & Reynoso y Becerra (2013) & 19 & Respuestas fisiológicas, conductuales y cognitivas \\
\hline $\begin{array}{l}\text { Ansiedad B } \\
\text { (Anexo 7) }\end{array}$ & Reynoso (2002) & 23 & Respuestas fisiológicas \\
\hline
\end{tabular}

Nota: Elaboración propia.

En la tabla 13 se describen las propiedades psicométricas de las escalas seleccionadas para esta evaluación.

\section{Tabla 13}

Escalas propuestas para la evaluación complementaria

\begin{tabular}{llll} 
Escala & $\begin{array}{l}\text { Diabetes } 39 \\
(\text { Anexo 8) }\end{array}$ & $\begin{array}{l}\text { Versión Actualizada de la Escala } \\
\text { de Adherencia Terapéutica } \\
(\text { Anexo 9) }\end{array}$ & $\begin{array}{l}\text { Medication Adherence Report } \\
\text { Scale (MARS) } \\
(\text { Anexo 10) }\end{array}$ \\
\cline { 1 - 2 } & Boyer y Earp (1997) & Pedraza-Banderas y Valero (2018) & Horne y Hankins (2002)
\end{tabular}




\begin{tabular}{|c|c|c|c|}
\hline $\begin{array}{l}\text { Propósito } \\
\text { y administración }\end{array}$ & $\begin{array}{l}\text { Evalúa la calidad de vida } \\
\text { relacionada con la salud }\end{array}$ & $\begin{array}{l}\text { Evalúa el cumplimiento de las } \\
\text { recomendaciones médicas }\end{array}$ & $\begin{array}{l}\text { Evalúa el patrón de conductas } \\
\text { de falta de adherencia al } \\
\text { tratamiento }\end{array}$ \\
\hline $\begin{array}{l}\text { Reactivos } \\
\text { y dominios }\end{array}$ & $\begin{array}{l}39 \text { reactivos; } 5 \text { dominios: } \\
\text { energía-movilidad, control } \\
\text { de la diabetes, ansiedad- } \\
\text { preocupación, carga social y } \\
\text { funcionamiento sexual }\end{array}$ & $\begin{array}{l}30 \text { reactivos; } 3 \text { dominios: } \\
\text { atención médica y cumplimiento } \\
\text { de recomendaciones efectuadas } \\
\text { por el personal sanitario, } \\
\text { cambios en estilo de vida } \\
\text { y situaciones de barrera o } \\
\text { aspectos que interfieren ante la } \\
\text { adherencia }\end{array}$ & $\begin{array}{l}7 \text { reactivos de falta de } \\
\text { adherencia intencional }\end{array}$ \\
\hline $\begin{array}{l}\text { Formato } \\
\text { del instrumento }\end{array}$ & $\begin{array}{l}\text { Escala de tipo análoga visual } \\
\text { donde se ubican los números } 1 \\
\text { al } 7 \text {, donde } 1 \text { = nada afectado } \\
\text { en lo absoluto y } 7 \text { = sumamen- } \\
\text { te afectado en la calidad de } \\
\text { vida. Se tomó como punto de } \\
\text { corte para definir mejor }(<29) \text { y } \\
\text { peor }(\geq 29) \text { calidad de vida }\end{array}$ & $\begin{array}{l}\text { Escala tipo Likert con } 5 \text { opciones } \\
\text { de respuesta para frecuencia }\end{array}$ & $\begin{array}{l}\text { Escala tipo Likert de } 4 \text { puntos, } \\
\text { que va de: "siempre lo hago } \\
\text { así" a "nunca lo hago así" }\end{array}$ \\
\hline $\begin{array}{l}\text { Consistencia } \\
\text { interna de versión } \\
\text { original }\end{array}$ & $\begin{array}{l}\text { Los dominios de la escala } \\
\text { presentaron } a=\geq 0.80\end{array}$ & $a=0.890$ para toda la escala & $a=.85$ para toda la escala \\
\hline $\begin{array}{l}\text { Validación } \\
\text { en población } \\
\text { mexicana }\end{array}$ & $\begin{array}{l}\text { Pacientes adultos con } \\
\text { diagnóstico de DM- } 2 \text { de ambos } \\
\text { sexos en tratamiento médico } \\
\text { (López \& Rodríguez, 2006) }\end{array}$ & $\begin{array}{l}\text { Originalmente la escala se } \\
\text { desarrolló en México }\end{array}$ & $\begin{array}{l}\text { Pacientes asmáticos, } a=.85 \\
\text { (Lugo \& Vega, 2020) }\end{array}$ \\
\hline
\end{tabular}

Nota: Elaboración propia.

\subsection{Canalización}

El objetivo de la evaluación, especialmente de la entrevista inicial, es la recolección de datos del paciente sobre su diagnóstico médico de DM tipo 2 y la identificación de síntomas de estrés, derivados o no de la enfermedad crónica. Por ello, si durante la evaluación el especialista en MC identifica problemáticas distintas a las de interés, será necesario que canalice al paciente al especialista correspondiente. En la figura 7 se presenta el flujograma para favorecer la toma de decisiones para dictaminar en qué casos se requiere canalizar. Las posibles problemáticas que se pueden presentar se enlistan a continuación:

- Prevalencia de otros problemas clínicos tales como violencia, trastornos de abuso de sustancias o ansiedad, entre otros, o aquellos que requieren atención psiquiátrica.

- Ante la presencia de problemas clínicos como ideación e intento suicida, trastornos alimentarios, depresión severa u otros que necesiten atención por un psiquiatra.

- Detección de comorbilidades con trastornos cromosómicos o aquellos que afectan el desarrollo cognitivo del paciente.

- Apoyo adicional de un especialista en nutrición, ya sea nutriólogo o bariatra. 


\section{Figura 7}

Flujograma para la toma de decisión sobre canalización

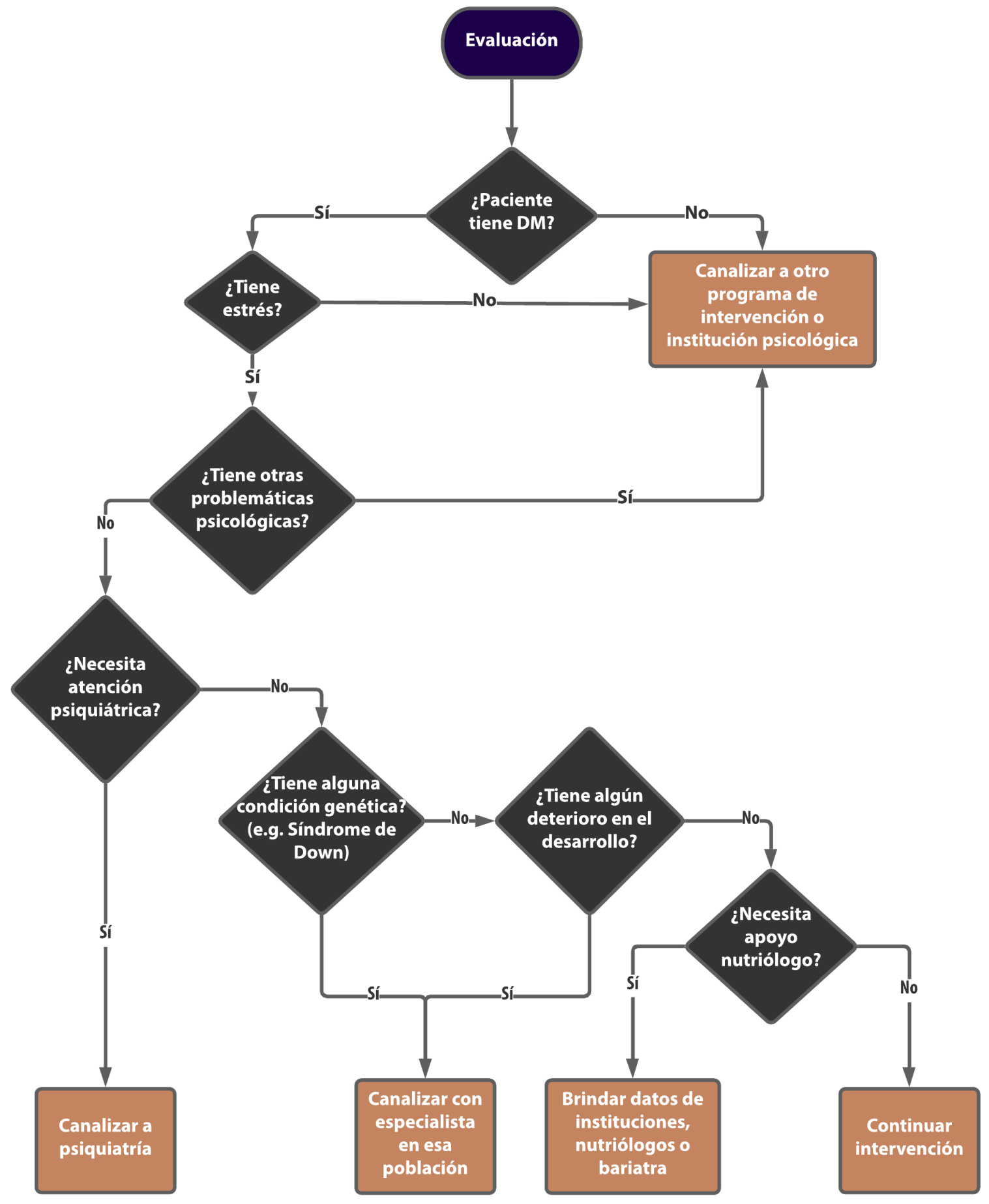

Nota: Elaboración propia.

\subsection{Planeación de la intervención}

Los programas de intervención cognitivo conductual muestran resultados favorables en poblaciones de pacientes que padecen de enfermedades crónicas y estrés. Este tipo de programas deben ser parte del tratamiento integral, manejando tres necesidades básicas de los pacientes con estrés: ofrecer información y educación sobre el estrés y la enfermedad, desarrollar estrategias que permitan tener una sensación de control sobre el estrés y la enfermedad, y emplear correctamente su red de apoyo. Por ello, deben contemplarse programas multicomponente que aborden dichas necesidades, como en este caso donde se debe llevar a cabo las tareas de psicoeducación, fomentar estrategias para el control del 
estrés, y el aprendizaje de un modelo de solución de problemas para aplicarlo, esto sin olvidar que es necesario que se ajusten a un modelo de tratamiento integral y a las necesidades particulares de los pacientes (Castro-Meza, Pérez-Zumano, \& Salcedo-Álvarez, 2017).

\subsubsection{Identificación de áreas problema}

En un inicio cuando el terapeuta tiene el primer contacto con el paciente, se debe considerar la posibilidad de que el paciente no solo presente estrés, sino que también tenga síntomas relacionados con otros trastornos como ansiedad, depresión, trastornos de alimentación, consumo de sustancias, déficit en capacidades cognitivas, etcétera. Para identificar la problemática por la que requieren el servicio es indispensable realizar el AFC y hacer uso adecuado de las herramientas validadas y estandarizadas.

El análisis del comportamiento se debe realizar para identificar los excesos y déficits conductuales, corroborando esta información con los diferentes instrumentos de evaluación que se aplican en caso de ser necesario. El AFC es la piedra angular de la evaluación conductual, es una tarea que implica tiempo y esfuerzo para recolectar la información relevante para tener la posibilidad de formular la hipótesis del caso, determinar la metas y estrategia de intervención (Bravo \& Mora, 2014).

\subsubsection{Selección de estrategias}

Esta guía es de carácter flexible, donde la técnica es asignada a partir de una evaluación de la problemática de cada individuo, centrada en las necesidades específicas, con el propósito de optimizar los resultados en materia de cuidado de la salud y calidad de vida.

A partir de ello, se asignan las técnicas tomando en cuenta los siguientes lineamientos:

1. Estrategias parabrindar información. Son básicas para alcanzar un cambio contemplando tanto la habilidad y la efectividad como elementos fundamentales para seguir instrucciones, además de considerar los efectos emocionales de la comunicación verbal y no verbal, entre otros aspectos. Una correcta adherencia a los regímenes terapéuticos no está garantizada por adquirir información y conocimientos sobre el estrés y enfermedad, es decir, la información per se no produce cambio conductual. La técnica con finalidad de informar es, y debe ser, compatible con otras técnicas conductuales que permitan dirigirse al manejo del estrés (García-Cedillo, Guillén, Martínez, \& SánchezArmáss, 2017).

2. Estrategias de manejo de estrés. La respiración rítmica y la respiración diafragmática son ejemplos claros, cuyo sustento fisiológico implica el realizar estimulación vagal. Esta estrategia permitirá que gradualmente se logre un decremento de respuestas fisiológicas, como es el caso de la frecuencia cardiaca, a través de la respiración. Así también, el uso de técnica de autoinstrucciones supone que el paciente verbalice frases que le ayuden a desarrollar la sensación de control o realizar conductas y, con ello, consiga manejar 
de manera más saludable sus niveles de estrés y ansiedad (Meichenbaum, 2002). Además, el entrenamiento en solución de problemas debe ser dirigido a incrementar las habilidades del paciente para afrontar situaciones estresantes y superar obstáculos de situaciones relacionadas con su padecimiento, identificando y poniendo en marcha las opciones de afrontamiento más adaptativas y eficientes para la solución de problemáticas de manera constructiva. El paciente descubre, crea o identifica formas efectivas de comportamiento y pensamiento para afrontar los elementos estresantes relacionados con la enfermedad (D’Zurilla \& Nezu, 1999).

Esta guía tiene el fin de realizar una intervención a las necesidades específicas y metas individualizadas. Para el diseño de dicha intervención, es necesaria la adaptación de las estrategias mencionadas a la cultura del paciente, tomando en cuenta creencias, valores, lenguaje, escolaridad y costumbres. Una vez hecho esto, se recomienda realizar estrategias como: relajación, reforzadores, moldeamiento, modelamiento y estrategias de solución de problemas para reforzar tanto la adherencia como la efectividad del tratamiento (GonzálezCantero \& Oropeza-Tena, 2016). En estas últimas, se realiza una retroalimentación periódica para verificar progreso, en donde las metas de la reducción de estrés sean evaluadas y, en caso de recaer, se desarrolle un plan personalizado. Finalmente, es necesario diseñar un plan de seguimiento conductual y estrategias de automonitoreo.

\subsubsection{Selección de las $T I C$ 's}

La utilización de las TIC's ha impulsado de forma acelerada el desarrollo científico-tecnológico, surgiendo nuevos escenarios de aprendizaje y la utilización de nuevos medios de enseñanza (videoconferencias, teleconferencias, aulas virtuales, sistemas de software educativo multimedia y cursos a distancia). Su implementación desde finales del siglo pasado produjo, a escala mundial, importantes cambios en todo ámbito, sea privado o público, desde la forma de organización personal e institucional hasta el proceso de comunicación, de convivencia y aprendizaje y, por ende, en el ámbito clínico (Cárdenas, 2013; Veloz et al., 2012).

No todos los países han llegado a alcanzar esta modalidad asistencial, ya que es necesario que al mismo tiempo se produzca un grado de desarrollo tecnológico suficiente. La psicología ya había usado la tecnología virtual, tanto para terapias como para evaluación, a manera de instrumento complementario de la terapia presencial o para obtener muestras más amplias. Los equipos de cómputo y el internet son una alternativa viable debido a la portabilidad y personalización, tienen gran beneficio y ventajas en el paciente, así se percibe seguridad, control y confiabilidad para poder mantener su proceso. Con lo descrito anteriormente, se puede observar cómo los cambios que sustentan las nuevas TIC's invitan a un continuo cambio en la práctica clínica de los profesionales de salud (González-Peña, Torres, Barrio, \& Olmedo, 2017). 
La elaboración de esta guía se hizo con el fin de implementarse a distancia, y se eligió la plataforma Zoom ${ }^{\circledast}$ como aplicación de software de videoconferencia para lograr tal objetivo. De acuerdo con la guía de Zoom ${ }^{\circledast}$ (2020), esta plataforma online de videoconferencia cuenta con diversas funciones como: compartir escritorio, pizarra, chat, grabación, sistema telefónico y compartir documentos. Es de fácil acceso, ya que está disponible para dispositivos móviles, tabletas y equipos de cómputo, que cuenten con acceso a internet, solo es necesario instalar la aplicación. En su versión gratuita permite reuniones de hasta 60 minutos, encuentros seguros, privados y agendados, lo cual lo convierte en una herramienta versátil para la aplicación de intervenciones terapéuticas.

Como parte de la evaluación de las distintas variables psicológicas que puedan presentarse, se puede hacer uso de una aplicación para realizar y aplicar formularios. La herramienta de elección fue el software Google Forms ${ }^{\oplus}$, que tiene una variedad de ventajas como: compatibilidad con todos los sistemas operativos disponibles, gratuito y no tiene límite respecto a su uso. Esta aplicación permite recopilar información de forma fácil y eficiente.

Finalmente, la herramienta digital para realizar el entrenamiento en relajación es la aplicación móvil Breathe ${ }^{\circledast}$ o BreatheSync ${ }^{\circledast}$, la cual se puede descargar en los sistemas operativos iOS y Android. También se utilizarán los softwares Ritmo cardíaco-Monitor ${ }^{\circledast}$ (para sistema operativo Android) y Heart Rate Free ${ }^{\oplus}$ (para sistema operativo iOS), con la finalidad de medir el pulso cardiaco. Se seleccionaron estas aplicaciones porque ambas se ejecutan y tienen contenidos similares, aun en sistemas operativos diferentes. El uso de estas aplicaciones permitirá complementar el entrenamiento en relajación (respiración), en consecuencia, llevará a la adquisición satisfactoria de datos sobre la ejecución del ejercicio en cada participante. Dicho de otra manera, el paciente tendrá al alcance retroalimentación sobre la aplicación de técnica y el resultado fisiológico logrado.

\subsubsection{Normatividad (reglas generales)}

Al ser una propuesta de intervención con una nueva modalidad se debe considerar la normatividad del proceso terapéutico, con el fin de establecer procedimientos aplicables a las diferentes condiciones que se pudieran presentar.

Con base en el protocolo de intervención telefónica de la World Health Organization (WHO, 2014) se adapta a la modalidad propuesta. Así, se plantea la comunicación con el paciente ante la solicitud de intervención, como se puede observar en la figura 8 . Se debe recalcar que el criterio del límite de contactos al paciente aplica a lo largo de todo el proceso terapéutico. 


\section{Figura 8}

Flujograma para solicitud de intervención

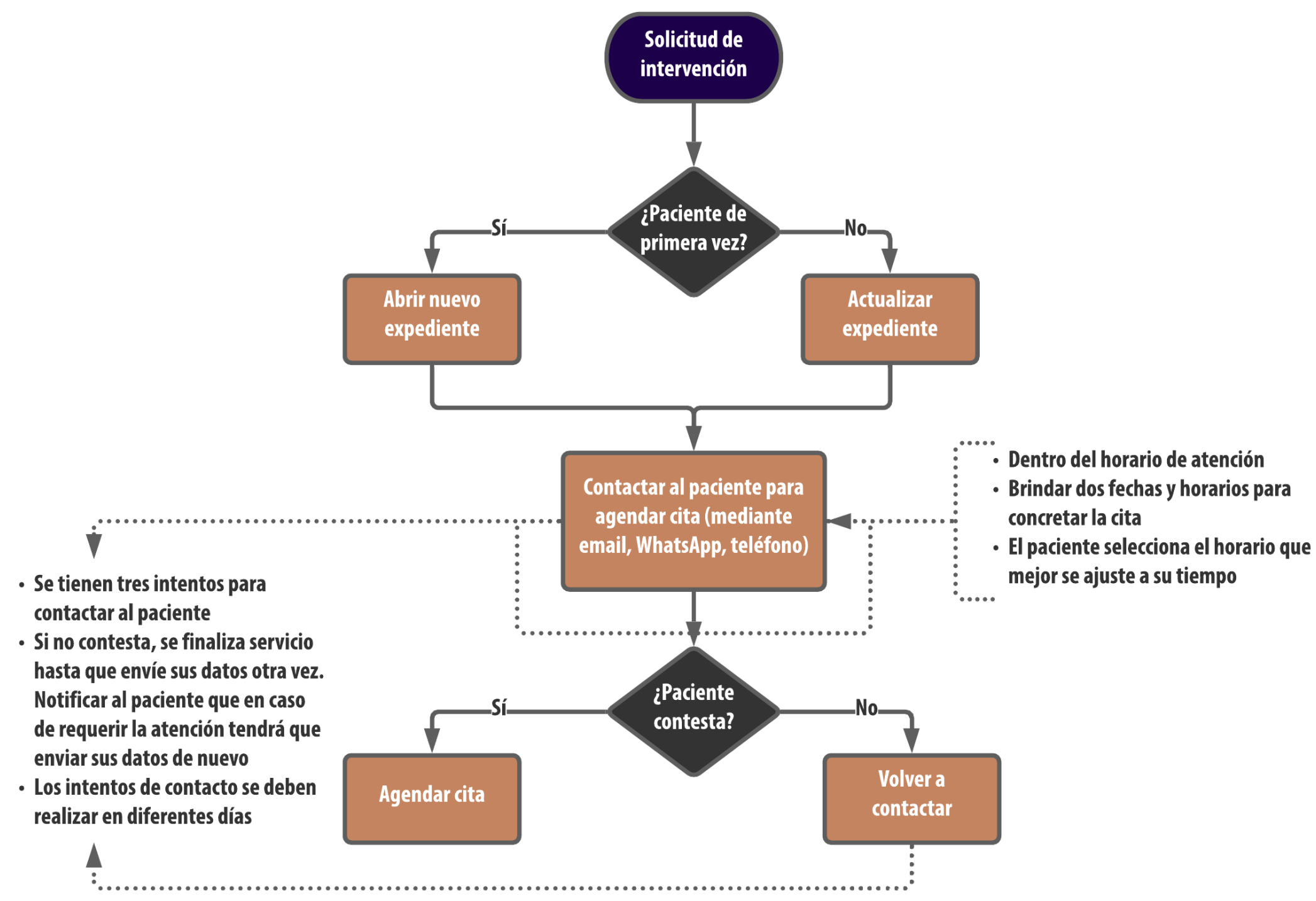

Nota: Adaptado de Training for tobacco quit line counsellors: Telephone counselling por World Health Organization (WHO), 2014.

La adaptación a la nueva modalidad terapéutica propicia nuevos escenarios retadores para el terapeuta, conduciendo al desarrollo de planes de acción ante estas circunstancias. Por ello, se plantean los flujogramas que establecerán una guía para el procedimiento a seguir y la toma de decisiones en caso de: ausencia del paciente a la sesión (figura 9); derivar al paciente con un especialista (figura 10); presentar fallas en la conexión que interrumpan la sesión (figura 11); dar de baja (figura 12) y dar de alta (figura 13) del servicio. 
Figura 9

Flujograma para procedimiento por inasistencia del paciente a sesión

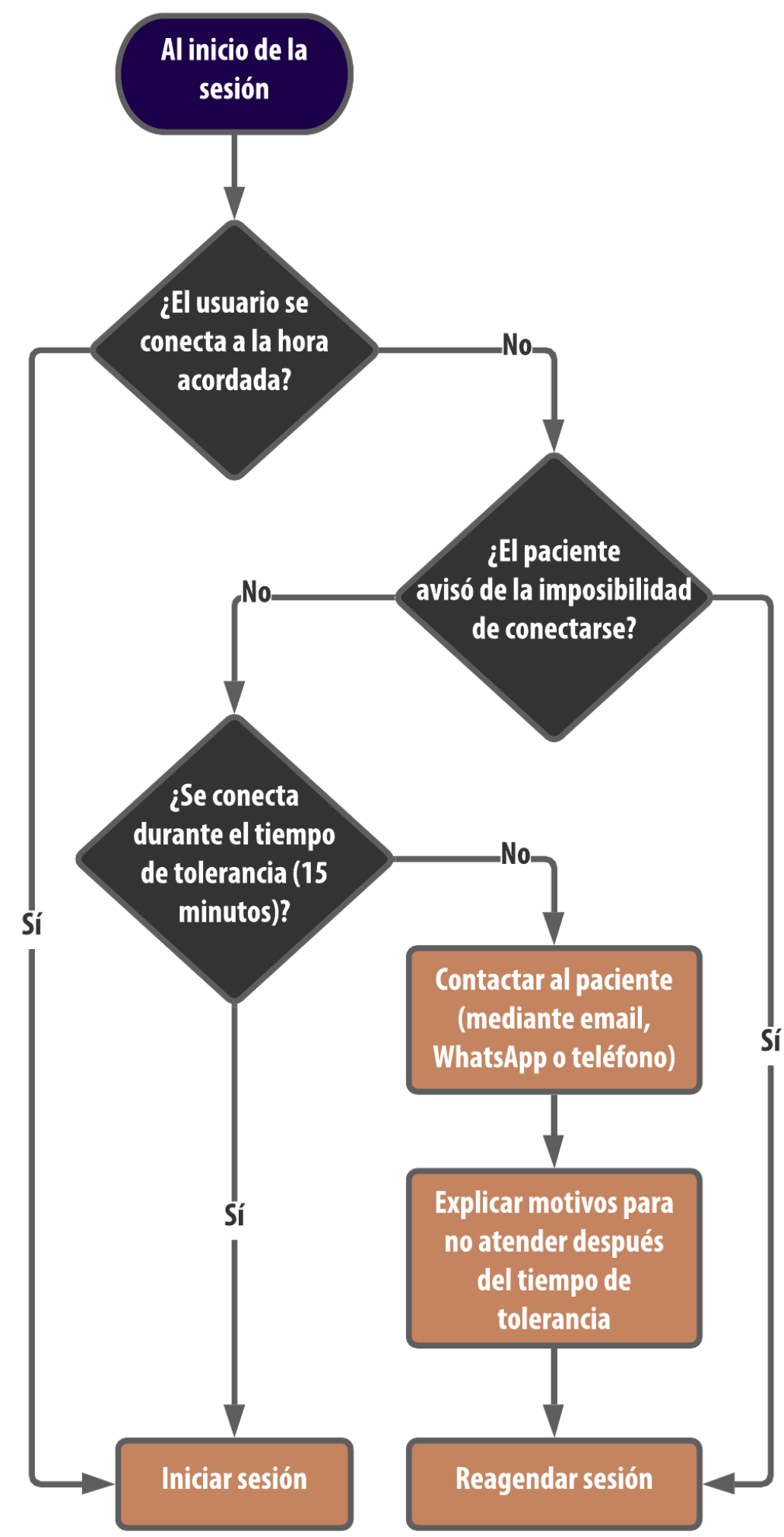

Nota: Elaboración propia. 
Figura 10

Flujograma para procedimiento de canalización

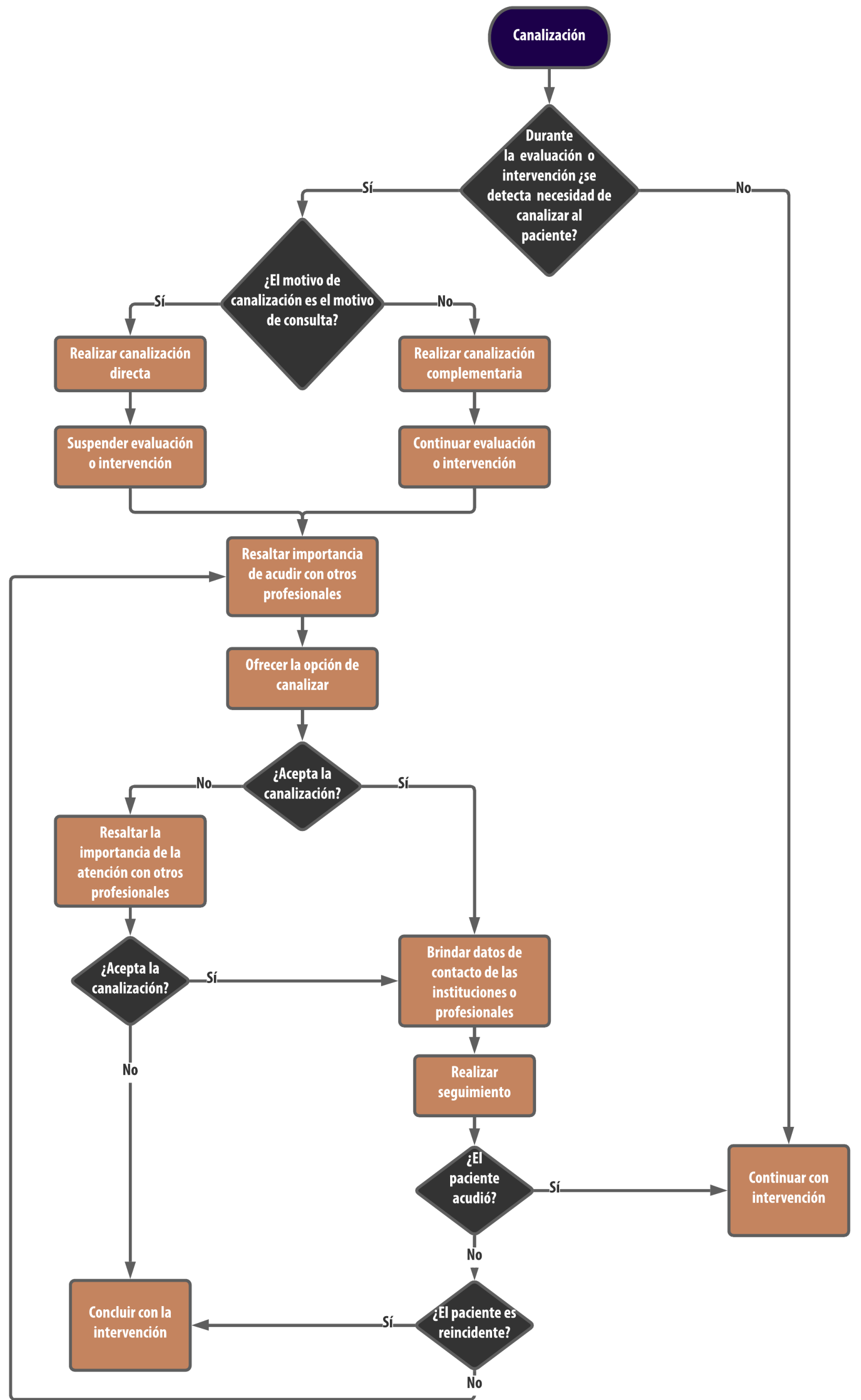

Nota: Elaboración propia. 


\section{Figura 11}

Flujograma para procedimiento ante desconexión de internet

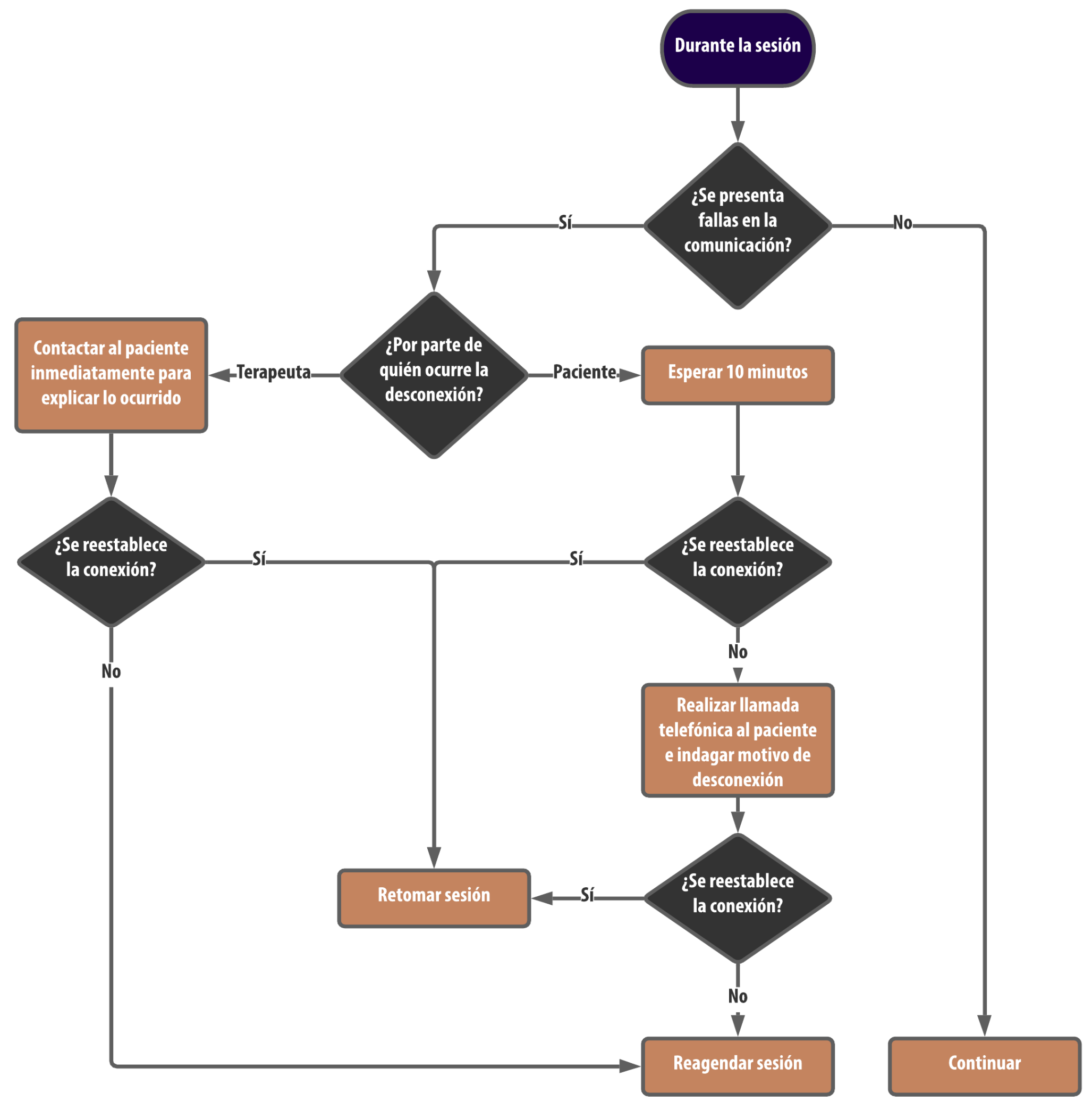

Nota: Elaboración propia. 
Figura 12

Flujograma de mecanismos para dar de baja del servicio

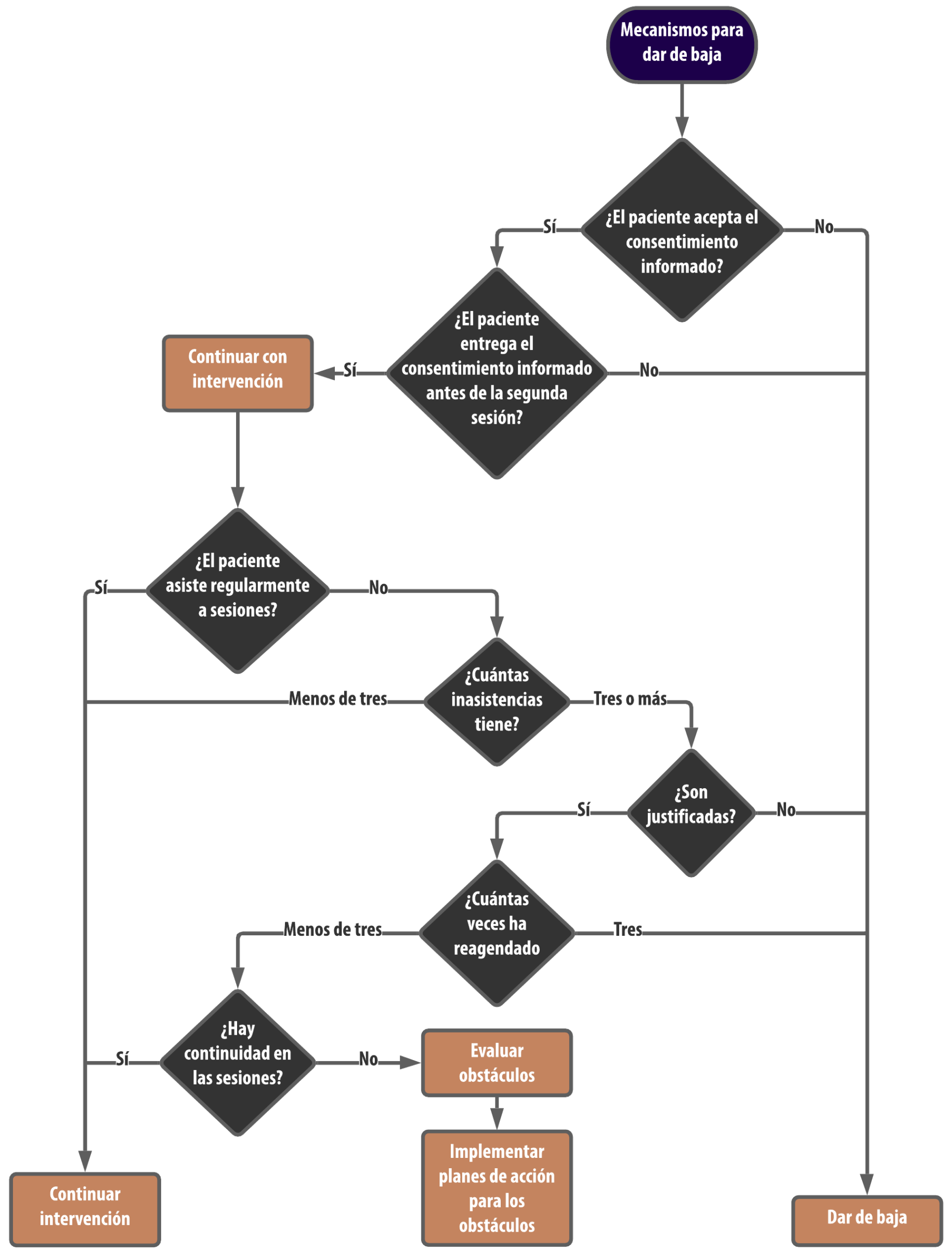

Nota: Elaboración propia. 
Figura 13

Flujograma de mecanismos para dar de alta del servicio

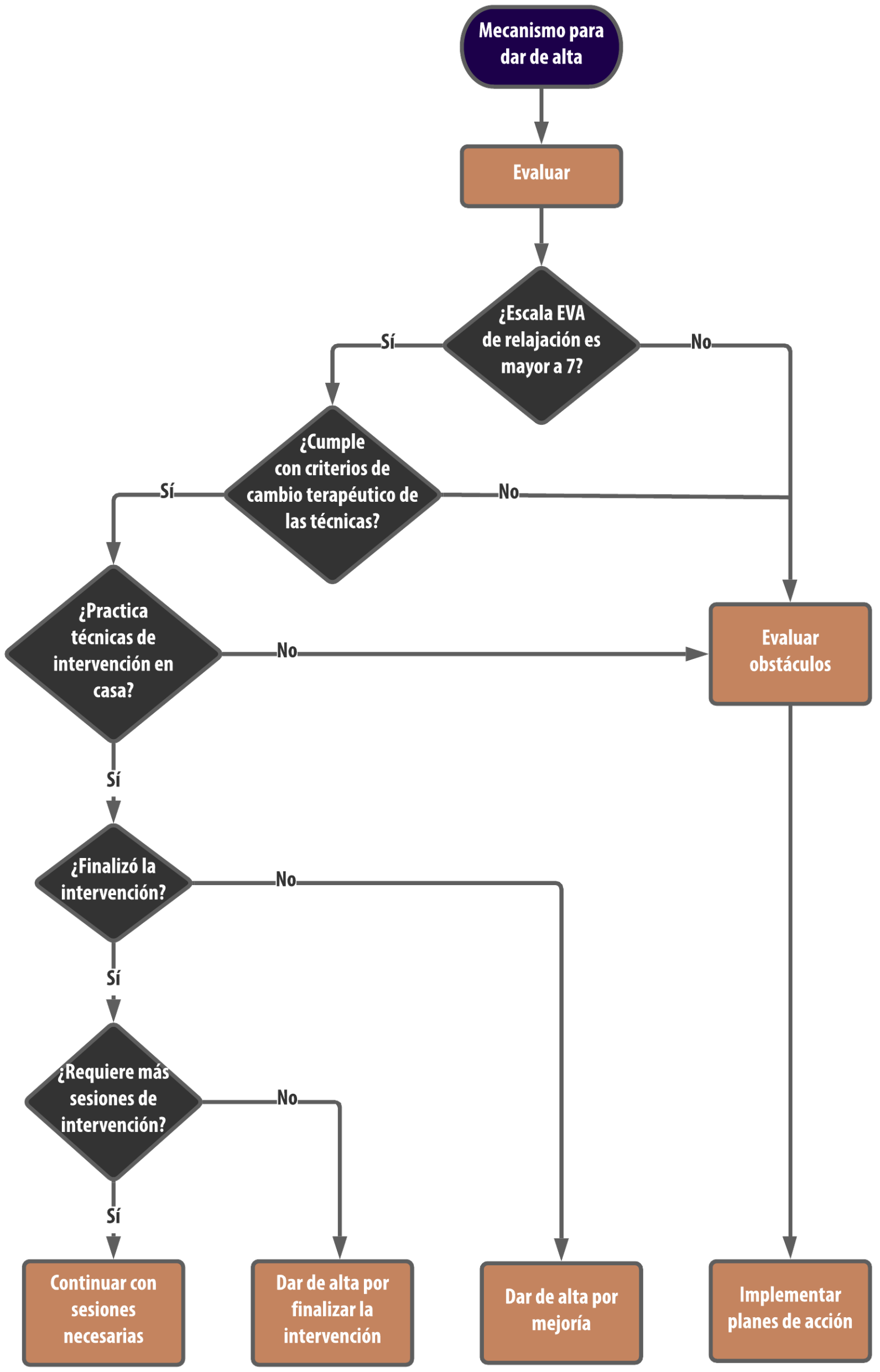

Nota: Elaboración propia. 


\subsection{Elección y descripción de las técnicas}

Se llevará a cabo un programa de intervención basado en diferentes técnicas bajo el modelo cognitivo conductual siguiendo las fases del tratamiento que se describe en el desarrollo de la intervención.

\subsubsection{Psicoeducación}

La psicoeducación debe ser el primer paso para iniciar cualquier tratamiento. Gavino (2006) menciona que esta técnica consiste en proporcionar información sobre algún tema en particular; se utiliza cuando la falta de esta hace que una persona no lleve a cabo ciertas conductas o no actúe adecuadamente en determinada(s) situación(es). Según la autora se deben estimar los siguientes puntos:

1. Definir la información que se le proporcionará al paciente.

2. Transmitir la información de manera clara, concisa y fácil de entender.

3. Preguntar al paciente o familiar si la explicación se entiende correctamente, a modo de corroborar que no hay malentendidos o suposiciones.

4. Si se cree oportuno, proporcionar la información con apoyo de material escrito.

De acuerdo con Colom (2011) hay dos tipos de psicoeducación: la primera se centra en la información sobre la enfermedad, no contempla el cambio de actitud, su eficacia es limitada. Con la psicoeducación centrada en la conducta, el papel del aprendiz es activo, su principal objetivo es el entrenamiento y práctica de repertorios conductuales que se relacionen con la detección e intervención de enfermedades, por ello, se modifican hábitos, reestructuran prejuicios acerca de la enfermedad, se identifican factores de riesgo o desencadenantes, entre otras.

Por otra parte, Cuevas y Moreno (2017) comentan que toda técnica de psicoeducación debe estar compuesta por tres fases, las cuales se explican brevemente en la tabla 14.

Esta técnica está diseñada para proporcionar herramientas a los pacientes para manejar su tratamiento y prevenir complicaciones, manteniendo su calidad de vida (OMS, 2016). Acorde con Montiel y Guerra (2016), la psicoeducación no solo se concibe como un proceso educativo, sino que también se considera una forma de intervención psicoterapéutica, ya que va más allá de la mera transmisión de información, y tiene como principal propósito un cambio en los estilos de vida, en las creencias y en las actitudes hacia la enfermedad.

Tomando en cuenta que el desconocimiento de la enfermedad y los cuidados hacia la misma son de las principales dificultades en los pacientes, es necesario proporcionar no solo información sino la implementación de estrategias para llevar a cabo ese conocimiento (Castro, Rico, \& Padilla, 2014). En este sentido, la psicoeducación puede beneficiar al personal de salud y a las instituciones, ya que les permite compartir el conocimiento clínico con el paciente y su familia, aliviando la angustia de estos al brindar información precisa sobre 
Tabla 14

Fases que componen la psicoeducación

\begin{tabular}{ll}
\multicolumn{1}{c}{ Fase } & $\begin{array}{l}\text { Objetivo } \\
\text { Educativa }\end{array}$ \\
& $\begin{array}{l}\text { la correcta interpretación de fenómenos y un adecuado manejo de la información en distintos } \\
\text { escenarios prácticos. }\end{array}$ \\
\hline $\begin{array}{l}\text { Jerarquización de } \\
\text { problemas, déficits o } \\
\text { necesidades }\end{array}$ & $\begin{array}{l}\text { Identificar los problemas o situaciones que se presenten en sus vidas de acuerdo con su } \\
\text { condición, dándoles una jerarquía con base en su percepción. }\end{array}$ \\
& $\begin{array}{l}\text { Esto permitirá centrarse en los déficits percibidos por la persona y serán la guía para realizar } \\
\text { una acción de aprendizajes como el correcto uso y entendimiento de entrenamientos en } \\
\text { distintas habilidades. }\end{array}$ \\
\hline $\begin{array}{l}\text { Práctica de las } \\
\text { habilidades aprendidas } \\
\text { en la vida cotidiana }\end{array}$ & $\begin{array}{l}\text { Se espera que se practique lo aprendido logrando modificar actitudes y conductas de los } \\
\text { implicadoniendo nuevos estilos de vida y una mayor adaptación a los cambios. }\end{array}$ \\
\hline
\end{tabular}

Nota: Recuperado de "Psicoeducación: intervención de enfermería para el cuidado de la familia en su rol de cuidadora" por J. Cuevas y E. Moreno, 2017, Enfermería Universitaria, 14(3), p. 210.

su condición, además el saber de las personas respecto a una situación permite que las intervenciones en recaídas sean en fases iniciales, promueve la adherencia a las indicaciones prescritas optimizando el cumplimiento terapéutico y en conjunto reduce la incidencia de ingreso en instituciones de salud; esto permite ahorrar recursos humanos, económicos y temporales (Campero \& Ferraris, 2014).

Por sus características, la psicoeducación puede ser aplicada en diversas situaciones en las que se puede intervenir psicológicamente, siendo importante ajustar los elementos de la técnica en pro de la mejora del paciente. Bravo (2014) señala pautas importantes a considerar dentro del proceso salud enfermedad: análisis de las creencias y expectativas de curación, brindar información relacionada con los diferentes tratamientos posibles, intervención orientada a la reducción de respuestas ansiógenas o depresivas, así como preparar al paciente en el proceso de tratamiento terapéutico, remarcando los beneficios del seguimiento de recomendaciones. De igual manera, se recomienda revisar las creencias del paciente respecto a los efectos secundarios y las atribuciones asociadas con la evolución de la enfermedad. Para la presente guía, durante las sesiones se brinda información acerca de las reacciones ante el estrés y sus consecuencias a nivel fisiológico, cognitivo y conductual, de manera clara y entendible. Es necesario recalcar el papel de los dos aspectos esenciales de la respuesta de cualquier evento estresante (Lazarus \& Folkman, 1984). Por una parte, el aumento de la activación fisiológica, con especial atención hacia las respuestas cardiovasculares ante el estrés, debida a la estimulación simpática y a la liberación de catecolaminas. Por otro lado, se subraya la importancia de la aparición de pensamientos automáticos que interpretan la situación como amenazante. 


\subsubsection{Estrategias de relajación}

Las técnicas de relajación constituyen una pieza fundamental del repertorio terapéutico dentro del campo de las técnicas conductuales, son un tratamiento psicológico eficaz y efectivo. Se engloban bajo el epígrafe de técnicas de relajación aquellos procedimientos cuyo objetivo es enseñar a las personas a controlar sus propios niveles de activación (Pagnini, Manzoni, Castelnuovo, \& Molinari, 2010; Soriano, 2012). Dentro de ellas, se encuentran las siguientes: técnicas de relajación muscular progresiva, las técnicas de relajación autógena, las técnicas de control de la respiración y las visualizaciones.

Las técnicas de relajación suponen una importante alternativa preventiva y terapéutica, debido a que permite a los individuos controlar sus propios niveles de activación generando una respuesta fisiológica incompatible con la de la ansiedad que se caracteriza por un patrón reducido de actividad somática y autónoma, y cambios cognitivos que implican sensaciones de tranquilidad, confort, y sosiego. Estas técnicas no pretenden eliminar totalmente la tensión, sino disminuirla, suprimiendo la cantidad de estrés que puede interferir con el buen funcionamiento del individuo (Vázquez, 2008).

Estas técnicas son ampliamente utilizadas para disminuir comorbilidades como el estrés, la ansiedad y la depresión. Además, son útiles para: a) disminuir el dolor y las molestias de la tensión muscular, b) reducir la activación simpática, c) lograr un estado de tranquilidad y eliminar la tensión subjetiva, d) conciliar el sueño y el descanso, e) centrarse en las sensaciones corporales del aquí y ahora, y desviar la atención de los pensamientos catastróficos, y g) como estrategia de afrontamiento dar un sentido de control a las situaciones (Larios et al., 2019). En el caso particular del estrés, es una herramienta efectiva que ayuda al paciente afrontar el evento estresante que permitirá disminuir los efectos fisiológicos producidos por el estrés (e.g. frecuencia cardiaca, tensión arterial y tensión muscular), a la vez disminuir la experiencia emocional subjetiva negativa asociada a los efectos fisiológicos (Coffin \& Salinas, 2018; Larios et al., 2019; Norelli \& Krepp, 2019).

El aprendizaje de esta técnica es sencillo; sin embargo, se requiere inicialmente del entrenamiento y supervisión por parte del profesional de la salud mediante intervenciones breves y sencillas (Vázquez, 2008). El terapeuta al aplicarla debe contemplar, definir, y precisar las instrucciones en la ejecución del ejercicio por medio de verbalizaciones de cada paso utilizando un ritmo, tono y volumen de voz adecuado.

La técnica en relajación es definida como un instrumento psicoterapéutico para el tratamiento de trastornos emocionales, psicosomáticos y médicos, y es importante para la regulación del organismo mediante la activación del sistema parasimpático y la prevención de estados de tensión muscular. En una sesión de relajación, se le facilita al usuario la identificación de las situaciones estresantes, para prevenir los estados de tensión orgánica (Dewey, 1984; Granda \& Sáez, 2000). Por lo que es evidente que la finalidad es enseñar al paciente a restaurar el patrón respiratorio, para así proporcionar la oxigenación necesaria, generando una reducción en la activación del sistema simpático y en la cantidad de esfuerzo muscular. 


\subsubsection{Relajación pasiva}

La frecuencia y duración de los movimientos respiratorios de inspiración y espiración constituyen el ritmo respiratorio, cuyo objetivo principal es proveer al organismo de oxígeno. Las técnicas de control de la respiración son procedimientos diseñados para dotar al sujeto del control voluntario de la respiración, de manera que pueda utilizar patrones respiratorios adecuados, especialmente en los momentos de estrés, donde la respiración y oxigenación del organismo se encuentran alterados (Ibáñez-Tarín \& Manzanera-Escartí, 2012; Labrador, de Arce, \& Florit, 1996; Payne, 2009). Una vez aprendido el control de la respiración, debe automatizarse, de forma que su regulación se mantenga en las situaciones que implican altos niveles de activación. Los distintos procedimientos utilizados en las técnicas de respiración se dirigen a conseguir un ritmo respiratorio más lento, para reducir la activación fisiológica y psicológica, generando una disminución de la irritabilidad, estrés, fatiga, y ansiedad, logrando a la vez una sensación generalizada de tranquilidad y bienestar (Vázquez, 2008).

Como parte del entrenamiento del ejercicio de respiración se debe contemplar los intervalos de inhalación con la nariz y exhalación por la boca del paciente; dado que cada paciente tiene un modelo de respiración diferente, lo ideal es llegar a ajustarse a patrones fisiológicos oportunos (Martí, Gallego, Pellisa, López, \& Nolla, 2011). Para facilitar esta tarea el terapeuta puede invitar al paciente a realizar la respiración pasiva en diferentes posturas (e.g. de pie, acostado), esto dependerá del objetivo del tratamiento y las condiciones del organismo del paciente (Labrador et al., 1996). Las posturas pueden ser empleadas cuando solo se dispone de cortos intervalos para retomar el control de la situación, además se pueden aplicar en cualquier lugar sin necesidad de interrumpir una actividad.

La dinámica del ejercicio es la siguiente: inhalación-pausa-exhalación, y dependerá de cada paciente la duración de intervalo para cada pausa, lo mismo con la profundidad de aire (Cea, González-Pinto, \& Cabo, 2015). Estas técnicas se han aplicado como única estrategia de intervención o en combinación con otras técnicas en el tratamiento de ansiedad ante situaciones determinadas, ansiedad en las relaciones personales, ansiedad generalizada, depresión, agresividad, obsesiones, y fatiga crónica (Vallejo, 2000; Vázquez, 2008).

\subsubsection{Respiración diafragmática}

La respiración profunda, también conocida como respiración diafragmática o abdominal, consiste en respirar profundamente para que el cuerpo reciba un mayor suministro de oxígeno; a diferencia de la respiración superficial, que no le proporciona al cuerpo el aire suficiente, la respiración profunda reduce el ritmo cardiaco y estabiliza la presión sanguínea. Esta técnica es efectiva cuando se desea mantener la calma y reducir el nivel de ansiedad y estrés, por lo que puede ser controlada por la propia persona. Es así como una respiración regulada y controlada puede ayudar a tener presente un buen estado de ánimo y a mantenerse relajado (Cea et al., 2015; García, Fusté, \& Bados, 2011). 
Esta técnica permite una respiración más profunda debido a que los movimientos del diafragma permiten mayor expansión pulmonar y niveles mayores de oxigenación, ya que los pulmones tienen un mayor llenado de aire. Además, cuando el abdomen se expande, hay poca implicación de los músculos del pecho y los hombros, por lo que la respiración requiere un mínimo esfuerzo. Este patrón respiratorio se asocia y puede estimular una respuesta parasimpática (Ibáñez-Tarín \& Manzanera-Escartí, 2012). En las situaciones de estrés la respiración es torácica, por lo que es necesario hacer el cambio a una respiración diafragmática. Dado que la respiración diafragmática disminuye la tensión muscular en el tronco y mejora la ventilación de la parte baja de los lóbulos pulmonares, puede ser una estrategia terapéutica para utilizar en aquellas condiciones en las que el esfuerzo respiratorio o la elevada tensión en la parte baja del tronco son problemáticas, como en el caso de los espasmos y dolores musculares en la espalda o el abdomen (Labrador et al., 1996; Vázquez, 2008).

Es una habilidad que requiere de práctica diaria que implica de 15 a 20 minutos para obtener los resultados. Se han desarrollado varios métodos de entrenamiento para el control de la respiración, dirigidos a propiciar una respiración lenta, constituyen entrenamiento psicofisiológico no invasivo que favorece los estados de relajación, sin necesidad de requerir ningún equipo especial, ni consumo de fármacos, además, es de fácil aplicación y ejecución por su forma flexible, sencilla y eficaz de conseguir la reducción del estrés (Larios et al., 2019). Los pasos para implementar la técnica se pueden observar en la figura 14.

\section{Figura 14}

Instrucciones para la respiración diafragmática

\section{Posición}

Se recomienda estar sentado cómodo en una silla, apoyando completamente la espalda contra el respaldo.

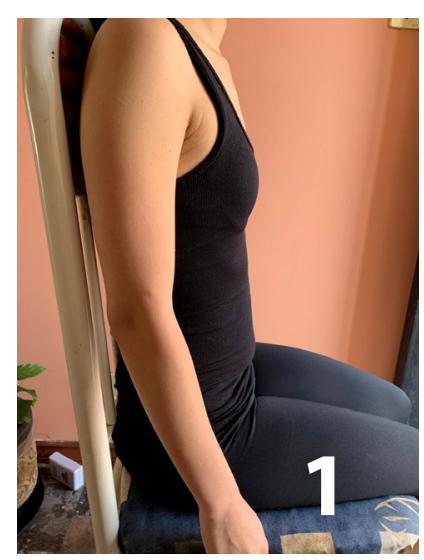

\section{Inspirar}

La inhalación debe ser lenta y por la nariz. A medida que se inhale, el abdomen debe empujar la mano sobre este; y la del pecho no se mueve.

\section{Manos}

Se recomienda ubicar una mano sobre el pecho y la otra sobre el abdomen.

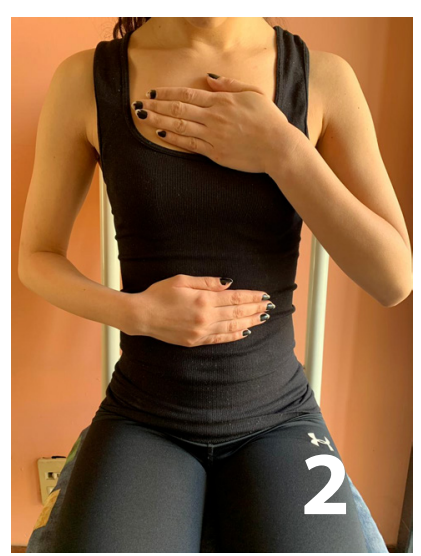

\section{Exhalar}

La exhalación debe ser lenta y con los labios casi cerrados. A medida que se expulsa el aire, observe que el abdomen y la mano se mueven.
El abdomen se debe distender o relajar. Es necesario respirar cómodamente.
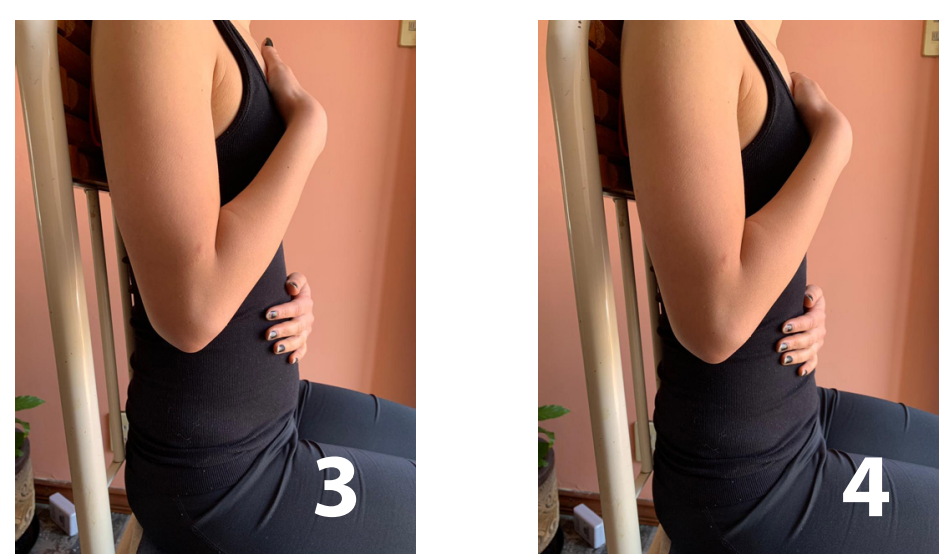

Nota: Elaboración propia. Fotografía: Diana Lucero Muñoz Arellano.

Observe cómo los músculos torácicos y el diafragma se relajan al practicar la técnica. 
Como complemento a esta técnica, el terapeuta puede sugerir al paciente utilizar aplicaciones que refuercen el entrenamiento de la técnica de relajación. Se propone utilizar Breathe $^{\circledast}$ (para dispositivos Android) y BreatheSync ${ }^{\circledast}$ (para dispositivos iOS), donde es indispensable que el terapeuta ajuste el intervalo para la inhalación y exhalación y evitar algún malestar. Otras aplicaciones por utilizar son para medir la frecuencia cardiaca como Ritmo cardíaco-Monitor $^{\circledast}$ (para sistema operativo Android) y Heart Rate Free ${ }^{\circledast}$ (para sistema operativo iOS), los cuales miden la frecuencia cardiaca, y su uso permitirá identificar si el entrenamiento es útil y de esta manera retroalimentar la ejecución de la técnica del paciente.

\subsubsection{Autoinstrucciones}

La autoinstrucción es una técnica cognitivo conductual empleada en la modificación de conducta en pacientes con enfermedades crónicas. Es una herramienta útil para modificar los pensamientos automáticos que surgen en todo evento de naturaleza estresante.

Se trata de una técnica cognitiva de cambio de comportamiento en la que se modifican las autoverbalizaciones (verbalizaciones internas o pensamientos) que una persona realiza ante cualquier tarea o problema, sustituyéndolas por otras que, en general, son más útiles para llevar a cabo la actividad. Estas verbalizaciones son coherentes con su propia actuación (Caballo, 1998; Casado \& Laguna-Bonilla, 2017). Son instrucciones u órdenes que se da a sí mismo dirigiendo su comportamiento en la tarea asignada.

Esta herramienta se utiliza para modificar o contrarrestar los efectos de "pensamientos negativos" que interfieren con la ejecución correcta de una tarea o el afrontamiento de una situación. Las autoinstrucciones son pensamientos estructurados en palabras que ayudan a actuar de forma eficaz y controlada. Se aconseja que esta técnica se utilice con las habilidades de relajación y de afrontamiento para ejercer presión sobre los hechos que se consideran perturbadores, mientras se respira profundamente, aflojando los músculos y utilizando autoinstrucciones para el afrontamiento del estrés (Casado \& Laguna-Bonilla, 2017; IbáñezTarín \& Manzanera-Escartí, 2012).

De acuerdo con Meichenbaum (2002), nuestra manera de pensar puede afectar la manera de sentir de una forma directa e intencional. Es decir, influimos en nuestros pensamientos mediante una especie de monólogo interno, una serie continua de afirmaciones hacia nosotros mismos en las que nos decimos lo que hemos de pensar y creer, e incluso cómo comportarnos.

Esta técnica se utiliza con mucha frecuencia para modificar o contrarrestar los efectos de pensamientos automáticos que interfieren con la ejecución correcta de una tarea o el afrontamiento de una situación. En estos casos, la parte principal del entrenamiento se dedica a detectar las verbalizaciones internas interferentes y generar instrucciones. Otros aspectos que conviene resaltar cuando se realiza este tipo de ejercicio son: la importancia que tiene que el paciente comprenda por qué está aprendiendo a utilizar determinadas 
autoverbalizaciones y reglas generales, y el peso que ha de concederse a la práctica constante de las autoinstrucciones, inicialmente hacia una tarea o acción concreta y, posteriormente, ante una amplia gama de tareas, acciones o situaciones (Labrador, Cruzado, \& Muñoz, 1995). El objetivo de la técnica es enseñar a pensar y planificar antes de actuar y simultáneamente favorecer la creencia en la propia capacidad de ejecución. Según Ruiz, Díaz y Villalobos (2012), se debe considerar: a) definición de la tarea; b) aproximación al problema; c) focalización de la atención; d) guiar la conducta; e) autorrefuerzo y retroalimentación; f) autoevaluación; y g) reducir la ansiedad.

Meichenbaum (2002) propone el uso de frases-guía adecuadas para cada momento: preparación ("puedo hacer esto"), confrontación real con la situación ("lo estoy haciendo bien"), afrontamiento de la activación emocional ("voy a relajarme") y reforzamiento del éxito ("no lo hice tan mal"). En la tabla 15 se pueden observar los pasos para la implementación de esta técnica.

\section{Tabla 15}

Pasos para realizar la técnica de autoinstrucciones

\begin{tabular}{cl} 
Pasos & Acciones \\
1 & El modelo realiza la conducta, dándose las autoinstrucciones pertinentes en voz alta. \\
\hline 2 & El paciente realiza la conducta y el modelo le da las instrucciones en voz alta. \\
\hline 3 & El paciente realiza la conducta y se da las autoinstrucciones en voz alta. \\
\hline 4 & Mientras el paciente realiza la tarea se dan las instrucciones en voz baja. \\
\hline 5 & El sujeto realiza la tarea con autoinstrucciones encubiertas.
\end{tabular}

Nota: Recuperado de Manual de técnicas de intervención cognitivo conductuales por M. A. Ruiz, M. A. Díaz y A. Villalobos, A, 2012, España: Desclée de Brouwer.

\subsubsection{Solución de problemas}

Es una técnica psicoterapéutica breve y práctica derivada de la TCC, que se puede llevar a cabo de forma individual o en grupo con técnicas dirigidas a desarrollar habilidades para la solución de problemas de una manera estructurada. D'Zurilla y Nezu (1999) la definen como un proceso cognitivo y conductual en el cual una persona identifica o descubre soluciones efectivas a dificultades específicas de la vida cotidiana.

De acuerdo con Nezu, Nezu y D'Zurilla (2013) es una intervención dirigida a incrementar la habilidad de un individuo para afrontar las experiencias estresantes de la vida, identificando y poniendo en marcha las opciones de afrontamiento más adaptativas y eficientes en la solución de estas. Los objetivos de esta terapia son dos: 
1. La adopción de una visión del mundo más adaptativa hacia las dificultades de la vida (orientación a los problemas).

2. La implementación efectiva de comportamientos específicos de solución de problemas.

Es una técnica que favorece la adherencia en pacientes con enfermedades crónicas para adquirir habilidades en el manejo de su enfermedad y superar las dificultades de apego al tratamiento e incrementar conductas saludables (Suárez, Reynoso, Lira, \& Ordaz, 2019).

El entrenamiento en solución de problemas se entiende como la ejecución de una respuesta de afrontamiento que permite solucionar de manera eficaz una situación problemática (D'Zurilla \& Nezu, 1999). De manera análoga, definida como un proceso metacognitivo comportamental autodirigido, por medio del cual una persona intenta identificar soluciones efectivas o adaptativas para dificultades específicas de su vida (D'Zurilla \& Nezu, 2001 citado por Bravo \& Valadez, 2013).

Además, Nezu et al. (2013) enfatizan las cinco fases del proceso para el entrenamiento en solución de problemas como se observa en la tabla 16.

\section{Tabla 16}

Proceso para el entrenamiento en solución de problema

\begin{tabular}{ll}
$\begin{array}{ll}\text { 1. Orientación hacia } \\
\text { el problema }\end{array}$ & $\begin{array}{l}\text { Se pretende que las personas desarrollen una actitud positiva hacia la situación } \\
\text { problema y hacia su autoeficacia. Además, que reconozcan sus habilidades y empleen } \\
\text { una regulación emocional que les permita afrontar de mejor forma la situación problema. }\end{array}$ \\
\hline $\begin{array}{l}\text { 2. Definición y formulación } \\
\text { del problema }\end{array}$ & $\begin{array}{l}\text { En esta fase se delimita y establece la naturaleza del problema (se organiza la } \\
\text { información para comprenderlo) basándose únicamente de hechos. Además, se plantean } \\
\text { metas y objetivos realistas considerando si el problema tiene o no solución. }\end{array}$ \\
\hline $\begin{array}{l}\text { 3. Generación de alternativa } \\
\text { de solución }\end{array}$ & $\begin{array}{l}\text { Se generan diversas soluciones para el problema, sin valorar su viabilidad o adecuación. } \\
\text { 4. Toma de decisiones }\end{array}$ \\
$\begin{array}{l}\text { A partir de la generación de alternativas, en esta fase se realiza un análisis de las } \\
\text { alternativas en función de la viabilidad, ventajas y desventajas; además se anticipan las } \\
\text { consecuencias de estas. Posteriormente, se toma una decisión acerca de la opción más } \\
\text { viable en función de un análisis de costo-beneficio. }\end{array}$ \\
$\begin{array}{l}\text { En esta última fase se lleva a cabo la solución en función de los pasos y recursos ya } \\
\text { planificados, además se realiza una valoración de la solución considerando si se está } \\
\text { solución y verificación }\end{array}$
\end{tabular}

Nota: Recuperado de Problem-Solving Therapy. A Treatment Manual por A. Nezu, C. Nezu y T. D'Zurilla, 2013, New York: Springer. 


\subsubsection{Uso de técnicas complementarias}

La reducción de los niveles de estrés en pacientes con DM tipo 2 puede llevar al especialista en MC a plantear la intervención en áreas adicionales donde se detecten necesidades relacionadas con el manejo del estrés. Cabe recordar que el enfoque de esta guía es flexible, es un recurso que ayudará a intervenir en las diferentes necesidades del paciente con el bagaje de técnicas además de las propuestas.

El especialista en MC deberá delimitar qué técnicas complementarias son las necesarias para las particularidades y condiciones de cada paciente. De acuerdo con Ibáñez-Tarín y Manzanera-Escartí (2012), las técnicas cognitivo conductuales han demostrado ser útiles y eficaces para el manejo de una gran variedad de trastornos emocionales y físicos en enfermedades crónicas. En el ámbito psicológico, la TCC ha mostrado eficacia para que las personas con DM tipo 2 desarrollen las habilidades de autocuidado, adherencia al tratamiento, identificación de barreras de afrontamiento en situaciones estresantes, todos elementos necesarios para lograr el control metabólico (González \& Oropeza, 2016). La mayoría de las intervenciones se basan en técnicas como: psicoeducación, prescripción de plan alimentario-actividad física, automonitoreo, control de estímulos, conductas alternativas, reestructuración cognitiva, apoyo social y habilidades para mantenimiento de los cambios (Rodríguez, Rentería, \& García, 2013).

De ser necesario, pueden incluirse técnicas cognitivo conductuales complementarias; en la tabla 17 se describen algunas y en la figura 15 se presenta el flujograma para la selección de estas.

\section{Tabla 17}

Técnicas utilizadas en la TCC para el manejo del estrés

\section{Técnica \\ Objetivo \\ Descripción del procedimiento}

Relajación muscular Obtener la reducción de las respuestas Se expone paulatinamente al paciente ante el estímuprogresiva condicionadas (respuestas de estrés).

lo condicionado, agregando otros procedimientos de exhibición de estímulos incompatibles (estímulos que desencadenen respuestas de relajación). Es una técnica para modificar la conducta con base en el contracondicionamiento (Vallejo-Slocker \& Vallejo, 2016).

Relajación autógena Generar respuestas de relajación a través de las sensaciones de peso y calor en el cuerpo.
La ejecución de esta técnica enseña al paciente a relajar el cuerpo mediante cuatro elementos: a) la disminución de la estimulación externa (luz, ruido, estímulos invasivos, entre otros); b) una actitud de concentración pasiva; c) la reiteración de las frases inductoras que inducen a un estado de relajación dirigidas a sensaciones de pesadez y calidez en los brazos, piernas abdomen y frente; y d) la percepción de la parte del cuerpo a la que se hace referencia (Vázquez, 2008). 


\begin{tabular}{|c|c|c|}
\hline Técnica & Objetivo & Descripción del procedimiento \\
\hline Autocontrol & $\begin{array}{l}\text { Entrenar a las personas para que } \\
\text { tengan la capacidad de poner en } \\
\text { marcha estrategias que les permitan } \\
\text { regular su comportamiento de } \\
\text { acuerdo con sus objetivos. }\end{array}$ & $\begin{array}{l}\text { Proceso por el cual las personas manejan su propia con- } \\
\text { ducta aun cuando están presentes restricciones inme- } \\
\text { diatas (Bandura, 1977). Involucra el establecimiento de } \\
\text { metas, los procesos relacionados a estas metas, expecta- } \\
\text { tivas y planes. Rachlin (2000) describe esta técnica como } \\
\text { una habilidad que proviene de elegir un patrón compor- } \\
\text { tamental y el esfuerzo para guiar la conducta en función } \\
\text { de la gratificación a largo plazo. }\end{array}$ \\
\hline $\begin{array}{l}\text { Entrenamiento } \\
\text { en comunicación } \\
\text { asertiva }\end{array}$ & $\begin{array}{l}\text { Generar estrategias de comunicación } \\
\text { adecuadas ante diferentes situaciones. }\end{array}$ & $\begin{array}{l}\text { Implica entrenar al paciente en un conjunto de habili- } \\
\text { dades que le permitan ser capaz de expresar sus senti- } \\
\text { mientos, ideas y opiniones, haciéndolo de forma que, aun } \\
\text { defendiendo sus propios derechos, se respeten de forma } \\
\text { meticulosa los derechos de los demás, adaptándose al } \\
\text { contexto donde se produzca la comunicación, y contribu- } \\
\text { yendo a facilitar que se resuelvan los problemas inmedia- } \\
\text { tos y futuros relacionados con la comunicación (Caballo, } \\
\text { 1998). }\end{array}$ \\
\hline $\begin{array}{l}\text { Desensibilización } \\
\text { sistemática }\end{array}$ & $\begin{array}{l}\text { Obtener la reducción de las respuestas } \\
\text { condicionadas (respuestas de estrés). }\end{array}$ & $\begin{array}{l}\text { Se expone paulatinamente al paciente ante el estímulo } \\
\text { condicionado, agregando otros procedimientos de } \\
\text { exhibición de estímulos incompatibles (estímulos } \\
\text { que desencadenen respuestas de relajación). Es una } \\
\text { técnica para modificar la conducta con base en el } \\
\text { contracondicionamiento (Vallejo-Slocker \& Vallejo, 2016). }\end{array}$ \\
\hline $\begin{array}{l}\text { Manejo de } \\
\text { contingencias }\end{array}$ & $\begin{array}{l}\text { Reducir las conductas no deseadas } \\
\text { mediante el uso de técnicas } \\
\text { operantes. }\end{array}$ & $\begin{array}{l}\text { Conjunto de técnicas con base en el condicionamiento } \\
\text { operante, donde se establece que la correcta aplicación } \\
\text { de consecuencias a las conductas individuales permite } \\
\text { su modificación (Kazdin, 1996) y, por ello, es posible } \\
\text { desarrollar o incrementar conductas deseables mediante } \\
\text { reforzamiento, y disminuir o eliminar las inadecuadas } \\
\text { mediante castigo/extinción. Se puede hacer uso de } \\
\text { técnicas como: sobrecorrección, costo de respuesta, } \\
\text { tiempo fuera, extinción y saciedad del estímulo, } \\
\text { instigación, instrucciones, modelamiento, guía física, } \\
\text { inducción situacional, moldeamiento o aproximaciones } \\
\text { sucesivas, solo por mencionar algunas. La técnica } \\
\text { dependerá de si se desea iniciar, mantener o eliminar } \\
\text { cierta conducta. }\end{array}$ \\
\hline $\begin{array}{l}\text { Técnicas de } \\
\text { modificación } \\
\text { cognitiva }\end{array}$ & $\begin{array}{l}\text { Modificar los pensamientos } \\
\text { distorsionados y disfuncionales. }\end{array}$ & $\begin{array}{l}\text { Permiten la modificación de patrones cognitivos } \\
\text { (pensamientos distorsionados y creencias disfuncionales), } \\
\text { para que, como consecuencia, se dé un cambio de } \\
\text { emociones y conductas motoras. Es necesario entrenar } \\
\text { al paciente en la autoobservación, el análisis y la } \\
\text { modificación de sus pensamientos (Dahab, Minici, \& } \\
\text { Rivadeneira, 2016; Dongil-Collado, 2008;). }\end{array}$ \\
\hline
\end{tabular}

Nota: Elaboración propia. 
Figura 15

Flujograma de aplicación de técnicas complementarias

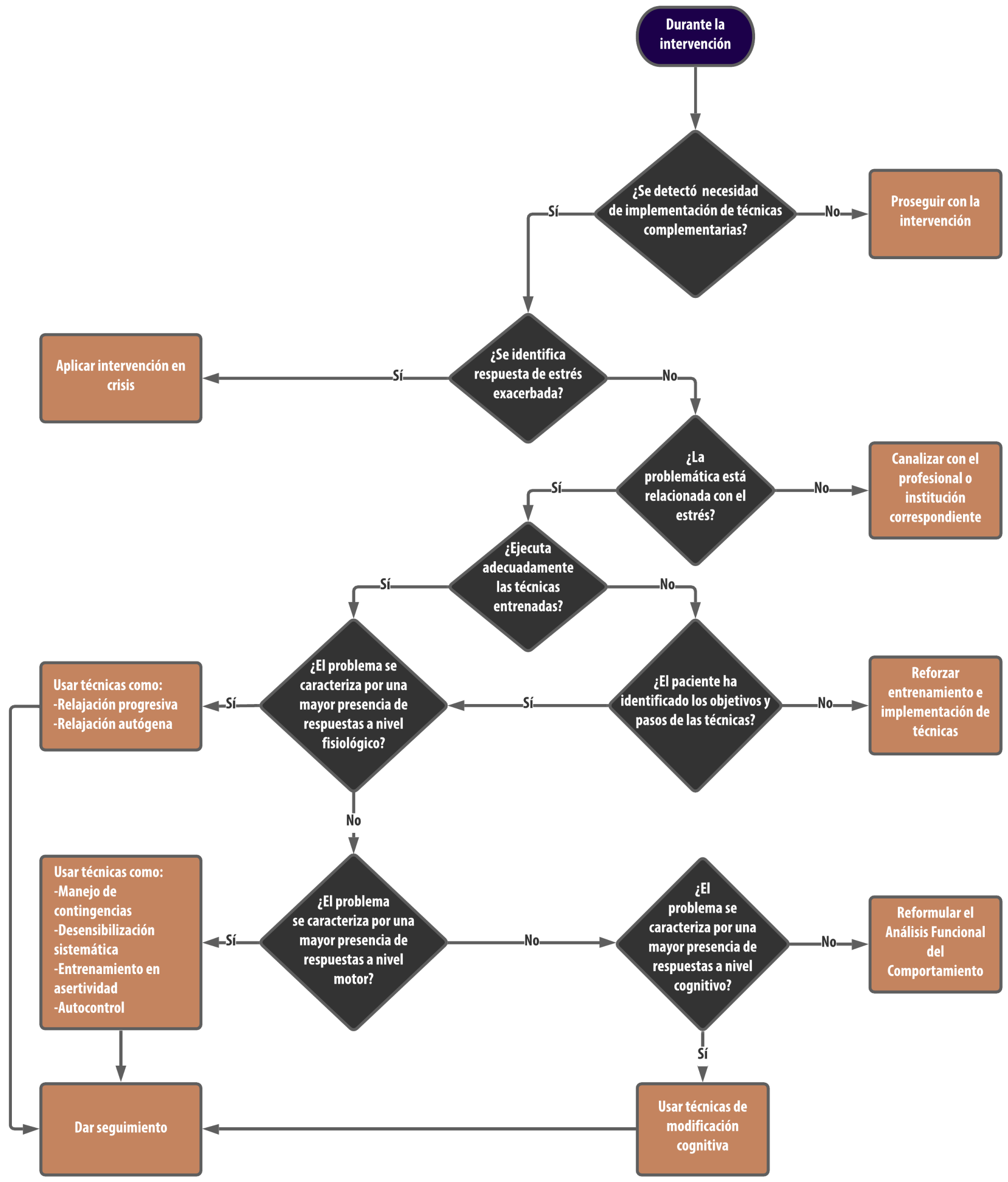

Nota: Elaboración propia. 


\section{Tratamiento}

El programa está diseñado para implementarse de manera online para la población con DM tipo 2. Sin embargo, también puede aplicarse a otro tipo de población haciendo las modificaciones pertinentes.

De acuerdo con el Consejo General de la Psicología (2017), la comunicación mediante las TIC's puede realizarse de manera sincrónica o asincrónica. En la primera, la información se presenta de manera interactiva entre el terapeuta y el paciente. En la segunda, se proporciona la información de manera unidireccional asincrónica. La propuesta de intervención utilizará ambos medios de comunicación, el primero para brindar la atención psicológica vía videollamada y el segundo será utilizado para contactar al paciente con el objetivo de concretar la cita de la primera sesión y la entrega de materiales psicoeducativos.

Migues, Vázquez y Becoña (2000) desarrollaron un modelo de intervención telefónica para fumadores y clasificaron la modalidad de contacto con el paciente, estableciendo que el procedimiento donde el paciente recibe una llamada de un consejero es proactivo, y si el consumidor de cigarros es quien llama a un número designado o se pone en contacto para solicitar asistencia o información se denominan reactivas. Basándonos en esta división, la presente propuesta divide la modalidad de comunicación en: 1) reactiva, en la cual el paciente solicita el servicio o informes, ya sea mediante la página web o por correo electrónico; 2 ) proactiva, donde el paciente recibirá la videollamada por parte del terapeuta.

El programa incluye ocho etapas para su desarrollo e implementación, las cuales se pueden observar en la tabla 18.

La primera etapa consiste en la difusión del programa, donde a través de los medios digitales y redes sociales oficiales de la residencia (Instagram ${ }^{\oplus}$, Twitter ${ }^{\oplus}$, Facebook ${ }^{\circledR}$ ) se compartirán posts o carteles diseñados para este fin. Estos proporcionarán los siguientes datos: a) instituciones de adscripción; b) programa de maestría en MC; c) nombre de la intervención; d) beneficios de la intervención; y e) datos de contacto, mencionando: 1) sitio en línea para acceder a más información o solicitar la atención (https://www.mciztacala.org/); 2) correo electrónico para solicitar más información.

La siguiente etapa, envío de datos, tiene dos vertientes:

1. A partir del acceso al sitio web (https://www.mciztacala.org/), el paciente encontrará un botón "solicitar atención", el cual lo redirigirá al enlace para enviar sus datos.

2. A partir del envío de correo electrónico, después de proporcionar la información requerida por la persona, se anexará el enlace para enviar sus datos.

En ambos casos, al seleccionar el vínculo lo enlazará con la hoja de datos generales del paciente, en donde se pedirá nombre, edad, diagnóstico, teléfono, correo electrónico y los instrumentos seleccionados para la batería. Una vez recibidos los datos del paciente, el terapeuta en turno recuperará los datos y resultados con el objetivo de comunicarse con el 
Tabla 18

Generalidades de las etapas de tratamiento

\begin{tabular}{|c|c|c|}
\hline Etapa & $\begin{array}{l}\text { Modalidad } \\
\text { de contacto }\end{array}$ & Generalidades \\
\hline Difusión & Reactiva & $\begin{array}{l}\text { Divulgación de materiales promoviendo la intervención en redes sociales } \\
\text { para la captación de pacientes. }\end{array}$ \\
\hline Envío de datos & Reactiva & $\begin{array}{l}\text { Para solicitar atención se contestará una ficha de identificación y la batería } \\
\text { de instrumentos para la evaluación inicial. }\end{array}$ \\
\hline Contacto al paciente & Proactiva & Comunicación con el solicitante para concretar sesión. \\
\hline Evaluación & Proactiva & $\begin{array}{l}\text { Consiste en el análisis de la información obtenida mediante la entrevista } \\
\text { inicial, conductual y batería inicial y, en su caso, instrumentos para } \\
\text { evaluación complementaria. }\end{array}$ \\
\hline Intervención & Proactiva & $\begin{array}{l}\text { Abarca desde la psicoeducación de las variables de interés (enfermedad y } \\
\text { estrés), el entrenamiento y ejercicio de las técnicas. }\end{array}$ \\
\hline Mantenimiento & Proactiva & $\begin{array}{l}\text { Generación de alternativas para propiciar el manejo de estrés ante } \\
\text { diferentes condiciones. }\end{array}$ \\
\hline $\begin{array}{l}\text { Evaluación } \\
\text { postintervención }\end{array}$ & Proactiva & $\begin{array}{l}\text { Aplicación de la misma batería de instrumentos enviados al solicitar la } \\
\text { atención. }\end{array}$ \\
\hline Seguimiento & Proactiva & Evaluación de los cambios conductuales a través del tiempo. \\
\hline
\end{tabular}

Nota: Elaboración propia.

paciente y concretar una cita para la sesión vía correo electrónico. En la etapa de contacto al paciente, el terapeuta brindará dos opciones de horarios y días diferentes para que el paciente seleccione la más acorde.

La cuarta etapa, evaluación, abarca la presentación de la modalidad de trabajo online del terapeuta, la lectura del consentimiento informado y la realización de la entrevista inicial con el objetivo de identificar la problemática de cada paciente en los tres niveles de respuesta. En esta etapa, el terapeuta puede hacer uso de instrumentos adicionales para realizar un diagnóstico diferencial, este proceso es la evaluación complementaria. Al finalizar la evaluación, el terapeuta proporcionará a manera de devolución al paciente los datos obtenidos y las hipótesis funcionales realizadas con base en el AFC.

Posteriormente, se inicia la etapa de intervención, donde se proporcionará información, se entrenará y se implementarán las técnicas descritas previamente, además se hará uso de sistemas de registro acordes al objetivo de las técnicas. El terapeuta puede modificar o añadir otras técnicas de intervención acordes al modelo (véase 8.7.5 Uso de técnicas complementarias), esta decisión será tomada con base en la evaluación y AFC realizados para cada paciente. 
Entrenar a los pacientes utilizando distintas técnicas es una de las metas a cumplir, aunque el ideal es lograr la permanencia de los cambios conductuales realizados en la intervención, a través del mantenimiento. Este consiste en el entrenamiento y en la elaboración de planes de acción para modificar las situaciones que impidan la puesta en marcha de las estrategias entrenadas durante la intervención. Lo anterior, con los objetivos de mantener la implementación y resultados de las técnicas.

Al momento de finalizar con el mantenimiento, se prosigue con la evaluación post intervención aplicando la misma batería que contestó el paciente para solicitar la intervención. Finalmente, el seguimiento consiste en la evaluación de dichos cambios conductuales a través del tiempo. Esta evaluación se realiza mediante la batería mencionada anteriormente. En esta etapa se realiza un monitoreo, una sesión de seguimiento, o bien, en caso de ser necesario, se activa el protocolo de intervención en crisis. Además, se reitera al paciente que puede solicitar atención antes de las citas de seguimiento dentro de los horarios habilitados para esta.

Las intervenciones cortas y medianas de hasta ocho semanas han demostrado ser más efectivas que las intervenciones largas, nueve semanas o más (Heber et al., 2017). Por ello, la presente propuesta se ajusta a ese criterio y se circunscribe a 10 sesiones que se desglosan en: dos sesiones de evaluación, seis de intervención y dos de mantenimiento.

\section{Tabla 19}

Generalidades de las etapas de tratamiento

\begin{tabular}{|c|c|c|}
\hline Sesión & Etapa & Técnica \\
\hline 1 & Evaluación & Entrevista \\
\hline \multirow[t]{3}{*}{2} & Evaluación & Entrevista \\
\hline & & Evaluación complementaria \\
\hline & Intervención & Respiración diafragmática o pasiva \\
\hline \multirow[t]{5}{*}{3} & Evaluación & Análisis de secuencias y funcional del comportamiento problema \\
\hline & & Elaboración de hipótesis \\
\hline & & Devolución de AFC \\
\hline & Intervención & Relajación \\
\hline & & Respiración diafragmática o relajación pasiva \\
\hline 4 & Intervención & Psicoeducación \\
\hline 5 & Intervención & Autoinstrucciones \\
\hline 6 & Intervención & Solución de problemas (Paso: Identificación del problema) \\
\hline 7 & Intervención & Solución de problemas (Paso: Generación de alternativas) \\
\hline 8 & Intervención & Solución de problemas (Paso: Toma de decisiones) \\
\hline 9 & Mantenimiento & Plan de acción \\
\hline 10 & Mantenimiento & Plan de acción \\
\hline
\end{tabular}

Nota: Elaboración propia. 
En la tabla 19 se puede observar la distribución del número de sesiones de acuerdo con la etapa y las técnicas a ejecutar.

Finalmente, se debe resaltar que en caso de que el paciente se presente con elevada sintomatología de estrés a cualquier sesión de tratamiento, ya sea de evaluación, intervención, mantenimiento o seguimientos, se aplicarán el protocolo de intervención en crisis.

\subsection{Sistema de registros}

Para reunir evidencia del comportamiento del paciente, el terapeuta puede utilizar autorregistros, que son una herramienta que posibilita contar con detalles particulares de comportamientos, pensamientos y otras variables. Inicialmente, el terapeuta y el paciente identifican las conductas a modificar; ya identificadas, se cuantifican por medio de los autorregistros; de esta se tiene una medida para evaluar la eficacia de un programa de intervención (Caballo, 1998; Vargas \& Ibáñez, 1998). Cada uno de los registros que se utilizarán en la propuesta de intervención se describirá a continuación. El proceso de implementación de registros se muestra en la figura 16.

\subsubsection{Escalas visuales análogas}

Es una herramienta válida, fácilmente comprensible, correlaciona bien con la escala numérica verbal. Consiste en una línea horizontal de aproximadamente 10 centímetros, en cuyos extremos se encuentran las expresiones extremas de un síntoma, su implementación se realiza de manera más usual en evaluación de dolor. En un extremo significa ausencia de dolor (izquierda) y el otro extremo significa el peor dolor (derecha) que se pueda imaginar. El paciente marca un punto en la línea y el número que coincide con la cantidad de dolor que siente. Para algunos autores, la forma en la que se presenta al paciente ya sea horizontal o vertical, no afecta el resultado. Para otros, una escala vertical presenta menores dificultades de interpretación para población con dificultades o deterioro cognitivo, porque le recuerda a un termómetro (Crespo \& Cruzado, 2008; Vicente, Delgado, Bandrés, Ramírez, \& Capdevilla, 2018).

Este tipo de escalas se ha utilizado como herramienta para cuantificar los niveles de relajación (antes y después) de un paciente al emplear alguna técnica para verificar su efectividad. Un valor izquierdo en la EVA significa nada relajado, un valor cercano a la derecha o ubicado en la derecha implica la apreciación de muy relajado. Para la intervención concebida en esta guía, el paciente deberá indicar en la línea cómo se siente antes de emplear la técnica y después de hacerla (véase en Rodríguez, Abaroa, Reynoso, \& Lugo, 2020, p. 102).

\subsubsection{Registro de frecuencia cardiaca}

Como se señaló anteriormente, el estrés produce cambios fisiológicos cuantificables como: aumento en frecuencia cardiaca, en la temperatura corporal, en la frecuencia respiratoria, en la presión arterial, entre otras (Cepeda, López, Plancarte, Moreno, \& Alvarado, 2014; Kim, 
Figura 16

Flujograma para uso de registros

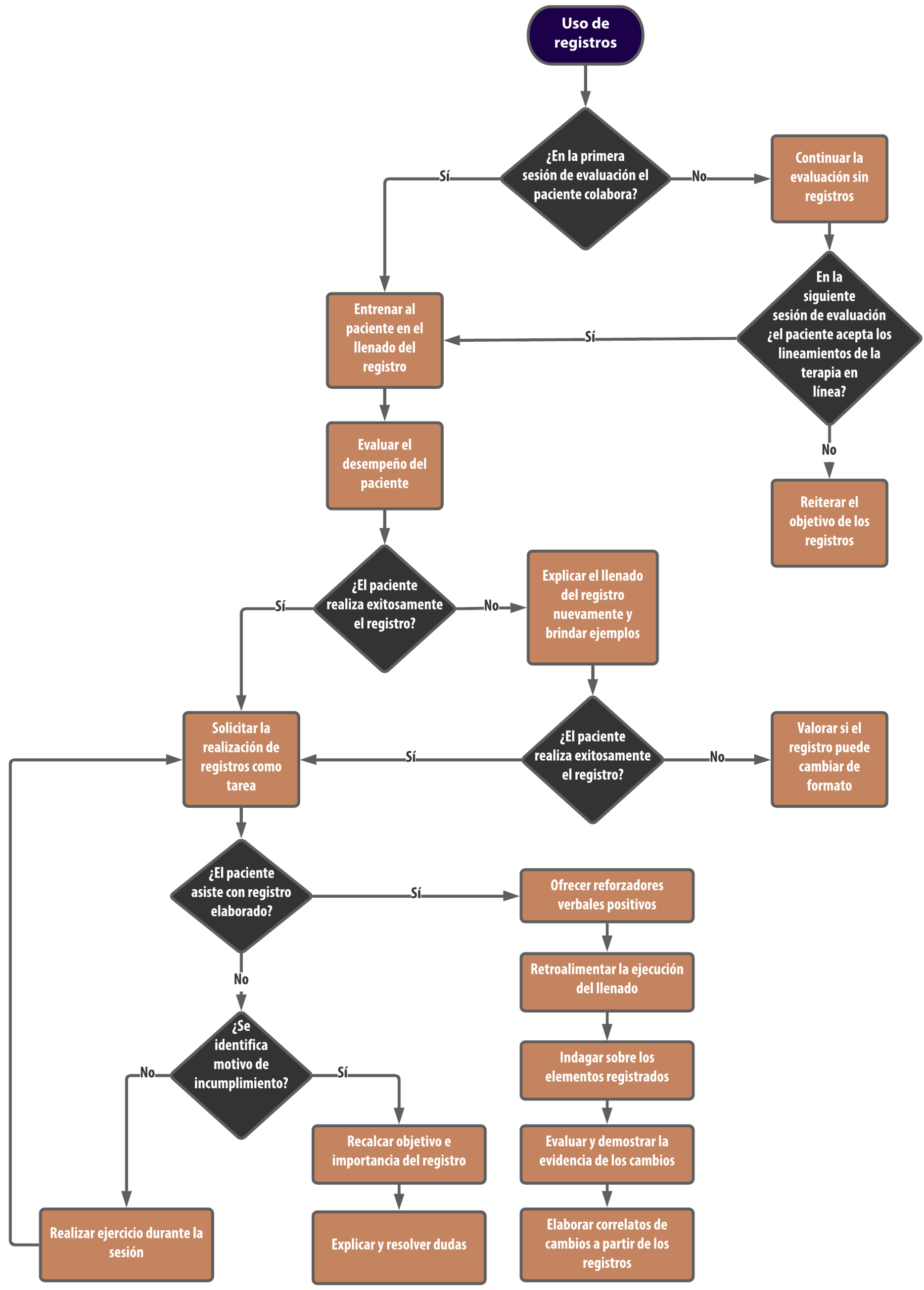

Nota: Elaboración propia. 
Cheon, Bai, Lee, \& Koo, 2018). La utilización de este tipo de medidas permite cuantificar la respuesta de estrés y comparar los cambios fisiológicos cuando el paciente ejecuta la técnica de relajación. Para fines de la intervención se le solicitará al paciente que realice el registro de la frecuencia cardiaca antes y después del entrenamiento en relajación obtenida mediante la aplicación digital Ritmo cardíaco-Monitor ${ }^{\circledast}$ (para sistema operativo Android) y Heart Rate Free ${ }^{\circledast}$ (para sistema operativo iOS) o de manera análoga, para identificar los efectos del entrenamiento sobre la activación parasimpática (véase en Rodríguez et al., 2020, p.103).

\subsubsection{Registro de eventos estresantes}

Para que el paciente identifique las situaciones particulares que desatan el estrés a nivel cognitivo, motor o fisiológico relacionadas a la enfermedad se dispondrá de un sistema de registro que consiste en la elaboración de una lista de eventos relacionados con el manejo de la enfermedad crónico-degenerativa en diferentes contextos tales como situaciones sociales, económicas, ambientales, entre otras (Suárez, 2010) (véase en Rodríguez et al., 2020, p.100).

\subsubsection{Registro de autoinstrucciones}

Tras el entrenamiento, el paciente escribirá al menos tres autoverbalizaciones que sean útiles ante eventos estresantes relacionados con el manejo de DM tipo 2. Lo primero que debe hacer para la ejecución de la técnica de autoinstrucciones es definir la tarea que se quiere lograr, la cual se complementará con las autoverbalizaciones que guíen dicha conducta. El terapeuta deberá identificar el diálogo que el paciente tiene ante situaciones evaluadas como estresantes, se le solicitará al paciente que identifique y registre el tipo de verbalizaciones que tiene en tales situaciones; si reconoce que estas facilitan la ejecución de la tarea deberán de utilizarse, de lo contrario se deberán eliminarse o sustituirse.

\subsubsection{Identificación del problema}

La técnica de solución de problemas se dividió para fines de entrenamiento en tres etapas: 1) identificación del problema; 2) generación de alternativas de solución; y 3) toma de decisiones.

En la primera etapa, el paciente deberá definir y delimitar el problema real, y descomponerlo en secuencias o cadenas de situaciones problemáticas. El paciente deberá describir los hechos en términos claros, precisos y objetivos; identificando los factores involucrados en la situación. Para esto deberá escribir brevemente el problema, anotando: quién está implicado; qué, dónde, cuándo y por qué sucede; cómo responde. Ello ha de hacerse con un lenguaje concreto, evitando la realización de inferencias y suposiciones (Gavino, 2006; Nezu \& Nezu, 1991) (véase en Rodríguez et al., 2020, p.104). 


\subsubsection{Generación de alternativas}

La siguiente fase es la generación de alternativas, cuya finalidad es dotar al paciente de aqueIlas habilidades necesarias que le hagan constituirse en un buen solucionador de problemas. La meta es buscar posibles soluciones a los problemas formulados. Mediante la estrategia denominada lluvia de ideas se elabora una lista de alternativas (Gavino, 2006). Para beneficiar la lluvia de ideas se deben considerar los elementos de cantidad, aplazamiento de juicio y variedad.

El registro de esta etapa consta en la realización de una lista donde se le solicita al paciente que anote las ideas que surjan considerando los tres elementos mencionados. La cantidad de alternativas puede variar, pero se recomienda que sean mínimo cinco (véase en Rodríguez et al., 2020, p.105).

\subsubsection{Toma de decisiones}

El objetivo de esta fase es el de seleccionar aquella(s) alternativa(s) que, siendo plausible(s), contribuya $(n)$ a la solución del problema. Se analizarán los costos y beneficios de cada una de las alternativas generadas para identificar las más viables. Para ello, el cliente debe analizar las consecuencias a corto y a largo plazo, una a una, para cada alternativa disponible y anticiparse a los resultados de la solución evaluada.

Se propone un registro organizado en ocho columnas. En la primera se enumeran las alternativas discutidas, en la segunda se escriben cuáles son las consecuencias positivas a corto plazo, en la tercera cuáles son las consecuencias positivas en un largo periodo, en la cuarta cuáles son las consecuencias negativas próximas, en la quinta cuáles son las consecuencias negativas a largo plazo, la sexta cuáles son los resultados en el plano personal y la séptima cuáles son los efectos en el plano social y, finalmente, la octava en relación con lo explicado en las columnas anteriores se contesta a la pregunta ¿Puedo llevarlo a cabo? (véase en Rodríguez et al., 2020, p.106).

Si existiera el caso donde el paciente genere dos alternativas al final y se sienta indeciso de cuál realizar, es recomendable utilizar el siguiente registro de dos columnas: la primera consiste en escribir las ventajas de la alternativa y la segunda, las desventajas. La finalidad es hacer este análisis con las dos últimas alternativas para esclarecer qué opción realizar primero.

\subsection{Mantenimiento}

El mantenimiento tiene como finalidad la preservación de nuevos comportamientos en el tiempo, la perseverancia en las acciones, considerando las metas terapéuticas. Es necesario tener en cuenta los criterios de evaluación de los efectos del tratamiento en general, en términos del establecimiento de un repertorio terminal y conservación de este, a lo largo de un periodo prolongado después de suspender los procedimientos técnicos. Habla entonces de los efectos de promover el uso constante de estrategias y modificar conductas, pensamientos y ambientes relacionados con la conducta problema (Caballo, 1998; Ribes, 1972). 
Para las sesiones de mantenimiento se deberá establecer una hipótesis, la cual se genera a partir del AFC y de la(s) hipótesis funcional(es), esta hipótesis está organizada en los problemas funcionales del paciente, los objetivos terapéuticos y el repertorio de conductas adquiridas durante el proceso terapéutico (Bravo \& Mora, 2014). El objetivo del terapeuta es fomentar el cambio en el paciente a través de la retroalimentación y el reforzamiento de conductas deseadas, para lo cual tiene que saber si las estrategias adquiridas fueron empleadas. Por ello, es necesario evaluar y retroalimentar la eficacia de determinadas técnicas psicoterapéuticas mediante la evaluación de los resultados (Garyfallos et al., 2002). Un objetivo de esta etapa será analizar junto con el paciente los cambios obtenidos en las sesiones, utilizando métodos de representación gráfica de registros, y con ello evaluar el progreso, los cambios generados, además de señalar en qué aspectos hay que seguir trabajando y qué hacer para mantenerlos (Medina et al., 2012). Enseguida, se debe indagar sobre aquellas situaciones que dificultan la práctica de las técnicas o que limitan sus resultados, con el objetivo de diseñar un plan para la modificación de estas situaciones. En caso de situaciones de recaída se deberá establecer un método de contacto para realizar sesiones de apoyo.

\subsection{Seguimiento}

La meta principal del seguimiento es analizar si se están manteniendo las conductas aprendidas sin intervención formal, permitiendo entonces saber si se debe continuar con la intervención, o si ya es posible dar de alta al paciente. El seguimiento se refiere a la evaluación posterior a una intervención, y el tiempo de evaluación depende del objetivo principal del seguimiento.

La evaluación será importante para la prevención de recaídas y el mantenimiento de los logros obtenidos durante la terapia. Bados y García (2009) recomiendan los seguimientos a los tres y seis meses, pueden ser menos completos que las evaluaciones pretratamiento y postratamiento, pero el último seguimiento debería emplear los mismos métodos e instrumentos utilizados en dichas evaluaciones. Al menos en este último control, no se aconseja el seguimiento realizado por teléfono o por correo, debido a las deficiencias e insuficiencias de estos métodos; sin embargo, en ocasiones no quedará más remedio que acudir a los mismos. Se ha sugerido que las valoraciones repetidas son la mejor manera de calcular los cambios conseguidos mediante una intervención psicoterapéutica. Hay pocos estudios que se encarguen de investigar los resultados terapéuticos varios años después de que finalizara la terapia (Garyfallos et al., 2002).

En el Manual del Terapeuta para la Aplicación de la Intervención Breve Motivacional para Fumadores (IBMF) del Centro Nacional para la Prevención y el Control de las Adicciones (Medina et al., 2012) se indica que las consideraciones para la primera sesión de seguimiento son: preparar los instrumentos, establecer el número se seguimientos y revisar los registros y el expediente del paciente. Se establece que se realicen seguimientos al primer mes, a los 
tres, a los seis y al finalizar cada sesión se agendará la próxima cita. Un sistema organizado de seguimiento proporciona ventajas, ya que permite: 1) evaluar la conservación del cambio, 2) obtener indicadores que sustenten la eficiencia de la intervención, 3) reforzar el proceso terapéutico, e 4) identificar recaídas y prevenirlas. En las sesiones de cierre es el momento donde se establece el plan de seguimiento a realizar.

\subsubsection{Intervención en crisis}

Las crisis han sido interpretadas como existencia, crecimiento, etapa de desarrollo, etcétera; y estudiadas de manera individual o grupal (Slaikeu, 2000). En general, las crisis grupales ofrecen la posibilidad de evaluar e intervenir. La evaluación tiene como propósito identificar las respuestas fisiológicas de pelea que algunas personas manifiestan en un estado de crisis (e.g. gritar, quejarse, culpabilizar a algo o alguien, desquitarse); mientras que otras personas pueden estar aparentemente muy tranquilas, sin llorar o sin hacer nada.

Desde la teoría conductual, la mayoría de las crisis son referidas en una perspectiva comunitaria, en la cual se asume que el involucrado en la crisis tiene el mismo problema (e.g. en un terremoto, una inundación, una explosión, entre otros). Diferenciar la evaluación de manera grupal o individual recae en la concepción de evento proporcionada por Lazarus y Folkman (1984), donde este es similar para todos en determinadas características (tipo, duración), pero cada uno lo evalúa de acuerdo con sus recursos y contexto. De este modo, un evento dado puede ser una catástrofe para un individuo, pero para otro es la posibilidad de obtener un beneficio que necesitaba.

Para la presente guía, la perspectiva se centra en la enfermedad crónica, donde la evolución de la enfermedad y los cambios abruptos relacionados a las complicaciones de esta (e.g. recibir un nuevo diagnóstico, cambiar el curso de la enfermedad, recibir información de un mal pronóstico, presencia de síntomas mas no mejoría, saber que es un tratamiento no curativo o saber que se encuentra en estado terminal) también pueden ser catalogados como crisis.

Al referirnos a crisis, se menciona un estado temporal de desequilibrio posterior a la ocurrencia de un evento altamente estresante, donde el paciente no se encuentra preparado para tal evento, carece de recursos para afrontarlo y no descubre una solución. Es preciso aclarar que la reacción emocional natural inicial tiende a estar relacionada con las estrategias de afrontamiento que el paciente desarrolló en su vida; sin embargo, se pueden presentar variaciones de respuesta (Lazarus \& Folkman, 1984). En otras palabras, el evento de crisis desencadena estrés acompañado de emociones (e.g. miedo) y reacciones fisiológicas del fight or flight, así que el paciente huye o pelea, con todas las connotaciones conductuales de esta dicotomía. 
Para Dattilio y Freeman (2000), la crisis emerge cuando se rompe la homeostasis, el paciente no es capaz de afrontar la situación de manera efectiva, por lo que experimenta un número de síntomas que se vuelven los marcadores de la respuesta ante la crisis, requiriendo generalmente algún tipo de intervención para restaurarlo - al menos-al nivel de precrisis.

La alteración en el sistema de funcionamiento de una persona es percibida como negativa, amenazante, insuperable y sobre la que no se puede hacer nada (Stone \& Conley, 2006); en ella, el paciente experimenta altos niveles de estrés, malestar emocional y a nivel conductual no cuenta con el repertorio para solucionar los problemas que en ese momento surgen, lo que produce modificaciones en el mismo con resultados poco eficaces, los cuales favorecen la permanencia del estado de crisis.

Ante la evolución de una crisis ocurren cambios que van mostrando la transformación de las ideaciones catastróficas, sentimientos de indefensión y conductas de huida o evitación por comportamientos relacionados a un compromiso activo para salir adelante, asumir las consecuencias por los resultados de sus acciones u omisiones. En este momento, el paciente tiene la capacidad de buscar y asimilar información sobre el evento y el modo en que este afecta su vida y la de los demás, se encuentra dispuesto a la autoobservación tanto de sus necesidades físicas, emocionales, pensamientos como de sus conductas y a realizar ajustes para satisfacerlas (Golan, 1978).

La intervención para resolver la crisis desde la TCC mantiene ciertas características del enfoque, como estructura, directividad, trabajo conjunto, enfoque proactivo, contextualización del paciente y eficacia. La estructura hace referencia a tener un esquema para dar guía a la actuación tanto del terapeuta como del paciente, así, la directividad establece que el terapeuta guía de manera activa. Por su parte, el clínico y el paciente deben asegurar que en su relación se incluyen los insumos necesarios para lograr los mejores resultados. Plantear que se debe asumir la solución de problemas como estrategia principal es el enfoque proactivo. Se debe valorar el contexto del paciente, ya que él es parte de una familia, grupo y sociedad, donde existen hábitos comportamentales definidos.

Referente a las crisis, existe el afrontamiento comunitario o communality coping, este se refiere a conductas colaborativas, en las cuales la percepción de un evento estresante se evalúa como nuestro problema y se trabajará de manera conjunta para resolverlo (Helgeson et al., 2020; Zajdel, Helgeson, Seltman, Korytkowski, \& Hausmann, 2018). Finalmente, la eficacia hace referencia a la maximización de ganancias y minimización de las pérdidas a partir de las elecciones que se realicen. Adicionalmente, el trabajo en TCC se caracteriza por el cumplimiento de objetivos planteados, por lo que en la tabla 20 se muestran los objetivos de la intervención en crisis desde este modelo, los cuales también se aplican para el especialista en MC. 


\section{Tabla 20}

Objetivos y acciones de la intervención en crisis

\begin{tabular}{ll}
\multicolumn{1}{c}{ Objetivos } & \multicolumn{1}{c}{$\begin{array}{c}\text { Acciones del terapeuta } \\
\begin{array}{l}\text { Construcción de una relación terapéutica de ayuda para la } \\
\text { crisis. }\end{array}\end{array}$} \\
\hline $\begin{array}{l}\text { Identificar las dimensiones de la crisis, del suceso } \\
\text { desencadenante, el impacto personal, social y contextual. }\end{array}$ & $\begin{array}{l}\text { Emplear todas las estrategias de búsqueda y obtención de } \\
\text { información. }\end{array}$ \\
\hline $\begin{array}{l}\text { Comunicar apoyo al individuo. } \\
\text { Buscar que el paciente obtenga algún nivel de control y } \\
\text { predicción sobre lo ocurrido y sus consecuencias. }\end{array}$ \\
\hline $\begin{array}{l}\text { Fortalecer las estrategias de afrontamiento que le permita } \\
\text { hacer frente a la situación, disminuyendo los posibles } \\
\text { resultados negativos }\end{array}$ & \begin{tabular}{l} 
Emplear un enfoque de solución de problemas. \\
\hline
\end{tabular}
\end{tabular}

Nota: Elaboración propia a partir de "La intervención psicológica cognitivo-conductual en las crisis asociadas a desastres: una revisión teórica" por I. C. Salazar, V. E. Caballo y D. C. González, 2007, Psicología Conductual, p. 393.

El primer paso de la intervención consiste en realizar una evaluación para obtener los datos relacionados a los factores de riesgo y protectores del paciente; además, permite una base para diseñar planes de acción. Los procesos de evaluación ante la crisis deben ser rápidos, pero no superficiales y deben incluir: características del acontecimiento que ocasionó la crisis; procesos involucrados en el funcionamiento del individuo y el impacto sufrido por la situación que desencadenó la crisis a nivel de respuestas biológicas, emocionales y cognitivas; antecedentes individuales y características del contexto físico y social (Salazar et al., 2007).

A través de los años se han desarrollado diferentes mecanismos para la evaluación de las crisis. Meichenbaum (1977) propuso el entrenamiento en inoculación de estrés para enfrentar la crisis. Beck (1976) propuso la alternativa de trabajo a la crisis utilizando su terapia cognitiva. Uno de ellos es el denominado Triage Assessment System (TAS) (Myer \& Conte, 2006), utilizado para evaluar a los pacientes en estado de crisis identificando tres áreas: afectiva, conductual y cognitiva. Por su parte, Lazarus (1992) estableció el BASIC-ID basado en un modelo conductual que denominó multimodal y que explora la conducta, afecto, sensaciones, imágenes, cogniciones, relaciones interpersonales y biología, el cual se explica en la tabla 21.

Al conjuntar la evaluación de Lazarus (1992) y Salazar et al. (2007), el especialista en MC evaluará al paciente en crisis indagando sobre: ¿Cuál fue el evento que ocasionó la crisis? ¿En qué contexto se desató la crisis? ¿Cuáles fueron las respuestas conductuales, afectivas, biológicas/fisiológicas y cognitivas del paciente ante la crisis? ¿Qué historia tiene el paciente de su enfermedad, estrés y afrontamiento? Al respecto se debe aclarar que la evaluación a realizar ante una respuesta de crisis es profunda y larga, pero en el contexto propuesto para esta 
Tabla 21

Modelo BASIC-ID

\begin{tabular}{ll} 
B: Conducta & Respuestas, actos, hábitos, gestos y reacciones motoras que son observables y medibles. \\
\hline A: Afectivo & Emociones, estados de ánimo y sentimientos. \\
\hline S: Sensación & $\begin{array}{l}\text { Cubre la información de cada uno de los cinco sentidos básicos. Normalmente se abordan } \\
\text { las sensaciones negativas: tensión, mareos, dolor, rubor, etcétera. }\end{array}$ \\
\hline I: Imágenes & $\begin{array}{l}\text { Sueños, fantasías, recuerdos vívidos, imágenes mentales y la forma en que las personas se } \\
\text { ven a sí mismas (autoimagen). Las "imágenes auditivas", melodías o sonidos recurrentes, } \\
\text { también entran en esta categoría. }\end{array}$ \\
\hline C: Cognición & $\begin{array}{l}\text { Actitudes, valores, opiniones, ideas y autoverbalizaciones (diálogo interno). La tarea principal } \\
\text { es identificar y modificar creencias disfuncionales y reemplazarlas con puntos de vista que } \\
\text { mejoren el funcionamiento adaptativo. }\end{array}$ \\
\hline I: Relaciones & $\begin{array}{l}\text { Todas las interacciones significativas con otras personas (familiares, pareja, amigos, colegas, } \\
\text { compañeros de trabajo, etcétera.) }\end{array}$ \\
\hline D: Biología & $\begin{array}{l}\text { Incluye medicamentos (recetados por el médico o automedicados) además de nutrición, } \\
\text { higiene, ejercicio y todos los insumos fisiológicos y patológicos básicos. }\end{array}$ \\
\hline
\end{tabular}

Nota: Elaboración propia a partir de "The multimodal approach to the treatment of minor depression" por A. Lazarus, 1992, American Journal of Psychotherapy, 46(1), 50-57.

guía se ve modificada debido a que, para el especialista, el paciente es conocido, fue evaluado previamente y cuenta con componentes de relación previos, por lo que podrá aprovechar estas condiciones y recabar la información de una manera más sencilla y breve.

Respecto a la intervención en crisis de la TCC, Salazar et al. (2007) la plantean en tres apartados. El primero consiste en establecer un contacto psicológico y una relación terapéutica adecuada, en donde el psicólogo demuestra, comunica y obtiene. Demuestra empatía, calidez, transmite sensibilidad, confiabilidad, expresa incondicionalidad, maneja silencios, comprende, no emite juicios, empareja su estilo de comunicación con el del sujeto, comprende sus formas y lenguaje para expresarse, atiende a las señales no verbales y paraverbales de incomodidad, permite expresar la no aceptación y las dificultades para el cambio, muestra respeto, y valida los sentimientos y el recuento de la persona indicando, cuando sea factible, el nivel de control que tiene sobre la situación (Cormier \& Cormier, 1994; Ivey \& Ivey, 1999; Marinho, Caballo, \& Silveira, 2003; Ruiz \& Villalobos, 1994). Comunica apoyo emocional, empleando señales que les permita darse cuenta de que se perciben sus emociones; expresándoles que se reconocen sus sentimientos; y dándoles información acerca de la normalidad de sus respuestas (emocionales, cognitivas y conductuales), en consecuencia a la situación que atraviesan; explicando cómo estas fluyen en la medida que se afronte la situación, haciendo énfasis en la transitoriedad de la situación, donde se pretende fomentar 
la asimilación de dicha información y disminuir los niveles de incertidumbre y de ansiedad (Salazar \& Ventura, 2007). Además, obtiene datos para llevar a cabo la evaluación ante la crisis, tal y como se especificó anteriormente. En este punto, uno de los aspectos en los que más se debe fijar el clínico, es en la aparición de ideaciones, planes y acciones suicidas, y en tal caso, es factible que este sea el principal problema que deba solucionarse antes de abordar cualquier otro (Westefeld \& Heckman-Stone, 2003).

El segundo apartado es identificar y fortalecer algunas de las estrategias que el paciente utiliza para mantener el control emocional, en este se recolecta información de las alternativas que ha utilizado el paciente en ese tiempo, así como aquellas que emplea frecuentemente para disminuir el malestar emocional y los síntomas, pudiéndose aprovechar este punto para dar retroalimentación y reforzar la utilización de aquellas estrategias que puedan ser pertinentes, e iniciar la enseñanza-aprendizaje de aquellas que podrían ser necesarias para favorecer el afrontamiento de las emociones.

Una vez realizada la recolección de información se prosigue a intervenir sobre el(los) mayor(es) problema(s) y el estado emocional del individuo, para ello, va a ser muy importante aumentar el sentido de autoeficacia de la persona, definiendo las alternativas y las herramientas que le servirán para afrontar y manejar la situación, haciendo uso de los modelos de solución de problemas que han demostrado ser de gran utilidad. En este proceso se destacan dos propósitos relevantes: 1) ayudar al individuo a crear posibilidades en su sistema de intercambio con el medio que le permitan disminuir las incongruencias entre las condiciones ambientales y las necesidades y valores propios, y 2) orientarlo a solucionar el conflicto entre las alternativas.

Adicionalmente, se puede hacer uso de técnicas de modificación cognitiva para modificar las creencias desadaptativas y es primordial alentar la búsqueda de otros apoyos externos, de carácter social (Salazar et al., 2007). Es imperante que el psicólogo detecte posibles canalizaciones a otros profesionales con el objetivo de atender otros aspectos relacionados con la crisis o consecuencias del comportamiento mantenido por el paciente.

Como intervención dentro de la TCC, se puede identificar el éxito de esta a partir de criterios de logro, donde el paciente consigue modificar la conceptualización de la situación concebida como un obstáculo o impedimento que le impedía funcionar como lo haría cualquier otro día, encontrando una mejor forma de superar dicho obstáculo, lo cual representa el aprendizaje de nuevas estrategias e integrarlas a su repertorio.

\subsubsection{Monitoreo}

De acuerdo con Urrego y Rodríguez (2012), el objetivo del monitoreo consiste en medir y estimar los resultados logrados en la práctica y ayudar a constatar el alcance ganado, además de identificar si las actividades o tareas solicitadas o planeadas se realizan. Por su parte, Álvarez y Bucay (2018) indican que el monitoreo rutinario de resultados sirve para evaluar 
efectividad, identificar posibles cambios necesarios a la práctica clínica y facilitar el proceso terapéutico. Se caracteriza por ser un continuo de evaluación del estado general del paciente. Sus resultados indican el cumplimiento de los objetivos tanto particulares como de sesión propuestos, con base en ellos se puede modificar el plan de intervención (agregando sesiones o técnicas, adecuando las técnicas), lo que permite supervisar el avance del paciente e identificar barreras o limitaciones en la implementación de las técnicas entre sesiones o de la intervención. Por ello, su propósito es ayudar a tomar decisiones informadas respecto a la eficacia de las técnicas y el uso eficiente de los recursos (Frankel \& Gage, 2009).

Para el terapeuta, el monitoreo se deberá realizar de manera sistemática para tasar los resultados obtenidos, es un breve contacto que puede realizarse de manera coloquial con el paciente mediante llamada telefónica o correo electrónico. Permite mantener una relación terapéutica, reforzar el desempeño del paciente e identificar posibles problemáticas, lo que se traduce en la adecuación del plan de intervención. Para la presente guía, el monitoreo no tiene un periodo específico de ocurrencia, se dejará con un intervalo variable con el fin de que el terapeuta tome la decisión de acuerdo con las características, desempeño y resultados del paciente.

\subsection{Evaluación de satisfacción}

La eficacia de la TCC se ha demostrado en diferentes estudios para diferentes problemáticas psicológicas. No obstante, por la condición de la pandemia de COVID 19, se han modificado las condiciones en el trabajo terapéutico, lo que ha fomentado la presentación de las diversas modalidades terapéuticas, entre ellas, la terapia basada en el uso de recursos tecnológicos como es la terapia online. A pesar de que esta modalidad tiene ventajas, como accesibilidad, confidencialidad, comodidad, adaptación de los tiempos, reducción de gastos por el traslado, entre otras (Gutiérrez, 2020), es imperante realizar una evaluación de satisfacción para analizar la opinión de los elementos que conforman el trabajo terapéutico como: facilidad del uso de las aplicaciones, envío instantáneo y satisfactorio de registros, material psicoeducativo, infografías, claridad en las preguntas de los cuestionarios de la plataforma de Google Forms ${ }^{\circledR}$. Esto permitirá mejorar el tratamiento presente y considerar dichos aspectos en el futuro con el propósito de evaluar la calidad de la atención terapéutica (Doward \& McKenna, 2004; Flores, Cárdenas, Durán, \& De la Rosa, 2014; Gutiérrez, 2020; Mira, 2000; Villar, Lizán, Soto, \& Peiró, 2009).

Debido al aumento de la prevalencia de las enfermedades crónicas, parece previsible que cada vez será más necesario tener en cuenta el punto de vista de los pacientes en cuanto a su satisfacción, de la misma forma que se valora en otros aspectos de la vida. Por tal motivo, se pretende analizar el grado en que se han cumplido las expectativas, la calidad del proceso terapéutico o la existencia de posibles y deficiencias (Villar et al., 2009). 


\subsection{Cartas descriptivas}

A continuación, se presentan las cartas descriptivas del programa de intervención psicológica. En este apartado se condensan el objetivo general y los objetivos específicos con sus respectivas técnicas psicológicas, temas y actividades que realizarán el terapeuta y el paciente. Adicionalmente, se describen los materiales que servirán de apoyo en la sesión, el equipo tecnológico necesario para su realización y las formas de evaluación.

\section{Tabla 22}

\section{Carta descriptiva de la sesión 1}

\section{Objetivo de la sesión \\ Procedimiento \\ Técnica de evaluación \\ Inicio de sesión}

El terapeuta iniciará con la identificación de la problemática asociada al estrés y otras variables emocionales.

Evaluación.

Entrevista conductual, observación y reporte verbal.

Dará la bienvenida al paciente.

Establecerá rapport, y se presentará.

Explicará modalidad online para la atención.

Durante la sesión

1. Objetivo: El paciente recabará información general sobre los resultados de la batería de pruebas respondidas previamente.

Actividades del terapeuta Evaluará los resultados obtenidos a partir de la batería de pruebas que respondió el paciente previamente en la etapa de envío de datos.

Brindará información y retroalimentación sobre el desempeño en los resultados obtenidos de la batería aplicada que incluye los siguientes instrumentos:

- Escala de Ansiedad y Depresión Hospitalaria (HADS) (Zigmond \& Snaith, 1983)

- Escala de estrés percibido (PSS-14) (Cohen et al., 1983)

- Breve Check list de Afrontamiento (Abaroa et al., 2020)

- Síntomas de estrés

Responderá dudas.

Actividades del paciente Escuchará al terapeuta.

Realizará preguntas.

2. Objetivo: El paciente identificará los derechos y responsabilidades de la terapia en línea.

Actividades del terapeuta Proporcionará información sobre el modelo de la TCC.

Explicará la modalidad de trabajo a través de uso de TIC's.

Enviará infografías de las indicaciones y sugerencias para las sesiones en línea. ${ }^{1}$

Enviará y ejecutará la lectura del Consentimiento Informado (CI) (Anexo 1).

Actividades del paciente Escuchará y elaborará preguntas acerca de la TCC.

Escuchará la explicación de modalidad de trabajo.

Atenderá a las infografías con indicaciones y sugerencias para las sesiones en línea.

Escuchará y leerá el $\mathrm{Cl}$ al tiempo de la lectura del terapeuta.

Formulará dudas y preguntas acerca del $\mathrm{Cl}$.

Firmará el Cl. 


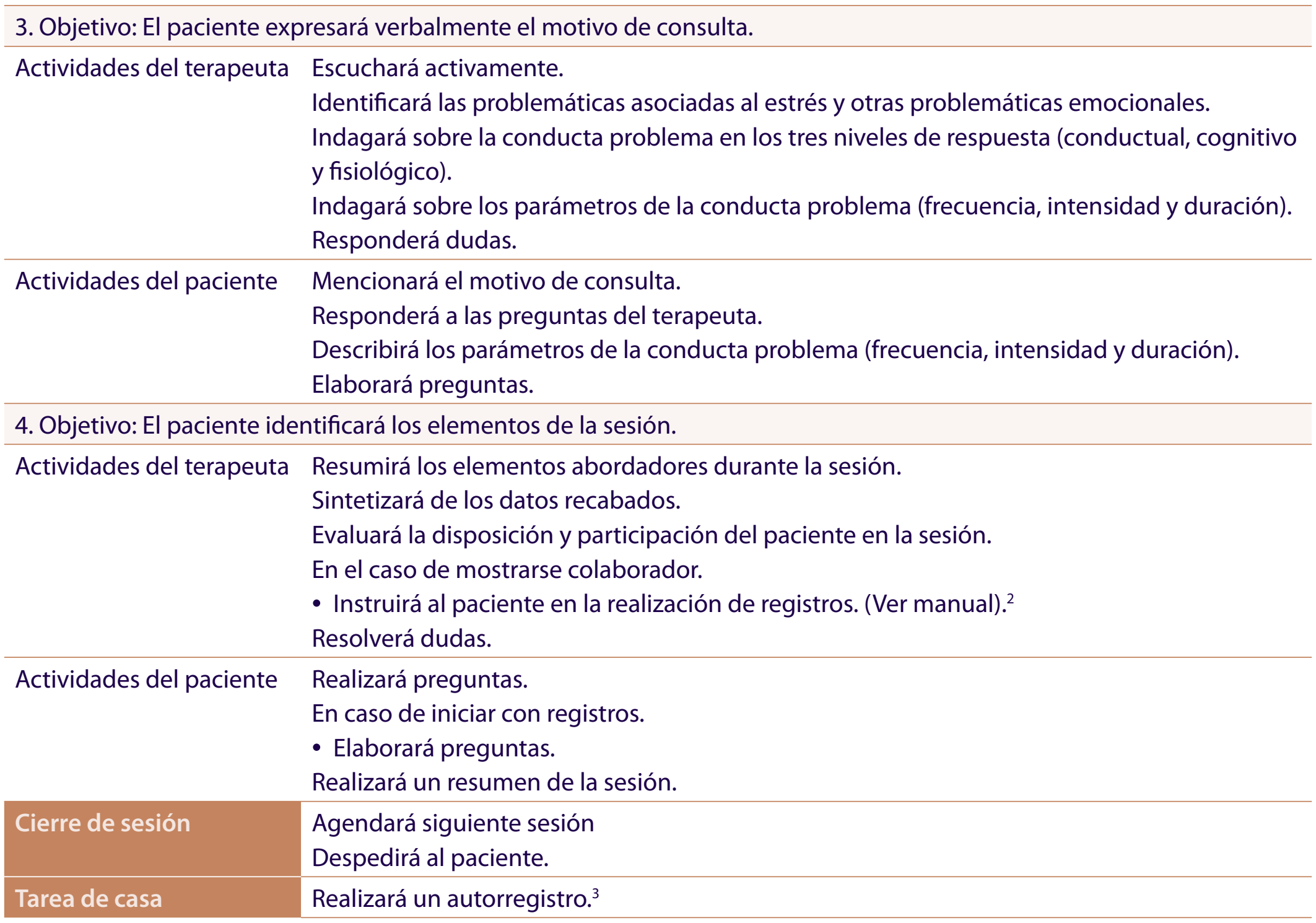

Nota: Elaboración propia. 'Disponible en https://tinyurl.com/apsiel ${ }^{2}$ Disponible en https://tinyurl.com/gppdm2 ${ }^{3}$ Considerando las características, problemática y colaboración del paciente para la implementación del registro.

\section{Tabla 23}

\section{Carta descriptiva de la sesión 2}

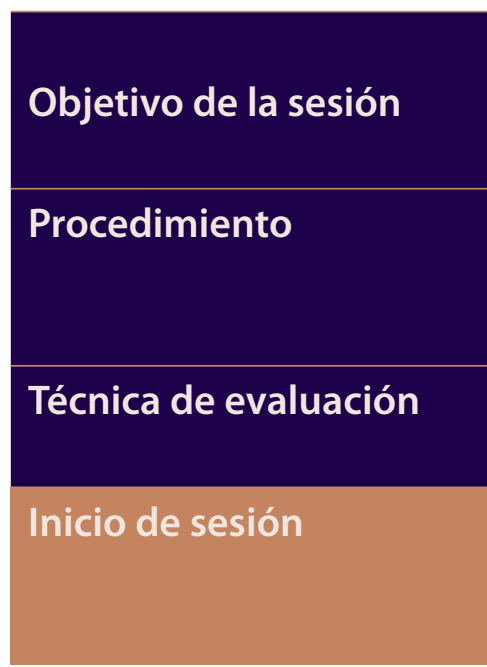

El terapeuta proseguirá con la evaluación de la problemática asociada al estrés y otras variables emocionales.

El terapeuta brindará psicoeducación de la técnica de relajación.

Evaluación.

Psicoeducación en relajación: beneficios y pasos de la respiración diafragmática profunda o rítmica.

Entrevista conductual, registro de relajación mediante Escala Visual Análoga (EVA), reporte verbal y observación.

Saludará al paciente.

Continuará con el rapport.

Realizará un resumen de la sesión anterior. 


\section{Durante la sesión}

1. Objetivo: El paciente expresará verbalmente la conducta problema relacionada al estrés u otras problemáticas emocionales asociadas.

Actividades del terapeuta Escuchara activamente.

Indagará la presencia de algún malestar emocional y los parámetros de este (frecuencia e intensidad).

Proseguirá con la entrevista conductual para identificar estímulos, respuestas y consecuencias derivadas de estas, además de determinar las posibles variables mediadoras. Elaborará, acorde con la información recabada, un análisis topográfico y funcional de la conducta (AFC).

Elaborará hipótesis funcionales relacionadas a los datos obtenidos durante la evaluación con base en el AFC.

- Efectuará una evaluación complementaria, en caso de ser necesaria la confirmación de un diagnóstico diferencial (e.g. depresión) a partir del uso de instrumentos validados.

Resolverá dudas.

Actividades del paciente Responderá a las preguntas elaboradas por el terapeuta.

- Responderá la evaluación complementaria en caso de que el terapeuta lo indique. Realizará preguntas.

2. Objetivo: El paciente identificará la relación entre la relajación y la respiración.

Actividades del terapeuta Brindará la explicación de la técnica de relajación y el entrenamiento en respiración con apoyo de un video. ${ }^{2} 3$

Solicitará un resumen verbal de la explicación proporcionada.

Resolverá dudas.

Actividades del paciente Escuchará y observará el video de entrenamiento en respiración. ${ }^{4}$

Proporcionará el resumen verbal de la explicación brindada.

Realizará preguntas.

Criterio de cambio El paciente verbalizará mínimo tres beneficios de la implementación de la técnica de relajación.

3. Objetivo: El paciente identificará el uso de los registros de relajación por medio de las Escalas Visuales Análogas (EVA).

Actividades del terapeuta Instruirá al paciente en el uso de los registros de relajación, específicamente en la EVA de relajación. (Ver manual). ${ }^{3}$

Responderá dudas.

Actividades del paciente Efectuará el llenado del registro de la EVA de relajación. Expresará dudas.

Criterio de cambio El paciente escribirá mínimo un ejemplo del estado de relajación en el registro.

4. Objetivo: El paciente identificará el uso de las aplicaciones digitales para apoyo a la intervención.

Actividades del terapeuta Expondrá el uso de aplicaciones digitales para la retroalimentación fisiológica del desempeño en el entrenamiento en respiración.

Expondrá la relación entre el uso de las aplicaciones digitales, el registro y apoyo a la intervención.

Pedirá la realización de tareas.

Resolverá dudas.

Actividades del paciente Escuchará la explicación del uso de las aplicaciones digitales para la retroalimentación fisiológica del entrenamiento en respiración y del registro de variables fisiológicas. Realizará preguntas. 


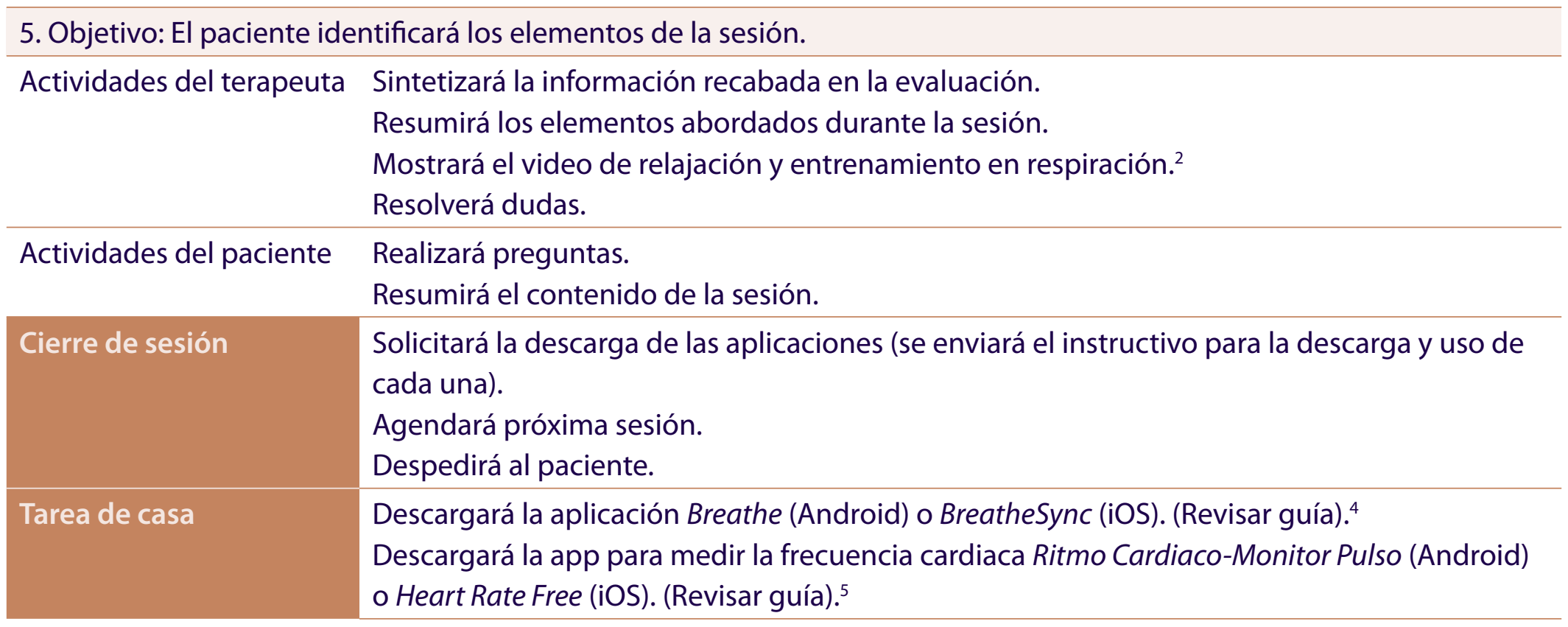

Nota: Elaboración propia. 'Para la evaluación complementaria, el terapeuta utilizará instrumentos validados y checklists disponibles en el repertorio digital ubicado en Google Forms ${ }^{\circledR}$ o si lo prefiere desarrollará registros acordes a las necesidades y características del paciente. ${ }^{2}$ Disponible en https://tinyurl.com/estresDM ${ }^{3}$ Disponible en https://tinyurl.com/gppdm2 ${ }^{4}$ Disponible en https://tinyurl.com/apfres ${ }^{5}$ Disponible en ttps://tinyurl.com/apfrecard

\section{Tabla 24}

\section{Carta descriptiva de la sesión 3}

\begin{tabular}{|c|c|}
\hline Objetivo de la sesión & $\begin{array}{l}\text { El terapeuta brindará psicoeducación en la técnica de respiración diafragmática o rítmica } \\
\text { (tipos de respiración, beneficios ante el estrés y pasos). } \\
\text { El terapeuta instruirá al paciente en la técnica en respiración diafragmática o rítmica. }\end{array}$ \\
\hline Técnica & Respiración diafragmática o rítmica. \\
\hline Procedimiento & Psicoeducación (tipos de respiración, beneficios y pasos). \\
\hline Técnica de evaluación & Registros, reporte tanto verbal como escrito, y observación. \\
\hline Inicio de sesión & $\begin{array}{l}\text { Saludará al paciente. } \\
\text { Continuará con el rapport. } \\
\text { Realizará un resumen de la sesión anterior. }\end{array}$ \\
\hline \multicolumn{2}{|l|}{ Durante la sesión } \\
\hline \multicolumn{2}{|c|}{ 1. Objetivo: El paciente identificará las generalidades del AFC. } \\
\hline Actividades del terapeuta & $\begin{array}{l}\text { Proporcionará las generalidades acerca del AFC del paciente. } \\
\text { Responderá dudas. }\end{array}$ \\
\hline Actividades del paciente & $\begin{array}{l}\text { Escuchará al terapeuta. } \\
\text { Realizará preguntas. }\end{array}$ \\
\hline \multicolumn{2}{|c|}{ 2. Objetivo: El paciente identificará los síntomas fisiológicos del estrés. } \\
\hline Actividades del terapeuta & $\begin{array}{l}\text { Expondrá la medición de las variables fisiológicas como son los síntomas del estrés con } \\
\text { apoyo del manual para pacientes. }{ }^{1} \\
\text { Resolverá dudas. } \\
\text { Solicitará un resumen verbal de la información presentada. }\end{array}$ \\
\hline Actividades del paciente & $\begin{array}{l}\text { Escuchará y observará el video. } \\
\text { Realizará preguntas. } \\
\text { Realizará un resumen de la información brindada. }\end{array}$ \\
\hline Criterio de cambio & El paciente verbalizará mínimo tres síntomas fisiológicos relacionados con el estrés. \\
\hline
\end{tabular}


3. Objetivo: El paciente señalará la relación entre la respiración diafragmática o rítmica y la reducción de los síntomas de estrés.

Actividades del terapeuta Explicará la relación entre la respiración diafragmática o rítmica y la reducción de los síntomas de estrés.

Resolverá dudas.

Solicitará un resumen acerca de la información brindada.

Actividades del paciente Escuchará la explicación de la relación entre respiración y la reducción de los síntomas de estrés.

Elaborará preguntas.

Elaborará un resumen verbal sobre la relación entre la respiración y la reducción de síntomas de estrés.

4. Objetivo: El paciente identificará los distintos tipos de respiración.

Actividades del terapeuta Proporcionará la explicación sobre los distintos tipos de respiración con apoyo del manual' y de un video. ${ }^{23}$

Resolverá dudas.

Solicitará un resumen verbal acerca de la información presentada.

Actividades del paciente Escuchará y observará el video.

Realizará preguntas.

Realizará un resumen verbal de la información brindada.

Criterio de cambio El paciente verbalizará mínimo tres tipos de respiración.

5. Objetivo: El paciente señalará los beneficios relacionados a la respiración rítmica o diafragmática.

Actividades del terapeuta Expondrá los beneficios de la respiración diafragmática o rítmica con apoyo del manual ${ }^{1}$ y de un video. ${ }^{2}$

Resolverá dudas.

Solicitará un resumen de la información brindada.

Actividades del paciente Escuchará y observará el video.

Realizará preguntas.

Realizará un resumen verbal de la información brindada.

Criterio de cambio El paciente verbalizará al menos tres beneficios de la respiración diafragmática o rítmica.

6. Objetivo: El paciente señalará el uso de la aplicación digital para la retroalimentación de la respiración.

Actividades del terapeuta Instruirá en el uso de la app Breathe o BreatheSync. ${ }^{3}$

Resolverá dudas.

Actividades del paciente Señalará el uso de la app Breathe o BreatheSync y su relación con los ejercicios de respiración.

Realizará preguntas.

Criterio de cambio El paciente utilizará mínimo una vez la app Breathe o BreatheSync.

7. Objetivo: El paciente señalará el uso de la aplicación digital para el registro de la frecuencia cardiaca.

Actividades del terapeuta Instruirá en el uso de la app Ritmo Cardiaco-Monitor Pulso o Heart Rate Free. ${ }^{4}$

Resolverá dudas.

Actividades del paciente Señalará la relación entre el uso y beneficio de la app Ritmo Cardiaco-Monitor Pulso o Heart

Rate Free.

Realizará preguntas.

Criterio de cambio El paciente ejemplificará mínimo una vez el uso de la app Ritmo Cardiaco-Monitor Pulso o Heart Rate Free y lo registrará. (Ver manual). ${ }^{1}$ 
8. Objetivo: El paciente identificará los pasos de la respiración diafragmática profunda o rítmica.

Actividades del terapeuta Expondrá los pasos de la respiración diafragmática profunda o rítmica con apoyo del manual' y de un video. ${ }^{2}$

Resolverá dudas.

Pedirá un resumen verbal de la explicación brindada.

Actividades del paciente Escuchará y observará el video de la relación entre la relajación y el entrenamiento en respiración. ${ }^{2}$

Realizará preguntas.

Brindará el resumen verbal de la explicación presentada.

Realizará preguntas.

Criterio de cambio El paciente verbalizará los cinco pasos de la técnica en respiración

(diafragmática o rítmica).

9. Objetivo: El paciente realizará el entrenamiento en respiración diafragmática profunda o rítmica.

Actividades del terapeuta Identificará el tipo de respiración que emplea el paciente habitualmente.

Solicitará el registro de relajación mediante la EVA de relajación antes de iniciar con el entrenamiento en respiración. (Ver manual). ${ }^{1}$

Solicitará el registro de la frecuencia cardiaca antes de iniciar con el entrenamiento en respiración. (Ver manual). ${ }^{\top}$

A través de la cámara, modelará la técnica de respiración rítmica o diafragmática.

Solicitará la ejecución de la técnica mientras menciona los pasos de la técnica con apoyo de un video. ${ }^{2}$

Proporcionará retroalimentación sobre la ejecución de la técnica.

Solicitará el registro de relajación a través una EVA después del entrenamiento en respiración. (Ver manual).'

Solicitará el registro de la frecuencia cardiaca después del entrenamiento en respiración.

(Ver manual). ${ }^{1}$

Reforzará la ejecución de la técnica.

Resolverá dudas.

Solicitará tareas.

Actividades del paciente Completará el registro de relajación mediante una EVA antes de iniciar el entrenamiento en respiración.

Completará el registro de la frecuencia cardiaca antes de iniciar el entrenamiento en respiración.

Observará la ejecución del terapeuta.

Ejecutará el ejercicio de respiración escuchando las instrucciones verbales de los pasos proporcionadas por el terapeuta.

Completará el registro de relajación a través una EVA después del entrenamiento en respiración.

Completará el registro de la frecuencia cardiaca después del entrenamiento en respiración. Realizará preguntas.

Criterio de cambio El paciente ejecutará los ejercicios de respiración (diafragmática o rítmica) mínimo tres veces.

10. Objetivo: El paciente identificará los elementos de la sesión.

Actividades del terapeuta Realizará un resumen de la técnica de relajación, del uso de aplicaciones y de los registros. Resolverá dudas.

Actividades del paciente Escuchará y observará el video.

Realizará preguntas.

Realizará un resumen de la sesión. 


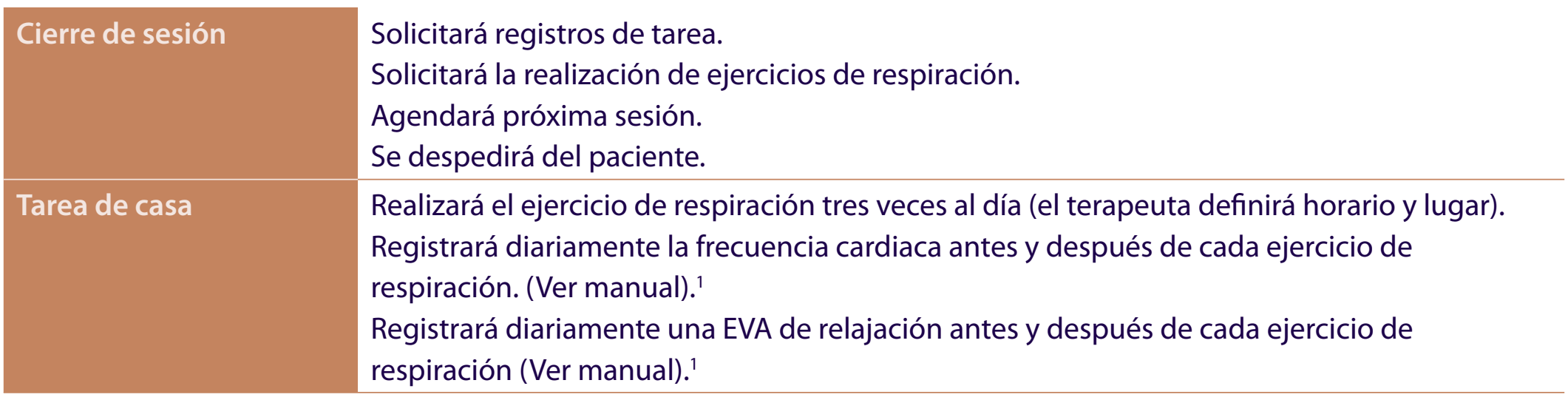

Nota: ${ }^{1}$ Disponible en https://tinyurl.com/gppdm2 ${ }^{2}$ Disponible en https://tinyurl.com/apfres ${ }^{3}$ Se omitirá el uso de aplicación para la retroalimentación de la respiración, en el caso de que el paciente no cuente con ella. ${ }^{4}$ Se entrenará la toma de frecuencia cardiaca análoga, si el paciente no cuenta con la aplicación disponible en https://tinyurl.com/apfrecard para este fin. Elaboración propia.

\section{Tabla 25}

\section{Carta descriptiva de la sesión 4}

\begin{tabular}{|c|c|}
\hline Objetivo de la sesión & $\begin{array}{l}\text { El terapeuta brindará psicoeducación de la Diabetes Mellitus Tipo } 2 \text { (DM2) respecto a } \\
\text { generalidades médicas (factores de riesgo, síntomas, complicaciones y tratamiento). } \\
\text { El terapeuta instruirá al paciente en la identificación de eventos estresantes relacionados } \\
\text { con la enfermedad. }\end{array}$ \\
\hline Procedimiento & Psicoeducación tanto de enfermedad, estrés y estilos de afrontamiento. \\
\hline Técnica de evaluación & Observación, registro, reporte verbal y escrito y cuestionario. \\
\hline Inicio de sesión & $\begin{array}{l}\text { Saludará al paciente. } \\
\text { Continuará con el rapport. } \\
\text { Realizará un resumen de la sesión anterior. }\end{array}$ \\
\hline \multicolumn{2}{|l|}{ Durante la sesión } \\
\hline \multicolumn{2}{|c|}{ 1. Objetivo: El paciente recibirá retroalimentación de los registros (tarea). } \\
\hline Actividades del terapeuta & $\begin{array}{l}\text { Examinará los registros realizados en casa. } \\
\text { Proporcionará retroalimentación sobre los registros. } \\
\text { Resolverá dudas. }\end{array}$ \\
\hline Actividades del paciente & $\begin{array}{l}\text { Escuchará al terapeuta. } \\
\text { Realizará preguntas. }\end{array}$ \\
\hline \multicolumn{2}{|c|}{$\begin{array}{l}\text { 2. Objetivo: El paciente señalará las generalidades médicas (factores de riesgo, signos síntomas, complicaciones } \\
\text { y tratamiento) de la DM2. }\end{array}$} \\
\hline Actividades del terapeuta & $\begin{array}{l}\text { Expondrá los factores de riesgo, signos, síntomas, complicaciones y tratamiento de la DM2. } \\
\text { (Ver manual). }{ }^{1} \\
\text { Proporcionará ejemplos. } \\
\text { Pedirá ejemplos. } \\
\text { Resolverá dudas. }\end{array}$ \\
\hline Actividades del paciente & $\begin{array}{l}\text { Escuchará activamente la explicación. } \\
\text { Proporcionará ejemplos. } \\
\text { Realizará preguntas. }\end{array}$ \\
\hline Criterio de cambio & $\begin{array}{l}\text { El paciente contestará mínimo cinco de las siete preguntas del cuestionario de Diabetes } \\
\text { Mellitus Tipo 2. (Ver manual). }{ }^{1}\end{array}$ \\
\hline
\end{tabular}




\begin{abstract}
3. Objetivo: El paciente identificará los componentes del estrés.
Actividades del terapeuta Cuestionará el conocimiento sobre el tema.

Proporcionará ejemplos del estrés en la vida cotidiana.

Expondrá el estrés con el apoyo de un video. ${ }^{2}$

Resolverá dudas.

Actividades del paciente Escuchará activamente la explicación.

Elaborará preguntas.

Criterio de cambio El paciente mencionará tres componentes del estrés.
\end{abstract}

4. Objetivo: El paciente identificará la relación entre la enfermedad y el estrés.

Actividades del terapeuta Explicará la relación entre estrés y enfermedad con apoyo del manual. ${ }^{1}$

Resolverá dudas.

Actividades del paciente Escuchará activamente la explicación.

Realizará preguntas.

Criterio de cambio El paciente mencionará mínimo dos consecuencias del estrés respecto a su enfermedad.

5. Objetivo: El paciente identificará eventos estresantes relacionados con la DM2.

Actividades del terapeuta Brindará ejemplos de situaciones estresantes en la vida diaria.

Resolverá dudas.

Actividades del paciente Escuchará atentamente al terapeuta.

Realizará preguntas.

Criterio de cambio El paciente escribirá en el formato tres situaciones estresantes en cuanto a su enfermedad. (Ver manual). ${ }^{1}$

6. Objetivo: El paciente señalará las estrategias de afrontamiento utilizadas ante eventos estresantes.

Actividades del terapeuta Expondrá los diferentes estilos de afrontamiento con apoyo del manual ${ }^{1} \mathrm{y}$ de un video. ${ }^{2}$

Proporcionará ejemplos de las estrategias de afrontamiento.

Solicitará dos ejemplos de formas de afrontar el estrés utilizadas por el paciente.

Resolverá dudas.

Actividades del paciente Escuchará atentamente al terapeuta.

Mencionará dos ejemplos de las estrategias de afrontamiento.

Realizará preguntas.

Criterio de cambio El paciente mencionará la estrategia de afrontamiento que utiliza con mayor frecuencia ante eventos estresantes y las razones por las cuales la utiliza.

7. Objetivo: El paciente identificará la forma como se relacionan el entrenamiento en relajación de respiración y el estrés.

Actividades del terapeuta Expondrá la relación entre entrenamiento de respiración y estrés en apoyo del manual' y de un video. ${ }^{2}$

Pedirá de tarea realizar el ejercicio de respiración ante situaciones estresantes relacionadas con su enfermedad.

Resolverá dudas.

Actividades del paciente Escuchará atentamente al terapeuta.

Realizará preguntas.

Criterio de cambio El paciente seleccionará dos situaciones donde implementaría la técnica.

8. Objetivo: El paciente señalará los elementos de la sesión.

Actividades del terapeuta Elaborará un resumen de la sesión.

Mostrará un video. ${ }^{2}$

Resolverá dudas.

Actividades del paciente Escuchará y observará el video.

Realizará preguntas.

Realizará un resumen de la sesión. 
Cierre de sesión

Tarea de casa
Solicitará la realización de registros de tarea y la ejecución del ejercicio de respiración ante eventos estresantes.

Agendará próxima sesión.

Despedirá al paciente.

El paciente escribirá en el formato tres situaciones estresantes en cuanto a su enfermedad. (Ver manual). ${ }^{1}$

Realizará el ejercicio de respiración ante algún evento estresante que presente en el día.

Registrará diariamente la frecuencia cardiaca antes y después de cada ejercicio de respiración.

Registrará diariamente una EVA de relajación antes y después de cada de respiración.

Nota: Elaboración propia. ${ }^{1}$ Disponible en https://tinyurl.com/gppdm2 2 2 isponible en https://tinyurl.com/estresDM

\section{Tabla 26}

\section{Carta descriptiva de la sesión 5}

\begin{tabular}{|c|c|}
\hline Objetivo de la sesión & $\begin{array}{l}\text { El terapeuta instruirá al paciente en la ejecución de la técnica de autoinstrucciones ante } \\
\text { situaciones estresantes. }\end{array}$ \\
\hline Técnica & Autoinstrucciones. \\
\hline Procedimiento & Psicoeducación, modelamiento y ensayo conductual. \\
\hline Técnica de evaluación & Observación, registro, reporte verbal y escrito, y cuestionario. \\
\hline Inicio de sesión & $\begin{array}{l}\text { Saludará al paciente. } \\
\text { Continuará con el rapport. } \\
\text { Realizará un resumen de la sesión anterior. }\end{array}$ \\
\hline \multicolumn{2}{|l|}{ Durante la sesión } \\
\hline \multicolumn{2}{|c|}{ 1. Objetivo: El paciente recibirá retroalimentación de los registros (tarea). } \\
\hline Actividades del terapeuta & $\begin{array}{l}\text { Examinará los registros realizados en casa. } \\
\text { Proporcionará retroalimentación sobre los registros. } \\
\text { Resolverá dudas. }\end{array}$ \\
\hline Actividades del paciente & $\begin{array}{l}\text { Escuchará al terapeuta. } \\
\text { Realizará preguntas. }\end{array}$ \\
\hline \multicolumn{2}{|c|}{ 2. Objetivo: El paciente señalará los pasos para la técnica de autoinstrucciones. } \\
\hline Actividades del terapeuta & $\begin{array}{l}\text { Expondrá la psicoeducación de la técnica de autoinstrucciones con el apoyo del manual }{ }^{1} \text { y } \\
\text { de un video. } \\
\text { Especificará los pasos para implementar la técnica en una tarea determinada. } \\
\text { Resolverá dudas. }\end{array}$ \\
\hline Actividades del paciente & $\begin{array}{l}\text { Observará y escuchará el video. } \\
\text { Escuchará al terapeuta. } \\
\text { Indicará los pasos para realizar la técnica de autoinstrucciones. } \\
\text { Realizará preguntas. }\end{array}$ \\
\hline Criterio de cambio & $\begin{array}{l}\text { El paciente mencionará mínimo cuatro de los pasos para la implementación de la técnica de } \\
\text { autoinstrucciones. }\end{array}$ \\
\hline \multicolumn{2}{|c|}{ 3. Objetivo: El paciente elaborará autoinstrucciones para un evento estresante. } \\
\hline Actividades del terapeuta & $\begin{array}{l}\text { Solicitará la selección de evento estresante. (Ver manual). }{ }^{1} \\
\text { Facilitará la realización de autoinstrucciones para ese evento. } \\
\text { Resolverá dudas. }\end{array}$ \\
\hline
\end{tabular}




\begin{tabular}{|c|c|}
\hline Actividades del paciente & $\begin{array}{l}\text { Seleccionará y escribirá un evento estresante. (Ver manual). }{ }^{1} \\
\text { Realizará preguntas. }\end{array}$ \\
\hline Criterio de cambio & $\begin{array}{l}\text { El paciente enlistará mínimo tres autoinstrucciones para evento estresante seleccionado. } \\
\text { (Ver manual). }{ }^{1}\end{array}$ \\
\hline \multicolumn{2}{|c|}{ 4. Objetivo: El paciente ejecutará la técnica de autoinstrucciones. } \\
\hline Actividades del terapeuta & $\begin{array}{l}\text { Modelará en vivo a través de la cámara la ejecución de la técnica. } \\
\text { Solicitará al paciente la ejecución de la técnica. } \\
\text { Brindará retroalimentación de la ejecución. } \\
\text { Resolverá dudas. }\end{array}$ \\
\hline Actividades del paciente & $\begin{array}{l}\text { Observará y escuchará el modelado de la técnica. } \\
\text { Realizará la técnica. } \\
\text { Escuchará la retroalimentación del ejercicio. } \\
\text { Realizará preguntas. }\end{array}$ \\
\hline Criterio de cambio & $\begin{array}{l}\text { El paciente efectuará los cinco pasos para la implementación de la técnica de } \\
\text { autoinstrucciones. }\end{array}$ \\
\hline \multicolumn{2}{|c|}{ 5. El paciente señalará la relación entre la técnica de respiración diafragmática o pasiva y las autoinstrucciones. } \\
\hline Actividades del terapeuta & $\begin{array}{l}\text { Expondrá la relación entre la técnica de respiración (diafragmática o pasiva) y } \\
\text { autoinstrucciones } \\
\text { Mencionará los beneficios de implementar estás técnicas juntas. } \\
\text { Resolverá dudas. }\end{array}$ \\
\hline Actividades del paciente & $\begin{array}{l}\text { Escuchará atentamente al terapeuta. } \\
\text { Elaborará preguntas. }\end{array}$ \\
\hline Criterio de cambio & $\begin{array}{l}\text { El paciente mencionará dos beneficios de aplicar el entrenamiento en respiración con } \\
\text { autoinstrucciones. }\end{array}$ \\
\hline \multicolumn{2}{|c|}{$\begin{array}{l}\text { 6. Objetivo: El paciente ejecutará la técnica de respiración diafragmática o rítmica en complemento con las } \\
\text { autoinstrucciones. }\end{array}$} \\
\hline Actividades del terapeuta & $\begin{array}{l}\text { Mediante la cámara, modelará en vivo la ejecución del entrenamiento en respiración } \\
\text { (diafragmática o rítmica) con las autoinstrucciones que enlistó el paciente. } \\
\text { Solicitará al paciente la ejecución del ejercicio. } \\
\text { Proporcionará retroalimentación la ejecución. } \\
\text { Resolverá dudas. }\end{array}$ \\
\hline Actividades del paciente & $\begin{array}{l}\text { Observará y escuchará el modelado de la técnica. } \\
\text { Ejecutará la técnica. } \\
\text { Escuchará la retroalimentación del ejercicio. } \\
\text { Realizará preguntas. }\end{array}$ \\
\hline Criterio de cambio & $\begin{array}{l}\text { El paciente efectuará mínimo en una ocasión el entrenamiento en respiración junto con la } \\
\text { implementación de autoinstrucciones. }\end{array}$ \\
\hline \multicolumn{2}{|c|}{ 7. Objetivo: El paciente señalará los elementos de la sesión. } \\
\hline Actividades del terapeuta & $\begin{array}{l}\text { Elaborará un resumen de la técnica de autoinstrucciones. } \\
\text { Mostrará un video. } \\
\text { Resolverá dudas. }\end{array}$ \\
\hline Actividades del paciente & $\begin{array}{l}\text { Escuchará y observará el video. } \\
\text { Realizará preguntas. } \\
\text { Realizará un resumen de la sesión. }\end{array}$ \\
\hline Cierre de sesión & $\begin{array}{l}\text { Solicitará la realización de registros de tarea y la implementación de la técnica de } \\
\text { autoinstrucciones junto con los ejercicios de respiración ante situaciones estresantes. } \\
\text { Agendará próxima sesión. } \\
\text { Despedirá al paciente. }\end{array}$ \\
\hline
\end{tabular}


Tarea de casa

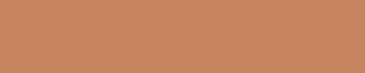

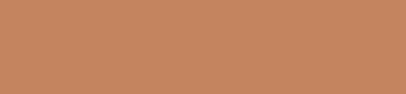

Realizará el ejercicio de respiración diafragmática o rítmica con autoinstrucciones ante un evento estresante.

Registrará diariamente la frecuencia cardiaca antes y después de cada ejercicio de respiración.

Registrará diariamente una EVA de relajación antes y después de cada de respiración.

Practicará los ejercicios de respiración en los momentos indicados previamente y ante las situaciones estresantes que se le presenten.

Nota: Elaboración propia. 'Disponible en https://tinyurl.com/gppdm2 2 Disponible en https://tinyurl.com/estresDM

\section{Tabla 27}

\section{Carta descriptiva de la sesión 6}

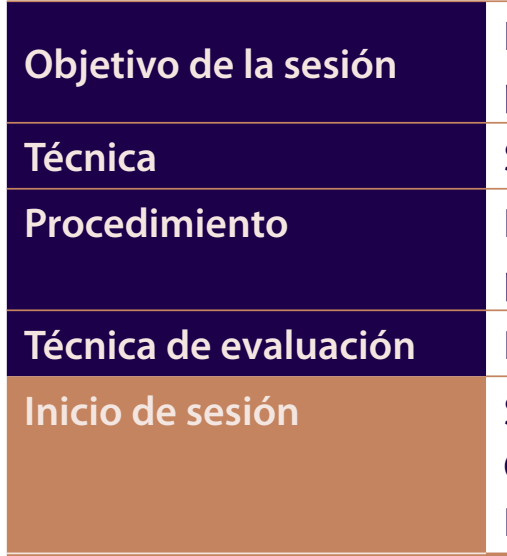

Durante la sesión
El terapeuta instruirá al paciente en la técnica de solución de problemas (identificación de problemas).

Solución de problemas.

Psicoeducación en identificación del problema (paso 1) de la técnica de solución de problemas.

Registro de identificación de problema, observación y reporte verbal.

Saludará al paciente.

Continuará con el rapport.

Realizará un resumen de la sesión anterior.

1. Objetivo: El paciente recibirá retroalimentación de los registros (tarea).

Actividades del terapeuta Examinará los registros realizados en casa.

Proporcionará retroalimentación sobre los registros.

Resolverá dudas.

Actividades del paciente Escuchará al terapeuta.

Realizará preguntas.

2. Objetivo: El paciente identificará los elementos de la técnica de solución de problemas (SP).

Actividades del terapeuta Expondrá la técnica de SP con apoyo del manual ${ }^{1}$ y de un video. ${ }^{2}$

Solicitará explicación de la técnica.

Resolverá dudas.

Actividades del paciente Escuchará y observará el video.

Resumirá la técnica.

Realizará preguntas

Criterio de cambio El paciente verbalizará mínimo dos características de la técnica.

3. Objetivo: El paciente identificará la relación entre la técnica de SP y el manejo de estrés.

Actividades del terapeuta Brindará la explicación sobre la relación entre la técnica de SP y el manejo de estrés.

Proporcionará ejemplos.

Solicitará ejemplos.

Resolverá dudas.

Actividades del paciente Escuchará la explicación.

Proporcionará ejemplos.

Realizará preguntas.

Criterio de cambio El paciente mencionará mínimo dos beneficios de implementar la técnica de SP para el manejo de estrés. 
4. Objetivo: El paciente identificará los elementos de un problema (el qué, quién/quiénes, dónde, cuándo y cómo).

Actividades del terapeuta Expondrá la importancia de la identificación del problema en apoyo del manual' y de un video. ${ }^{2}$

Proporcionará ejemplos.

Solicitará ejemplos.

Explicará el llenado del registro de identificación de problema. (Ver manual). ${ }^{1}$

Resolverá dudas.

Actividades del paciente Escuchará y observará el video.

Proporcionará ejemplos.

Realizará preguntas.

Completará el registro de identificación de problema.

Criterio de cambio El paciente señalará en un problema los elementos qué, quién/quiénes, dónde, cuándo y cómo. (Ver manual). ${ }^{1}$

5. Objetivo: El paciente identificará los problemas relacionados con su enfermedad.

\begin{tabular}{|c|c|}
\hline Actividades del terapeuta & $\begin{array}{l}\text { Facilitará la identificación de problemas. } \\
\text { Solicitará la jerarquización de problemas. } \\
\text { Resolverla dudas. }\end{array}$ \\
\hline Actividades del paciente & $\begin{array}{l}\text { Identificará los problemas relacionados con su enfermedad. } \\
\text { Jerarquizará los problemas. } \\
\text { Realizará preguntas. }\end{array}$ \\
\hline Criterio de cambio & $\begin{array}{l}\text { El paciente señalará mínimo cinco problemas relacionados con su enfermedad. } \\
\text { (Ver manual). }{ }^{1}\end{array}$ \\
\hline \multicolumn{2}{|c|}{ 6. Objetivo: El paciente señalará los elementos de la sesión. } \\
\hline Actividades del terapeuta & $\begin{array}{l}\text { Realizará un resumen de la información abordada durante (solución de problemas y el } \\
\text { primer paso de la técnica). } \\
\text { Mostrará el video. } \\
\text { Resolverá dudas. }\end{array}$ \\
\hline Actividades del paciente & $\begin{array}{l}\text { Escuchará y observará el video. } \\
\text { Realizará preguntas. } \\
\text { Realizará un resumen del contenido de la sesión. }\end{array}$ \\
\hline Cierre de sesión & $\begin{array}{l}\text { Solicitará la realización registros de tarea. } \\
\text { Agendará próxima sesión. } \\
\text { Despedirá al paciente. }\end{array}$ \\
\hline Tarea de casa & $\begin{array}{l}\text { Realizará el ejercicio de respiración diafragmática o rítmica con autoinstrucciones ante un } \\
\text { evento estresante. } \\
\text { Registrará diariamente la frecuencia cardiaca antes y después de cada ejercicio de } \\
\text { respiración. } \\
\text { Registrará diariamente una EVA de relajación antes y después de cada de respiración. } \\
\text { Practicará los ejercicios de respiración en los momentos indicados previamente y ante las } \\
\text { situaciones estresantes que se le presenten. }\end{array}$ \\
\hline
\end{tabular}

Nota: Elaboración propia. 'Disponible en https://tinyurl.com/gppdm2 2 Disponible en https://tinyurl.com/estresDM 
Tabla 28

\section{Carta descriptiva de la sesión 7}

\begin{tabular}{|c|c|}
\hline Objetivo de la sesión & $\begin{array}{l}\text { El terapeuta instruirá al paciente en la técnica de solución de problemas (generación de } \\
\text { alternativas). }\end{array}$ \\
\hline Técnica & Solución de problemas. \\
\hline Procedimiento & $\begin{array}{l}\text { Psicoeducación en generación de alternativas (paso 2) de la técnica de solución de } \\
\text { problemas. }\end{array}$ \\
\hline Técnica de evaluación & Registro de generación de alternativas, observación, reporte verbal y escrito. \\
\hline Inicio de sesión & $\begin{array}{l}\text { Saludará al paciente. } \\
\text { Continuará con el rapport. } \\
\text { Realizará un resumen de la sesión anterior. }\end{array}$ \\
\hline \multicolumn{2}{|l|}{ Durante la sesión } \\
\hline \multicolumn{2}{|c|}{ 1. Objetivo: El paciente recibirá retroalimentación de los registros realizados en casa y los de la sesión anterior (SP). } \\
\hline Actividades del terapeuta & $\begin{array}{l}\text { Revisará los registros realizados en casa. } \\
\text { Proporcionará retroalimentación sobre los registros. } \\
\text { Resolverá dudas. }\end{array}$ \\
\hline Actividades del paciente & $\begin{array}{l}\text { Escuchará al terapeuta. } \\
\text { Realizará preguntas. }\end{array}$ \\
\hline \multicolumn{2}{|c|}{ 2. Objetivo: El paciente generará alternativas de solución. } \\
\hline Actividades del terapeuta & $\begin{array}{l}\text { Expondrá la importancia de la generación de alternativas de acuerdo con los criterios de } \\
\text { cantidad, aplazamiento de juicio y variedad con apoyo del manual' y de un video. }{ }^{2} \\
\text { Proporcionará ejemplos. } \\
\text { Solicitará ejemplos. } \\
\text { Explicará el llenado del registro de generación de alternativas. (Ver manual). }{ }^{1} \\
\text { Resolverá dudas }\end{array}$ \\
\hline Actividades del paciente & $\begin{array}{l}\text { Escuchará y observará el video. } \\
\text { Resumirá la técnica. } \\
\text { Realizará preguntas } \\
\text { Completará el registro de generación de alternativas. }\end{array}$ \\
\hline Criterio de cambio & $\begin{array}{l}\text { El paciente enlistará mínimo cinco alternativas con los criterios del paso en el registro de } \\
\text { generación de alternativas. (Ver manual). }{ }^{1}\end{array}$ \\
\hline \multicolumn{2}{|c|}{ 3. Objetivo: El paciente identificará los elementos de la sesión. } \\
\hline Actividades del terapeuta & $\begin{array}{l}\text { Realizará un resumen de los elementos de la sesión. } \\
\text { Mostrará un video. } \\
\text { Resolverá dudas. }\end{array}$ \\
\hline Actividades del paciente & $\begin{array}{l}\text { Escuchará y observará el video. } \\
\text { Realizará preguntas. } \\
\text { Realizará un resumen de la sesión. }\end{array}$ \\
\hline Cierre de sesión & $\begin{array}{l}\text { Solicitará de tarea la realización registros. } \\
\text { Solicitará la generación de alternativas para el segundo problema. } \\
\text { Agendará próxima sesión. } \\
\text { Despedirá al paciente. }\end{array}$ \\
\hline
\end{tabular}


Tarea de casa
Registrará cinco alternativas de solución atendiendo a los criterios (cantidad, aplazamiento de juicio y variedad) para el segundo problema de su lista elaborada la sesión previa.

Realizará el ejercicio de respiración diafragmática o rítmica con autoinstrucciones ante un evento estresante.

Registrará diariamente la frecuencia cardiaca antes y después de cada ejercicio de respiración.

Registrará diariamente una EVA de relajación antes y después de cada de respiración. Practicará los ejercicios de respiración en los momentos indicados previamente y ante las situaciones estresantes que se le presenten.

Nota: Elaboración propia. 'Disponible en https://tinyurl.com/gppdm2 2Disponible en https://tinyurl.com/estresDM

\section{Tabla 29}

\section{Carta descriptiva de la sesión 8}

\section{Objetivo de la sesión \\ Técnica \\ Procedimiento \\ Técnica de evaluación \\ Inicio de sesión}

El terapeuta instruirá al paciente en la técnica de solución de problemas (toma de decisiones).

Solución de problemas.

Psicoeducación en la toma de decisiones (paso 3) de la técnica de solución de problemas. Registro de costo y beneficio, observación, reporte verbal y escrito.

Saludará al paciente.

Continuará con el rapport.

Realizará un resumen de la sesión anterior.

\section{Durante la sesión}

1. Objetivo: El paciente recibirá retroalimentación de los registros realizados en casa y los de la sesión anterior (SP).

Actividades del terapeuta Examinará los registros realizados en casa.

Proporcionará retroalimentación sobre los registros.

Resolverá dudas

Actividades del paciente Escuchará al terapeuta.

Realizará preguntas.

2. Objetivo: El paciente identificará las ventajas y desventajas de las alternativas de solución.

Actividades del terapeuta Expondrá el paso 3 de la técnica: la toma de decisiones, con apoyo del manual ${ }^{1}$ y de un video. $^{2}$

Proporcionará ejemplos.

Solicitará ejemplos.

Explicará el llenado del registro de toma de decisiones y el análisis costo-beneficio. (Ver manual).

Actividades del paciente Escuchará y observará el video.

Brindará ejemplos.

Realizará preguntas.

Completará el registro.

Escribirá ventajas y desventajas de cada alternativa.

Criterio de cambio El paciente enlistará mínimos dos ventajas y dos desventajas de cada alternativa.

3. Objetivo: El paciente seleccionará una alternativa de solución.

Actividades del terapeuta Incitará la realización del análisis de las ventajas y desventajas de cada alternativa planteada. Resolverá dudas.

Actividades del paciente Analizará las ventajas y desventajas de las alternativas enlistadas.

Criterio de cambio El paciente seleccionará máximo dos alternativas de solución. 


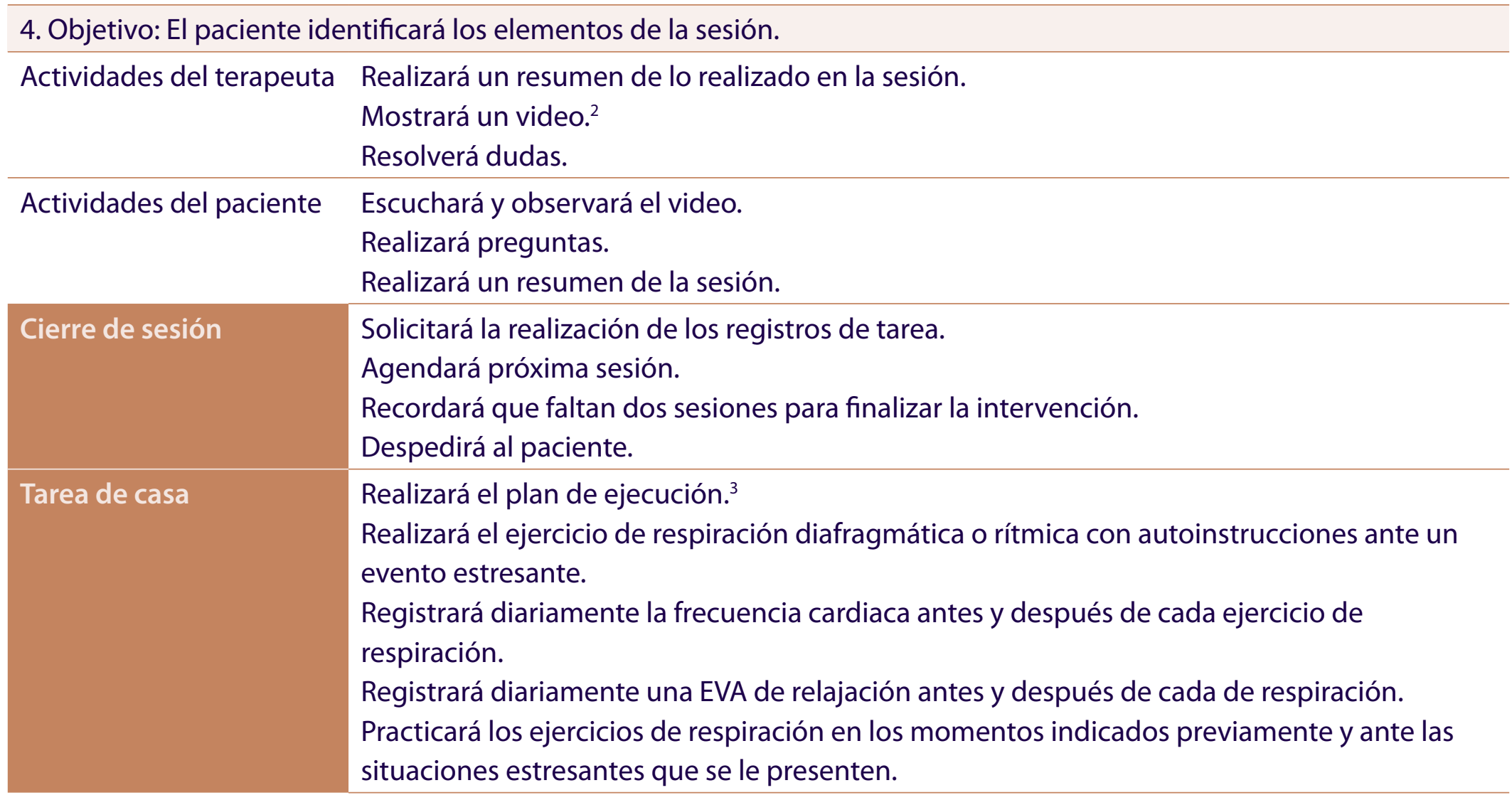

Nota: Elaboración propia. 'Disponible en https://tinyurl.com/gppdm2 22Disponible en https://tinyurl.com/estresDM ${ }^{3}$ El terapeuta sopesará la necesidad de implementar otras técnicas cognitivo conductuales con base en las características y habilidades del paciente.

\section{Tabla 30}

\section{Carta descriptiva de la sesión 9}

\section{Objetivo de la sesión} Técnica

Técnica de evaluación

Inicio de sesión
El terapeuta instruirá al paciente en la elaboración de planes de acción.

Psicoeducación y plan de acción.

Registro plan de acción, reporte verbal, reporte escrito y observación.

Saludará al paciente.

Reiterará que es la penúltima sesión.

Continuará con el rapport.

Realizará un resumen de la sesión anterior.

\section{Durante la sesión}

1. Objetivo: El paciente obtendrá retroalimentación de los registros realizados en casa y la puesta en marcha de la solución de la sesión anterior (SP).

Actividades del terapeuta Revisará los registros realizados en casa.

Proporcionará retroalimentación sobre los registros.

Indagará sobre los resultados de la implementación de la alternativa de solución.

- En caso de que los resultados sean favorables, brindará retroalimentación y reforzará al paciente.

- En caso de que los resultados no sean los esperados, reiterará la posibilidad de utilizar otra alternativa siguiendo los últimos dos pasos de la técnica.

Resolverá dudas.

Actividades del paciente Escuchará al terapeuta.

Realizará preguntas. 
2. Objetivo: El paciente señalará las condiciones en las que practica las técnicas.

Actividades del terapeuta Indagará sobre la práctica de las técnicas entrenadas durante la intervención. Solicitará la descripción del momento y condiciones en que pone en práctica las técnicas.

Actividades del paciente Escuchará al terapeuta.

Indicará el momento en que practica las técnicas.

Describirá las condiciones (dónde, cuándo, con quién y ante qué situaciones) en que implementa las técnicas.

Criterio de cambio El paciente describirá al menos dos situaciones donde las puso a prueba.

3. Objetivo: El paciente señalará situaciones problemáticas que interrumpen la implementación de las técnicas.

Actividades del terapeuta Expondrá la relevancia de señalar estas situaciones y su relación para mejorar el desempeño en las técnicas y la efectividad de los resultados.

Retomará la información recabada mediante los registros.

Cuestionará sobre situaciones que pudieron intervenir en la aplicación de las técnicas.

Actividades del paciente Escuchará al terapeuta.

Especificará los eventos que intervienen en la implementación de las técnicas.

Especificará las condiciones que impiden la implementación de las técnicas.

Criterio de cambio El paciente señalará como mínimo dos condiciones que impiden la implantación de las técnicas.

4. Objetivo: El paciente identificará la relación entre situaciones problemáticas, la efectividad de la implementación de las técnicas y el estrés.

Actividades del terapeuta Explicará la relación entre las técnicas de manejo de estrés entrenadas y las situaciones que impiden su práctica.

Expondrá la relevancia de identificar esas situaciones en cuanto al manejo de estrés con apoyo del manual.'

Solicitará realizar un resumen de lo expuesto.

Actividades del paciente Escuchará al terapeuta.

Realizará un resumen de lo expuesto.

5. Objetivo: El paciente producirá un plan de acción.

Actividades del terapeuta Especificará la función de un plan de acción.

Recuperará la información obtenida en la sesión (condiciones de práctica y situaciones problema).

Facilitará la elección de dos barreras (condiciones que impidan la práctica de las técnicas).

Solicitará la escritura de esas barreras en el registro de plan de acción. (Ver manual). ${ }^{1}$

Promoverá la generación de alternativas de solución (tres por cada barrera).

Pedirá la escritura de ellas en el registro de plan de acción.

Para ello, preguntará: "¿Qué podría realizar para tener resultados diferentes?" o "Ante estas

situaciones ¿qué haría que la práctica de las técnicas fuese más funcional?"

Proporcionará retroalimentación sobre la ejecución del paciente.

Explicará que la elección de la alternativa para implementar una solución puede basarse en funcionalidad o facilidad.

Solicitará la selección de la alternativa señalándolo en el registro.

Actividades del paciente Escuchará al terapeuta.

Elegirá situaciones que sean una barrera en la práctica de las técnicas.

Redactará las situaciones en el registro.

Proporcionará tres soluciones para cada barrera, escribiéndolas en el registro.

Elegirá una alternativa de solución para cada barrera que señalará en el registro

Criterio de cambio El paciente enlistará mínimo dos soluciones a cada barrera en el registro. 


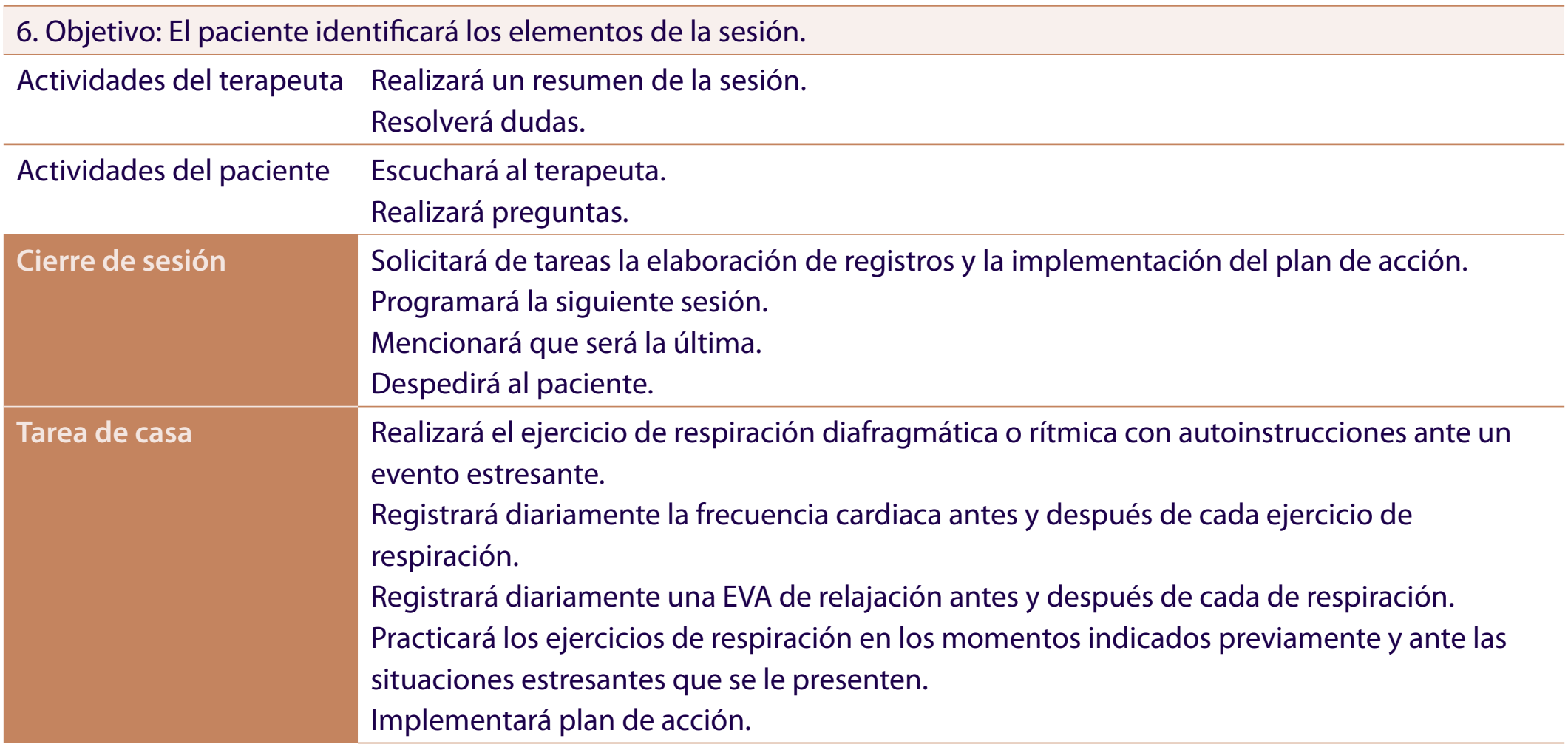

Nota: ${ }^{1}$ Viviendo con Diabetes Mellitus: pautas y sugerencias para controlar mi estrés disponible en https://www.mciztacala.org/ uploads/1/3/2/8/132887507/gu\%C3\%ADa_para_pacientes_dm2.pdf Elaboración propia.

\section{Tabla 31}

\section{Carta descriptiva de la sesión 10}

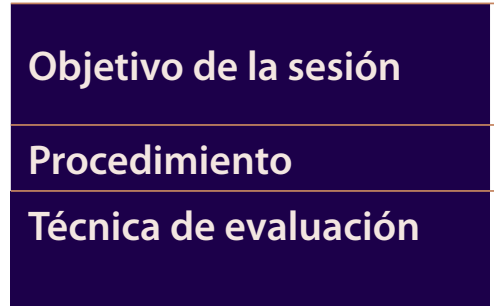

Inicio de sesión
El terapeuta evaluará los resultados del plan de acción.

El terapeuta evaluará el progreso del paciente con respecto a la intervención.

Plan de acción y Evaluación Post-Intervención.

Registro de plan de acción, reporte escrito, reporte verbal y evaluación (Batería de instrumentos).

Saludará al paciente.

Continuará con el rapport.

Recordará que es la última sesión de la intervención.

Mencionará que de ser necesario la intervención puede extenderse.

Realizará un resumen de la sesión anterior.

\section{Durante la sesión}

1. Objetivo: El paciente recibirá retroalimentación de los registros (tarea).

Actividades del terapeuta Examinará los registros realizados en casa.

Proporcionará retroalimentación sobre los registros.

Resolverá dudas.

Actividad del paciente Escuchará al terapeuta.

Realizará preguntas.

2. Objetivo: El paciente elaborará plan de acción.

Actividades del terapeuta Preguntará sobre la aplicación del plan de acción de la sesión pasada y sus resultados. Indagará si el paciente identificó otras barreras en la implementación de las técnicas.

En caso de haberlas identificado solicitará al paciente:

- Señalar las barreras identificadas.

- Realizar un plan de acción para cada barrera con base en el registro.

- Seleccionar una solución para cada barrera. 


\begin{tabular}{|c|c|}
\hline & $\begin{array}{l}\text { En caso de no haberlas identificado solicitará al paciente: } \\
\text { - Describir las condiciones en que implementó las técnicas en la última semana. } \\
\text { - Señalar las barreras durante la implementación de las técnicas. } \\
\text { - Realizar un plan de acción para cada barrera con base en el registro. } \\
\text { - Seleccionar una solución para cada barrera. } \\
\text { Resolverá dudas. }\end{array}$ \\
\hline Actividades del paciente & $\begin{array}{l}\text { Describirá el plan de acción implementado y sus resultados. } \\
\text { En caso de que haya identificado otras barreras: } \\
\text { - Señalará si identificó alguna otra barrera en la implementación de las técnicas. } \\
\text { - Elaborará un plan de acción de acuerdo con el registro para cada barrera. } \\
\text { - Seleccionará una solución para cada barrera. } \\
\text { En caso de no haber identificado otras barreras: } \\
\text { - Describirá las condiciones en que implementó las técnicas en la última semana. } \\
\text { - Señalará si identifica alguna otra barrera en la implementación de las técnicas. } \\
\text { - Elaborará un plan de acción de acuerdo con el registro para cada barrera. } \\
\text { - Seleccionará una solución para cada barrera. } \\
\text { Realizará preguntas. }\end{array}$ \\
\hline Criterio de cambio & $\begin{array}{l}\text { El paciente elaborará un plan de acción de al menos una situación barrera en la } \\
\text { implementación de técnicas. }\end{array}$ \\
\hline \multicolumn{2}{|c|}{ 3. Objetivo: El paciente describirá sus resultados en la evaluación pre y post de la intervención. } \\
\hline Actividades del terapeuta & $\begin{array}{l}\text { Aplicará instrumentos empleados al inicio (batería inicial). } \\
\text { Proporcionará una comparativa de los resultados pre y post de los instrumentos y del AFC. } \\
\text { Proporcionará retroalimentación de los resultados. } \\
\text { Realizará una gráfica con los datos de los registros (EVA y Pulso). } \\
\text { Brindará explicación y retroalimentación de la gráfica. } \\
\text { Resolverá dudas. } \\
\text { Solicitará al paciente la realización de un resumen de los resultados pre y post intervención. } \\
\text { Con base en los resultados, presentará la opción de agregar sesiones adicionales necesarias } \\
\text { o señalará el fin de la intervención. }\end{array}$ \\
\hline Actividades del paciente & $\begin{array}{l}\text { Contestará la batería de instrumentos. } \\
\text { Escuchará al terapeuta. } \\
\text { Realizará preguntas. } \\
\text { Realizará un resumen de los resultados obtenidos. } \\
\text { Tomará una decisión, en caso de que el terapeuta brinde la opción de agregar sesiones de } \\
\text { intervención. }\end{array}$ \\
\hline \multicolumn{2}{|c|}{ 4. Objetivo: El paciente identificará los elementos de la sesión. } \\
\hline Actividades del terapeuta & $\begin{array}{l}\text { Realizará un resumen de los resultados obtenidos. } \\
\text { Resolverá dudas. }\end{array}$ \\
\hline Actividades del paciente & $\begin{array}{l}\text { Escuchará al terapeuta. } \\
\text { Realizará preguntas. }\end{array}$ \\
\hline Cierre de sesión & $\begin{array}{l}\text { Recordará la decisión terapéutica tomada (sesiones adicionales }{ }^{1} \text { o terminación de } \\
\text { intervención) } \\
\text { Solicitará la realización de registros de tarea y la puesta en marcha de los planes de acción } \\
\text { Despedirá al paciente. }\end{array}$ \\
\hline
\end{tabular}


Tarea de casa
Realizará el ejercicio de respiración diafragmática o rítmica con autoinstrucciones ante un evento estresante.

Registrará diariamente la frecuencia cardiaca antes y después de cada ejercicio de respiración.

Registrará diariamente una EVA de relajación antes y después de cada de respiración.

Practicará los ejercicios de respiración en los momentos indicados previamente y ante las situaciones estresantes que se le presenten.

Pondrá en marcha el de plan de acción.

Nota: ' $\mathrm{Si}$ se termina la intervención: agradecerá al paciente su tiempo, agendará sesión de seguimiento, solicitará que conteste una encuesta de opinión sobre la intervención online y enviará la encuesta. ${ }^{2} \mathrm{Si}$ se añaden sesiones: indicará el plan para la siguiente sesión, agendará siguiente sesión de intervención y despedirá al paciente. Elaboración propia.

\section{Tabla 32}

\section{Carta descriptiva de seguimiento}

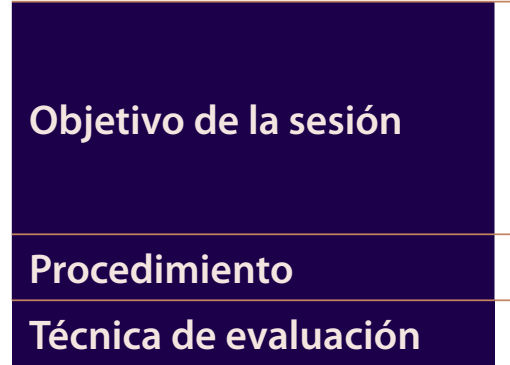

Inicio de sesión
El terapeuta realizará monitoreo.

El terapeuta evaluará el mantenimiento de la práctica de las técnicas en el paciente.

El terapeuta evaluará las dificultades y beneficios de la intervención para el paciente.

El terapeuta evaluará la incidencia de comorbilidades psicológicas.

Evaluación y plan de acción.

Reporte verbal, reporte escrito y evaluación (Batería de instrumentos).

Saludará al paciente.

Establecerá el rapport con una mayor duración.

Realizará un resumen de la intervención.

\section{Durante la sesión}

1. Objetivo: El paciente recibirá retroalimentación de los registros (tarea).

Actividades del terapeuta Examinará los registros realizados en casa.

Proporcionará retroalimentación sobre los registros.

Resolverá dudas.

Actividad del paciente

Escuchará al terapeuta.

Realizará preguntas.

2. Objetivo: El paciente identificará la importancia de los seguimientos.

Actividades del terapeuta Expondrá el objetivo y la relevancia continuar con los seguimientos y seguir monitoreando su respuesta ante el estrés.

Solicitará al paciente un resumen de lo expuesto.

Actividad del paciente Realizará un resumen de la importancia de los seguimientos y monitoreo de su actividad.

3. Objetivo: El paciente identificará los cambios que ha tenido en el desempeño del manejo de estrés.

Actividades del terapeuta Indagará sobre el manejo del estrés del paciente: síntomas de estrés e implementación de técnicas.

Aplicará al paciente batería de instrumentos empleados al inicio.

Brindará retroalimentación al desempeño del paciente.

- Si implementa las técnicas: reforzará y resaltará la importancia de continuar así. Continúa con la sesión.

- Si no utiliza las técnicas: invitará al proceso de nuevo. Indicará que el entrenamiento y la práctica requiere de más tiempo. Normalizará el necesitar más tiempo. Agendará sesión para intervención terapéutica.

- Si se presenta con elevada sintomatología de estrés se realiza la aplicación del protocolo de crisis. Agendará sesión para intervención terapéutica. 


\begin{tabular}{|c|c|}
\hline & $\begin{array}{l}\text { Cuestionará sobre las consecuencias del entrenamiento en el manejo de estrés. } \\
\text { Pudiendo usar las siguientes preguntas: ¿Cómo se siente al controlar su estrés? ¿Qué } \\
\text { beneficios y complicaciones ha tenido del entrenamiento? } \\
\text { Solicitará al paciente la elaboración de un resumen de los resultados pre, post intervención } \\
\text { y seguimiento. }\end{array}$ \\
\hline Actividad del paciente & $\begin{array}{l}\text { Contestará la batería de instrumentos. } \\
\text { Escuchará al terapeuta. } \\
\text { Responderá a las preguntas solicitadas por el terapeuta. } \\
\text { Indicará los cambios que ha generado el entrenamiento en el manejo de estrés. } \\
\text { Señalará las consecuencias de la intervención. } \\
\text { Realizará un resumen de los resultados obtenidos. }\end{array}$ \\
\hline Criterio de cambio & El paciente señalará al menos dos dificultades y beneficios del manejo de estrés. \\
\hline \multicolumn{2}{|c|}{ 4. Objetivo: El paciente realizará un plan de acción en caso de ser necesario. } \\
\hline Actividades del terapeuta & $\begin{array}{l}\text { Cuestionará la identificación de nuevas barreras que dificulten la implementación de las } \\
\text { técnicas. } \\
\text { Si identificó: } \\
\text { - Realizarán colaborativamente planes de acción para esas situaciones usando el registro. } \\
\text { Si no identificó: } \\
\text { - Solicitará la descripción de las condiciones ante la práctica de las técnicas en la } \\
\text { cotidianidad para encontrar barreras. } \\
\text { Si aún con la descripción no se identifican barreras: proseguirá con la sesión. } \\
\text { Reiterará la importancia del plan de acción respecto a las estrategias para el manejo de } \\
\text { estrés. }\end{array}$ \\
\hline Actividades del paciente & $\begin{array}{l}\text { Escuchará al terapeuta. } \\
\text { Señalará si identificó otra barrera en la implementación de las técnicas. } \\
\text { Si las identificó: } \\
\text { - Realizará un plan de acción haciendo uso del registro para cada barrera junto con el } \\
\text { terapeuta. } \\
\text { - Elegirá una solución para cada barrera. } \\
\text { Si no las identifica: } \\
\text { - Especificará las condiciones en que practica las técnicas. } \\
\text { Indicará si identifica más barreras en la implementación de las técnicas. }\end{array}$ \\
\hline \multicolumn{2}{|c|}{ 5. Objetivo: El paciente identificará los elementos abordados en el seguimiento. } \\
\hline Actividades del terapeuta & $\begin{array}{l}\text { Solicitará al paciente un resumen de la sesión de seguimiento. } \\
\text { Realizará un breve resumen de lo abordado durante el seguimiento. } \\
\text { Resolverá dudas. }\end{array}$ \\
\hline Actividades del paciente & $\begin{array}{l}\text { Realizará un resumen de la sesión. } \\
\text { Escuchará al terapeuta. } \\
\text { Realizará preguntas. }\end{array}$ \\
\hline Cierre de sesión & $\begin{array}{l}\text { Solicitará el llenado de registros e implementación de planes de acción y despedirá al } \\
\text { paciente. } \\
\text { - Si se continua con seguimiento: agendará el siguiente y reiterará que puede solicitar } \\
\text { atención antes dentro de los horarios establecidos. } \\
\text { - Si requiere intervención: programará la sesión en los horarios establecidos. }\end{array}$ \\
\hline
\end{tabular}




Tarea de casa
evento estresante.
Registrará diariamente la frecuencia cardiaca antes y después de cada ejercicio de
respiración.
Registrará diariamente una EVA de relajación antes y después de cada de respiración.
Practicará los ejercicios de respiración en los momentos indicados previamente y ante las
situaciones estresantes que se le presenten.
Pondrá en marcha el plan de acción.

Nota: Si en algún momento de la intervención el paciente acude con una elevada sintomatología de estrés, el terapeuta aplicará el protocolo de intervención en crisis. Elaboración propia. 


\section{Referencias}

Abaroa, M. F., González, A., Ortega, A. Reyes, E. L., \& Reynoso, L. (2020). Desarrollo de un nuevo instrumento: Breve Checklist de Afrontamiento. Eureka, 17(2), 7-24.

Ali, B. A., Abdallah, S. T., Abdallah, A. M., \& Hussein, M. M. (2013). The frequency of type 2 diabetes mellitus among diabetic children in El Minia Governorate, Egypt. Sultan Qaboos University Med J, 13(3), 399-403.

Aljawarneh, Y. M., Al-Qaissi, N. M., \& Ghunaim, H. Y. (2020). Psychological interventions for adherence, metabolic control, and coping with stress in adolescents with type 1 diabetes: a systematic review. World Journal of Pediatrics, 16, 456-470. https://doi. org/10.1007/s12519-020-00352-6

Alvárez, A., \& Bucay, L. (2018). Modelo de tamizaje, atención y monitoreo de la salud mental para adultos en casos de desastre. Salud Pública México, 60 (supl.1), S24-S30. https:// doi.org/10.21149/9340

American Diabetes Association (ADA). (2015). Mitos sobre la diabetes. Recuperado de http:// archives.diabetes.org/es/informacion-basica-de-la-diabetes/mitos/

American Diabetes Association (ADA). (2019a). Diabetes Overview - Symptoms, Causes, Treatment. Recuperado de https://www.diabetes.org/diabetes

American Diabetes Association (ADA). (2019b). DKA (Ketoacidosis) \& Ketones. Recuperado de https://www.diabetes.org/diabetes/complications/dka-ketoacidosis-ketones

American Diabetes Association (ADA). (2019c). Hyperglycemia (High Blood Glucose). Recuperado de https://www.diabetes.org/diabetes/medication-management/bloodglucose-testing-and-control/hyperglycemia

American Diabetes Association (ADA). (2019d). Hypoglycemia (LowBlood Glucose). Recuperado de https://www.diabetes.org/diabetes/medication-management/blood-glucosetesting-and-control/hypoglycemia

American Diabetes Association (ADA). (2019e). Medication Management. Recuperado de https://www.diabetes.org/diabetes/medication-management

American Psychological Association (APA). (2014). Guidelines for Clinical Supervision in Health Service Psychology. Washington, DC: APA. Recuperado de http://apa.org/about/policy/ guidelines-supervision.pdf 
Anguiano, S. (2014). El tratamiento de la Diabetes Mellitus tipo 2 en el campo de la Medicina Conductual. En L. Reynoso \& A. L. Becerra (Coords.), Medicina Conductual: teoría y práctica (pp. 147-164). México: Qartuppi. https://doi.org/10.29410/QTP.14.01

Anguiano, S., Mora, M. M., Reynoso, E. L., \& Vega, V. C. (2017). Prevalencia de ansiedad y depresión en pacientes hospitalizados. Eureka, 14(1), 24-38. http://psicoeureka.com. py/sites/default/files/articulos/eureka-14-1-9.pdf

Association of State and Provincial Psychology Boards (ASPPB). (2015). ASPPB Supervision Guidelines for Education and Training leading to Licensure as a Health Service. Georgia: ASPPB. Recuperado de https://cdn.ymaws.com/www.asppb.net/resource/resmgr/ guidelines/supervision_guidelines_for_h.pdf

Ayala, H., Reyes-Lagunes, I., Macotela, S., Acle, G., Vázquez, F., Seligson, I., \& Reynoso, L., (1998). Proyecto de adecuación del Programa de maestría y doctorado en psicología.

Bados, A., \& García, E. (2009). El proceso de evaluación y tratamiento. Facultat de Psicologia Departament de Personalitat, Avaluació i Tractament Psicològics. Recuperado de $\quad$ http://diposit.ub.edu/dspace/bitstream/2445/9893/1/Proceso\%20de\%20 intervenci\%C3\%B3n.pdf

Bados, A., \& García, E. (2011). Habilidades terapéuticas. Facultat de Psicologia Departament de Personalitat, Avaluació i Tractament Psicològics. Recuperado de http://diposit.ub.edu/ dspace/handle/2445/18382

Bandura, A. (1977). Self-efficacy:Toward a unifying theory of behavioral change. Psychological Review, 84,191-215.

Barba, J. R. (2019). Diabetes: epidemic or pandemic? Revista Mexicana de Patología Clínica y Medicina de Laboratorio, 65(4), 211-221. Recuperado de https://www.medigraphic. com/cgi-bin/new/resumenl.cgi?IDARTICULO $=85082$

Barrios, B. A. (1998). On the changing nature of behavioral assessment. En A.S. Bellack \& M. Hersen (Eds.), Behavioral Assessment. A practical handbook (pp. 3-41). Nueva York: Pergamon.

Beck, A. T. (1976). Cognitive therapy and the emotional disorders. New York: International Universities Press.

Ben-Zur,H. (2019).Transactional model of stress and coping. EnV.Zeigler-Hill, \&T.K.Shackelford (Eds.), Encyclopedia of Personality and Individual Differences. Switzerland: Springer.

Björntorp, P. (1991). Visceral fat accumulation: the missing link between psychosocial factors and cardiovascular disease? Journal of Internal Medicine, 230(3), 195-201. https://doi. org/10.1111/j.1365-2796.1991.tb00431.x

Björntorp, P. (1997). Body fat distribution, insulin resistance, and metabolic diseases. Nutrition, 13(9), 795-803. https://doi.org/10.1016/s0899-9007(97)00191-3 
Borba, A. K. de O.T., Marques, A. P. de O., Ramos, V.P., Leal, M.C.C., Arruda, I. K. G., \& Ramos, R. S. P. da S. (2018). Factors associated with elderly diabetic adherence to treatment in primary health care. Ciência \& Saúde Coletiva, 23(3), 953-961. https://doi.org/10.1590/141381232018233.03722016

Boronat, C. M., \& Wägner, M. A. (2016). Protocolo diagnóstico etiológico de la diabetes. Enfermedadesendocrinológicasymetabólicas, 12(17).982-986. https://doi.org/10.1016/j. med.2016.09.005

Boyer, J. G., \& Earp, J. A. L. (1997). The development of an instrument for assessing the quality of life of people with diabetes: Diabetes-39. Medical Care, 35(5), 440-453. https://doi. org/10.1097/00005650-199705000-00003

Bravo, M. (2014). Generalidades psicológicas de los padecimientos crónico- degenerativos. En L. Reynoso \& A. L. Becerra (Coords.), Medicina conductual: Teoría y práctica (pp. 4364). México: Qartuppi. https://doi.org/10.29410/QTP.14.01

Bravo, M., \& Valadez, A. (2013). Solución de Problemas. En P. Valladares \& A. Rentería (2013), Psicoterapia cognitivo-conductuales. Técnicas y procedimientos (pp. 89-132). México: UNAM-FESI.

Bravo, M., \& Mora, M. (2014). Análisis Funcional y diseño de intervención en el ámbito hospitalario. En L. Reynoso \& A. L. Becerra (Coords.), Medicina Conductual: teoría y práctica (pp. 101-128). México: Qartuppi. https://doi.org/10.29410/QTP.14.01

Caballo,V.(1998).Manualparael tratamientocognitivo-conductualdelos trastornospsicológicos. Formulación clínica, medicina conductual y trastornos de relación. España: Siglo XXI.

Caballo, V. E., \& Anguiano, S. A. (2002). Estrés, estilos de personalidad y contratiempos contidianos. En L. Reynoso \&I. Seligson (Coords.), Psicología y salud (pp. 71-104). México: Universidad Nacional Autónoma de México.

Campero, M. A., \& Ferraris, L. (2014). La psicoeducación como herramienta estratégica en el abordaje de la patología mental en el dispositivo de guardia. Revista del Hospital Interzonal General de Agudos (HIGA), Eva Perón, 4(2), 52-55. Recuperado de https://www.semanticscholar.org/paper/Lapsicoeducaci\%C3\%B3n-como-herramienta-estrat\%C3\%A9gica-en-Campero-Ferraris/ b6d2764172cda9924d459108d02aac57fc8da7b0

Cano, F. J., Rodríguez, L., \& García, J. (2007). Adaptación española del Inventario de Estrategias de Afrontamiento. Actas Españolas de Psiquiatría, 35(1), 29-39. Recuperado de https:// fjcano.info/images/test/CSI_art_esp.pdf

Cárdenas, I. (2013). Criterios para seleccionar tecnologías educativas y estrategias didácticas, en el colegio Guillermo León Valencia. Educación y Ciencia, (16), 37-52. https://doi. org/10.19053/01207105.3239 
Carpenter, R., DiChiacchio, T., \& Barker, K. (2019). Interventions for self-management of type 2 diabetes: An integrative review. International Journal of Nursing Sciences, 6(1), 70-91. https://doi.org/10.1016/j.ijnss.2018.12.002

Casado, M., \& Laguna-Bonilla, S. (2017). Trastorno de síntomas somáticos: de la sospecha de simulación al tratamiento cognitivo-conductual. Clínica y Salud, 28(3), 131-138. https:// doi.org/10.1016/j.clysa.2017.05.004

Castro-Meza, A. N., Pérez-Zumano, S. E., \& Salcedo-Álvarez, R. A. (2017). La enseñanza a pacientes con diabetes: significado para profesionales de enfermería. Enfermería Universitaria, 14(1), 39-46. https://doi.org/10.1016/j.reu.2016.12.003

Castro, C., Rico, H., \& Padilla, R. (2014). Efecto del apoyo educativo para la adherencia al tratamiento en pacientes con diabetes tipo 2: un estudio experimental. Enfermería Clínica, 24(3), 162-167. Recuperado de http://www.sciencedirect.com/science/article/ pii/S1130862113001745

Cea, J. I., González-Pinto, A., \& Cabo, O. M. (2015). Efectos de la respiración controlada sobre los síntomas de estrés y ansiedad en una población de 55 a 65 años: estudio piloto. Gerokomos, 26(1), 18-22. https://doi.org/10.4321/s1134-928x2015000100005

Cepeda, M., López, M., Plancarte, P., Moreno, D., \& Alvarado, I. (2014). El proceso de investigación. Medición y observación. México: Universidad Nacional Autónoma de México. Facultad de Estudios Superiores Iztacala.

Chang, E. Y. Y., \& Wong, C. S. (2020). Public Health Prevention Hierarchy in Disaster Context. In E. Y. Y. Chang \& R. Shaw (Eds.), Public Health and Disasters. Health Emergency and Disaster Risk Management in Asia (pp. 7-17). United Kingdom: Springer. https://doi. org/10.1007/978-981-15-0924-7

Coffin, N., \& Salinas, J. L. (2018). Técnicas de relajación y meditación. En P. Valladares \& A. Rentería (2013), Psicoterapia cognitivo-conductuales. Técnicas y procedimientos ( $\mathrm{pp}$. 1-58). México: UNAM-FESI.

Cohen, S., Kamarck, T., \& Mermelstein, R. (1983). A global measure of perceived stress. Journal of health and social behavior, 24(4), 385-396. https://doi.org/10.2307/2136404

Colom, F. (2011). Psicoeducación, el litio de las psicoterapias. Algunas consideraciones sobre su eficacia y su implementación en la práctica diaria. Revista Colombiana de Psiquiatría, 40, 147-165. https://doi.org/10.1016/S0034-7450(14)60200-6

Consejo General de la Psicología (2017). Guía para la práctica de la telepsicología. España: CGP. https://doi.org/10.23923/cop.telepsicologia.2017

Copeland, K. C., Silverstein, J., Moore, K. R., Prazar, G. E., Raymer, T., Shiffman, R. N., Springer, S. C., Thaker, V. V., Anderson, M., Spann S. J., \& Flinn, S.K. (2013). Management of newly diagnosed type 2 diabetes mellitus (T2DM) in children and adolescents. Pediatrics, 131(2), 364-382. 
Cormier, W. H., \& Cormier, L. S. (1994). Estrategias de entrevista para terapeutas: habilidades básicas e intervenciones cognitivo conductuales. Bilbao: Desclée de Brouwer.

Craig, M. E., Femia, G., Broyda, V., Lloyd, M., \& Howard, N. J. (2007). Type 2 diabetes in Indigenous and non-Indigenous children and adolescents in New South Wales. Medical Journal of Australia, 186(10), 497-499.

Crespo, O., \& Cruzado, E. (2008). Evaluación psicológica del dolor. Clínica y Salud, 19(3), 321341. Recuperado de https://www.redalyc.org/pdf/1806/180617473004.pdf

Cuevas, C. J., \& Moreno, P. E. (2017). Psicoeducación: intervención de enfermería para el cuidado de la familia en su rol de cuidadora. Enfermería Universitaria, 14(3), 207-218. https://doi.org/10.1016/j.reu.2017.06.003

D'Zurilla, J., \& Nezu, M. (1999). Problem-Solving Therapy: A social competence approach to clinical intervention. New York: Springer.

Dahab, J., Minici, A., \& Rivadeneira, C. (2016). Técnicas conductuales para la modificación de cogniciones. Revista de terapia cognitivo conductual, (29), 1-10. Recuperado de http://cetecic.com.ar/revista/pdf/tecnicas-conductuales-para-la-modificacion-decogniciones.pdf

Dattilio, F. M., \& Freeman, A. (2000). Cognitive behavioral strategies in crisis intervention. New York: Guilford.

Dewey, M. (1984). Relaxation techniques for stress management. Critical Care Nurse, 4(1), 7779. https://doi.org/10.4037/ccn1984.4.1.77

De la Torre, M., \& Pardo, R. (2018). Guía para la intervención telepsicológica. Madrid: Colegio Oficial de Psicólogos de Madrid. Recuperado de https://www.copmadrid.org/web/ publicaciones/guia-para-la-intervencion-telepsicologica

Díaz, L., \& Delgado, E. (2016). Diabetes mellitus. Criterios diagnósticos y clasificación. Epidemiología. Etiopatogenia. Evaluación inicial del paciente con diabetes. Medicine - Programa de Formación Médica Continuada Acreditado, 12(17), 935-946. https://doi. org/10.1016/j.med.2016.09.001

Dongil-Collado, E. (2008). Reestructuración cognitiva, un caso de estrés postraumático. Ansiedad y estrés, 14(2), 265-288. Recuperado de https://www.researchgate. net/publication/233865433_Reestructuracion_cognitiva_Un_caso_de_estres_ postraumatico

Doward, L., \& McKenna, S. (2004). Defining Patient-Reported Outcomes. Value in Health, 7(7), S4-S8. https://doi.org/10.1111/j.1524-4733.2004.7s102

Fazeli, S., van der Aa, M. P., van der Vorst, M. M. J., Knibbe, C. A. J., \& de Boer, A. (2013). Global trends in the incidence and prevalence of type 2 diabetes in children and adolescents: a systematic review and evaluation of methodological approaches. Diabetologia, 56(7), 1471-1488. 
Flores, L., Cárdenas, G., Durán, X., \& De la Rosa, A. (2014). Psicoterapia vía internet: aplicación de un programa de intervención cognitivo conductual para pacientes con depresión. Psicología Iberoamericana, 22(1), 7-15. Recuperado de https://www.redalyc.org/ pdf/1339/133944229002.pdf

Folkman, S., Lazarus, R., Dunkel-Schetter, C., DeLongis, A., \& Gruen, R. (1986). Dynamics of a stressful encounter: cognitive appraisal, coping, and encounter outcomes. Journal of Personality and Social Psychology, 50(5), 992-1003.

Fraga, M. A., \& Valles, A. M. (2019). Historia natural de la enfermedad. En A. M. Valles (Ed.), Modelos y teorías de salud pública (pp. 31-38). México: Universidad Autónoma de Baja California. Recuperado de https://www.researchgate.net/profile/Ana_ Valles-Medina/publication/339662890_Modelos_y_Teorias_de_Salud_Publica/ enlaces/5e5eba32a6fdccbeba1826a7/Modelos-y-Teorias-de-Salud-Publica. pdf\#page $=31$

Frankel, N., \& Gage, A. (2009). Fundamentos de monitoreo y evaluación. Cursillo autodirigido. MEASURE Evaluation. Recuperado de https://www.measureevaluation.org/resources/ publications/ms-07-20-es

Galindo, O., Benjet, C., Juárez, F., Rojas, E., Riveros, A., Aguilar, J., Álvarez, M., \& Alvarado, S. (2015). Propiedades psicométricas de la Escala Hospitalaria de Ansiedad y Depresión (HADS) en una población de pacientes oncológicos mexicanos. Salud Mental, 38(4), 253-258. https://doi.org/10.17711/sm.0185-3325.2015.035

García, E., Fusté, A., \& Bados, A. (2011). Manual de entrenamiento en respiración. Barcelona: Universitat de Barcelona. Recuperado de http://www. ttmib.org/documentos/ ENTRENAMIENTO_EN_RESPIRACION.pdf

García-Cedillo, C., Guillén, C., Martínez, Y., \& Sánchez-Armáss, A. (2017). Promoción de la adherencia terapéutica de mujeres con obesidad mediante psicoeducación. Psychologia. Avances de la disciplina, 11(1), pp. 13-23. Recuperado de https://www. redalyc.org/pdf/2972/297251403001.pdf

Garyfallos, G., Adamopoulou, A., Karastergious, A., Voikli, M., Zlatanos, D., \& Tsifida, S. (2002). Evaluación de los resultados de la Terapia Cognitivo-analítica: Un Seguimiento de 4 a 8 años. The European Journal of Psychiatry (Edición En Español), 16(4), 189-203. Recuperado de http://scielo.isciii.es/scielo.php?script=sci_arttext\&pid=S1579699X2002000400001

Gavino, A., L. (2006). Guía de Técnicas de terapia de Conducta. España: Pirámide.

Ghosh, S., \& Verma, K. (2018). Stress and its effect on noncommunicable disease: An insight. Journal of Social Health and Diabetes, 6(1), 15-21. https://doi. org/10.1055/s-0038-1676191

Golan, N. (1978). Treatment in crisis situations. New York: Free Press. 
González, M. T., \& Landero, R. (2007). Factor structure of Perceveid Stress Scale (PSS) in a sample from Mexico. The Spanish Journal of Psychology, 10(1), 199-206.

González-Cantero, J., \& Oropeza-Tena, R. (2016). Intervenciones cognitivo conductuales para diabéticos en México. Salud Mental, 39(2), 99-105. https://doi.org/10.17711/sm.01853325.2016.006

González-Peña, P., Torres, R., Barrio, V., \& Olmedo, M. (2017). Uso de las nuevas tecnologías por parte de los psicólogos españoles y sus necesidades. Clínica y Salud, 28(2), 81-91. https://doi.org/10.1016/j.clysa.2017.01.001

Granda, A. B., \& Saez, R. B. (2000). Manual de Relajación. Lima, Perú: Organización Panamericana de la Salud.

Gutiérrez, M. (2020). Propuesta de atención para los servicios de psicoterapia en línea (telepsicoterapia) derivados del COVID-19 en México. Psicología y Salud, 30(1), 133136. Recuperado de https://psicologiaysalud.uv.mx/index.php/psicysalud/article/ view/2640

Hannon, T. S. Rao, G., \& Arslanian, S.A. (2005). Childhood Obesity and Type 2 Diabetes Mellitus. Pediatrics, 116(2), 473-480.

Haynes, S., N., \& O'Brien, W. H. (1990). Functional analysis in behavioral therapy. Clinical Psychology Review, 10(6), 649-668. https://doi.org/10.1016/0272-7358(90)90074-K

Heber, E., Ebert, D. D., Lehr, D., Cuijpers, P., Berking, M., Nobis, S., \& Riper, H. (2017). The Benefit of Web- and Computer-Based Interventions for Stress: A Systematic Review and MetaAnalysis. Journal of Medical Internet Research, 19(2), e32. https://doi.org/10.2196/ jmir.5774

Helgeson, V. S., Naqvi, J. B., Seltman, H., Vaughn, A. K., Korytkowski, M., Hausmann, L. R. M., \& Gary-Webb, T. L. (2020). Enlaces of communal coping to relationship and psychological health in type 2 diabetes: actor-partner interdependence models involving role, sex, and race. Annals of Behavioral Medicine, 54, 346-359. https://doi.org/10.1093/abm/ kaz052

Herrera, D., Coria, G., Muñoz, D., Graillet, O., Aranda, G., Rojas, F., Hernández, M. E., \& Nafissa, I. (2017). Impacto del estrés psicosocial en la salud. Neurobiología (Revista electrónica). Recuperado de https://www.uv.mx/eneurobiologia/vols/2017/17/Herrera/HTML.html

Horne, R., \& Hankins, M. (2002). The Medication Adherence Report Scale. Brighton, UK: Center for Health Care Research.

Ibáñez-Tarín, C., \& Manzanera-Escartí, R. (2012). Técnicas cognitivo-conductuales de fácil aplicación en atención primaria (I).SEMERGEN, 38(6),377-387.https://doi.org/10.1016/j. semerg.2011.07.019

Institute of Health Metrics and Evaluation (IHME). (2013). GBD Compare | Viz Hub. Recuperado de https://vizhub.healthdata.org/gbd-compare/ 
Instituto Nacional de Estadística y Geografía (INEGI). (2016). Estadística de mortalidad. Recuperado de https://www.inegi.org.mx/programas/mortalidad/

Instituto Nacional de Estadística y Geografía (INEGI). (2020, April 14). Mortalidad general. Recuperado de https://www.inegi.org.mx/sistemas/olap/Proyectos/bd/continuas/ mortalidad/MortalidadGeneral.asp?

International Diabetes Federation (IDF). (2017). Atlas de diabetes de la FID. Recuperado de http://fmdiabetes.org/atlas-idf-2017/

International Diabetes Federation (IDF). (2020, May 7). Mexico. Recuperado de https://idf.org/

our-network/regions-members/north-america-and-caribbean/members/66-mexico. html

Ivey, A., \& Ivey, M. B. (1999). Intentional interviewing and counseling. New York: Brooks/Cole. Jenicek, M. (1996). Epidemiología: La lógica de la medicina moderna. España: Masson. Joint Task Force for the Development of Telepsychology Guidelines for Psychologists. (2013). Guidelines for the practice of telepsychology. American Psychologist, 68(9), 791-800. https://doi.org/10.1037/a0035001

Kaholokula, J., Bello, I., Nacapoy, A., \& Haynes, S. (2009). Behavioral assessment and functional analysis. En D. Richard \& S. Huprich (Eds.), Clinical Psychology: Assessment, Treatment, and Research (pp.114-138). Massachusetts: Elsevier Academic Press.

Kaholokula, J., Godoy, A., O’Biren, W., Haynes, S., \& Gavino, A. (2013). Análisis funcional en evaluación conductual y formulación de casos clínicos. Clínica y Salud, 24(2), 117-127. https://doi.org/10.5093/cl2013a13

Kanfer, F. H., \& Saslow, G. (1969). Behavioral diagnosis. En C. Franks (Comp.), Behavior Therapy: Appraisal and status (pp. 417-444). New York: McGraw-Hill.

Kasper, D. L., Fauci, A. S., Hauser, S. L., Longo, D. L., Jameson, J. L., \& Loscalzo, J. (2017). Harrison. Manual de Medicina, 19e. México: McGraw-Hill Medical.

Kazdin, M. (1996). Modificación de conducta y sus aplicaciones prácticas. México: Manual Moderno.

Kim, H., Cheon, E., Bai, D., Lee, Y., \& Koo, B. (2018). Stress and Heart Rate Variability: A MetaAnalysis and Review of the Literature. Psychiatry Investigation, 15(3), 235-245. https:// doi.org/10.30773/pi.2017.08.17

Klandorf, H., \& Stark, S. (2019). Diabetes Mellitus. Magill's Medical Guide (Online Edition). Recuperadodehttps://learning.stacksdiscovery.com/eds/detail?db=ers\&an=86194054 Labrador, F. (2011). Situaciones difíciles en terapia. España: Pirámide.

Labrador, F. J., Cruzado, T., \& Muñoz, M. (1995). Manual de técnicas de modificación y terapia de la conducta. España: Pirámide.

Labrador, F. J., de Arce, F., \& Florit, A. (1996). Entrenamiento en respiración frente a entrenamiento en relajación: Diferencias en medidas psicofisiológicas. Análisis y Modificación de Conducta, 22(81), 93-114. Recuperado de https://dialnet.unirioja.es/ servlet/articulo?codigo $=7072229$ 
Larios, F. E., González, L. P., Montes, R., González-Betanzos, F., Morán-Mendoza, A., SolanoMurillo, P., Oceguera, A., Montero-Ramírez, M., \& Daneri-Navarro, A. (2019). Eficacia de las técnicas de relajación en la disminución de tensión, ansiedad y estrés percibidos por pacientes con cáncer bajo tratamiento de quimioterapia. Gaceta Mexicana de Oncología, 17(2), 42-47. https://doi.org/10.24875/j.gamo.m18000138

Lazarus, A.A. (1992). The multimodal approach to the treatment of minor depression. American Journal of Psychotherapy, 46(1), 50-57. https://doi.org/10.1176/appi. psychotherapy.1992.46.1.50

Lazarus, R. S. (2000). Toward better research on stress and coping. American Psychologist, 55(6), 665-73.

Lazarus, R. S., \& Folkman, S. (1984). Stress, appraisal, and coping. New York: Springer.

Leavell, H. R., \& Clark, E. G. (1958). Preventive medicine for the doctor in his community. An epidemiologic approach. New York: McGraw-Hill.

Leiva, A. M., Martínez, M. A., Petermann Rocha, F., Garrido, A., Poblete, F., Díaz, X., \& Celis, C. (2018). Factores asociados al desarrollo de diabetes mellitus tipo 2 en Chile. Nutrición Hospitalaria, 35(2), 249-502. https://doi.org/10.20960/nh.1434

Liese, A. D., Ma, X., Maahs, D. M., \& Trilk, J. L. (2013). Physical activity, sedentary behaviors, physical fitness, and their relation to health outcomes in youth with type 1 and type 2 diabetes: A review of the epidemiologic literature. Journal of Sport and Health Science, 2(1), 21-38.

López, J. M., \& Rodríguez, R. (2006). Adaptación y validación del instrumento de calidad de vida Diabetes 39 en pacientes mexicanos con diabetes mellitus tipo 2. Salud pública de México, 48(3), 200-211. Recuperado de http://www.scielo.org.mx/scielo.php?script=sci_ arttext\&pid=S0036-36342006000300004

Lugo, I. V., \& Vega, C. Z. (2020). Propiedades psicométricas de la Medication Adherence Report Scale-Asthma en adultos asmáticos mexicanos. Psicología y Salud, 30(2), 275285. https://doi.org/10.25009/pys.v30i2.2663

Lugo, I., Pérez, Y., \& Sánchez, C. (2018). Validación de la escala de ansiedad y depresión hospitalaria en pacientes con ERC en hemodiálisis. En R. Díaz, L. Reyes, \& F. López (Eds.), Aportes actuales a la psicología social. Volumen IV (1209-1225). México: Amepso.

Marinho, M. L., Caballo, V. E., \& Silveira, J. M. (2003). Cuestiones olvidadas en la terapia conductual: las habilidades del terapeuta. Psicología Conductual, 11, 135-161.

Marrow, C. E., Hollyoake, K., Hamer, D., \& Kenrick, C. (2002). Clinical supervision using video conferencing technology: A reflective account. Journal of Nursing Management, 10(5), 275-282. https://doi.org/10.1046/j.1365-2834.2002.00313.x

Martí, M. T., Gallego, J., Pellisa, T., López, G., \& Nolla, S. (2011). Entrenamiento en técnicas de relajación en pacientes sometidos a cirugía urológica. Enfuro, (117), 16-18. 
Medina, M. A., Chávez, M. E., López, F. Félix, V., Gordillo, T., \& Morales, S. (2012). Manual del Terapeuta para la Aplicación de la Intervención Breve para Usuarios de Marihuana. México: Secretaría de Salud.

Meichenbaum, D. (1977). Cognitive behaviour modification. Cognitive Behaviour Therapy, 6(4), 185-192. https://doi.org/10.1007/978-1-4757-9739-8

Meichenbaum, D. (2002). Manual de inoculación de estrés. Barcelona: Martínez Roca.

Mendoza, M. A. (2017). Teaching and Motivating Patients to Achieve Treatment Goals. En L. Poretsky (Ed.), Principles of Diabetes Mellitus (pp. 823-842). New York: Springer International Publishing.

Mezitis, N. H. E., \& Mezitis, S. G. E. (2017). Glycemic Goals. En L. Poretsky (Ed.), Principales of Diabetes Mellitus (pp. 823-842). New York: Springer International Publishing.

Migues, M., Vázquez, F., \& Becoña, E. (2000). El consejo telefónico aplicado al tratamiento de fumadores. Adicciones, 12(2), 235-243.

Mira, J. (2000). La satisfacción del paciente como una medida del resultado de la atención sanitaria. Med Clin (Barc), 114(2000), 26-33. Recuperado de http://calite-revista.umh.es/ extras/28-03-06-satisfaccion_paciente.pdf

Mochari-Greenberger, H., Vue, L., Luka, A., Peters, A., \& Pande, R. L. (2016). A Tele-Behavioral Health Intervention to Reduce Depression, Anxiety, and Stress and Improve Diabetes Self-Management. Telemedicine Journal and E-Health:The Official Journal of the American Telemedicine Association, 22(8), 624-630. https://doi.org/10.1089/tmj.2015.0231

Montiel, C. V., \& Guerra, M. V. (2016). Aproximaciones teóricas sobre psicoeducación. Análisis de su aplicación en mujeres con cáncer de mama. Psicogente, 9(36), 324-335. https:// doi.org/ 10.17081/psico.19.36.1301

Mooy, J. M., de Vries, H., Grootenhuis, P. A., Bouter, L. M., \& Heine, R. J. (2000). Major stressful life events in relation to prevalence of undetected type 2 diabetes: the Hoorn Study. Diabetes Care, 23(2), 197-201. https://doi.org/10.2337/diacare.23.2.197

Moral, J., \& Cázares, F. (2014). Validación de la escala de estrés percibido (PSS-14) en la población de dentistas colegiados de Monterrey: validación de la escala de estrés percibido. Ansiedad y Estrés, 20(2-3), 193-209.

Morales, T., Alfaro, O., Sánchez, S., Guevara, U., \& Vázquez, F. (2007). Ansiedad y depresión por dolor crónico neuropático y nociceptivo. Revista Médica del Instituto Mexicano del Seguro Social, 46(5), 479-484. Recuperado de https://www.redalyc.org/ pdf/4577/457745523004.pdf

Mulder, M., Ranchor, A.V., Sanderman, R., Bouma, J., \& van den Heuvel, W. J. (1998). The stability of lifestyle behaviour. International Journal of Epidemiology, 27(2), 199-207. https://doi. org/10.1093/ije/27.2.199

Myer, R. A., \& Conte, C. (2006). Assessment for Crisis Intervention. Journal of Clinical Psychology: In Session, 62(8), 959-970. https://doi.org/10.1002/jclp.20282 
Myers, S. B., Endres, M. A., Ruddy, M. E., \& Zelikovsky, N. (2012). Psychology graduate training in the era of online social networking. Training and Education in Professional Psychology, 6(1), 28-36. https://doi.org/10.1037/a0026388

National Institute of Diabetes and Digestive and Kidney Diseases (NIDDK). (2019, August 5). Síntomas y causas de la diabetes. Recuperado de https://www.niddk.nih.gov/healthinformation/informacion-de-la-salud/diabetes/informacion-general/sintomas-causas

Nava, C., Ollua, P., Vega, C. Z., \& Soria, R. (2010). Inventario de Estrategias de Afrontamiento: una replicación. Psicología y Salud, 20(2), 213-220. https://doi.org/10.25009/pys.v20i2.604

Nelson, R. O., \& Hayes, S. C. (1986). Conceptual Foundations of Behavioral Assessment. Nueva York: Guilford Press.

Nezu, A., \& Nezu, C. (1991). Entrenamiento en solución de problemas. En V. Caballo (Dir.), Manual de Técnicas de Terapia y Modificación de Conducta (pp. 527-553). Madrid: Siglo XXI.

Nezu, A., Nezu, C., \& D'Zurilla, T. (2013). Problem-Solving Therapy. A Treatment Manual. New York: Springer.

Nickelson, D. (1998). Telehealth and the evolving health care system: Strategic opportunities for professional psychology. Professional Psychology: Research and Practice, 29(6), 527535. https://doi.org/10.1037/0735-7028.29.6.527

Norelli, K., \& Krepp, M. (2019). Relaxation techniques. Florida: Stat Pearls. https://europepmc. org/article/NBK/NBK513238

Organización Mundial de la Salud (OMS). (2003). Adherencia a los tratamientos a largo plazo. Pruebas para la acción. Suiza: OMS. Recuperado de https://www.paho.org/hq/ dmdocuments/2012/WHO-Adherence-Long-Term-Therapies-Spa-2003.pdf

Organización Mundial de la Salud (OMS). (2016). Estrategia mundial sobre régimen alimentario, actividad física y salud. Actividad física. Recuperado de http://www.who. int/dietphysicalactivity/pa/es/

Organización Panamericana de la Salud (OPS)/Organización Mundial de la Salud (OMS). (2017). Manual para el cuidado de personas con enfermedades crónicas no transmisibles: manejo integral en el primer nivel de atención. Suiza: OMS. Recuperado de https://iris.paho.org/bitstream/handle/10665.2/34520/9789503802397_spa. pdf? sequence $=1$ \&isAllowed $=y$

Organización Mundial de la Salud (OMS). (2020, June 8). Diabetes. Recuperado de https:// www.who.int/es/news-room/fact-sheets/detail/diabetes

Ortega, A., \& Salanova, M. (2016). Evolución de los modelos sobre el afrontamiento del estrés: hacia el coping positivo. Agora de salut, 3(30), 285-293. https://doi.org/10.6035/ AgoraSalut.2016.3.30 
Pagnini, F. S., Manzoni, G, M., Castelnuovo, G., \& Molinari, E. (2010). The efficacy of relaxation training in treating anxiety. International Journal of Behavioral Consultation and Therapy, 5(3-4), 264-269. https://doi.org/10.1037/h0100887

Payne, R. A. (2009). Técnicas de relajación: guía práctica para el profesional de la salud. México: Paidotribo.

Pedraza-Banderas, G. L., \&Valero, C. Z.V. (2018). Versión actualizada de la escala de adherencia terapéutica. Revista Digital Internacional de Psicología y Ciencia Social, 4(2), 214-232. https://doi.org/10.22402/j.rdipycs.unam.4.2.2018.186.214-232

Perpiña, C. (2012). Manual de la entrevista psicológica. Saber escuchar, saber preguntar. España: Pirámide.

Petrie, K. J., \& Jones, A. S. K. (2019). Coping with chronic illness. En C. D. Llewellyn, S. Ayers, C. McManus, S. Newman, K. J. Petrie, T. A. Revenson, \& J. Weinman (Eds.), The Cambridge handbook ofpsychology, health andmedicine (pp.110-114). United Kingdom:Cambridge University Press.

Rachlin, H. (2000). The science of self-control. Massachusetts: Harvard University Press.

Reynoso, L. (2002). Lista chequeable de ansiedad. (Documento no publicado).

Reynoso, L. (2014). Medicina conductual: Introducción. En L. Reynoso \& A. L. Becerra (Coords.), Medicina conductual (pp. 11-26). México: Qartuppi. https://doi.org/10.29410/QTP.14.01

Reynoso, L. \& Becerra, A. L. (2013). Lista de datos de ansiedad ante procedimientos dentales. (Documento ex professo). Validado por expertos de diferentes especialidades de Odontología y Cirujanos Dentistas, docentes de la Carrera de Odontología de la FES Iztacala.

Reynoso, L., Becerra, A. L., \& Lugo, V. I. (2019). Trastorno de estrés postraumático en adultos. Intervención cognitivo-conductual para víctimas de sismos. México: Qartuppi. https:// doi.org/10.29410/QTP.19.02

Reynoso, L., \& Seligson, I. (1998). Proyecto de creación de la residencia en Medicina Conductual. Documento no publicado.

Reynoso, L. \& Seligson, I. (2005). Psicología clínica de la salud: un enfoque conductual. México: El Manual Moderno.

Ribes, E. (1972). Terapias conductuales y modificación del comportamiento. Revista Latinoamericana de Psicología, 4(1), 7-21. Recuperado de https://www.redalyc.org/ pdf/805/80540101.pdf

Ribes, E. (1990). Psicología y salud. Un análisis conceptual. Barcelona: Martínez Roca.

Rodríguez, P., Abaroa, M., Reynoso, L., \& Lugo, I. (2020). Viviendo con Diabetes Mellitus: pautas y sugerencias para controlar mi estrés. México: Autores. Recuperado de https://www. mciztacala.org/uploads/1/3/2/8/132887507/gu\%C3\%ADa_para_pacientes_dm2.pdf 
Rodríguez, L., Rentería, A., \& García, J. (2013). Adherencia a la dieta en pacientes diabéticos: efectos de una intervención. Summa Psicológica, 10(1), 91-101. Recuperado de http:// pepsic.bvsalud.org/pdf/summa/v10n1/a09.pdf

Rodríguez, A., Zúñiga, P., Contreras, K., Gana, S., \& Fortunato, J. (2016). Revisión Teórica de las Estrategias de Afrontamiento (Coping) según el Modelo Transaccional de Estrés y Afrontamiento de Lazarus \& Folkman en Pacientes Quirúrgicos Bariátricos, Lumbares y Plásticos. Revista El Dolor, 25(66), 14-23.

Ruiz, M. A. \& Villalobos, A. (1994). Habilidades terapéuticas. Madrid: Fundación UniversidadEmpresa.

Ruíz, M., Díaz, M., \& Villalobos, A. (2012). Manual de técnicas de intervención cognitivo conductuales. España: Desclée De Brouwer.

Salazar, I. C. \& Ventura M. (2007). Evaluación y tratamiento psicológico de la diabetes mellitus. En M. Arrivillaga, D. Correa, \& I. C. Salazar (Dirs.), Psicología de la salud: abordaje integral de la enfermedad crónica (pp. 53-83). Bogotá: El Manual Moderno.

Salazar, I. C., Caballo, V. E., \& González, D. C. (2007). La intervención psicológica cognitivoconductual en las crisis asociadas a desastres: una revisión teórica. Psicología Conductual, 15(3), 389-405.

Sanzana, M. G., \& Durruty, P. (2016). Otros tipos específicos de diabetes mellitus. Revista Médica Clínica Las Condes, 27(2), 160-170. https://doi.org/10.1016/j.rmclc.2016.04.005

Schwartz, G. E., \& Weiss, S. M. (1978). Behavioral Medicine revisited: An amended definition. Journal of Behavioral Medicine, 1(3), 249-251. https://doi.org/10.1007/BF00846677

Secretaría de Salud. (2016). Informe sobre la salud de los mexicanos 2015. Diagnóstico general de la salud poblacional. México: Secretaría de Salud. Recuperado de https:// www.gob.mx/cms/uploads/attachment/file/64176/INFORME_LA_SALUD_DE_LOS_ MEXICANOS_2015_S.pdf

Slaikeu, K. A. (2000). Intervención en crisis: Manual para práctica e investigación. México: Manual Moderno.

Soriano, G. J. (2012). Estudio cuasi-experimental sobre las terapias de relajación en pacientes con ansiedad. Enfermería Global, 11(26), 39-53. https://doi.org/10.4321/S169561412012000200004

Springer, S. C., Silverstein, J., Copeland, K., Moore, K. R., Prazar, G. E., Raymer, T., Shiffman, R. N., Thaker, V. V., Anderson, M., Spann S. J., \& and Flinn, S.K. (2013). Management of Type 2 Diabetes Mellitus in Children and Adolescents. Pediatrics, 131(2), 648-664.

Stone, D., \& Conley, J. (2006). A Partnership between Roberts' crisis intervention model and the multicultural competencies. Brief Treatment and Crisis Intervention, 4, 367-375. 
Suárez, A. R., Reynoso, L. E., Lira, J. M., \& Ordaz, M. C. (2019). Intervención cognoscitivoconductual para la adherencia al tratamiento no farmacológico en diabetes mellitus tipo 2. Revista Latinoamericana de Medicina Conductual / Latin American Journal of Behavioral Medicine, 9(1), 21-29. Recuperado de http://www.revistas.unam.mx/index. php/rlmc/article/view/68569/60517

Suárez, M. A. (2010). La importancia del análisis de los acontecimientos vitales estresantes en la práctica clínica. Revista Médica La Paz, 16(2), 58-62. Recuperado de http://www. scielo.org.bo/scielo.php?script=sci_arttext\&pid=S1726-89582010000200010\&lng=es \&tlng=es

Surwit, R. S., Schneider, M. S., \& Feinglos, M. N. (1992). Stress and diabetes mellitus. Diabetes Care, 15(10), 1413-1422. https://doi.org/10.2337/diacare.15.10.1413

Torres, M.A., Vega, E.G., Vinalay, I., Arenas, G., \& Rodríguez, E. (2015). Validación psicométrica de escalas PSS-14, AFA-R, HDRS, CES-D, EV en puérperas mexicanas con y sin preeclampsia. Enfermería universitaria, 12(3), 122-133. https://doi.org/10.1016/j.reu.2015.08.001

Tron, R., Ávila, M. R., \& Reynoso, L. (2014). Evaluación psicológica. En L. Reynoso \& A. L. Becerra (Coords.),Medicinaconductual(pp.83-100).México:Qartuppi.https://doi.org/10.29410/ QTP.14.01

Urrego, Z. C., \& Rodríguez, C. L. (2012). Plan de monitoreo y batería de indicadores para el seguimiento y evaluación de estrategias de atención en salud sexual y reproductiva y salud mental en contextos de emergencias humanitarias. Bogotá: Ministerio de Salud y Protección Social.

Vallejo, J, R. (2000). Trastornos Afectivos: Ansiedad y depresión. Barcelona: Masson.

Vallejo-Slocker, L., \& Vallejo, M. A. (2016). Sobre la desensibilización sistemática. una técnica superada o renombrada. Acción Psicológica, 13(2), 157. https://doi.org/10.5944/ ap.13.2.16539

Vargas, J. J., \& Ibáñez, E. J. (1998). La evaluación conductual. Revista Electrónica de Psicología Iztacala, 1(2). Recuperado de https:/www.iztacala.unam.mx/carreras/psicologia/ psiclin/numerodos/laevaluacionconductual.html

Vázquez, M. I. (2008). Técnicas de Relajación y Respiración. España: Síntesis.

Veloz, M., Almanza, E., Augusto, J., Libiend, L., Quintana, V., \& Alanís, P. (2012). Uso de tecnologías en información y comunicación por médicos residentes de ginecología y obstetricia. Investigación en Educación Médica, 1(4), 183-189. Recuperado de https://www. elsevier.es/es-revista-investigacion-educacion-medica-343-articulo-uso-tecnologiasinformacion-comunicacion-por-X2007505712427317.699X2002000400001

Vicente, M., Delgado, S., Bandrés, F., Ramírez, M., \& Capdevilla, L. (2018). Valoración del dolor. Revisión comparativa de escalas y cuestionarios. Revista de la Sociedad Española del Dolor, 25(4), 228-236. 
Villar, J., Lizán, L., Soto, J., \& Peiró, S. (2009). La satisfacción con el tratamiento. Atención Primaria, 41(11), 637-645. https://doi.org/10.1016/j.aprim.2008.10.021

Wales, J. K. (1995). Does Psychological Stress Cause Diabetes? Diabetic Medicine, 12(2), 109112. https://doi.org/10.1111/j.1464-5491.1995.tb00439.x

Westefeld, J. S., \& Heckman-Stone, C. (2003). The Integrated problem-solving model of crisis intervention: overview and application. The Counseling Psychologist, 31(2), 221-239. https://doi.org/10.1177/0011000002250638

Winkley, K., Upsher, R., Stahl, D., Pollard, D., Kasera, A., Brennan, A., ... Ismail, K. (2020). Psychological interventions to improve self-management of type 1 and type 2 diabetes: a systematic review. Health Technology Assessment, 24(28), 1-232. https://doi. org/10.3310/hta24280

Wood, J. A. V., Miller, T. W., \& Hargrove, D. S. (2005). Clinical Supervision in Rural Settings: A Telehealth Model. Professional Psychology: Research and Practice, 36(2), 173-179. https:// doi.org/10.1037/0735-7028.36.2.173

World Health Organization (WHO). (2014). Training for tobacco quit line counsellors: Telephone counselling. World Health Organization. Recuperado de https://www.who.int/tobacco/ publications/smoking_cessation/9789241507264/en/

Zaheri, H., Najar, S., \& Abbaspoor, Z. (2016). Effectiveness of cognitive-behavioral stress management on psychological stress and glycemic control in gestational diabetes: a randomized controlled trial. The Journal of Maternal-Fetal \& Neonatal Medicine, 30(11), 1378-1382. https://doi.org/10.1080/14767058.2016.1214699

Zajdel, M., Helgeson, V. S., Seltman, H. J., Korytkowski, M. T., \& Hausmann, L. R. (2018). Daily communal coping in couples with type 2 diabetes: Enlaces to mood and self-care. Annals of Behavioral Medicine, 52(3), 228-238.

Zigmond, A.S., \& Snaith, R.P. (1983).The hospital anxiety and depression scale.Acta Psychiatrica Scandinavica, 67, 361-370. http://dx.doi.org/10.1111/j.1600-0447.1983.tb09716.x

Zoom (2020). About us. Recuperado de https://zoom.us/about 
Anexos 


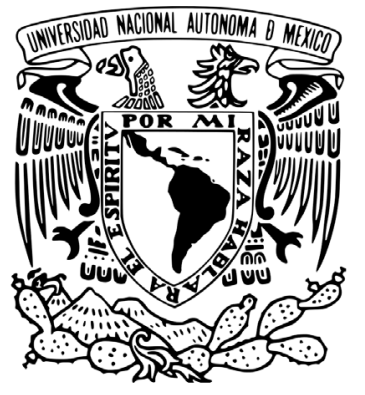

\author{
UNIVERSIDAD NACIONAL AUTÓNOMA DE MÉXICO \\ FACULTAD DE ESTUDIOS SUPERIORES IZTACALA \\ Programa de Maestría y Doctorado en Psicología \\ Residencia en Medicina Conductual
}

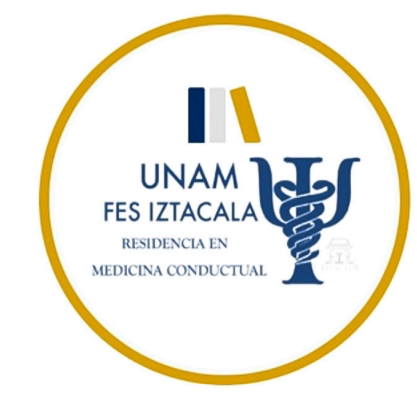

Lugar Fecha I

\title{
Consentimiento informado
}

Estimado(a) paciente:

Por favor lea con atención el siguiente formato, si tiene alguna duda puede aclararla con el (la) psicólogo (a) a cargo.

La Universidad Nacional Autónoma de México a través de la Residencia en Medicina Conductual sede FES Iztacala, le ofrece participar voluntariamente a recibir atención psicológica en línea para pacientes con enfermedades crónico degenerativas, cuidadores y personal de salud, por psicólogos titulados que actualmente están cursando estudios de posgrado en psicología.

A partir de un enfoque cognitivo conductual, en la terapia psicológica se establece una relación paciente-terapeuta, ambos trabajan en colaboración en la búsqueda de un objetivo común: favorecer la adquisición de estrategias psicológicas para la modificación del comportamiento y estilo de vida.

Antes de decidir iniciar el proceso, es muy importante que entienda con claridad sus derechos y responsabilidades como paciente.

El proceso de atención psicológica inicia con la evaluación, en la cual se recolectan datos que permiten comprender su caso; posteriormente se proporciona una intervención desde el enfoque cognitivo-conductual. La duración de la evaluación e intervención puede extenderse dependiendo de su cooperación, su asistencia a las sesiones y la naturaleza de su problemática. Es importante que llegue al término de la evaluación e intervención psicológica para lograr el objetivo terapéutico deseado.

La atención psicológica se brindará a través de las Tecnologías de Información y Comunicación (TICS) utilizando aparatos electrónicos para el fin expuesto, a partir de diversas plataformas (redes sociales, Zoom, Gmail, Hangouts, Microsoft teams, entre otras).

Durante el proceso obtendrá beneficios, sin embargo, también se presentarán riesgos e incomodidades, debido a que durante las sesiones se abordan temas delicados que le pueden provocar respuestas emocionales de tristeza, enojo, llanto, entre otros; para que el terapeuta le pueda brindar la atención que requiere y se obtengan resultados favorables es 
necesario que proporcione toda la información que se le solicite de forma veraz y confiable. Durante o después de la evaluación, se podría realizar una canalización a otros profesionales, programas e instituciones debido a la naturaleza de la problemática. Por otro lado, al hacer uso de las TICs también puede haber riesgos como comunicación intermitente, lentitud o fallas en la conexión.

Es importante considerar que la atención psicológica en línea, presenta los mismos beneficios de la modalidad presencial como mejorar la calidad de vida, disminuir el malestar emocional y adquisición de estrategias para la modificación del comportamiento. Adicionalmente, la modalidad a distancia promueve ciertas ventajas tales como: disposición de tiempo dentro del horario de atención, atención a medidas sanitarias y evitar desplazamiento a un consultorio físico.

La decisión de participar en la intervención es completamente voluntaria, destacando la importancia de la puntualidad y asistencia a la sesión. No habrá ninguna consecuencia desfavorable para usted, en caso de no aceptar la invitación. Si decide participar, puede retirarse en el momento que lo desee, pudiendo informar o no, las razones de su decisión, las cuales serán respetadas en su integridad.

La información de sus datos personales son de carácter confidencial; no serán divulgados a terceros ajenos, ni su identidad. De igual manera, se protegerán los datos evitando cualquier robo o divulgación de información. En el caso de que su información fuera utilizada con fines de investigación se eliminará cualquier fuente de información de identificación personal, respetando su derecho a la confidencialidad de la información. Finalmente, cabe mencionar que la intervención será completamente gratuita, en ningún momento se le solicitará alguna remuneración económica o material.

Yo acepto la evaluación e intervención psicológica señalada en el presente escrito. A su vez, expreso que se me proporcionó información sobre el derecho de poder retirarme de la atención psicológica en línea y todas mis dudas han sido aclaradas.

Nombre completo y firma del paciente

Número de teléfono para localizarlo en caso necesario

Nombre y firma del terapeuta

Acepto

Contacto:

Lic. en Psicología

Cédula Profesional

Teléfono

Correo electrónico 


\section{UNIVERSIDAD NACIONAL AUTÓNOMA DE MÉXICO FACULTAD DE ESTUDIOS SUPERIORES IZTACALA Programa de Maestría y Doctorado en Psicología Residencia en Medicina Conductual}

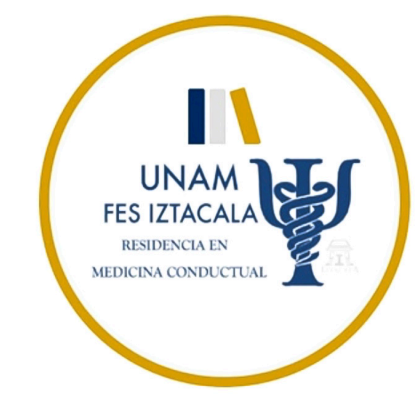

\section{Breve Checklist de Afrontamiento}

(Abaroa, González, Ortega, Reyes, \& Reynoso, 2020)

Sin fines de lucro

Nombre del paciente

Fecha

Instrucciones: A continuación, se enlistan una serie de comportamientos, por favor indica si realizas alguno de estos ante problemáticas relacionadas con tu salud.

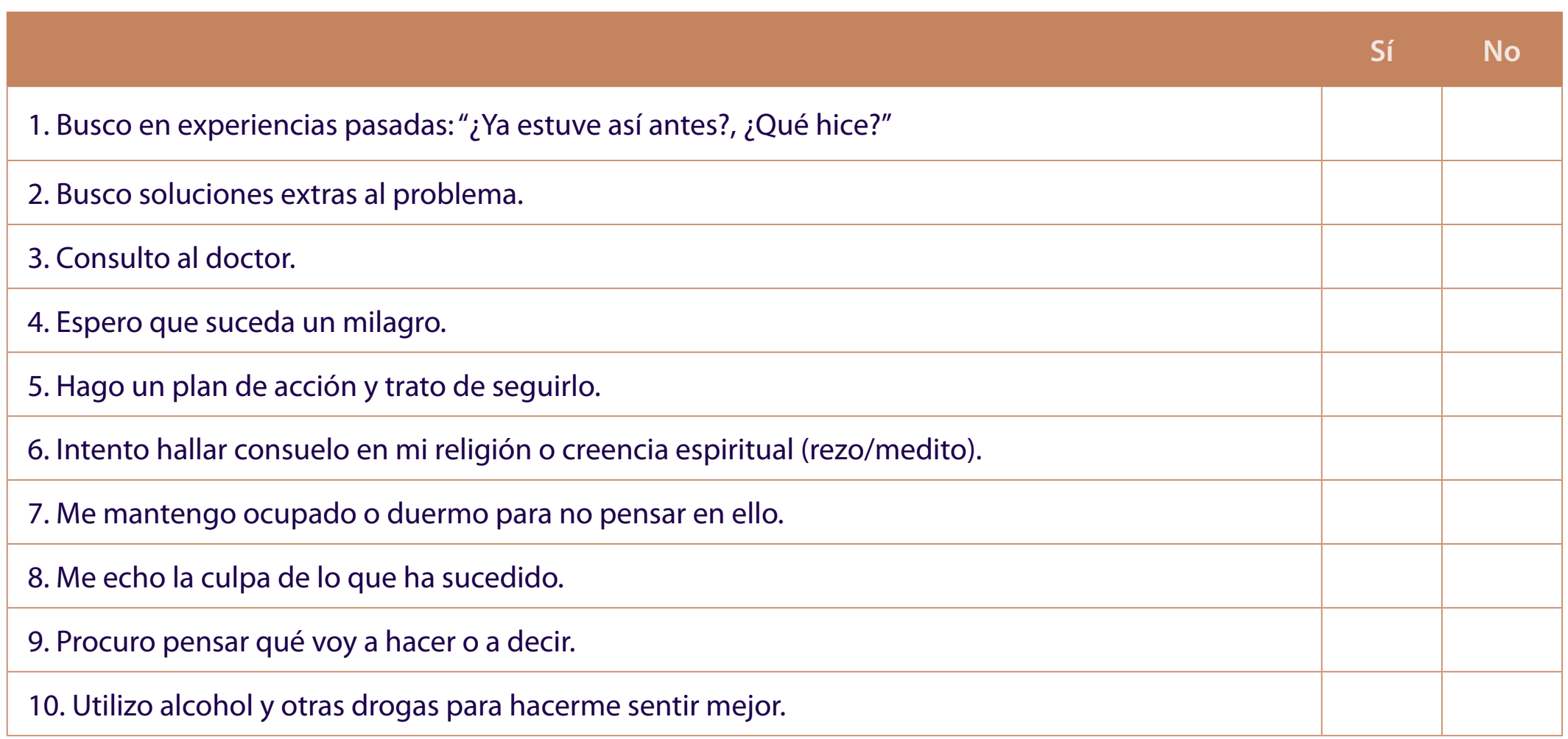

Gracias por sus respuestas. 


\section{UNIVERSIDAD NACIONAL AUTÓNOMA DE MÉXICO FACULTAD DE ESTUDIOS SUPERIORES IZTACALA Programa de Maestría y Doctorado en Psicología Residencia en Medicina Conductual}

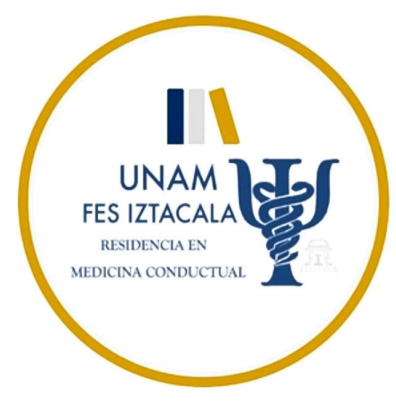

\section{Síntomas de Estrés}

(Reynoso \& Seligson, 2005)

Sin fines de lucro

Nombre del paciente

Fecha

Instrucciones: A continuación, se enlistan una variedad de síntomas. Lee cada uno cuidadosamente y decide si eso te ha ocurrido en los últimos dos o tres días.

1. Dolores musculares.

2. Cambios de apetito.

3. Insomnio y pesadillas.

4. Sudoración profusa.

5. Náuseas, dolor de estómago e indigestión.

6. Rechinar los dientes.

7. Dolores de cabeza, mareos.

8. Constipación (estreñimiento) o diarrea.

9. Pérdida del deseo sexual.

10. Presión alta.

11. Garganta y boca seca.

12. Irritabilidad o mal humor.

13. Letargo o incapacidad para trabajar.

14. Manos frías.

15. Depresión.

16. Miedo, pánico o ansiedad.

17. Fatiga o dormir en exceso.

18. Hiperventilación o respiración cortada. 
19. Incremento en el número de accidentes menores.

20. Pensamientos de apuro o falta de concentración.

21. Aumento de los lapsus de memoria.

22. Incremento en la frecuencia de los errores.

23. Cambio en las conductas habituales.

24. Falta de ganas de trabajar o jugar.

25. Sentimientos de desesperación o de inutilidad.

26. Pensar constantemente en cosas que no puede cambiar.

27. Sientes que el corazón se te sale del pecho.

28. Tensión muscular, torceduras musculares y tics.

Gracias por sus respuestas. 


\section{UNIVERSIDAD NACIONAL AUTÓNOMA DE MÉXICO FACULTAD DE ESTUDIOS SUPERIORES IZTACALA Programa de Maestría y Doctorado en Psicología Residencia en Medicina Conductual}

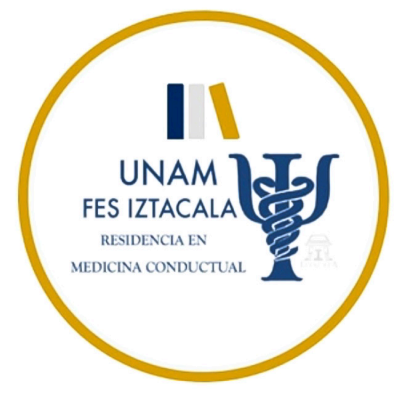

\section{Escala de Ansiedad y Depresión Hospitalaria (HADS)}

(Galindo et al., 2015)

Sin fines de lucro

Nombre del paciente

Fecha

Instrucciones: A continuación, se enlista una serie de enunciados acerca de cómo se siente emocionalmente. Lea cada pregunta y marque con una cruz $(\mathbf{X}$ ) la respuesta que se acerque más a cómo se ha sentido durante la última semana. No es necesario que piense mucho las respuestas.

1. Me siento tenso(a) o nervioso (a):
a) Todo el día
b) Casi todo el día
c) De vez en cuando
d) Nunca

2. Sigo disfrutando con las mismas cosas que siempre:
a) No en absoluto
b) Rara vez
c) Frecuentemente
d) Casi siempre

3. Siento una especie de temor como si algo me fuera a suceder:
a) Sí y muy intenso
b) Sí, pero no muy intenso
c) Sí, pero no me preocupa
d) No siento nada de eso

4. Soy capaz de reírme y ver el lado gracioso de las cosas:
a) No, en absoluto
b) Rara vez
c) Frecuentemente
d) Casi siempre

5. Tengo la cabeza llena de preocupaciones:
a) Todo el día
b) Frecuentemente
c) De vez en cuando
d) Nunca

6. Me siento alegre:
a) No, en absoluto
b) Rara vez
c) Frecuentemente
d) Casi siempre

7. Soy capaz de permanecer sentado(a) tranquila y relajadamente:
a) No en absoluto
b) Rara vez
c) Frecuentemente
d) Casi siempre 
8. Me siento lento(a) y torpe:
a) Todo el día
b) Casi todo el día
c) De vez en cuando
d) Nunca

9. Experimento una sensación de nervios y vacío en el estómago:
a) Casi siempre
b) Frecuentemente
c) Rara vez
d) No, en absoluto

10. He perdido el interés por mi aspecto personal:
a) Casi siempre
b) Frecuentemente
c) Rara vez
d) No, en absoluto

11. Me siento inquieto(a) como si no pudiera dejarme de mover:

\begin{tabular}{|l|l|l|l} 
a) Casi siempre & b) Frecuentemente & c) Rara vez & d) No, en absoluto
\end{tabular}

12. Espero las cosas con ilusión:

\begin{tabular}{|l|l|l|l}
\hline a) No, en absoluto & b) Rara vez & c) Frecuentemente & d) Casi siempre
\end{tabular}

13. Experimento de repente una sensación de gran angustia o temor:
a) Casi siempre
b) Frecuentemente
c) Rara vez
d) No, en absoluto

14. Soy capaz de disfrutar con un buen libro, programa de radio o televisión:
a) No, en absoluto
b) Rara vez
c) Frecuentemente
d) Casi siempre

\section{Gracias por sus respuestas.}




\section{UNIVERSIDAD NACIONAL AUTÓNOMA DE MÉXICO FACULTAD DE ESTUDIOS SUPERIORES IZTACALA Programa de Maestría y Doctorado en Psicología Residencia en Medicina Conductual}

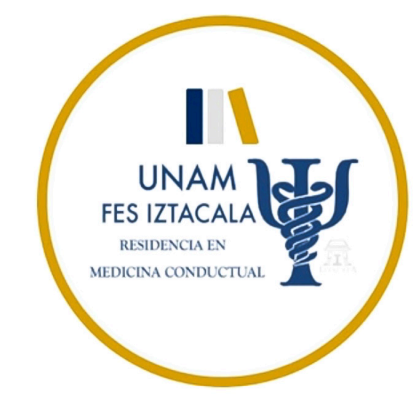

\section{Escala de Estrés Percibido (PSS-14) \\ (González \& Landero, 2007) \\ Sin fines de lucro}

Nombre del paciente Fecha 1

Instrucciones: Marca la opción que mejor se adecúe a tu situación actual.

\begin{tabular}{|c|c|c|c|c|c|}
\hline Durante el último mes: & ¿ & 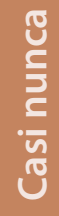 & $\begin{array}{l}y \\
\stackrel{y}{y} \\
\stackrel{\Delta}{4}\end{array}$ & $\begin{array}{l}\frac{0}{0} \\
\frac{0}{2} \\
\frac{\mathrm{C}}{\mathrm{d}} \\
\text { ह }\end{array}$ & 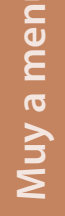 \\
\hline 1. ¿Con qué frecuencia has estado afectado(a) por algo que ha ocurrido inesperadamente? & 0 & 1 & 2 & 3 & 4 \\
\hline 2. ¿Con qué frecuencia te has sentido incapaz de controlar las cosas importantes de tu vida? & 0 & 1 & 2 & 3 & 4 \\
\hline 3. ¿Con qué frecuencia te has sentido nervioso(a) o estresado(a) (lleno de tensión)? & 0 & 1 & 2 & 3 & 4 \\
\hline 4. ¿Con qué frecuencia has manejado con éxito los pequeños problemas irritantes de la vida? & 0 & 1 & 2 & 3 & 4 \\
\hline $\begin{array}{l}\text { 5. ¿Con qué frecuencia has sentido que has afrontado efectivamente los cambios importantes } \\
\text { que han estado ocurriendo en tu vida? }\end{array}$ & 0 & 1 & 2 & 3 & 4 \\
\hline $\begin{array}{l}\text { 6. ¿Con qué frecuencia has estado seguro(a) sobre tu capacidad de manejar tus problemas } \\
\text { personales? }\end{array}$ & 0 & 1 & 2 & 3 & \\
\hline 7. ¿Con qué frecuencia has sentido que las cosas te van bien? & 0 & 1 & 2 & 3 & 4 \\
\hline 8. ¿Con qué frecuencia has sentido que no podías afrontar todas las cosas que tenías que hacer? & 0 & 1 & 2 & 3 & 4 \\
\hline 9. ¿Con qué frecuencia has podido controlar las dificultades de tu vida? & 0 & 1 & 2 & 3 & 4 \\
\hline 10. ¿Con qué frecuencia has sentido que tienes el control de todo? & 0 & 1 & 2 & 3 & 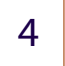 \\
\hline $\begin{array}{l}\text { 11. ¿Con qué frecuencia has estado enfadado(a) porque las cosas que te han ocurrido estaban } \\
\text { fuera de tu control? }\end{array}$ & 0 & 1 & 2 & 3 & \\
\hline 12. ¿Con qué frecuencia has pensado sobre las cosas que no has terminado (pendientes de hacer)? & 0 & 1 & 2 & 3 & \\
\hline 13. ¿Con qué frecuencia has podido controlar la forma de pasar el tiempo (organizar)? & 0 & 1 & 2 & 3 & 4 \\
\hline $\begin{array}{l}\text { 14. ¿Con qué frecuencia has sentido que las dificultades se acumulan tanto que no puedes } \\
\text { superarlas? }\end{array}$ & 0 & 1 & 2 & 3 & \\
\hline
\end{tabular}




\section{UNIVERSIDAD NACIONAL AUTÓNOMA DE MÉXICO FACULTAD DE ESTUDIOS SUPERIORES IZTACALA Programa de Maestría y Doctorado en Psicología Residencia en Medicina Conductual}

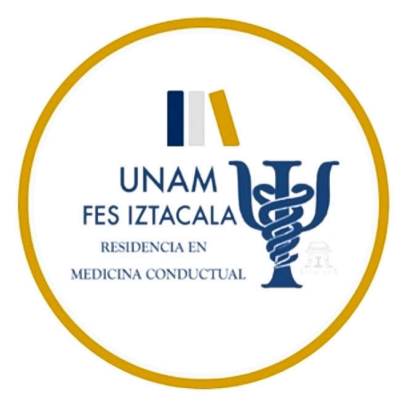

\section{Checklist Ansiedad A}

Adaptado de Reynoso y Becerra (2013)

Sin fines de lucro

Nombre del paciente

Fecha

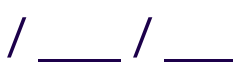

Instrucciones: Se enlistan una variedad de síntomas. Lee cada una cuidadosamente y decide si eso te ha ocurrido en los últimos dos o tres días. Si no te ha ocurrido, marca "No"; si el evento sí ocurrió, marca "Sí" en el espacio respectivo. Por favor, contesta de la forma más sincera que te sea posible.

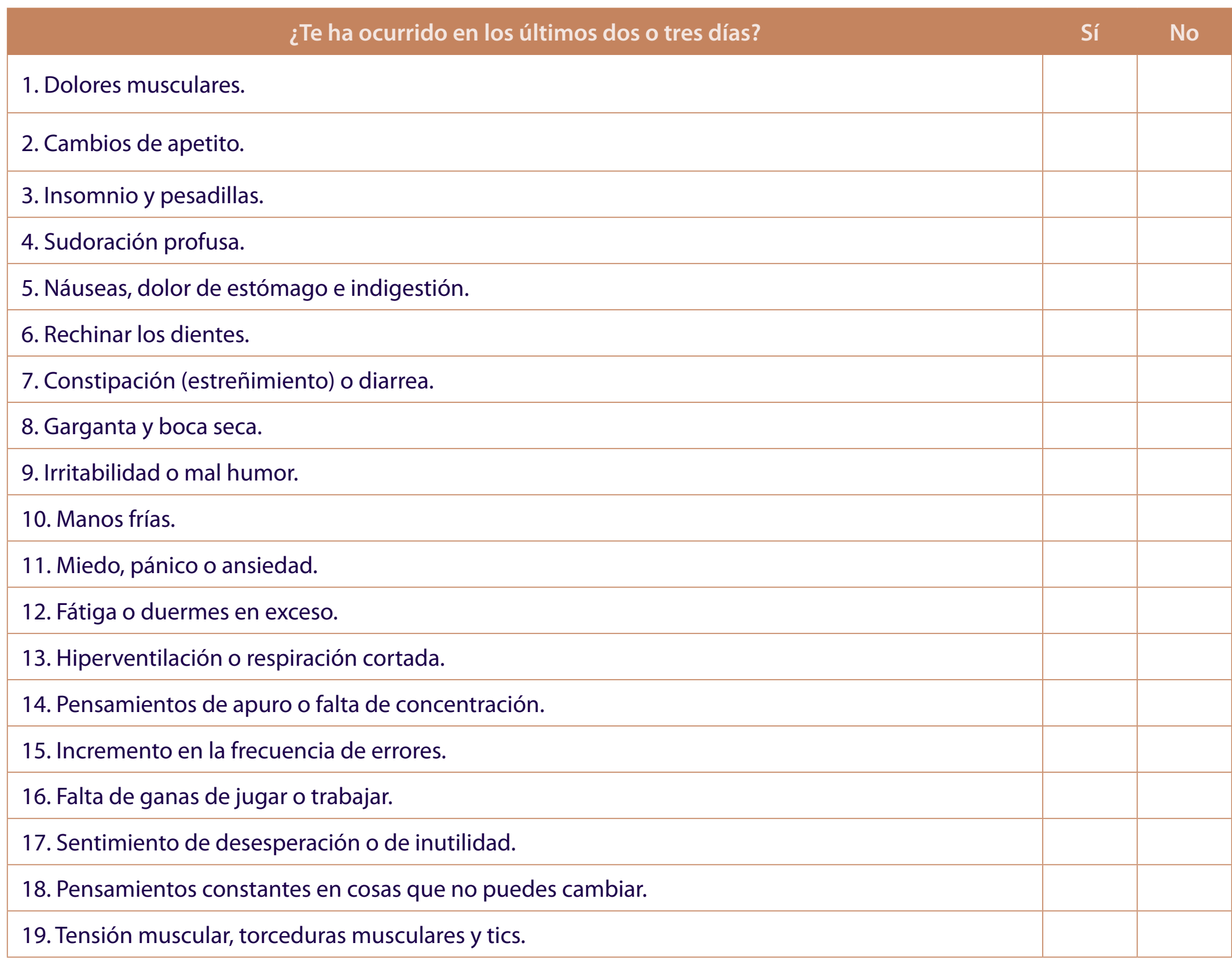




\section{UNIVERSIDAD NACIONAL AUTÓNOMA DE MÉXICO FACULTAD DE ESTUDIOS SUPERIORES IZTACALA Programa de Maestría y Doctorado en Psicología Residencia en Medicina Conductual}

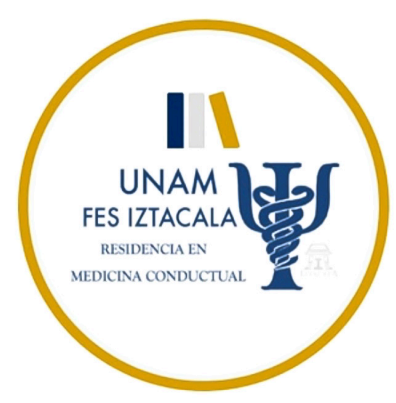

\section{Checklist Ansiedad B \\ Reynoso (2002) \\ Sin fines de lucro}

Nombre del paciente

Fecha

Instrucciones: Se enlistan una variedad de síntomas. Lee cada una cuidadosamente y decide si eso te ha ocurrido en los últimos dos o tres días. Si no te ha ocurrido, marca "No"; si el evento sí ocurrió, marca "Sí" en el espacio respectivo. Por favor, contesta de la forma más sincera que te sea posible.

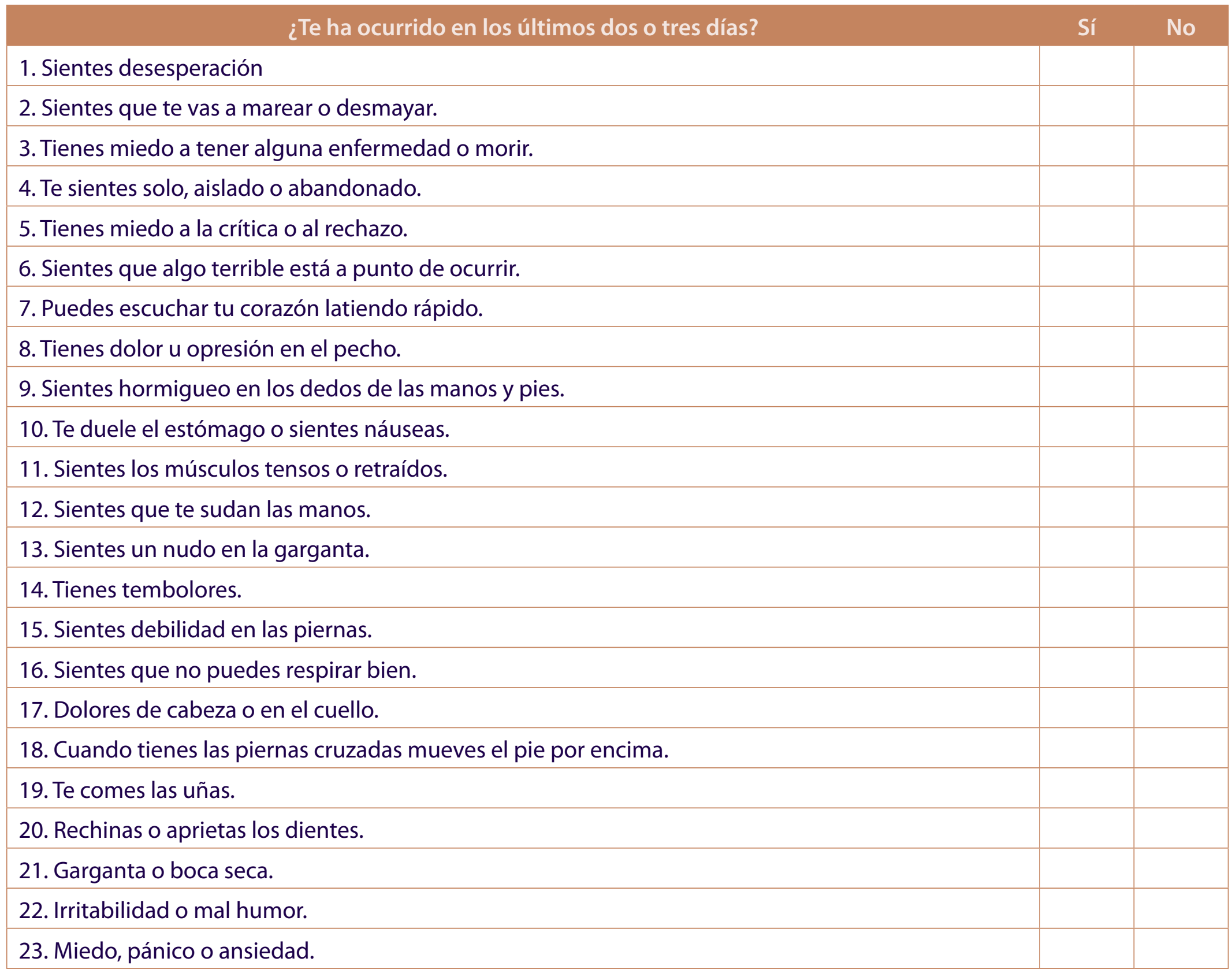

Gracias por sus respuestas. 


\section{UNIVERSIDAD NACIONAL AUTÓNOMA DE MÉXICO FACULTAD DE ESTUDIOS SUPERIORES IZTACALA Programa de Maestría y Doctorado en Psicología Residencia en Medicina Conductual}

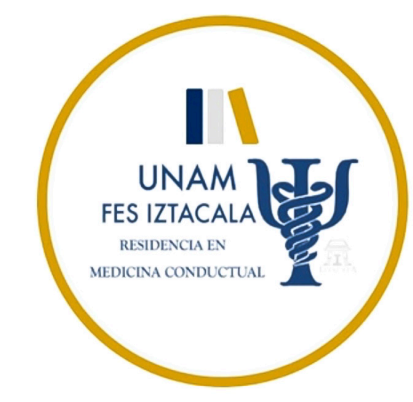

\section{Inventario de Estrategias de Afrontamiento}

(Cano, Rodríguez, \& García, 2007)

Sin fines de lucro

Nombre del paciente Fecha I

Instrucciones: El propósito de este cuestionario es encontrar el tipo de situaciones que causa problemas a las personas en su vida cotidiana y cómo estas se enfrentan a estos problemas.

Piensa durante unos minutos en un hecho o situación que ha sido muy estresante para ti en el último mes. Por estresante entendemos una situación que causa problemas, le hace sentirse a uno mal o que cuesta mucho enfrentarse a ella. Puede ser con la familia, en la escuela, en el trabajo, con los amigos, etc.

Describe esta situación en el espacio en blanco de esta página. Escribe qué ocurrió e incluye detalles como el lugar, quién o quiénes estaban implicados, por qué le diste importancia y qué hiciste. La situación puede estar sucediendo ahora o puede haber sucedido ya. No te preocupes por si está mejor o peor escrito o mejor o peor organizado, solo escríbela tal y como se te ocurra.

Instrucciones: De nuevo piensa unos minutos en la situación o hecho que hayas elegido. Responde a la siguiente lista de afirmaciones basándote en cómo manejaste esta situación. Lee cada frase y determina con un tache $(\mathbf{X})$ el grado en que hiciste lo que cada frase indica en la situación que antes elegiste marcando el número que corresponda:

$\mathbf{0}=$ En absoluto; $\mathbf{1}=$ Un poco; $\mathbf{2}=$ Bastante; $\mathbf{3}=$ Mucho; $\mathbf{4}=$ Totalmente

Asegúrate de que respondas todas las frases. No hay respuestas correctas o incorrectas; solo se evalúa lo que hiciste, pensaste o sentiste en ese momento. 
$\begin{array}{lllll}0 & 1 & 2 & 3 & 4\end{array}$

1. Luché por resolver el problema.

2. Me culpé a mí mismo.

3. Dejé salir mis sentimientos para reducir el estrés.

4. Deseé que la situación nunca hubiera empezado.

5. Encontré a alguien que escuchó mi problema.

6. Repasé el problema una y otra vez en mi mente y al final vi las cosas de una forma diferente.

7. No dejé que me afectara; evité pensar en ello demasiado.

8. Pasé algún tiempo solo.

9. Me esforcé para resolver los problemas de la situación.

10. Me di cuenta de que era personalmente responsable de mis dificultades y me lo reproché.

11. Expresé mis emociones, lo que sentía.

12. Deseé que la situación no existiera o que de alguna manera terminase.

13. Hablé con una persona de confianza.

14. Cambié la forma en que veía la situación para que las cosas no parecieran tan malas.

15. Traté de olvidar por completo el asunto.

16. Evité estar con gente.

17. Hice frente al problema.

18. Me critiqué por lo ocurrido.

19. Analicé mis sentimientos y simplemente los deje salir.

20. Deseé no encontrarme nunca más en esa situación.

21. Dejé que mis amigos me echaran una mano.

22. Me convencí de que las cosas no eran tan malas como parecían.

23. Quité importancia a la situación y no quise preocuparme más.

24. Oculté lo que pensaba y sentía.

25. Supe lo que había que hacer, así que doblé mis esfuerzos y traté con más ímpetu de hacer que las cosas funcionaran.

26. Me recriminé por permitir que esto ocurriera.

27. Dejé desahogar mis emociones.

28. Deseé poder cambiar lo que había sucedido.

29. Pasé algún tiempo con mis amigos.

30. Me pregunté qué era realmente importante y descubrí que las cosas no estaban tan mal después de todo.

31. Me comporté como si nada hubiera pasado.

32. No dejé que nadie supiera como me sentía.

33. Mantuve mi postura y luché por lo que quería.

34. Fue un error mío, así que tenía que sufrir las consecuencias.

35. Mis sentimientos eran abrumadores y estallaron.

36. Me imaginé que las cosas podrían ser diferentes. 
37. Pedí consejo a un amigo o familiar que respeto.

38. Me fijé en el lado bueno de las cosas.

39. Evité pensar o hacer nada.

40. Traté de ocultar mis sentimientos.

41. Me consideré capaz de afrontar la situación.

\section{Gracias por sus respuestas.}




\section{UNIVERSIDAD NACIONAL AUTÓNOMA DE MÉXICO FACULTAD DE ESTUDIOS SUPERIORES IZTACALA Programa de Maestría y Doctorado en Psicología Residencia en Medicina Conductual}

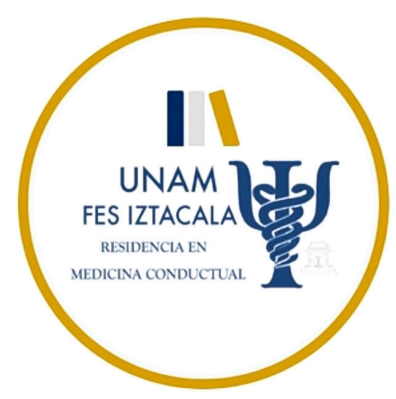

\section{(López \& Rodríguez, 2006) \\ Sin fines de lucro}

Cuestionario sobre Calidad de Vida Diabetes 39

Nombre del paciente Fecha 1

Instrucciones: La calidad de vida de las personas está afectada por muchas causas. Estas causas pueden incluir el estado de salud, la oportunidad para vacacionar o divertirse, los amigos, la familia o el trabajo. El siguiente cuestionario se diseñó para ayudar a conocer lo que afecta la calidad de vida en las personas con diabetes. Las siguientes preguntas se relacionan con el grado de afectación que la diabetes le ocasionó en su calidad de vida durante el último mes.

Se le agradecerá que lea cuidadosamente las siguientes preguntas y conteste colocando una cruz $(\mathbf{X}$ ) en el cuadro del número que refleje mejor el grado de afectación en su vida respecto a cada una de las preguntas señaladas, tomando en cuenta que el número 1 indica falta de afectación y, al avanzar la numeración, aumenta el grado de afectación en forma progresiva hasta llegar al máximo, que es el número 7, que indica afectación extrema. Se le suplica responder todas las preguntas.

Durante el último mes, ¿en qué medida se vio afectada la calidad de su vida por las siguientes causas?

1. El horario de los medicamentos para su diabetes.

Nada afectada en lo absoluto

\begin{tabular}{|l|l|l|l|l|l|l|}
1 & 2 & 3 & 4 & 5 & 6 & 7 \\
\hline
\end{tabular}

Sumamente afectada

2. Preocupaciones por problemas económicos.

Nada afectada en lo absoluto

\begin{tabular}{|l|l|l|l|l|l|l|}
1 & 2 & 3 & 4 & 5 & 6 & 7 \\
\hline
\end{tabular}

Sumamente afectada

3. Limitación en su nivel de energía.

Nada afectada en lo absoluto

\begin{tabular}{|l|l|l|l|l|l|l|}
\hline 1 & 2 & 3 & 4 & 5 & 6 & 7 \\
\hline
\end{tabular}

Sumamente afectada

4. Seguir el plan indicado por su médico para el tratamiento de la diabetes.

Nada afectada en lo absoluto

\begin{tabular}{|l|l|l|l|l|l|l|}
1 & 2 & 3 & 4 & 5 & 6 & 7 \\
\hline
\end{tabular}

Sumamente afectada 
5. No comer ciertos alimentos para poder controlar su diabetes.

Nada afectada en lo absoluto

\begin{tabular}{|l|l|l|l|l|l|l|}
1 & 2 & 3 & 4 & 5 & 6 & 7 \\
\hline
\end{tabular}

Sumamente afectada

6. Estar preocupado(a) por su futuro.

Nada afectada en lo absoluto

\begin{tabular}{|l|l|l|l|l|l|l|}
\hline 1 & 2 & 3 & 4 & 5 & 6 & 7 \\
\hline
\end{tabular}

Sumamente afectada

7. Otros problemas de salud aparte de la diabetes.

Nada afectada en lo absoluto

\begin{tabular}{|l|l|l|l|l|l|l|}
\hline 1 & 2 & 3 & 4 & 5 & 6 & 7 \\
\hline
\end{tabular}

Sumamente afectada

8. Tensiones o presiones en su vida.

Nada afectada en lo absoluto

\begin{tabular}{|l|l|l|l|l|l|l|}
\hline 1 & 2 & 3 & 4 & 5 & 6 & 7 \\
\hline
\end{tabular}

Sumamente afectada

9. Sensación de debilidad.

Nada afectada en lo absoluto

\begin{tabular}{|l|l|l|l|l|l|l|}
\hline 1 & 2 & 3 & 4 & 5 & 6 & 7 \\
\hline
\end{tabular}

Sumamente afectada

10. Restricciones sobre la distancia que puede caminar.

Nada afectada en lo absoluto

\begin{tabular}{|l|l|l|l|l|l|l|}
1 & 2 & 3 & 4 & 5 & 6 & 7 \\
\hline
\end{tabular}

Sumamente afectada

11. Los ejercicios diarios que ha de hacer por su diabetes.

Nada afectada en lo absoluto

\begin{tabular}{|l|l|l|l|l|l|l|}
\hline 1 & 2 & 3 & 4 & 5 & 6 & 7 \\
\hline
\end{tabular}

Sumamente afectada

12. Visión borrosa o pérdida de la visión.

Nada afectada en lo absoluto

\begin{tabular}{|l|l|l|l|l|l|l|}
1 & 2 & 3 & 4 & 5 & 6 & 7 \\
\hline
\end{tabular}

Sumamente afectada

13. No poder hacer lo que quisiera.

Nada afectada en lo absoluto

\begin{tabular}{|l|l|l|l|l|l|l|}
\hline 1 & 2 & 3 & 4 & 5 & 6 & 7 \\
\hline
\end{tabular}

Sumamente afectada

14. Tener diabetes.

Nada afectada en lo absoluto

\begin{tabular}{|l|l|l|l|l|l|l|}
\hline 1 & 2 & 3 & 4 & 5 & 6 & 7 \\
\hline
\end{tabular}

Sumamente afectada

15. El descontrol de su azúcar en sangre.

Nada afectada en lo absoluto

\begin{tabular}{|l|l|l|l|l|l|l|}
\hline 1 & 2 & 3 & 4 & 5 & 6 & 7 \\
\hline
\end{tabular}

Sumamente afectada

16. Otras enfermedades aparte de la diabetes.

Nada afectada en lo absoluto

\begin{tabular}{|l|l|l|l|l|l|l|}
1 & 2 & 3 & 4 & 5 & 6 & 7 \\
\hline
\end{tabular}

Sumamente afectada

17. Hacerse análisis para comprobar sus niveles de azúcar en sangre.

Nada afectada en lo absoluto

\begin{tabular}{|l|l|l|l|l|l|l|}
\hline 1 & 2 & 3 & 4 & 5 & 6 & 7 \\
\hline
\end{tabular}

Sumamente afectada 
18. El tiempo requerido para controlar su diabetes.

Nada afectada en lo absoluto

\begin{tabular}{|l|l|l|l|l|l|l|}
\hline 1 & 2 & 3 & 4 & 5 & 6 & 7 \\
\hline
\end{tabular}

Sumamente afectada

19. Las restricciones que su diabetes impone a su familia y amigos.

Nada afectada en lo absoluto

\begin{tabular}{|l|l|l|l|l|l|l|}
1 & 2 & 3 & 4 & 5 & 6 & 7 \\
\hline
\end{tabular}

Sumamente afectada

20. La vergüenza producida por tener diabetes.

Nada afectada en lo absoluto

\begin{tabular}{|l|l|l|l|l|l|l|}
1 & 2 & 3 & 4 & 5 & 6 & 7 \\
\hline
\end{tabular}

Sumamente afectada

21. La interferencia de su diabetes en su vida sexual.

Nada afectada en lo absoluto

\begin{tabular}{|l|l|l|l|l|l|l|}
\hline 1 & 2 & 3 & 4 & 5 & 6 & 7 \\
\hline
\end{tabular}

Sumamente afectada

22. Sentirse triste o deprimido.

Nada afectada en lo absoluto

\begin{tabular}{|l|l|l|l|l|l|l|}
\hline 1 & 2 & 3 & 4 & 5 & 6 & 7 \\
\hline
\end{tabular}

Sumamente afectada

23. Problemas con respecto a su capacidad sexual.

Nada afectada en lo absoluto

\begin{tabular}{|l|l|l|l|l|l|l|}
\hline 1 & 2 & 3 & 4 & 5 & 6 & 7 \\
\hline
\end{tabular}

Sumamente afectada

24. Tener bien controlada su diabetes.

Nada afectada en lo absoluto

\begin{tabular}{|l|l|l|l|l|l|l|}
\hline 1 & 2 & 3 & 4 & 5 & 6 & 7 \\
\hline
\end{tabular}

Sumamente afectada

25. Complicaciones debidas a su diabetes.

Nada afectada en lo absoluto

\begin{tabular}{|l|l|l|l|l|l|l|}
1 & 2 & 3 & 4 & 5 & 6 & 7 \\
\hline
\end{tabular}

Sumamente afectada

26. Hacer cosas que su familia y amigos no hacen.

Nada afectada en lo absoluto

\begin{tabular}{|l|l|l|l|l|l|l|}
\hline 1 & 2 & 3 & 4 & 5 & 6 & 7 \\
\hline
\end{tabular}

Sumamente afectada

27. Tener que anotar sus niveles de azúcar en sangre.

Nada afectada en lo absoluto

\begin{tabular}{|l|l|l|l|l|l|l|}
\hline 1 & 2 & 3 & 4 & 5 & 6 & 7 \\
\hline
\end{tabular}

Sumamente afectada

28. La necesidad de tener que comer a intervalos regulares.

Nada afectada en lo absoluto

\begin{tabular}{|l|l|l|l|l|l|l|}
\hline 1 & 2 & 3 & 4 & 5 & 6 & 7 \\
\hline
\end{tabular}

Sumamente afectada

29. No poder realizar labores domésticas u otros trabajos relacionados con la casa.

Nada afectada en lo absoluto

\begin{tabular}{|l|l|l|l|l|l|l|}
\hline 1 & 2 & 3 & 4 & 5 & 6 & 7 \\
\hline
\end{tabular}

Sumamente afectada

30. Menor interés en su vida sexual.

Nada afectada en lo absoluto

\begin{tabular}{|l|l|l|l|l|l|l|}
\hline 1 & 2 & 3 & 4 & 5 & 6 & 7 \\
\hline
\end{tabular}

Sumamente afectada 
31. Tener que organizar su vida cotidiana alrededor de la diabetes.

Nada afectada en lo absoluto

\begin{tabular}{|l|l|l|l|l|l|l|}
\hline 1 & 2 & 3 & 4 & 5 & 6 & 7 \\
\hline
\end{tabular}

Sumamente afectada

32. Tener que descansar a menudo.

Nada afectada en lo absoluto

\begin{tabular}{|l|l|l|l|l|l|l|}
\hline 1 & 2 & 3 & 4 & 5 & 6 & 7 \\
\hline
\end{tabular}

Sumamente afectada

33. Problemas al subir escaleras.

Nada afectada en lo absoluto

\begin{tabular}{|l|l|l|l|l|l|l|}
\hline 1 & 2 & 3 & 4 & 5 & 6 & 7 \\
\hline
\end{tabular}

Sumamente afectada

34. Dificultades para sus cuidados personales (bañarse, vestirse o usar el sanitario).

Nada afectada en lo absoluto

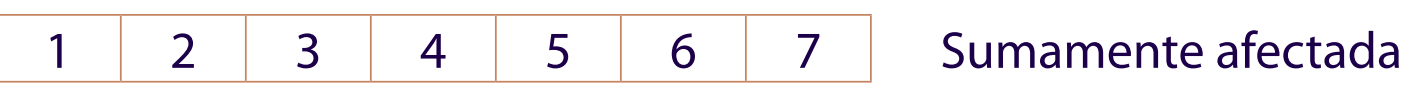

35. Tener el sueño intranquilo.

Nada afectada en lo absoluto

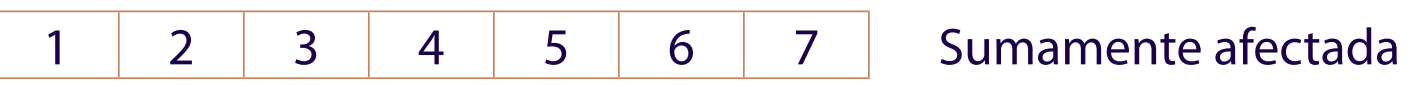

36. Andar más despacio que otras personas.

Nada afectada en lo absoluto

\begin{tabular}{|l|l|l|l|l|l|l|}
\hline 1 & 2 & 3 & 4 & 5 & 6 & 7 \\
\hline
\end{tabular}

Sumamente afectada

37. Ser identificado como diabético.

Nada afectada en lo absoluto

\begin{tabular}{|l|l|l|l|l|l|l|}
\hline 1 & 2 & 3 & 4 & 5 & 6 & 7 \\
\hline
\end{tabular}

Sumamente afectada

38. Interferencia de la diabetes con su vida familiar.

Nada afectada en lo absoluto

\begin{tabular}{l|l|l|l|l|l|l|}
1 & 2 & 3 & 4 & 5 & 6 & 7 \\
\hline
\end{tabular}

Sumamente afectada

39. La diabetes en general.

Nada afectada en lo absoluto

\begin{tabular}{|l|l|l|l|l|l|l|}
\hline 1 & 2 & 3 & 4 & 5 & 6 & 7 \\
\hline
\end{tabular}

Sumamente afectada

\section{Calificación Global:}

1. Por favor, marque con una cruz ( $\mathbf{X}$ ) el cuadro que indique la calificación de su calidad de vida. Mínima calidad

\begin{tabular}{|l|l|l|l|l|l|l|}
\hline 1 & 2 & 3 & 4 & 5 & 6 & 7 \\
\hline
\end{tabular}

Máxima calidad

2. Por favor, marque con una cruz ( $\mathbf{X}$ ) el cuadro que indique la calificación de su calidad de vida.

Ninguna gravedad

\begin{tabular}{|l|l|l|l|l|l|l|}
\hline 1 & 2 & 3 & 4 & 5 & 6 & 7 \\
\hline
\end{tabular}

Extremadamente grave

Gracias por sus respuestas. 


\section{UNIVERSIDAD NACIONAL AUTÓNOMA DE MÉXICO FACULTAD DE ESTUDIOS SUPERIORES IZTACALA Programa de Maestría y Doctorado en Psicología Residencia en Medicina Conductual}

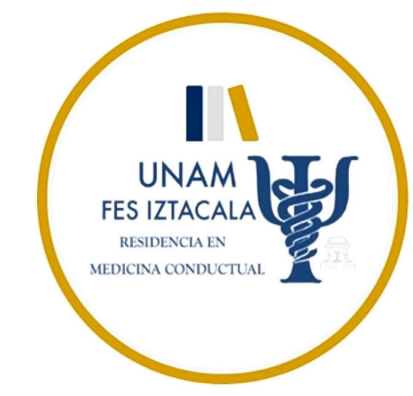

\section{Versión actualizada de la Escala de Adherencia Terapéutica (Pedraza-Banderas \& Valero, 2018) \\ Sin fines de lucro}

Nombre del paciente Fecha l

Instrucciones: En este instrumento se presentan diversas frases relacionadas a tu salud. Lee cada frase y determina el grado con el que mejor te identificas marcando el número que corresponda: nunca, casi nunca, pocas veces, frecuentemente o casi siempre. Selecciona solo una respuesta por frase. Asegúrate de que respondas todas las frases. No hay respuestas correctas o incorrectas.

\begin{tabular}{|c|c|c|c|c|c|}
\hline & ֻ & 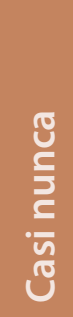 & 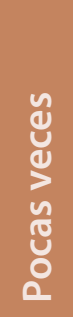 & 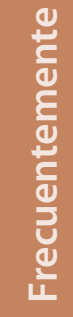 & 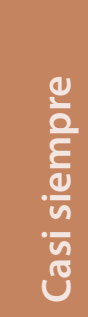 \\
\hline \multicolumn{6}{|l|}{ 1. Respeto la dieta indicada, aunque esta sea rigurosa. } \\
\hline \multicolumn{6}{|l|}{ 2. Asisto a mis consultas de manera puntual. } \\
\hline \multicolumn{6}{|l|}{ 3. Estoy al pendiente de cualquier síntoma que pueda afectar mi estado de salud. } \\
\hline \multicolumn{6}{|l|}{$\begin{array}{l}\text { 4. Atiendo todas las recomendaciones del médico, en cuanto a los cambios en mi estilo de } \\
\text { vida (por ejemplo, dejar de fumar, no consumir alcohol, sal, azúcar, picante, etc.). }\end{array}$} \\
\hline \multicolumn{6}{|l|}{ 5. Como solo aquellos alimentos que el médico me permite. } \\
\hline \multicolumn{6}{|l|}{ 6. Si el médico me inspira confianza, entonces sigo el tratamiento. } \\
\hline \multicolumn{6}{|l|}{$\begin{array}{l}\text { 7. Después de haber terminado un tratamiento, regreso a consulta si el médico me indica } \\
\text { que es necesario para verificar mi estado de salud. }\end{array}$} \\
\hline \multicolumn{6}{|l|}{$\begin{array}{l}\text { 8. Cuando me dan los resultados de mis análisis clínicos, estoy más seguro(a) de lo que } \\
\text { tengo y me apego más al tratamiento. }\end{array}$} \\
\hline \multicolumn{6}{|l|}{ 9. Cuando tengo muchas cosas que hacer, se me olvida tomar mis medicamentos. } \\
\hline \multicolumn{6}{|l|}{ 10. Cuando los síntomas desaparecen dejo el tratamiento, aunque este no esté concluido. } \\
\hline \multicolumn{6}{|l|}{ 11. Si en poco tiempo no percibo mejoría en mi salud, dejo el tratamiento. } \\
\hline \multicolumn{6}{|l|}{ 12. Si el tratamiento exige hacer ejercicio, lo hago. } \\
\hline $\begin{array}{l}\text { 13. Para que yo siga el tratamiento es necesario que otros me recuerden que debo tomar } \\
\text { mis medicamentos. }\end{array}$ & & & & & \\
\hline
\end{tabular}




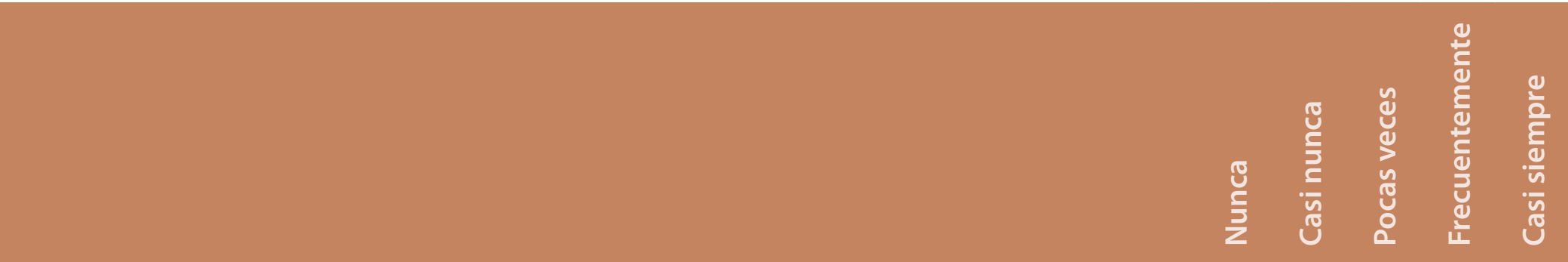

14. Como me lo recomienda el médico, acudo a realizarme análisis.

15. Me inspira confianza que el médico demuestre conocer mi enfermedad.

16. Si se sospecha que mi enfermedad es grave, hago todo lo que esté en mis manos para mejorar.

17. Me apego al tratamiento, aunque este sea complicado.

18. Si el médico me explica detalladamente en qué consiste mi enfermedad y qué es lo que tengo que hacer para mejorar mi salud, entonces me adhiero al tratamiento.

19. Si el medicamento es costoso, ingiero cantidades menores a las indicadas por el médico.

20. Le tengo más confianza a los medicamentos de patente que a los remedios naturales u homeopáticos.

21. Ingiero mis medicamentos respetando la dosis indicada por el médico.

22. Asisto a revisiones periódicas, aunque no me sienta mal.

23. Acudo al médico, únicamente cuando presento algún síntoma.

24. Notar mejoría en mi estado de salud, favorece que me adhiera al tratamiento.

25. Cuando presento síntomas de deterioro, me adhiero más al tratamiento.

26. Realizo las mediciones indicadas en casa, por ejemplo, tomas de presión arterial, el nivel de glucosa, etc.

27. Respeto la dieta indicada por el médico, sin importar el lugar donde me encuentre.

28. Realizo algún tipo de modificación al tratamiento, sin consultarlo con el médico.

29. Hago todo lo que está en mis manos para mantenerme controlado(a).

30. Estoy más seguro(a) de lo que tengo cuando me informan los resultados arrojados en los análisis clínicos.

\section{Gracias por sus respuestas.}




\section{UNIVERSIDAD NACIONAL AUTÓNOMA DE MÉXICO FACULTAD DE ESTUDIOS SUPERIORES IZTACALA \\ Programa de Maestría y Doctorado en Psicología \\ Residencia en Medicina Conductual}

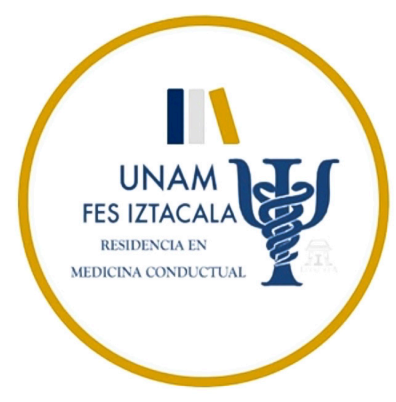

Escala Reporte de Adherencia a la Medicación (MARS)

(Horne \& Hankins, 2002; validado por Lugo \& Vega, 2020)

Sin fines de lucro

Nombre del paciente Fecha -

Instrucciones: Muchas personas encuentran una manera de usar su MEDICAMENTO DE CONTROL que les resulta adecuada y conveniente, y nos interesa saber cómo los usa usted. Por favor lea cada afirmación y responda sinceramente marcando con una cruz $(\mathbf{X})$ la casilla que mejor represente la forma en la que usted usa su medicamento.

\section{Acciones}

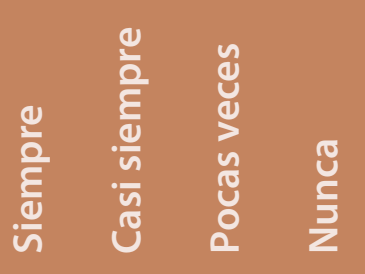

1. Uso mi medicamento de CONTROL solo cuando lo necesito.

2. Uso mi medicamento de CONTROL solo cuando me falta el aire.

3. Decido cuándo no usar mi medicamento de CONTROL

4. Trato de no usar mi medicamento de CONTROL.

5. Cambio el número de inhalaciones de mi medicamento de CONTROL.

6. Dejo de usar mi medicamento de CONTROL por un tiempo cuando estoy mejor.

7. Uso mi medicamento de CONTROL menos veces de lo que me indicó el doctor.

Gracias por sus respuestas. 


\section{Reseñas curriculares}

\section{Autores}

\section{Lic. Diana Lucero Muñoz Arellano}

Licenciada en Psicología con Mención Honorífica por la Facultad de Estudios Superiores Iztacala, Universidad Nacional Autónoma de México (UNAM). Actualmente está cursando la Maestría en Psicología con Residencia en Medicina Conductual. Colaboradora en el proyecto Efectividad de dos modalidades intervención para dejar de fumar en la misma institución. Terapeuta en el Centro de apoyo y orientación para estudiantes. Ponente en el II Coloquio: Docencia, Servicio e Investigación en la Psicología Aplicada. Participó en la difusión y sensibilización de la estrategia Atención al consumo de sustancias para la comunidad universitaria. Ponente y capacitadora en diferentes talleres.

\section{Lic. Yunery Marlen Bautista Gómez}

Licenciada en Psicología por la Facultad de Estudios Superiores Iztacala, Universidad Nacional Autónoma de México (UNAM). Ha colaborado en el Instituto Mexicano del Seguro Social (IMSS) UMF 186 como terapeuta en los programas denominados "Yo puedo" y "Pasos a la salud" donde se abordaban estrategias educativas dirigido a personas que sufren obesidad, sobrepeso, hipertensión y diabetes. Ha participado en proyectos de investigación y publicación de artículos. Colaboró como asistente y ponente en cursos, talleres y congresos a nivel nacional con temas relacionados con la salud. Actualmente está cursando la Maestría en Psicología con especialidad en Medicina Conductual.

\section{Lic. Andrea Ortega Mondragón}

Licenciada en Psicología por la UNAM-FES Zaragoza y egresada de la Maestría en Psicología residencia en Medicina Conductual por la Universidad Nacional Autónoma de México (UNAM). Colaboradora en proyectos de investigación el área de la salud. Ha participado en congresos nacionales y ha publicado artículos en revistas indizadas y de divulgación, orientados a la evaluación e intervención psicológica en personas con enfermedades crónico-degenerativas como Cáncer, Diabetes y Enfermedad Renal Crónica. 


\section{Dra. Ana Leticia Becerra Gálvez}

Licenciada en Psicología con Mención Honoríica por la Facultad de Estudios Superiores Iztacala. Maestra en Psicología con Residencia en Medicina Conductual. Doctora en Psicología con Mención Honorífica por la Universidad de las Américas de la Ciudad de México. Docente de la Carrera de Psicología, Facultad de Estudios Superiores Zaragoza, Universidad Nacional Autónoma de México (UNAM). Tutora de la Maestría en Psicología con Residencia en Medicina Conductual, FESI-UNAM. Autora de artículos publicados en revistas nacionales e internacionales. Coordinadora de la obra: Medicina Conductual: Teoría y Práctica (2014) y autora del libro Trastorno de Estrés Postraumático en adultos: Intervención Cognitivo Conductual en Víctimas de Sismos (2019).

\section{Mtro. Leonardo Reynoso Erazo}

Médico Cirujano y Maestro en Modificación de Conducta por la Universidad Nacional Autónoma de México (UNAM); miembro de la Society of Behavioral Medicine, de la American Psychological Association, de la Society for Neuroscience y de la Sociedad Mexicana de Análisis de la Conducta (SMAC); coordinador de la residencia en Medicina Conductual de la FES Iztacala UNAM. Es autor -entre otros- de los siguientes libros: Cuide su corazón, Psicología y Salud, Psicología clínica de la salud: un enfoque conductual, Electrocardiografía, Sistema Cardiovascular, Hipertensión arterial: Manual de intervenciones en actividad física, alimentación y solución de problemas para niños, Medicina Conductual: teoría y práctica y Trastorno de Estrés postraumático.

\section{Revisores}

\section{Mtro. Isaías Vicente Lugo-González}

Licenciado, Maestro y candidato a Doctor en Psicología, especialista en Medicina Conductual, por Facultad de Estudios Superiores Iztacala de la Universidad Nacional Autónoma de México (FESI-UNAM). Profesor de asignatura a nivel Licenciatura y Posgrado en la FESI-UNAM (Residencia en Medicina Conductual, Especialidad de Enfermería Nefrológica y Especialidad de Enfermería y Salud Laboral). Sus líneas de investigación se centran en adherencia a los tratamientos percepción de enfermedad y factores de riesgo conductuales en personas con cáncer, asma, Enfermedad Renal Crónica, sobrepeso y obesidad; en estas áreas ha publicado 15 artículos, cinco capítulos de libro y es coautor de un libro. 


\section{Dra. María De Lourdes Rodríguez Campuzano}

Licenciada en Psicología y Maestra de excelencia en Psicología en la Facultad de Estudios Superiores Iztacala, Doctora en Investigación Psicológica en la Universidad Iberoamericana. Profesor Titular C tiempo completo en la FES Iztacala en el Área de Psicología Clínica. Ponente en diversos congresos y eventos tanto nacionales como internacionales. Coordinadora y ponente de talleres y cursos destinados a pacientes con diabetes. Autora de más de 60 artículos en revistas especializadas. Autora del libro Análisis Contingencial, coautora, coordinadora y compiladora de libros especializados, así como de capítulos. Dictaminadora de artículos para revistas especializadas.

\section{Mtra. Cintia Tamara Sánchez}

Licenciada y Maestra en Psicología por la Universidad Nacional Autónoma de México (UNAM), con especialidad en Medicina Conductual. Cuenta con distintas publicaciones en el área de medicina conductual. Ha sido supervisora in situ del Posgrado en Medicina Conductual, con sede en el Hospital Juárez de México. Es Psicóloga adscrita al servicio de Salud Mental del Hospital Juárez de México, en el que colabora en la atención psicológica de pacientes con enfermedades crónico-degenerativas y familiares. Actualmente, colabora en la atención psicológica de pacientes hospitalizados con sospecha o diagnóstico confirmado por COVID-19, en dicho nosocomio.

\section{Mtra. Mariana Alejandra Sierra Murguía}

Licenciada y Maestra en Psicología con Residencia en Medicina Conductual. Especialista en Psico-oncología (Instituto Superior de Estudios Psicológicos de Barcelona). Diplomado en Psicología Bariátrica (Colegio Mexicano de Cirugía de Obesidad y Enfermedades Metabólicas). General Biofeedback Training (Behavioral Medicine Training Foundation). Alumna del Doctorado Interinstitucional, Psicología de la Salud. Estancia de investigación (Psico-oncología, Instituto Catalán de Oncología), Barcelona. Fue coordinadora de estudios clínicos (Fundación Clínica Médica Sur), investigadora en Ciencias Médicas y psicóloga clínica (Hospital “Dr. Manuel Gea González"), psico-oncóloga (Cancer Center Tec100, Querétaro), y docente (pregrado, posgrado). Ha participado en publicaciones y congresos nacionales e internacionales. 
Qartuppi, S. de R.L. de C.V. está inscrita de forma definitiva en el Registro Nacional de Instituciones y Empresas Científicas y Tecnológicas (RENIECYT) con el número 1600052.

Qartuppi, S. de R.L. de C.V. es miembro activo de la Cámara Nacional de la Industria Editorial Mexicana (CANIEM) con número de registro 3751.

Esta obra se terminó de producir en marzo de 2021. Su edición y diseño estuvieron a cargo de:

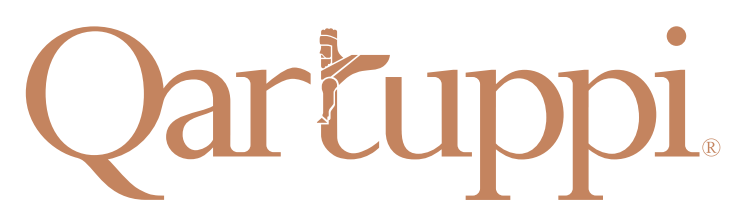

Qartuppi, S. de R.L. de C.V. http://www.qartuppi.com 


\section{(c) 1 (1) 80}

Esta obra se edita bajo una Licencia Creative Commons Atribución-NoComercial-Compartirlgual 4.0 Internacional. 
Vivir con un padecimiento crónico degenerativo como la Diabetes Mellitus (DM) implica seguir tratamientos e indicaciones, que podrían suponer un reto para los pacientes y llegar a generar situaciones de estrés. Se sabe que el estrés en pacientes con DM se asocia a un aumento en las cifras de glucosa y a una baja adherencia al tratamiento.

Este libro tiene como objetivo ser una guía flexible de un modelo de intervención psicológica en línea atendiendo condiciones contemporáneas. Se desarrolla una propuesta de trabajo breve, con una metodología cognitivo conductual, proponiendo un enfoque práctico que permite al terapeuta tomar diferentes decisiones y seleccionar técnicas ajustadas a las necesidades de cada paciente, adaptando las estrategias y materiales haciendo uso de las Tecnologías de Información y Comunicación (TIC's).
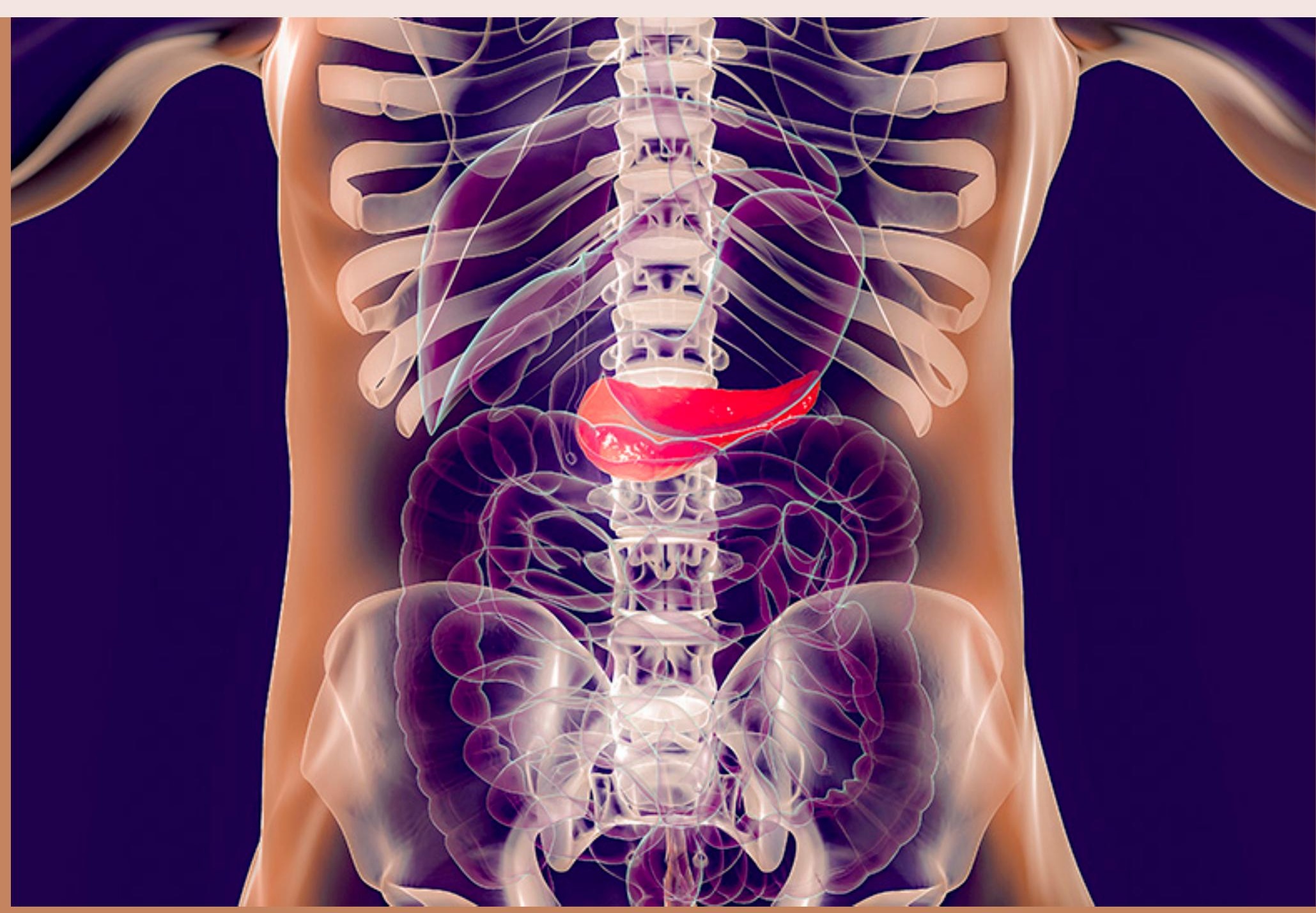

ISBN 978-607-8694-06-8
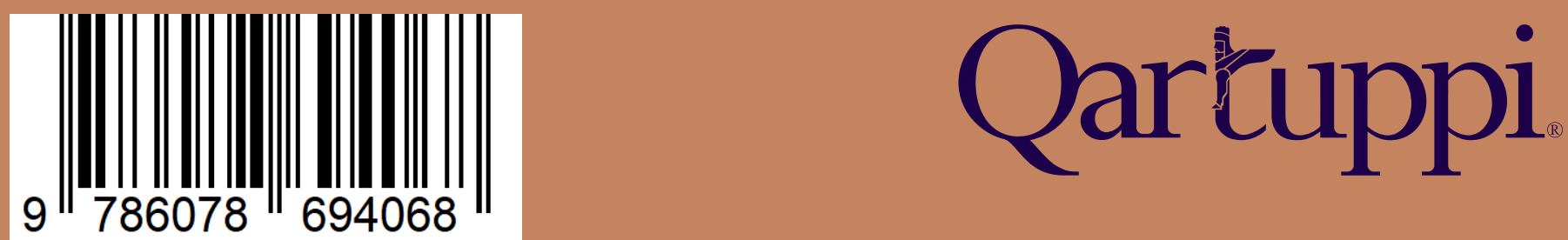